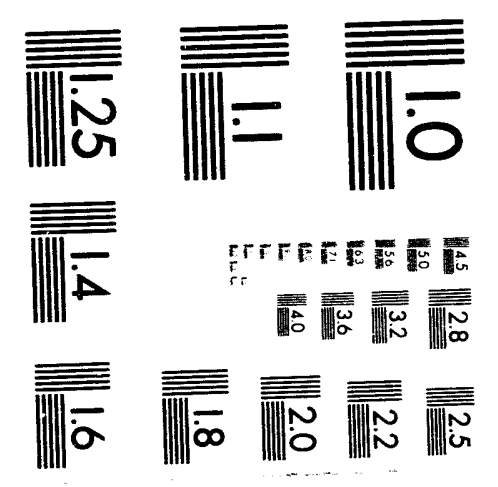



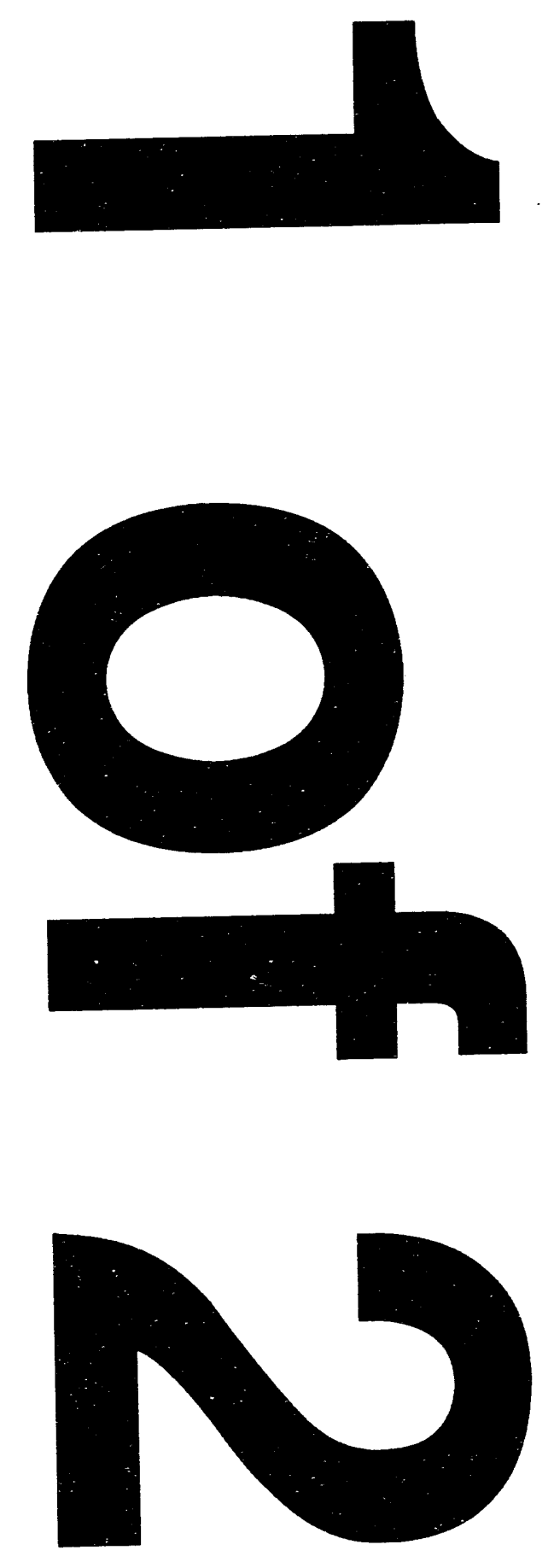


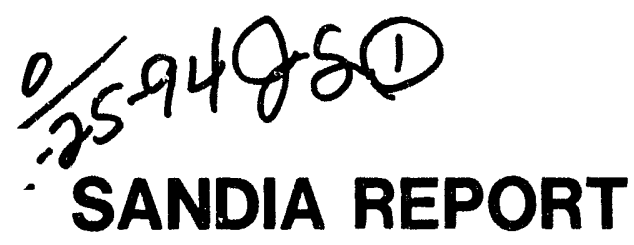

SAND91-2089 - UC-610

Unlimited Release

Printed January 1994

\section{Independent Review of SCDAP/RELAP5 Natural Circulation Calculations}

Gale M. Martinez, Robert J. Gross, Mario J. Martinez, Gina S. Rightley

Prepared by

Sandla National Laboratorles

Albuquerque, New Mexico 87185 and Livermore, Callfornla 94550

for the Unlted States Department of Energy

under Contract DE-AC04-94AL85000 
Issued by Sandia National Laboratories, operated for the United States Department of Energy by Sandia Corporation.

NOTICE: This report was prepared as an account of work sponsored by an agency of the United States Government. Neither the United States Government nor any agency thereof, nor any of their employees, nor any of their contractors, subcontractors, or their employees, makes any warranty, express or implied, or assumes any legal liability or responsibility for the accuracy, completeness, or usefulness of any information, apparatus, product, or process disclosed, or represents that its use would not infringe privately owned rights. Reference herein to any specific commercial product, process, or service by trade name, tradernark, manufacturer, or otherwise, does not necessarily constitute or imply its endorsement, recommendation, or favoring by the United States Government, any agency thereof or any of their contractors or subcontractors. The views and opinions expressed herein do not necessarily state or reflect those of the United States Government, any agency thereof or any of their contractors.

Printed in the United States of America. This report has been reproduced directly from the best available copy.

Available to DOE and DOE contractors from Office of Scientific and Technical Information

PO Box 62

Oak Ridge, TN 37831

Prices available from (615) 576-8401, FTS 626-8401

Available to the public from

National Technical Information Service

US Department of Commerce

5285 Port Royal Rd

Springfield, VA 22161

NTIS price codes

Printed copy: A08

Microfiche copy: A01 
SAND91 - 2089

Unlimited Release

Printed January 1994
Distribution

Category UC-610

\title{
INDEPENDENT REVIEW OF SCDAP/RELAP5 NATURAL CIRCULATION CALCULATIONS
}

\author{
Gale M. Martinez, Robert J. Gross, \\ Mario J. Martinez and Gina S. Rightley \\ Sandia National Laboratories \\ Albuquerque, New Mexico 87185
}

\begin{abstract}
A review and assessment of the uncertainties in the calculated response of reactor coolant system natural circulation using the SCDAP/RELAP5 computer code were completed. The SCDAP/RELAP5 calculation modeled a station blackout transient in the Surry nuclear power plane and concluded that primary system depressurization from natural circulation inciced primary system failure is more likely than previously thought. This review included results from a supporting COMMIX natural circulation computer code calculation and Westinghouse natural circulation experiments; both of which were used to build the SCDAP/RELAP5 mode1 of the Surry plant. Use of these results was identified as a major source of uncertainty in the SCDAP/RELAP5 analysis. Some of these uncertainties were examined by building a MELCOR model of the Surry nuclear power plant, which gave consistent results to the SCDAP/RELAP5 calculation, and performing sensitivity studies with MELCOR on several modeling parameters. Of all the parameters studied, variation in the decay heat most affected the results. A variation from the basecase by as much as $25 \%$ resulted in surge line failure times within -25 minutes. Variation of other parameters affecting the hot leg countercurrent flow modeling assumptions altered the basecase predicted failure times by less than -10 minutes. To study the relationship between the steam temperatures in the inlet plenum of the steam generator and the steam generator circulation rate, an independent computer model was developed. This calculation indicated a deficiency in the SCDAP/RELAP5 natural circulation modeling. Sensitivity studies on various inlet plenum mixing parameters were also performed with this model. Finally, a total loop natural circulation calculation, induced by a pump seal leak scenario, was performed with MELCOR, a case that was not analyzed with SCDAP/RELAP5. This calculation showed that the steam generator tubes are more vulnerable to failure than in the case that did not model total loop natural circulation. rinally, recommendations are made for additional SCDAP/RELAP5 analyses necessary to investigate the natural circulation-induced primary system failure conclusions.
\end{abstract}




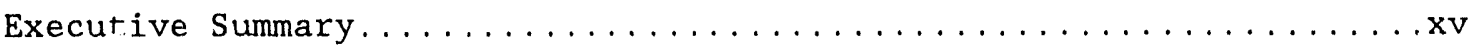

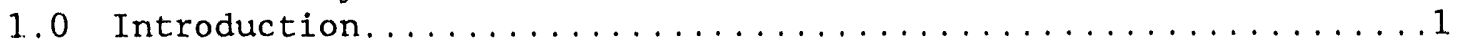

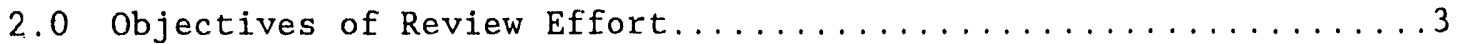

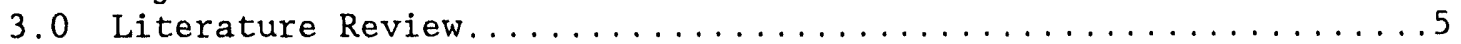

4.0 Review of SCDAP/RELAP5 Natural Circulation Analyses.........6 4.1 SCDAP/RELAP5 Analysis Assumptions................

4.2 SCDAP/RELAP5 Code Model Limitations...............

$4.3 \mathrm{SCDAP} /$ RELAP5 Analysis Uncertainties.................. 10

4.4 SCDAP/RELAP5 Input Deck Assessment.................. 12

5.0 Review of COMMIX Natural Circulation Analyses...............13

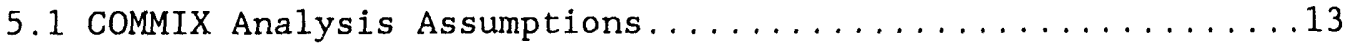

5.2 COMMIX Code Model Limitations...................... 14

5.3 COMMIX Analysis Uncertainties..................... 14

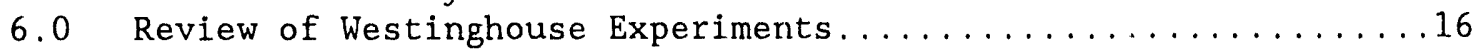

6.1 Summary of the Low Pressure Tests.................17

6.2 Sunmary of the High Pressure Tests................... 17

6.3 Review of Low and High Pressure Test Results............18

6.4 Similitude Issues........................... 20

6.5 Summary of the Westinghouse Experiments.............22

7.0 Summary and Prioritization of SCDAP/RELAP5 Analysis

Uncertainties. . . . . . . . . . . . . . . . . . . . . . 24

8.0 Surry Natural Circulation MELCOR Model Development...........27

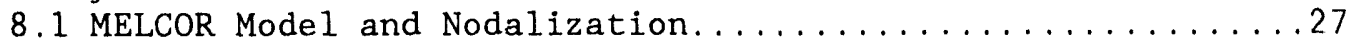

8.2 MELCOR Basecase Model Results......................... 31

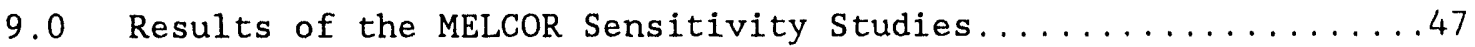

9.1 Decay Heat Sensitivity Study...................48

9.2 Zircaloy Oxidation Heating Sensitivity Study..........56

9.3 Circulation Rate Sensitivity Study..............61

9.4 Radial Conduction Effects on the Split Hot Leg

Piping Model........................67

9.5 Effect of Heat/Mass Transfer Between Hot Leg Hot/Cold

Flows................................ 70

10.0 Simplified Steam Generator Model Calculations..............76

10.1 Thermosyphoning Model Description............... 76

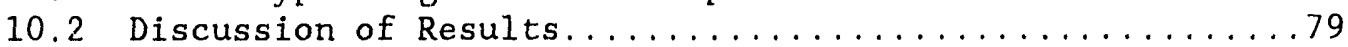

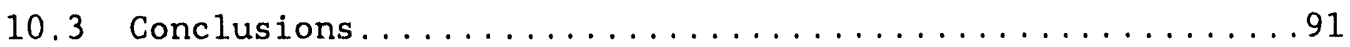

11.0 MELCOR Simulation of a Pump Seal Leak.................93

11.1 MELCOR Model of the Pump Seal Leak Scenario...........994

11.2 MELCOR Results of the Pump Seal Leak Simulation..........95

11.3 Limitations of the Pump Seal Leak MELCOR Analysis........106

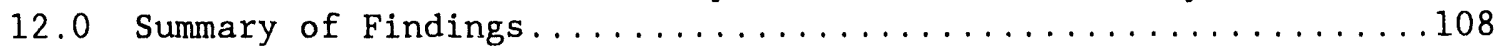

13.0 Applicability of Results and Analyses to Full-Scale Plants....113

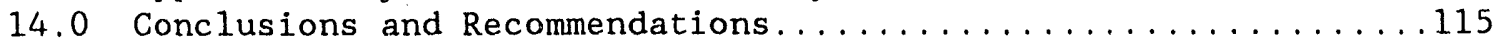

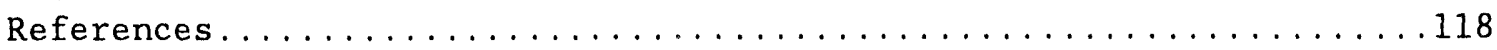

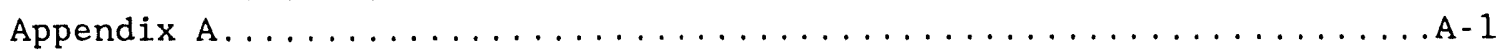

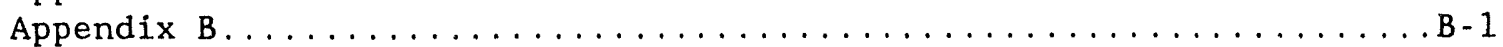


1.0.1 Severe accident natural circulation flows...........

8.1.1 Nodalization of the reactor coolant system for the Surry MELCOR calculations with hot leg natural

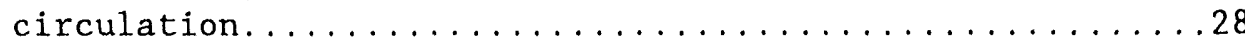

8.1.2 Nodalization of the hot $\mathrm{leg}$ and steam generator for the Surry SCDAP/RELAP5 calculations with hot leg

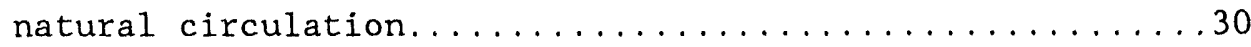

8.2.1 Core decay heat and oxidation energy used in the MELCOR basecase calculation.......................

8.2.2 Fraction of core input energy removed by the coolant in the MELCOR basecase calculation............33

8.2.3 System pressures of the MELCOR basecase calculation......34

8.2.4 Mass flow rate of steam through the PORV valves in the MELCOR basecase calculation.................. 34

8.2.5 Mass flow rate of steam through the steam generator secondary PORV valves in the MELCOR basecase

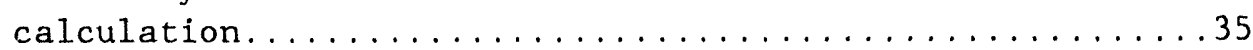

8.2.6 Comparison of the MELCOR basecase core collapsed liquid level history with the SCDAP/RELAP5 Sensitivity Case 1 results...................... 35

8.2.7 Comparison of the hot leg mass flow rate between the MELCOR basecase, SCDAP/RELAP5, and

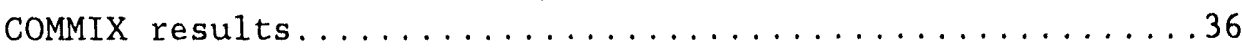

8.2.8 Comparison of the hot leg and steam generator mass flow rates between the MELCOR basecase,

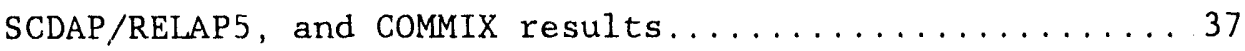

8.2.9 Reactor coolant system vapor temperatures for the MELCOR basecase calculation..................... 38

8.2.10 Comparison of the MELCOR basecase hot leg top and bottom vapor temperature histories with the SCDAP/RELAP5 Sensitivity Case 1 results.............39 


\section{FIGURES (continued)}

Figure

8.2.11 Steam generator secondary side vapor temperature history for the MELCOR basecase calculation............39

8.2.12 Comparison of the MELCOR basecase upper plenum structure temperatures with the SCDAP/RELAP5

Sensitivity Case 1 results.....................40

8.2.13 Comparison of the MELCOR basecase hot leg pipe temperatures with the SCDAP/RELAP5 Sensitivity Case 1 results..............................41

8.2.14 Comparison of the MELCOR basecase surge line pipe temperature with the SCDAP/RELAP5 Sensitivity Case 1 results..............................42

8.2.15 Comparison of the MELCOR basecase steam generator tube temperature with the SCDAP/RELAP5 Sensitivity Case 1 result.............................43

8.2.16 Comparison of the MELCOR basecase critical component temperature histories with the SCDAP/RELAP5

Sensitivity Case 1 results...................43

8.2.17 Warp factor (ratio of problem time to CPU time)

for the MELCOR basecase calculation..............45

8.2.18 CPU time used in the MELCOR basecase calculation........46

9.1.1 Comparison of the hot leg piping temperature of the MELCOR basecase with the MELCOR sensitivity study which varied the decay heat by $\pm 10 \%$ and $\pm 25 \% \ldots \ldots .50$

9.1.2 Comparison of the surge line piping temperature of the MELCOR basecase with the MELCOR sensitivity study which varied the decay heat by $\pm 10 \%$ and $\pm 25 \% \ldots \ldots 50$

9.1.3 Comparison of the steam generator hot tube temperature of the MELCOR basecase with the MELCOR sensitivity study which varied the decay

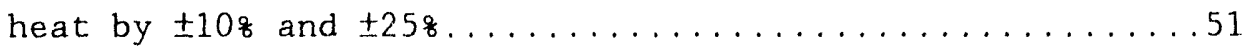

9.1.4 Comparison of the critical component (hot leg piping, surge line piping, steam generator hot tube) temperatures of the MELCOR basecase with the MELCOR

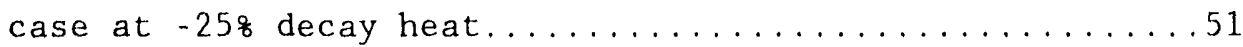


Figure

9.1 .5

9.1 .6

9.1 .7

9.1 .8

9.1 .9

9.1 .10

9.1 .11

Comparison of the hot leg piping temperature of

the MELCOR basecase with the MELCOR sensitivity study which varied the decay heat by $\pm 25 \%$, and the MELCOR sensitivity study which varied the decay by \pm 25 including zircaloy oxidation time advance

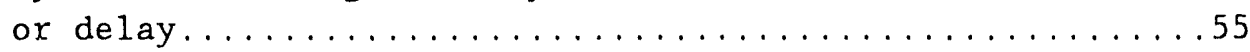

9.1.12 Comparison of the surge line piping temperature of the MELCOR basecase with the MELCOR sensitivity study which varied the decay heat by \pm 258 , and the MELCOR sensitivity study which varied the decay by \pm 258 including zircaloy oxidation time

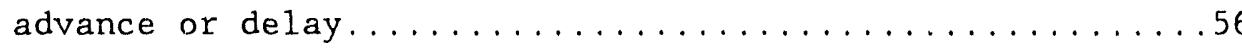

Comparison of the surge line piping temperature study which varied the decay heat by $\pm 10 \%$ and \pm 258 , including zircaloy oxidation time advance or delay............................... 54

Comparison of the steam generator hot tube temperature the MELCOR basecase with the MELCOR sensitivity study which varied the decay heat by $\pm 10 \%$ and \pm 258 , including zircaloy oxidation time advance or delay......54

Comparison of the critical component (hot leg piping, surge line piping, steam generator hot tube)
temperatures of the MELCOR basecase with the MELCOR

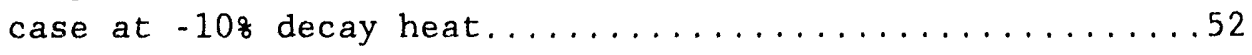

Comparison of the critical component (hot leg piping, surge line piping, steam generator hot tube) temperatures of the MELCOR basecase with the Comparison of the critical component (hot leg
piping, surge line piping, steam generator hot tube) temperatures of the MELCOR basecase with the MELCOR

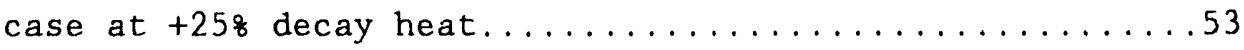

Comparison of the hot leg piping temperature of the MELCOR basecase with the MELCOR sensitivity study which varied the decay heat by \pm 10 \% and $\pm 25 \%$, including zircaloy oxidation time advance or delay......53 . 


\section{FIGURES (continued)}

9.2.1 Comparison of the hot leg piping temperature of the MELCOR basecase with the MELCOR sensitivity study which varied the magnitude of oxidation by zeroing it out and by a factor of two ...........57

9.2.2 Comparison of the surge line piping temperature of the MELCOR basecase with the MELCOR sensitivity study which varied the magnitude of oxidation by zeroing it out and by a factor of two.............. 58

9.2.3 Comparison of the steam generator hot tube temperature of the MELCOR basecase with the MELCOR sensitivity study which varied the magnitude of oxidation by zeroing it out and by a factor of two....58

9.2.4 Comparison of the hot leg piping temperature of the MELCOR basecase with the MELCOR sensitivity study which included hydrogen production.............59

9.2.5 Comparison of the surge line piping temperature of the MELCOR basecase with the MELCOR sensitivity study which included hydrogen production............60

9.2.6 Comparison of the steam generator hot tube temperature of the MELCOR basecase with the MELCOR sensitivity study which included hydrogen production....66

9.3.1 Comparison of the core energy removed by steam in the MELCOR basecase with the MELCOR sensitivity study which varied the loss coefficients in the hot leg flow loop by four orders of magnitude............62

9.3.2 Comparison of the "average" loop hot leg flow rate in the MELCOR basecase with the MELCOR sensitivity study which varied the loss coefficients in the hot leg flow loop by four orders of magnitude...............62

9.3.3 Comparison of the "average" loop steam generator flow rate in the MELCOR basecase with the MELCOR sensitivity study which varied the loss coefficients in the hot leg flow loop by four orders of magnitude....66

9.3.4 Comparison of the core and upper plenum vapor temperature in the MELCOR basecase with the MELCOR sensitivity study which varied the loss coefficients in the hot leg flow loop by four orders of magnitude....663 


\section{FIGURES (continued)}

Figure

9.3 .5

Comparison of the steam generator vapor temperature in the MELCOR basecase with the MELCOR sensitivity study which varied the loss coefficients in the hot leg flow loop by four orders of magnitude............64

9.3.6 Comparison of the hot leg piping temperature in the MELCOR basecase with the MELCOR sensitivity study which varied the loss coefficients in the hot leg flow loop by four orders of magnitude.............65

9.3.7 Comparison of the surge line piping temperature in the MELCOR basecase with the MELCOR sensitivity study which varied the loss coefficients in the hot leg flow loop by four orders of magnitude...........66

9.3.8 Comparison of the steam generator hot tube temperature in the MELCOR basecase with the MELCOR sensitivity study which varied the loss coefficients in the hot leg flow loop by four orders of magnitude.

9.4.1 Hot leg pipe radial conduction effects on the hot leg piping temperatures......................68

9.4.2 Conduction versus convection energy rates to the hot leg piping with radial conduction modeled...........69

9.4.3 Comparison of critical component temperature histories for the MELCOR radial conduction sensitivity calculation..........................69

9.5.1 Comparison of critical component temperature histories for the MELCOR sensitivity calculation including heat transfer between hot leg hot/cold flows............71

9.5.2 Schematic of the split hot leg MELCOR nodalization for the mixing simulation calculations................

9.5.3 Effect of mixing between the hot leg hot/cold flows on the hot leg flow rate......................

9.5.4 Mass flow rates between the hot leg hot/cold flows for high, medium, and no (basecase) mixing...........73

9.5.5 Effect of mixing between the hot leg hot/cold flows on the hot leg inlet vapor temperature history.........74

9.5.6 Effect of mixing between the hot leg hot/cold flows on the steam generator tube vapor temperature history....74 


\section{FIGURES (continued)}

Figure

9.5 .7

Comparison of critical component temperature

histories for the MELCOR sensitivity calculation

including mixing between the hot leg hot/cold flows.....75

10.1.1 Schematic of the steam generator mode1............78

10.2.1 Temperature history for the base case,

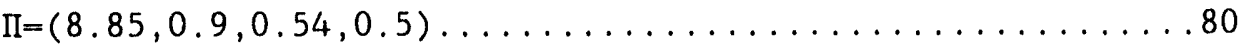

10.2.2 Steam generator mass flow rate variation with mass flow ratio, $m_{\mathrm{HL}} / m_{\mathrm{SG}}$, for $\Pi=(8.85,0.9,0.54$, var $) \ldots \ldots \ldots \ldots 1$

10.2.3 Temperature history for $\mathrm{r}=5.5 \mathrm{Kelvin} / \mathrm{min}$, $\Pi=(5.5,0.9,0.54,1.0)$.

10.2.4 Temperature history for $r=8.85 \mathrm{Kelvin} / \mathrm{min}$,

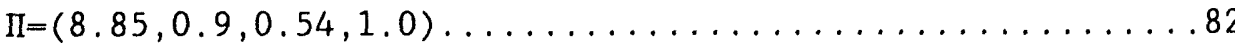

10.2.5 Temperature history for $r=16.2 \mathrm{Kelvin} / \mathrm{min}$,

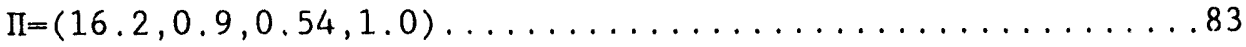

10.2.6 Steam generator flow rate variation with heating rate,

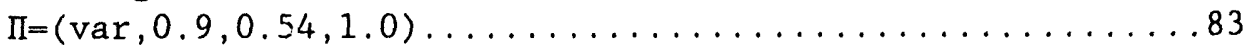

10.2.7 Secondary side steam temperature history for various heating rates, $\Pi=(\operatorname{var}, 0.9,0.54,1.0) \ldots \ldots \ldots \ldots \ldots . \ldots 84$

10.2.8 Profiles of steam temperature for various heating rates,

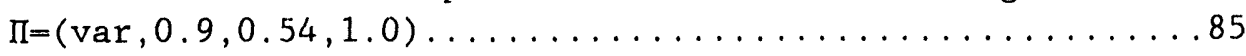

10.2.9 Variation of steam generator mass flow rate history with mixing fraction, $\Pi=(8.85$, var, $0.54,1.0) \ldots \ldots \ldots . \ldots 86$

10.2.10 Variation of steam generator mass flow rate history

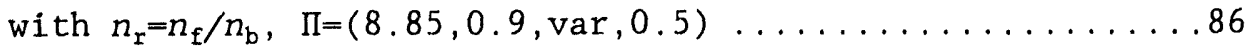

10.2.11 Temperature history for $m_{\mathrm{HL}} / m_{\mathrm{SG}}=2$,

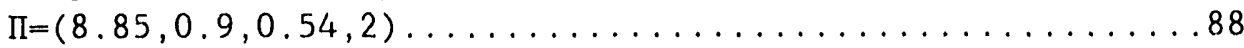

10.2.12 Temperature history for $K=20, \Pi=(8.85,0.9,0.54,0.5) \ldots \ldots 88$

10.2.13 Effect of loss coefficient on steam generator flow rate, $\Pi=(8.85,0.9,0.54,0.5) \ldots \ldots \ldots \ldots \ldots \ldots$

10.2.14 Effect of secondary side heat transfer on steam generator flow rate, $\Pi=(8.85,0.9,0.54,0.5) \ldots \ldots \ldots \ldots 90$ 


\section{FIGURES (continued)}

Figure

10.2.15 Temperature history without secondary side heat

transfer, $\Pi=(8.85,0.9,0.54,0.5) \ldots \ldots \ldots \ldots \ldots \ldots \ldots \ldots$

11.1.1 Nodalization of the reactor coolant system for the Surry MELCOR calculations for the pump seal leak scenario.................................94

11.2.1 System pressures for the MELCOR pump seal leak simulation. .............................96

11.2.2 Effect of the pump seal leak on the PORV flow rate

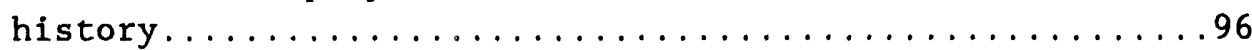

11.2.3 Pump seal leak flow rate history................97

11.2.4 Cold leg collapsed liquid level history during the pump seal leak MELCOR simulation................97

11.2.5 Effect of the pump seal leak on the hot and cold leg flow rates..............................98

11.2.6 Effect of the pump seal leak on the steam generator mass flow rates..........................100

11.2.7 Effect of the pump seal leak on the core and upper plenum vapor temperature history................ 100

11.2.8 Effect of the pump seal leak on the hot leg vapor temperature history.

11.2.9 Effect of the pump seal leak on the surge line vapor temperature history........................101

11.2.10 Efiect of the pump seal leak on the steam generator tube vapor temperature history....................102

11.2.11 Effect of the pump seal leak on the steam generator secondary vapor temperature history............... 102

11.2.12 Effect of the pump seal leak on the upper plenum structure temperatures.

11.2.13 Effect of the pump seal leak on the hot leg

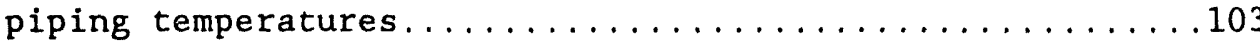

11.2.14 Effect of the pump seal leak on the surge line piping temperature. 


\section{FIGURES (continued)}

Figure

11.2 .15

Effect of the pump seal leak on the steam

Page

generator tube temperatures.................... 104

11.2.16 Comparison of critical component temperature histories

for the MELCOR pump seal leak calculation...........105

11.3.1 Effect of the pump seal leak on the MELCOR

calculated fuel rod surface temperature history.........107 


\section{TABLES}

$\underline{\text { Table }}$

$\underline{\text { Page }}$

8.2.1 RCS Energy Distribution Comparison (at 246.3 minutes).......44

9.1 .1 Decay Heat Sensitivity Study Results................... 49

9.5.1 Top/Bottom Countercurrent Flow Mixing Failure Times.......75

11.2.1 Comparison of Component Temperatures (K) at 249.7 Minutes... 105

12.0.1 Summary of MELCOR Sensitivity Study Results............110 


\section{ACKNOWLEDGMENTS}

The authors appreciate the input and guidance of John Kelly, Sam Thompson, and Terrv Heames during this review effort. The MELCOR staff, especially Randy Cole and Lubomyra Kmetyk, were most helpful in providing assistance for the MELCOR model development. Paul Bayless of EG\&G, Idaho and Dr. W.T. Sha of Argonne National Laboratory provided the SCDAP/RELAP5 and COMMIX models for their respective analyses. Dr. Y.S. Cher of the U.S. Nuclear Regulatory Commission, the sponsor of this work, was instrumental in providing us with Westinghouse experimental data reports. The efforts of Ed Boucheron, Lubomyra Kmetyk, Terry Heames, and Susan Dingman are appreciated for review of this manuscript. Thanks are extended to Maureen Locher and Darla Tyree for assistance with the preparation of this document. 
ara

$\underset{4}{*}$
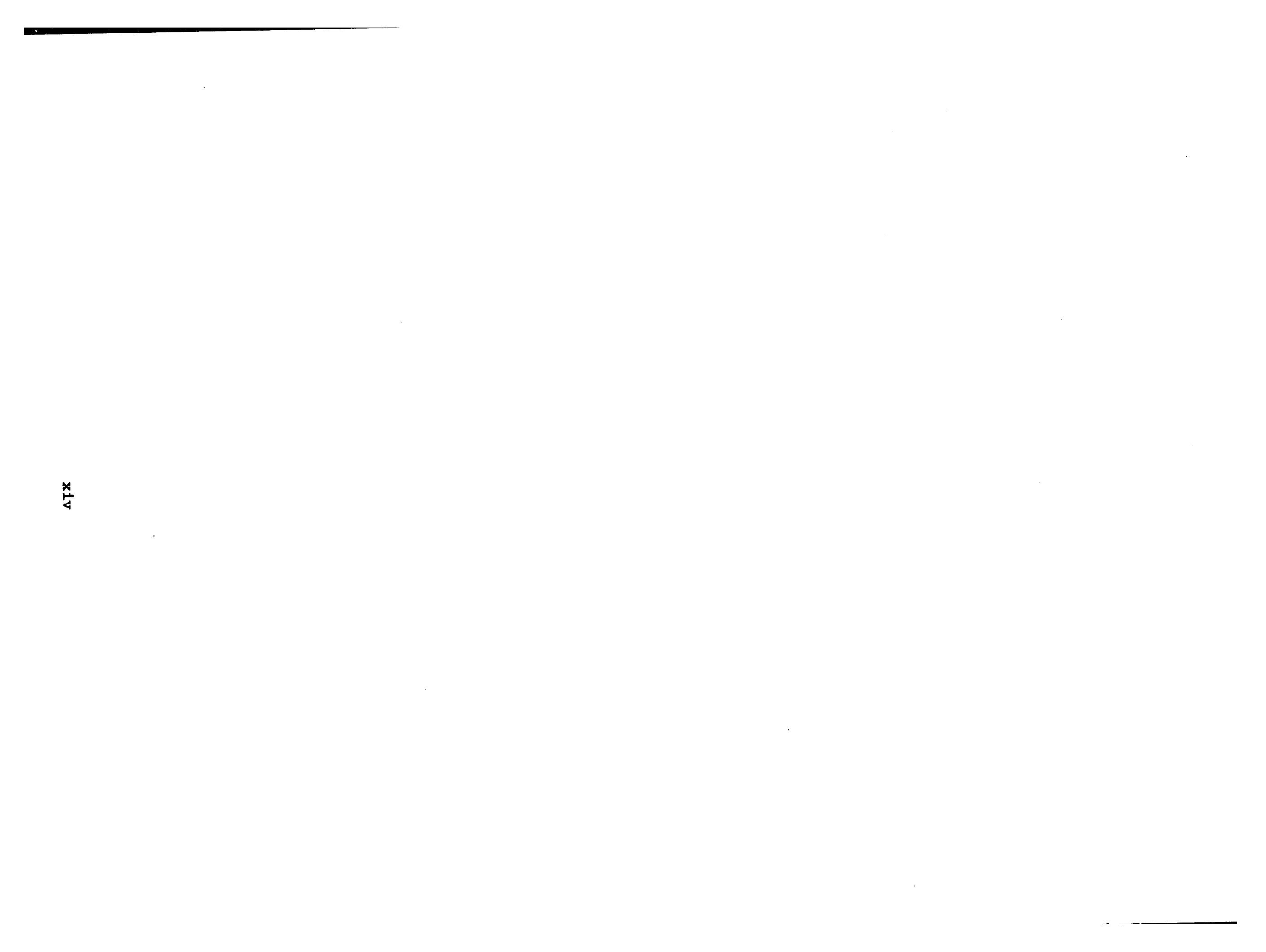


\section{EXECUTIVE SUMMARY}

The U.S. Nuclear Regulatory Commission has an ongoing research program to develop further understanding of the phenomena important to a number of nuclear power plant severe accidents. The specific accident addressed in this report is the station blackout transient (TMLB') accident which involves the loss of all ac power and auxiliary steam generator feedwater.

A major uncertainty in the predicted plant response to the TMLB' event concerns natural circulation in the reactor coolant system (RCS). Three types of natural circulation may occur during a high pressure boiloff transient in a pressurized water reactor (PWR): in-vessel, hot leg countercurrent flow, and flow through the coolant loops. Invessel natural circulation can occur as vapor heated by the core rises to the vessel upper regions, where it is cooled by large heatabsorbing structures, and then recirculates back down to the core region. Hot leg countercurrent flow circulates hot vapor from the vessel to the upper part of the hot leg and then to the steam generator. In the steam generator tubes, the vapor is cooled and then returns to the vessel along the bottom portion of the hot leg pipe. Loop natural circulation involves superheated vapor flowing through the coolant loops. This occurs only if the loop seals are cleared of 1iquid. These natural circulation loops have the potential to transfer a significant amount of energy from the reactor core to structures in the upper region of the vessel, the hot leg, the pressurizer, and the steam generators. Not only can core failure be significantly delayed, the RCS structures receiving this energy can fail before the vessel lower head, depressurize the system, and significantly alter the outcome of the accident.

A milestone in the research program investigating the TMLB' phenomena was the creation of a model, using the large systems code, SCDAP/RELAP5. The entire PWR system, including the core, reactor vesse1, hot legs, pressurizer, and primary and secondary sides of the steam generators were modeled with SCDAP/RELAP5. The Surry nuclear power plant was selected for this effort. The model, its results, and conclusions were documented in NUREG/CR-5214. The SCDAP/RELAP5 code (or any other large systems code) does not calculate all phenomena from first principles; many constitutive models are necessary. However, this particular model also relied heavily on results documented in NUREG/CR-5070 which were obtained from the multidimensional, single phase heat transfer and fluid flow analysis code, COMMIX, developed by Argonne National Laboratory. Both the SCDAP/RELAP5 and COMMIX code models relied further on data from Westinghouse natural circulation experiments.

The SCDAP/RELAP5 calculations of the Surry TMLB' accident scenario showed that natural circulation (both in-vessel and hot leg countercurrent flow) transfers core energy to other regions of the RCS. Furthermore, the code results predicted that either the hot leg 
pipe or surge line pipe will fail and depressurize the system. This would preclude failure of the reactor vessel due to severe core damage at high pressure.

The main objective of this report was to review and assess the results and conclusions in NUREG/CR-5214. Because the SCDAP/RELAP5 mode 1 relied heavily on results from the supporting calculation with the COMMIX code and the Westinghouse experiments, these studies were also examined in detail.

The foundation for these natural circulation studies rested on the experimental effort conducted by Westinghouse using a one-seventhscale half-model of a PWR. The initial phase of these experiments was completed before the code analyses were made. They were comprised of low pressure experiments in which similitude with full-scale was not achieved. Although much of the information gathered was not quantitative, these experiments were the first to demonstrate qualitatively that natural circulation in the hot legs and steam generators of a PWR could transfer a significant amount of energy from the core to other RCS structures, and delay core heat-up.

This Westinghouse low pressure data was used to benchmark the COMMIX code. The COMMIX code obtained generally good agreement with the low pressure experiments. Then, a COMMIX model of a full-scale PWR was created and run. Among the limitations of the COMMIX full-scale simulation were that half-symmetry was assumed to model the 3-1oop Surry RCS, the code was confined to modeling a single phase fluid (therefore, the simulation did not include the initial boiloff transient), the steam generator tubes were completely insulated, and turbulence was not modeled. Certain critical parameters obtained from the COMMIX results, among them flow rates and heat transfer in the hot leg, surge line, and steam generators served as guidelines for the development of the full systems model created with SCDAP/RELAP5. For example, the simulation of hot leg countercurrent flow and steam generator inlet plenum mixing required Westinghouse and COMMIX results to determine the nodalization and choice of flow loss coefficients. The SCDAP/RELAP5 calculation was able to match the COMMIX predicted heat transfer by using artificially high loss coefficients, but did not match the COMMIX predicted hot leg or steam generator flow rate. Use of these results, the best information available at the time, are a source of uncertainty in the hot leg countercurrent and steam generator modeling. In addition, other limitations were found with the SCDAP/RELAP5 analyses. Among these were limitations in the core models concerning oxidation, degradation, and in-vessel natural circulation. The inability of the code to calculate hydrogen stratification within the RCS and the neglect of fission product transport were additional limitations that were identified.

The review of these analyses and experiments indicated several code modeling assumptions, code limitations, modeling uncertainties, and experimental deficiencies which led to the SCDAP/RELAP5 analysis conclusions. These uncertainties were grouped into two categories of modeling issues: (1) core modeling uncertainties and (2) hot leg countercurrent flow modeling uncertainties. Furthermore, these 
issues indicated two key code calculated parameters which determine the RCS response and ultimate failure characteristics: (1) the hot leg inlet vapor temperature history and (2) the mass flow rate in the hot $\mathrm{leg} / \mathrm{steam}$ generator countercurrent flow loop.

To assess these SCDAP/RELAP5 calculational uncertainties, an examination of modeling assumptions affecting the key parameters was performed using alternate calculational tools. First, sensitivity studies were performed using the large systems code, MELCOR, developed by Sandia National Laboratories, to model the Surry TMLB' accident. The MELCOR model developed for this problem, because of programmatic constraints rather than code limitations, used more empirical models than the SCDAP/RELAP5 mode1. For example, the core was explicitly modeled in the SCDAP/RELAP5 model, but was empirically modeled as a volumetric heat source in the MELCOR model. In spite of the differences, the MELCOR results for the basecase TMLB' event were in good agreement with those of SCDAP/RELAP5. Note that the MELCOR mode1 relied on the same SCDAP/RELAP5 model heat transfer and flow loss coefficients as well as steam generator mixing fractions obtained from the COMMIX calculation and Westinghouse data.

The NUREG/CR-5214 study performed limited sensitivity analyses that we expanded upon using the MELCOR code. The effect of the hot leg inlet vapor temperature history on the transient was examined by varying the decay heat and oxidation energy developed in the core of the reactor vesse1. The effect of various modeling parameters on the developed mass flow rate in the hot leg countercurrent flow loop was examined by (1) varying flow loss coefficients, (2) including radial conduction modeling between the top and bottom portions of the the split hot leg model, and (3) modeling heat and mass transfer between the split hot leg countercurrent flows.

The MELCOR sensitivity analyses showed that, of all the parameters studied, variation in the decay heat most affected the results. The decay heat was varied by as much as \pm 258 from the basecase and resulted in failure times within \pm 25 minutes of the basecase. Much of the value in performing the sensitivity analyses lies in reaching the conclusion that the remainder of these parameters did not significantly alter the results as basecase predicted failure times were altered by less than \pm 10 minutes. In all cases, the surge line or hot leg were the predicted failure locations. Prior to performing these analyses, the importance of these parameters was open to question.

A total loop circulation calculation, which was not simulated with SCDAP/RELAP5 in NUREG/CR-5214, was also completed using MELCOR by examining the RCS response to a pump seal leak scenario. In this calculation the expected changes in the outcome of the accident if full coolant loop flow was reestablished in the Surry RCS were investigated. The calculation showed that the circulation flow rate was larger than in the natural circulation case. The surge line was not heated as much in this scenario, and was no longer the vulnerable RCS component. Most importantly, this calculation indicated that the steam generator tubes became much more vulnerable to failing. If they 
should fail before the hot leg, the accident could lead to fission product release to the secondary and eventually the environment.

Another major issue of concern in this review was that of proper fluid dynamic modeling of the natural circulation phenomena. Since the circulation phenomena is driven by buoyancy, it is important that the models be consistent in the relation between circulation rate and the heat transfer driving the process. Calibration of the circulation rate and heat transfer aspects of the SCDAP/RELAP5 model was accomplished to a large degree by matching the heat transfer rate computed with COMMIX as documented in NUREG/CR-5070. This exercise resulted in the application of larger flow loss coefficients in the SCDAP/RELAP5 model than would be commonly applied based solely on the RCS geometry and dimensions. However, the resulting mass flow rate in the SCDAP/RELAP5 simulation was higher than the COMMIX value by about a factor of two. This discrepancy was never resolved. Furthermore, since mixing in the inlet plenum is an important phenomenon affecting the degree of core energy removal, a sensitivity study of the effect of key parameters in this model was deemed highly desirable but would require several large calculations using MELCOR.

These two issues motivated the development of an independent model of the buoyancy driven circulation phenomena (thermosyphoning). This thermosyphon model was the second tool used in this review, and was designed to be as simple as possible but to retain the essential physics affecting the steam generator thermosyphoning phenomena. The major advantage of using this model over the MELCOR mode1, which relied on the same questionable assumptions used in the SCDAP/RELAP5 calculations, was that this model scrved as an independent investigation of the relationship between steam temperatures in the inlet plenum of the steam generator and the steam generator circulation rate. The thermosyphon model would hopefully provide a resolution to the discrepancy between heat transfer rate and circulation rate in the COMMIX and SCDAP/RELAP5 models by corroborating with one of the two models. In addition, the effect of various modeling choices on the two key parameters could be assessed with this model. The vapor heating rate was varied to assess the affect of inlet temperature history on the system behavior. The variables affecting the developing mass flow circulation rate in the steam generator tubes were examined by performing sensitivity studies.

The thermosyphon simulation, using the SCDAP/RELAP5 heating rates and mixing parameters, resulted in a similar circulation rate history as that computed with the SCDAP/RELAP5 model. However, the heat transfer rate from the steam through the steam generator tubes to the secondary side could not be matched without further "tuning" of model parameters. On the other hand, the thermosyphon model matched the steam generator heat transfer given by the COMMIX model, but not the circulation rate. Thus the thermosyphon model failed to provide full corroboration with either of the SCDAP/RELAP5 or COMMIX models, but resulted only in the same degree of agreement. Similarly, it was deduced that the SCDAP/RELAP5 model was capable of matching predicted COMMIX flow or heat transfer in the hot leg/steam generator assemblies, but not both. However, since natural circulation is 
buoyancy driven, energy and momentum transport are high coupled. Thus, the discrepancy between all model calculations suggests a deficiency still exists in modeling natural circulation phenomena and further consideration should be devoted to resolving this issue.

The sensitivity studies performed with the steam generator thermosyphon model identified that the heating rate, ratio of forwardrunning to backward-running steam generator tubes below values of 0.54 , loss coefficients, and neglect of secondary side heat exchange from the steam generator tubes affected the steam generator circulation rate. However, the circulation rate was relatively insensitive to the steam generator inlet plenum mixing fraction and mass flow ratio of the hot leg to the steam generator.

Based on all of the studies mentioned above, our recommendations are as follows. More appropriate Westinghouse high pressure experimental data has become available. After the low pressure test series, the Westinghouse facility was modified. Of the modifications made, two were major improvements. First, the facility was altered to accept high pressure tests to obtain a closer matching of similitude to fullscale. Second, prototypical steam generators were placed in the facility. With these modifications, another test series was conducted. In addition, the SCDAP/RELAP5 calculations discussed in NUREG/CR-5214 were performed using the MODO and MOD1 versions of the code. As with many large systems codes, SCDAP/RELAP5 has undergone periodic change and improvement. Version MOD3 is soon to become available. Therefore, we recommend using SCDAP/RELAP5/MOD3 to model the Westinghouse high pressure experiments directly; then scaling the SCDAP/RELAP5 model to the full-scale TMLB' scenario. This approach eliminates COMMIX from the computational chain, creating a direct link between SCDAP/RELAP5 and scaled natural circulation PWR experiments.

Using this approach, the SCDAP/RELAP5 model would derive its heat transfer and flow loss coefficients from realistic experiments. This course of action should result in greatly increased confidence in the events predicted by SCDAP/RELAP5 for the TMLB' accident. If the results of the revised SCDAP/RELAP5 calculation remain consistent with the initial conclusions reported in NUREG/CR-5214, confidence in the SCDAP/RELAP5 and complementary MELCOR sensitivity studies is justified. Furthermore, investigation of additional uncertainties not examined in these studies, such as core degradation modeling, the effects of fission product transport, and hydrogen stratification are recommended. 


\section{INDEPENDENT REVIEW OF SCDAP/RELAP5 NATURAL CIRCULATION CALCULATIONS}

\subsection{Introduction}

One of the major severe accident uncertainties listed in the report, "Reassessment of the Technical Bases for Estimating Source Terms," NUREG-0956 [1] was natural circulation in the reactor coolant system. During a high pressure boiloff transient in a PWR, such as a station blackout transient (TMLB'), the potential for single-phase steam natural circulation flow in several regions of the reactor coolant system (RCS) exists as schematically shown in Figure 1.0.1. This natural circulation may take three identified forms. The first is invessel natural circulation. As implied, this form involves hot fluids leaving the core, rising to the upper plenum and transferring energy to internal structures. The cooled fluid then flows down into the core where it is reheated and the process is repeated. The second form is hot leg countercurrent flow. For this to occur, the cooling loop must be blocked at the loop seals. Hot fluid enters the hot leg from the vessel and travels from the steam generator inlet plenum to the steam generator outlet plenum via some of the steam generator tubes. Once in the steam generator outlet plenum, the fluid is prevented from exiting the loop and returning to the vessel through the normal pipe path by water blockage near the pump seals. Therefore, the fluid is forced to return through the remaining steam generator tubes to the steam generator inlet plenum. All along this path, the fluid has been transferring energy to the piping and tubes, and is now substantially cooler than the fluid entering from the vesse1. The cooled fluid returns to the vessel along the bottom of the hot leg which is simultaneously carrying hot fluid from the vessel along the top of the pipe. Thus, countercurrent hot leg flow is established. The third form of natural circulation is flow through the coolant loops. In this circulation pattern, the loops are no longer blocked by water and the pumps are still inoperable. However, flow through the loops is established by fluid density differences.

Calculations [2,3] and experiments [4] have indicated that the establishment of natural circulation and the accompanying exchange of heat from the core to the upper plenum and coolant loop internals may induce failure in the RCS long before vessel failure is reached. This could cause system depressurization, thus preventing high pressure ejection at vessel breach and perhaps eliminating the direct containment heating (DCH) phenomena and their related uncertainties.

The major question involved in this issue is whether primary system depressurization from natural circulation-induced primary system failure is more likely than previously thought. 


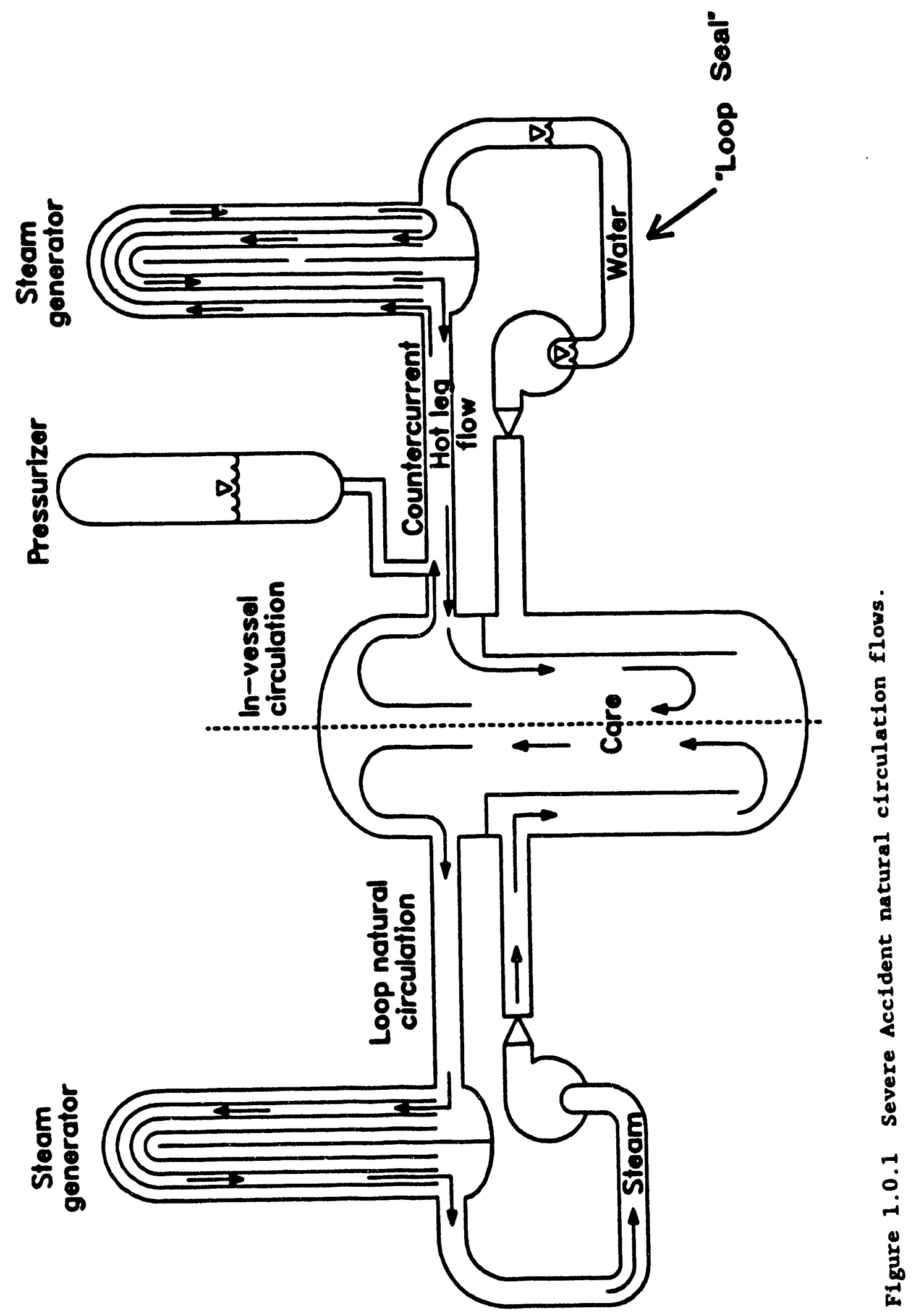




\subsection{Objectives of Review Effort}

A natural circulation study of the response of the Surry Nuclear Power plant's reactor coolant system to a TMLB' accident sequence was documented in the report entitled, "Analyses of Natural Circulation During a Surry Station Blackout Using SCDAP/RELAP5," NUREG/CR-5214 [2]. The results of this analysis supported the supposition that primary system depressurization due to a natural circulation induced failure of the surge line or hot leg would occur before core debris could fail the lower head of the reactor vessel.

The major objective of this effort is to review and assess the accuracy of the SCDAP/RELAP5 TMLB' natural circulation calculations for the Surry nuclear power plant. This involves examining the uncertainties associated with these calculations including those inherent in the modeling assumptions, code and user input, and code deficiencies. This also involves assessment of other code analyses and experimental data which was used to develop the SCDAP/RELAP5 model. In particular, the COMMIX code simulation of the accident scenario [3] was used to set various model parameters. In addition, results from Westinghouse $1 / 7$ th scale experimental data [4] were used in the development of both the SCDAP/RELAP5 and COMMIX code models. Therefore, a review of the COMMIX analysis and the Westinghouse experiments is also necessary to complete this review. Additional results from other natural circulation analyses applicable to these studies found in the literature are discussed as well.

A set of analysis uncertainties resulted from this review. The major uncertainties were examined by performing calculations to determine their impact on the SCDAP/RELAP5 conclusions. The MELCOR computer code was used for this assessment. A base case model was built which matched the results of the base SCDAP/RELAP5 calculation fairly well. The parameters of interest were varied using MELCOR's sensitivity study capability to quantify the uncertainties in the SCDAP/RELAP5 calculations. The results of these sensitivity studies are presented.

In addition, a simple model of the steam generator was built to examine the thermosyphoning phenomenon which produces the buoyancy driven natural circulation flows in the steam generators. This is an important issue because approximately $22 \%$ of the energy removed from the core will be transferred to the steam generator tubes. The parameters affecting the developing natural circulation flow rates, based on the solutions of the fundamental equations of mass, momentum, and energy, were studied, enabling an independent assessment of the results predicted by the codes. Other sensitivity studies were also performed with this model and will be discussed.

To complete the analysis of the possible natural circulation scenarios, a further analysis using MELCOR was performed to determine the effect of primary coolant loop seal clearing induced by a pump seal leak. This third natural circulation scenario was not modeled with the SCDAP/RELAP5 code.

The major findings of this study are summarized and the applicability 
of these calculations to full-scale plant analyses discussed. Finally, conclusions are drawn concerning the uncertainty in the SCDAP/RELAP5 results and recommendations are made for further work based on the results of this assessment effort. 


\subsection{Literature Review}

A literature review of work in the area of natural circulation in reactor coolant systems was completed. A summary of the relevant papers and analyses is documented in Appendix $A$. 


\subsection{Review of SCDAP/RELAP5 Natural Circulation Analyses}

The report, "Analyses of Natural Circulation During a Surry Station Blackout Using SCDAP/RELAP5" [2], is a study of the response of the Surry nuclear power plant's reactor cooling system to a TMLB' accident sequence. The TMLB' sequence is a total loss of ac power with an immediate loss of auxiliary feedwater. The study simulated the sequence from the initiation of the transient to the start of fuel rod relocation.

Three scoping calculations were run to determine the effects of invessel and hot leg natural circulation. Each scoping calculation used an increasingly more complex model of the plant. First, the transient was calculated using a once-through model of the reactor vessel and coolant loop, without natural circulation modeling. Second, the core and upper plenum model were changed to allow in-vessel natural circulation. Finally, the hot leg model was altered to allow hot leg countercurrent flow. These runs were performed using SCDAP/RELAP5/MOD0 Cycles 48 and 51 versions of the code. By comparing the results of each calculation with those of the previous one, the changes affected by each natural circulation flow could be determined. The inclusion of natural circulation resulted in the removal of more energy from the core and the transfer of it to other parts of the reactor coolant system. And, most significantly, heating of ex-vessel structures indicated that the RCS boundary would fail, probably in the surge line, before the vessel was breached. Such a failure could allow the RCS to depressurize before the vessel failed and significantly change the containment load at the time of melt ejection.

The coolant loops were modeled so that loop circulation could occur if the loop seals cleared of liquid in any of the calculations. However, the SCDAP/RELAP5 calculations did not predict loop seal clearing in any of these cases.

After the scoping calculations were completed, nine sensitivity calculations were run to examine the effects of several major phenomenological and modeling uncertainties on the system behavior until the time of RCS pressure boundary failure. Parameters that were varied in the calculations included the axial power profile in the core, the amount of mixing in the steam generator inlet plena, radial flow resistances in the core and upper plenum, and heat loss through the hot leg and pressurizer surge line piping. These calculations used the SCDAP/RELAP5/MOD 1 Cycle 5 version of the code and cannot be compared directly with the scoping calculations because a different decay heating history in the core was used. The major finding was that the fillure time did not appear to be very sensitive to the parameters varied. Also, in eight of the nine runs, the surge line was predicted to fail. The remaining run predicted the hot leg to fail. In all cases, however, the failures occurred near the time of fuel rod relocation and substantially before the predicted vessel failure time. 
SCDAP/RELAP5 [5] is a LWR system transient analysis code which was designed primarily to calculate the behavior of the RCS during severe accident sequences up to vessel failure. The core, primary and secondary systems, feedwater train and the system controls can be simulated. The code is intended to address accidents ranging from small break loss of coolant accidents (SBLOCAs) to more severe accidents.

The code is divided into three main portions by function. SCDAP models structures in the reactor core. TRAP-MELT provides the basis for fission product transport and deposition; however, this capability was not included in these analyses under review. RELAP models fluid behavior in the system and thermal behavior outside the core. The basis for the RELAP portion of the code is the use of a 1-D, two fluid, nonequilibrium, six equation hydrodynamic model. Continuity, momentum and energy equations for both liquid and vapor phases in a control volume are solved using a simplified capability to treat multidimensional flows. Heat structures are modeled as spherical, cylindrical and slab geometries.

The initial phase of the assessment of the SCDAP/RELAP5 natural circulation calculations resulted in a listing of analysis assumptions, modeling limitations and calculation uncertainties which might impact the modeling results. These are presented in the following sections. Each of these major headings is subdivided into smaller topics and discussed separately.

\subsection{SCDAP/RELAP5 Analysis Assumptions}

Initial Conditions: The assumed values or forms of certain initial conditions applied to the model plant in the SCDAP/RELAP5 study will impact the developing natural circulation flows and alter the calculated timing of events. Among these crucial initial conditions are core decay power, primary fluid temperature and pressure, and the state of the steam generator secondary side.

Failure Mode: Only the creep rupture failure of the hot leg, surge line and steam generator tubes was considered. Other small RCS component failures and their overall effect on the outcome of the transient were not modeled. Thus, the analysis ignored the possible failure of other components such as the pump shaft seal, small pipes and instrument penetrations. Of course, the ensuing leak must be substantial enough to justify inclusion of the component for failure analysis.

Hot Leg Countercurrent and Steam Generator Inlet Plenum Mode1s: The models used in the SCDAP/RELAP5 study were based on and compared to the Westinghouse low pressure, low temperature, small scale experiments $[4,6,7]$ which used liquid water and a simulant fluid, $\mathrm{SF}_{6}$, rather than high pressure steam. The TMLB' event occurs under high pressure and high temperature conditions. The scalability of the data to ful1-scale conditions was assumed since high pressure data was not available at the time these calculations were performed. 
In the SCDAP/RELAP5 analysis, the hot leg, undergoing countercurrent flow, was modeled as two separate pipes, one carrying flow from the vessel to the steam generator and the other carrying flow to the vessel from the steam generator. This exclusive configuration eliminated the possibility of any heat and mass transfer or mixing between the hot and cold fluid streams. In actuality, slight mixing between the streams was observed experimentally in Reference 4. Also, if fission product transport was found important and fission product modeling were to be included in this study, this model would not allow for the simulation of the settling of fission products between the hot and cold countercurrent flows. This is a limitation of the onedimensional pipe modeling in the SCDAP/RELAP5 code.

Countercurrent Flow Split Areas: The Westinghouse data [4] showed the hot leg countercurrent flow streams to have a sloping interface. The flow area for the countercurrent flows, therefore, varied along the hot leg pipe. The significance of this flow mechanism was approximated by modifying the steam generator inlet and outlet flow areas. The hot leg flow areas in the analysis, however, were assumed to be of constant and equal area all along the length of the hot leg pipe.

Pipe Bend Modeling: Any local effects caused by pipe bends were neglected; form loss coefficients were included. However, in Reference 8 , it was reported that the type of pipe bend modeled, smooth or sharp, was important only near the bend itself. Downstream, the pipe length "washed-out" any effects from the bend.

\subsection{SCDAP/RELAP5 Code Mode1 Limitations}

The following SCDAP/RELAP5 code model limitations apply to the code version used in these analyses (code versions MODO, cycles 48 and 51 , and MOD1, cycle 5 [2]). These limitations were not all necessarily of equal importance for this analysis but may be important for other severe accident scenarios.

Heat Transfer Model of Non-Core Structures: The one-dimensional treatment of conduction heat transfer in SCDAP/RELAP5 does not formally allow for the effect of circumferential heat transfer between the upper and lower sections of the hot leg split pipe model. User input approximations could have been made, but were not in the analysis. Additionally, a complete spatial distribution of energy within heat structures cannot be modeled with the one-dimensional heat structure approach [9]. The melting and relocation of heat structures is also ignored although the code predicted that the vessel upper plenum structures reached melting temperatures [2].

Oxidation: There are several areas concerning oxidation modeling where the SCDAP/RELAP5 analyses are limited. These limitations could provide non-conservative oxidation estimates. For example, the oxidation of the steel control rods is calculated only after all of the $\mathrm{Zr}$ clad is oxidized. Oxidation of any material during relocation 
is not calculated. However, for the analyses evaluated in Reference 2 RCS failure occurred prior to relocation. The oxidation of non-core materials (the upper plenum steel structures, for example) is ignored. No models of oxidation of flowing U-Zr-O mixtures on the exterior of fuel rods or in the gap between $\mathrm{UO}_{2}$ and $\mathrm{ZrO}_{2}$ crust exist $[10,11]$. Fully oxidized layers are not considered in oxygen diffusion caizulations for underlying layers and the inner surface of the clad is assumed to oxidize at the same rate as the outside when the clad balloons or ruptures. Additionally, steam flow to the inner clad is not calculated.

Hydrogen Stratification: During oxidation, hydrogen is produced and transported throughout the RCS. The SCDAP/RELAP5 code assumes all gases completely mix in any control volume. Therefore, possible trapping of the low density hydrogen gas in the top of the steam generator $U$-tubes is highly dependent on the nodalization.

Multi-dimensional Flow Treatment: RELAP5 uses a multiple flow channel approach with crossflow junctions to simulate multidimensional effects. References 10 and 11 stated that the crossflow junctions provide a reasonable alternative to a fuli multi-dimensional flow model for axially dominated flow situations. However, for invessel natural circulation simulations and flow around blockages, radial flow may be as significant as axial flow and may be dominant [12]. These flow conditions, therefore, cannot be adequately modeled using this technique because it does rot conserve momentum and implies that the SCDAP/RELAP5 calculations will be sensitive to the number of flow channels modeled. However, Reference 13 reports negligible differences between three and five channel core models in flow rates or temperatures.

Viscous/Turbulent Effects Due to Local Blockages: RELAP5 does not mode 1 viscous/turbulent effects due to local blockages. It was assumed that these effects are within the other modeling uncertainties of the chemical and thermal behavior of the core degradation models. To account for these effects, a boundary layer model of very small scale would be required rather than a lumped cell approach.

Candling: Candling is not modeled in the fuel-clad gap although References 10 and 11 stated that DF experiments show evidence of this behavior. Only bulk freezing is modeled and no crust formation models are available. The rivulet flow model is also simplified and does not include the change in the viscosity of the melt during the candling process.

Clad Failure: Clad failure models due to fracturing, cracking and dissolution of degraded cladding are parametric, not mechanistic. Also, grid spacer/cladding interactions were simulated by a code update (temperature failure).

Dissolution: The dissolution of the Zirconium oxide shell by inner clad molten Zircaloy is not modeled accurately. A user input oxide clad failure temperature determines breach. 
Interactions between Molten Material and the Liquid Pool: As molten material relocates below the core it can interact with the pool below causing boiling or fuel coolant energetic interactions. The SCDAP/RELAP5 model only transfers the energy of the molten material to the lower plenum heat structures which may then dissipate energy to the pool and boll the water.

Core Heat Structures: The SCDAP/RELAP5 code neglects convection and radiation heat transfer between corium and the fluid (steam/hydrogen) or the heat structures. Only lumped parameter thermal and mechanical behavior are modeled and the 1-D radiation model does not account for geometry changes. Additionally, axial radiation heat transfer is neglected and no radiation heat transfer to the debris beds in the lower plenum is calculated $[10,11]$.

Control Rods: The internal flow of $\mathrm{Ag}$-In-Cd inside the stainless steel clad is not modeled. Candling inside the gaps, crust formation of candled material, the liquefaction of the control rods by $\mathrm{Fe}-\mathrm{Zr}$ and $\mathrm{Ni}-\mathrm{Zr}$ eutectic mixtures and the grid spacer attack of the guide tubes are not modeled $[10,11]$.

Debris Bed: The oxidation of Zircaloy in the debris bed is neglected; thus, the models are only applicable to low temperature beds (below $1300 \mathrm{~K}$ ). The models offer poor treatment of debris bed melting. No superheating of debris is allowed until the debris is completely molten. Also, melt relocation, crust formation and molten pool convection are not modeled.

\subsection{SCDAP/RELAP5 Analysis Uncertainties}

Zircaloy Clad and Inconn 1 Grid Spacer Interactions: The scoping calculations presented in the analysis did not model these interactions. Clad failure was caused only by ballooning of the cladding. The nine sensitivity studies reported in Reference 2 included a simple temperature criterion to simulate melting of the eutectic formation of the Zircaloy and Inconel which caused clad failure at lower temperatures $(1470 \mathrm{~K})$.

Loop Seal Clearing: In the calculations loop seal clearing was not predicted to occur. Other studies have shown that the loop seals may clear randomly. Reference 9 showed a dramatic change in event sequence when pump seal leaks occurred and allowed cold leg components to void.

RCS Failure and Effect on DCH: The RCS failure characteristics (such as the size, location, possibility of multiple failure locations, and effect of containment response (DCH)) were not defined from these analyses.

Decay Power Leve 1: Of the parameters varied in the sensitivity studies, decay power levels were found to have the largest effects on the timing of crucial events. Accurate definition of the initial power level and the life cycle at the time the transient began for the accident sequence analyzed is necessary $[2,13]$. 
Flow Blockage: The flow blockages predicted by ballooning may be too conservative. Ballooning may not be as coplanar as the code calculations assumed.

Development of the Hot Leg Countercurrent Flow Model: Uncertainties concerning the applicability and scaling appropriateness of the hot leg model exist because the model was developed from COMMIX calculations and small scale, low pressure, low temperature, steady state experiments. Section 6 addresses this issue in more detail.

Use of Large Flow Loss Coefficients: In the hot leg/steam generator circulation model used in the SCDAP/RELAP5 analysis, artificially large loss coefficients were used. These were chosen by calibration of the model with the heat transfer rate computed by COMMIX [3]. However, the resulting steam generator mass flow rate in the SCDAP/RELi'P5 simulation was higher than the COMMIX value by about a factor of two. In addition the boundary conditions on the outside of the steam generator tubes were different than those used in the benchmarking calculation used to set loss coefficient parameters. In the COMMIX simulation, the outside of the tubes were adiabatic whereas in the actual situation there is heat transfer from the tubes to the secondary side of the steam generator. Since the natural circulation phenomena is buoyancy driven, it is important that the models be consistent in the relation between circulation rate and heat transfer. This was not achieved and will be discussed in more detail in the analyses of Section 10.

Insertion of Valve into Hot Leg: In the scoping calculations, the pressurizer surge line was not split like the hot leg. Because of difficulties with reverse flow through the pressurizer loop a nonexistent valve was inserted into the model. The valve was closed when the PORVs opened to prevent vapor in the vessel from entering the bottom of the hot leg and flowing to the steam generator inlet plenum, then back through the top of the hot leg to the surge line. This introduced another uncertainty into the scoping calculation model.

Analysis Comparisons: The scoping calculations and the sensitivity calculations were performed with different code versions and, therefore, cannot be rigorously compared.

Results of Other Studies Were Not Predicted: Mass flow leaving the core was shown by Reference 15 to increase during periods of accelerated oxidation and decrease when the core became steam starved. This was not predicted in the SCDAP/RELAP5 calculations.

Reverse Flow During PORV Venting: Both the Westinghouse experiments [7] and COMMIX calculations [16] showed reverse flow in the steam generator tubes and inlet plenum during PORV venting. This resulted in a net heat transfer back to the steam from the steam generator tubes due to isentropic expansion of the steam as the system depressurized while the valve was open. The SCDAP/RELAP5 calculation did not predict this result. 
Pressurizer Draining: The results of the Semiscale program [17] of station blackout tests showed that the pressurizer remained full throughout the period of primary mass reduction. The SCDAP/RELAP5 calculations show the pressurizer level decreasing in a more or less steady manner from the beginning of the calculation during PORV cycling and emptying completely around the time the vessel liquid level drops to the bottom of the core barrel.

\subsection{SCDAP/RELAP5 INPUT DECK ASSESSMENT}

The SCDAP/RELAPS input deck for the Sensitivity Case 1 analysis in Reference 2 was obtained from EG\&G. The deck was examined for geometrical correctness against the Surry nuclear power plant FSAR [18]. In general, the fluid volumes and radial and axial dimensions of all RCS structures were consistent with the FSAR. One exception is noted in the modeling of a flow path between the downcomer and the upper plenum which was not found in the FSAR. INEL analysts could not trace the origin of this flow path since the input deck was developed from a standard Surry plant deck used for other SCDAP/RELAP5 analyses. Minor differences existed in the total number of steam generator tubes used in the SCDAP/RELAP5 model: 3342 compared to 3388 in the FSAR. The tube thickness used in the SCDAP/RELAP5 mode $i$ was slight1y smaller ( $4 \%$ lower than the FSAR value).

The input deck received from EG\&G contained decay power history input which was not consistent with the values shown in Appendix $A$ of Reference 2. The reason for this discrepancy is not known. However, the values printed in the report were assumed to be the values actually used; these values were also used in the MELCOR sensitivity studies aiscussed later.

The only non-physical parameters used in the SCDAP/RELAP5 analysis were the flow loss coefficients used in the split hot leg and steam generator piping models as noted in Section 4.3. The loss coefficient usually represents flow resistance due to sudden area changes or bends in pipes. However, the coefficients used in this analysis were an order of magnitude higher than would be physically reasonable. This was done to match the heat transfer rates of the COMMIX analysis [3]. The appropriateness of this choice will be examined in Section 10. 


\subsection{Review of Comix Natural Circulation Analyses}

This section reviews the report entitled "Analysis of NaturalConvection Phenomena in a 3-Loop PWR During a TMLB' Transient Using the COMMIX Code" [3]. The objectives of this study were to perform multidimensional analyses of natural circulation phenomena and to generate data that are needed for guidance in 1-D simulations of reactor systems such as the SCDAP/RELAP5 analyses described in Section 4. Additional goals were to predict the heat transfer rates to various internal structures and to examine hot leg recirculating-flow patterns. The analysis studied the natural circulation phenomena after the hot legs dried out.

The calculations presented assumed half-symmetry of the 3-10op surry power plant and used hot leg characteristics from previous 2-D Zion calculations [19]. Thus, only one and one-half of the coolant loops were modeled. The analysis also assumed that the system pressure would cycle between the PORV set points of 16.20 and $15.72 \mathrm{MPa}$, that the secondary side of the steam generator was dry and acted as a negligible heat sink, and that the internal structures were the only heat sinks available. The pressurizer was not included and the PORV was modeled at the end of the surge 1 ine.

The results of the COMMIX work were used to develop the SCDAP/RELAP5 hot leg and steam generator inlet plena nodalizations. Thus, in order to fully understand and review the SCDAP/RELAP5 analysis, the COMMIX report must also be reviewed. A listing of analysis assumptions, modeling limitations and uncertainties for the COMMIX paper is presented and discussed in the following sections.

\subsection{COMMIX Analysis Assumptions}

Initial Conditions: The initial conditions for this analysis were assumed to be similar to the conditions calculated by a previous INEL TMLB' analysis of the Seabrook Power Plant after hot leg dryout, secondary side steam generator dryout, core uncovery and the beginning of clad heatup [3]. These conditions were isothermal $(620 \mathrm{~K})$ saturated steam at $16.1 \mathrm{MPa}$.

Boundary Conditions: The secondary side of the stean generator was assumed to be a negligible heat sink. Therefore, the external boundary conditions of the steam generator tubes were modeled as adiabatic. The external boundary conditions of all piping and the vessel were also considered adiabatic. The PORV set points were: (1) open when the pressure was greater than $16.203 \mathrm{MPa}$ and (2) closed when the pressure was less than $15.72 \mathrm{MPa}$. Steam production during core liquid boiling was neglected in the calculations and oxidation was assumed to begin 1000 seconds from the start of the calculation. The core decay power including the energy produced during cladding oxidation was assumed to follow the following profile: from 0 to 1000 seconds the power was $34 \mathrm{MW}$; from 1000 to 1500 seconds, the power varied linearly from 34 to $37.4 \mathrm{MW}$; and from 1500 to 2000 seconds, the power varied linearly from 37.4 to $44.2 \mathrm{MW}$. 
Model Geometry: Half symmetry of the three loop plant was assumed to be sufficient. The pressurizer was not modeled which resulted in the PORV being placed at the end of the surge line. Thus, the effect of the pressurizer water level on the transient was not simulated. The only heat sinks modeled were the internal structures (e.g., steam generator tubes, upper plenum internals, pipe walls, and core internals). A falrly coarse axial mesh was used to model steam generator tubes. Justification of the chosen nodalization or discussion of any mesh dependencies were not provided.

Calculation Time Period: The time window used for the COMMIX analysis was obtained from the sequence of events predicted by an INEL mode1 of the Seabrook Plant [Figure 1 of Reference 3], assumed to be similar to the Surry plant. The analysis began just prior to cladding heatup, approximately 8100 seconds into the TMLB' scenario.

\subsection{COMMIX Code Mode1 Limitations}

Single Phase: The code calculations were only applicable to the single phase portion of the TMLB' transient since continued boiling in the core during the transient could not be simulated.

Heat Structures: A one-dimensional conduction model was used in this analysis. The surge line was modeled as only one thermal structure whereas the hot leg walls were modeled as several thermal structures interacting thermally with each of the fluid cells in the hot leg to simulate axial conduction. The melting and relocation of structures could not be modeled.

Core Degradation Phenomenological Models: These models were not available in COMMIX. Only the thermal capacitance of the core materials and the flow resistances were modeled in the core. Therefore, the effects of cladding and steel oxidation, ballooning, clad failure, melting and relocation of core materials were not simulated. Oxidation was approximated by the increasing core power source. The analysis was limited to the portion of the transient before fuel degradation begins.

Hydrogen Production and Fission Product Transport: Neither of these phenomena could be modeled by the COMMIX code.

\subsection{COMMIX Analysis Uncertainties}

Experimental Validation: Reference 8 provided information stating that COMMIX did not predict the fluid temperatures in the Westinghouse steam-simulant experiments (using low pressure $S_{6}$ gas) as well as the low pressure water tests. Reference 8 also questioned whether the variation of $400 \mathrm{~K}$ between the hot and cold countercurrent flows predicted by COMMIX was realistic.

The COMMIX simulations were also compared with the Westinghouse steady state, low pressure data in Reference 7. Some differences between the data and the predictions were noted, but in general, good 
velocity and temperature agreement were observed. However, during PORV venting, COMMIX predicted higher steam generator heat removal rates than measured in the experiment. Unfortunately, high pressure data was not available at this time for code validation.

Loop Seal Clearing: The COMMIX calculations could not model the loop seal portion of the RCS or the possible total loop circulation through the coolant loops if the loop seals clear since COMMIX is a single phase code.

Decay Power Transient: To account for clad oxidation, an increase in the core power was assumed. However, this increase limited the applicability of the results to the period of very early oxidation in the core.

Turbulence: COMMIX contains four turbulence models but apparently none were used in these calculations [16] or in the simulations of the Westinghouse data and Zion plant simulation $[8,19]$. The interfacial shear could be important, however, particularly in the hot legs. 


\subsection{Review of Westinghouse Experiments}

The Westinghouse experimental facility [20] was designed to examine phenomena occurring in a PWR during postulated accidents. Specifically, the experiments were to focus on simulating scenarios in which core uncovering occurs slowly (such as in a TMLB' scenario) and the retardation of core degradation by natural circulation becomes possible. In such scenarios, natural circulation loops within the primary system and the multiple hot leg/steam generator assemblies can be the dominating physics that determine the final outcome of the accident. The fact that the event is transient should be emphasized because heat-absorbing structures will increase in temperature and, in time, approach the temperature of the working fluid. This heat transfer is the driving force for the natural circulation loops in both the primary system and steam generators, resulting in a gradual slow-down in the circulation velocities as the heat transfer diminishes. This in turn reduces convective cooling of the core. Periodic venting will also occur in the scenario when the increasing pressure exceeds safety valve limits. A major goal of the experimental test program was to determine the anticipated fluids/thermal behavior of the system for such scenarios. Baseline experimental tests, then, should focus on transient tests which include prototypic hot leg/steam generators and the venting phenomena. However, as discussed below, the experimental program did not provide such a baseline experiment. The establishment of this baseline experiment is an indispensable step in the program, the importance of which cannot be over-emphasized. Once the physics of this baseline condition are established, additional events that might change the baseline predictions should then be investigated. These include events such as: hydrogen generation, core blockage, and fission product deposition in the hot legs.

The one-seventh (linear dimension) scale experimental facility consisted of a half-model with the cutting plane a short distance from the centerline plane of symmetry. Such a half-model offers economies such as requiring only two hot leg/steam generator assemblies. Testing with the one-seventh scale half-model was performed in two stages. First, a number of tests were performed with single phase fluids (either water and $\mathrm{SF}_{6}$ ) at low pressure. The low pressure limitation existed because much of the reactor vessel was built of acrylic material incapable of withstanding high pressure. The clear acrylic material was used because, early in the program, flow visualization and LDA measurements were performed. However, at low pressure, the fluids/thermal behavior of the model was not prototypic with the full-scale reactor. After the addition of a pressure vessel and other changes, a second series of experiments at high pressure using only $\mathrm{SF}_{6}$ were performed. Again, although non-dimensional parameters did not match those anticipated for full-scale conditions, they came much closer. These two series of experiments have been summarized in two reports $[20,21]$. The following is a review of these two reports including comments on similitude between the scale model and full-scale prototype, the low pressure tests, and the high pressure tests. 


\subsection{Summary of the Low Pressure Tests}

Reported in the low pressure test series were a total of twenty-two steady-state and three transient tests. Steady-state tests are of limited value because the TMLB' scenario is a transient event. The tests were conducted in three phases: nineteen steady-state tests using non-prototypic steam generators; three transient tests; and finally three additional steady-state tests using one non-prototypic and one $49 \mathrm{U}$-tube steam generator. In all twenty-five tests, the hot legs were made of an acrylic material. This material served as an insulator and would not exhibit the same heat transfer characteristics as a steel hot leg pipe.

For the steady-state experiments in which the hot leg/steam generator assemblies participated in the tests (only 10 of the 19), the steam generators were cooled. The rate of cooling affects the importance of the steam generator loops. To investigate the impact of cooling, the rate was varied. This cooling rate was only quantified as "low," "medium," or "high." In six tests, the cooling rate was low; in two, the rate was medium; and in two, the rate was high.

In two of the three transient tests, the hot leg/steam generator assemblies were blocked. Thus, the data from these tests is of limited value in evaluating an actual TMLB' event. The third transient test, using $\mathrm{SF}_{6}$, again used the non-prototypic steam generators. Venting was not simulated during these low pressure transient tests.

In the final three steady-state tests, a $49 \mathrm{U}$-tube acrylic steam generator replaced one of the non-prototypic generators. Although representing an improvement towards geometric similitude, the new $U$ tube generator still did not match any of the pertinent fluids/heat transfer parameters compared to the full-scale $3388 \mathrm{U}$-tube inconel steam generator. Moreover, the one remaining non-prototypic generator transferred 2. 1/2 times more heat than the $49 \mathrm{U}$-tube generator. This introduced an asymmetry into a geometry where symmetry was tacitly assumed. The hot legs were also acrylic during this test series, thus still posing a concern for different pipe heat transfer characteristics as compared to a high conductivity material.

\subsection{Sumnary of the High Pressure Tests}

A total of fourteen steady-state and eight transient tests were discussed, which again fell into three phases. First, eleven standard steady-state tests were conducted, followed by three additional steady-state tests which examined the effect of simulated fission product debris in one of the two hot legs. The third group comprised eight transient tests. The larger percentage of transient tests in the high pressure test series compared to the low pressure test series appears to represent an increased awareness of the importance of the transient tests. There were also only two tests (as opposed to seven in the low pressure tests) performed with the hot legs blocked, which appears to show an increasing appreciation of the important 
fluids/heat transfer contributions of the hot leg/steam generator assemblies.

Two crucial improvements were made to the facility for the high pressure test series. First, modifications were made to accommodate high pressure by the addition of a pressure vessel. The second improvement is that two $216 \mathrm{U}$-tube inconel steam generators were added to the system. An important feature of the new steam generators is that some scaling calculations were performed to approximate the heat transfer and flow resistance characteristics of a scaled $3388 \mathrm{U}$-tube inconel steam generator. The hot legs were also of the proper scale and material.

In the first test series of eleven steady-state tests, two were without the hot leg/steam generator assemblies. In the remaining nine experiments only the $\mathrm{SF}_{6}$ pressure and core heating power were varied. In this test series, although not tacitly stated, the steam generator cooling appeared to be at one fixed rate and was not varied as was done in the low pressure tests. Phenomena secondary to the baseline physics such as "steaming," and light gas generation, etc., were not investigated in this test series. One secondary physics issue, that of the effect of simulated radioactive debris settling in one of the hot legs, was investigated in the second test series.

The third test series consisted of eight transient experiments which were broken into two major blocks. In one block four tests were conducted in which the venting was periodic, which is prototypic of actual PWRs. In the second block, four tests were conducted in which the venting was continuous, which is non-prototypic. As in the steady-state tests, only the $\mathrm{SF}_{6}$ pressure and core heating power were varied in these eight transient tests.

\subsection{Review of Low and High Pressure Tests}

The results of the low and high pressure tests are discussed in detail in [20] and [21]. Rather than repeating this information, it is relevant to compare the two test series, and make some general comments that may affect tying the experimental data to calculational efforts.

In section 6.0, the indispensability of baseline tests was discussed. We emphasize here that the definition of "baseline test" is the authors' definition and does not reflect the opinions of any other organization or individual.

The low pressure tests were conducted at a time in which the importance of various physical processes was still being established, such as the ability of natural circulation to transfer energy to the hot leg/steam generator components. The extensive discussion on qualitative flow visualization tests, the changes in the experimental geometry (such as the steam generator), and the frequent variation in test parameters from test to test all verify this. As defined, a 
baseline test should consist of a transient test with periodic venting using two prototypic hot leg/steam generator assemblies. By this definition, no low pressure baseline test was performed. However, it appears that at least four high pressure tests (T2, T4, T6, and T8) qualify to be baseline tests.

The overall impression given in the test reports is that, because of temperature limitations of certain critical components in the model, steady-state tests were preferred. In a steady-state test, temperatures could be more rigidly controlled; therefore likelihood of damaging an expensive component or instrumentation was reduced. This impression applied to both test series, though less so for the high pressure tests. The greatest problem with steady-state tests concerns the cooling necessary to reach steady-state conditions. Secondary cooling water or air was used to cool the guide tubes, the upper plenum, the upper head, and the steam generators. It is unlikely that the cooling rates for these components are prototypic of the actual structures for the one instant in time that the steady-state conditions are attempting to match. This is virtually confirmed in the low pressure test series when the cooling rate of the steam generators were varied so as to "bracket" actual conditions. Since temperatures in such tests were so low (the greatest temperature reached was $111.2 \mathrm{C}$ ), the effect of the different cooling rates, which were varied over a range of a factor of six, was minimal.

Besides concern with the lack of establishing baseline tests early in the experimental program and the concentration on steady-state tests when transient tests would perhaps have been more productive, scaling is an issue. The low pressure tests, especially for the Grashof number, were seriously deficient in matching the pertinent scaling parameters. This means that parameters such as flow rates, temperatures, mixing rates, etc., which are crucial to overall system behavior, might be quite different in a full-scale reactor as compared to the Westinghouse experiments. Moreover, when fluid mechanics and convective heat transfer are important, changing parameters which affect these physical processes are not always straightforward. This will become evident during the discussion of the sensitivity studies in the cases when the flow rate through the hot $\mathrm{leg} /$ steam generator assemblies was varied (Section 9.3).

A major difference between the low and high pressure test series was in the hot leg/steam generator assemblies. These assemblies can eventually absorb 35 to $41 \%$ of the total heat in the system. In the low pressure tests, the assemblies did not match similitude parameters, such as flow resistance and geometry. In the high pressure tests, a successful effort resulted in the match of the most important similitude parameters and a close approximation with others.

The results of the low pressure and high pressure tests should not be closely compared. So many changes were made in the experimental facility in the transition from low to high pressure that they must really be viewed as two separate experimental facilities with difference components and geometries. Most test parameters, such as pressure, temperature, and flow rates, are not comparable. 


\subsection{Similitude Issues}

Although much effort has gone into developing a one-seventh scale model as similar as possible to the full-scale prototype, the final product must be considered only similar to the prototype; true similitude does not exist (See [21], p. 3-37). The following is a partial list enumerating the differences between model and prototype to show why true similtude does not exist:

1. The lower plenum geometry was not completely modeled.

2 The upper head region features were not well replicated in the model.

3. Flow between the upper plenum and upper head was not prototypical.

4. The simulated power profile varied only in the radial direction, whereas in the full scale case the power profile was two-dimensional.

5. It was assumed that loop seals would never clear, so the model did not include the geometry for cold legs. This assumption is examined in some detail in Section 11.

6. Symmetry in the model was implicitly assumed by using a plane of symmetry modeling only half of the prototype. In addition, however, the cutting plane, instead of being along the centerline, was off-center to include $100 \%$ of the rods that lie along the centerline. The first problem, then, is that the symmetry assumption in fluid mechanics can often preclude flows that normally might occur in full models. Second, with the cutting plane for the half-model not located on the symmetry centerline, there is the possibility of non-prototypic flows.

7. Boiling and condensation are local phenomena not considered in the experiments. In essence, the accident scenarios demonstrate true two-phase flow whereas the experiments are single phase. The attempt to simulate boiling using the "steaming" approach should be viewed with some skepticism because the physical processes are so different.

8. Although globally great pains have been taken to approximate flow resistances in the core, geometric similarity between structures is mostly absent. Thus, boundary layers, shear layers and other local phenomena that may affect boiling, melting, etc. are entirely different.

9. For the low pressure tests, the two steam generators were totally non-prototypic. In the high pressure 
tests, new steam generators were installed that matched some heat transfer and fluid mechanic parameters, but certainly geometric and dynamic similitude were absent.

10. The analysis of [20] points out that the total power necessary for similtude is approximately $35 \mathrm{~kW}$, and according to the information given, the facility was designed to deliver this level of power. However, the maximum power reported in any of the tests, low or high pressure, is $30 \mathrm{~kW}$. There remains the question why none of the tests approached $35 \mathrm{~kW}$ in an attempt to better match similitude.

11. Grashof numbers in the low pressure tests were on the order of $10^{6}$, in the high pressure tests they were on the order of $10^{9}$, and in the full-scale case Grashof numbers are on the order of $10^{12}$. These numbers are based on using a length scale of $0.3048 \mathrm{~m}$ for full-scale and $1 / 7$ th that for the two scale model numbers. Reynolds numbers for the low pressure tests were $~ 435$; for the high pressure tests $\operatorname{Re}-3 \times 10^{4}$; and for fullscale $\operatorname{Re} \sim 3 \times 10^{5}$.

These observations underscore the importance of matching similitude everywhere in a model as much as possible.

A minor issue concerns the initial derivation of the governing equations as reported by Westinghouse. For the non-dimensionalization of the equations in Reference 20, the pressure gradient term was nondimensionalized with:

$$
p^{*}=(p) / q_{0} V_{0}^{2}
$$

where $p^{*}$ is the nondimensional pressure, $p$ is the pressure, $q_{0}$ is a reference density, and $V_{0}$ is a reference velocity. Using such a nondimensionalization, the non-dimensional pressure coefficient, $p^{*}$, should appear in front of the pressure gradient term, but in Reference 20 , it does not. Further, the pressure coefficient should then have been included in the section discussing the importance of the various nondimensional parameters.

In addition, as reported in Reference 22 a much more appropriate choice for non-dimensionalization of the pressure gradient term is

$$
p^{*}=\left(p-p_{0}\right) / q_{0} V_{0}^{2}
$$

where $p_{0}$ is a reference pressure. Using this non-dimensionalization, the pressure term will be of the same order as the inertial terms. The choice in Reference 20 results in non-dimensional terms that are not of the same order. This can result in removing terms of significance from the analysis. Fortunately, in Reference 20 this did not occur. 


\subsection{Summary of the Westinghouse Experiments}

The Westinghouse one-seventh scale experimental model of a PWR was competently designed, built, and instrumented to study natural circulation phenomena. However, the previous discussions of the experiments have focused on the negative aspects of the tests merely to emphasize that the results of the experiments should not have been so heavily relied upon to benchmark the code simulations of the TMLB' accident scenario under review.

The low pressure tests should be considered as the phase of every large, complex experiment when the capabilities and limitations of the apparatus and instrumentation of the facility are being discovered. obviously, early in the program, the emphasis on flow visualization and the mandate on the facility to provide capabilities to model a number of secondary issues diluted the primary concern of obtaining baseline experimental data. However, the two crucial limitations hampering the first test series - the low pressure and the nonprototypic hot leg/steam generator assemblies -- were eliminated by extensive modifications to the facility in the period of time between the low and high pressure test series.

We wish to emphasize the major differences between the low pressure and high pressure tests which lead to our recommendations that will be presented in Sertion 14. The high pressure tests obtained a much closer matching, of the crucial non-dimensional parameters. Also, the high pressure tests contained hot legs and steam generators that matched flow resistanca and geometry much better than those of the low pressure tests. The high pressure test series was a much more comprehensive transient test series. Further, because of these differences, the results of the low and high pressure tests should not be directly compared to one another. Trends such as a higher Grashof number increasing flow in the hot legs can be observed, and general observations concerning physics (such as the fact that natural circulation does occur and is important) can be made, but detailed comparisons cannot be made.

A number of analytical models were developed to explain various physical phenomena observed in the experiments, including the initial scaling models, steam generator scaling, and natural circulation in the steam generators. Although not all of the analytical models have been checked in detail, fundamental theoretical development was sound and the agreement with experiment was reasonable.

The test facility did not match similitude with the full-scale case in a number of areas. This observation concerns the fundamental limitations of similitude with respect to geometry and economics rather than any implied criticism of the facility. It is still important to recognize these limitations in the context that the test results, even for the high pressure tests, should not be applied directly to full-scale reactor situations. This was recognized with respect to the low pressure tests. COMMIX and SCDAP/RELAP5 were used to "scale up" the results of the low pressure tests and predict fullscale results. Thus, the proper methodology is to use the best 
experimental data available to validate computational models. Once confidence in these computational models to match relevant, wellthought-out experiments is realized, then the models can be used to make full-scale predictions. 


\subsection{Summary and Prioritization of SCDAP/RELAP5 Analysis Uncertainties}

Section 4 1isted, in extensive detail, the analysis assumptions, uncertainties, and code limitations present in the SCDAP/RELAP5 analysis of the natural circulation phenomena summarized in NUREG/CR5214 [2]. In addition, the assumptions and uncertainties with the COMMIX analysis and Westinghouse data results were also presented in Sections 5 and 6 , respectively, since both were used to develop the SCDAP/RELAP5 mode1.

The assumptions and uncertainties can be grouped into two main categories: those pertaining to core modeling and those pertaining to the hot leg countercurrent flow. These analyses have shown, in the majority of the cases considered, that the surge line or hot leg will fail long before the vessel. This indicates that the area of interest should 1 ie in those assumptions and uncertainties affecting the timing and outcome of the surge line or hot leg failure. Therefore, for the purpose of this assessment, the key parameters determining the time of these failures are (1) the inlet hot leg vapor temperature and (2) the mass flow rate in the countercurrent flow loop.

The major uncertainties for the SCDAP/RELAP5 analyses affecting the first key parameter, the calculation of the inlet hot leg vapor temperature, lie in the SCDAP/RELAP5 modeling of the core region. These modeling choices determined the amount of energy leaving the reactor vessel and the inlet temperature of steam entering the hot leg and can be summarized as follows:

1. Decay heat history applied during the transient,

2. Oxidation modeling and hydrogen production uncertainties,

3. In-vessel circulation modeling simplifications,

4. Core degradation modeling, and

$5 \quad$ Neglect of fission product transport.

The SCDAP/RELAP5 hot leg countercurrent flow modeling uncertainties which determine the circulation flow rate and piping temperatures are:

1. Circulation flow rate relied heavily on Westinghouse low pressure, non-prototypic experiments and was benchmarked to COMMIX code results using artificially high flow loss coefficients which matched the COMMIX predicted heat transfer but not the flow rate,

2. Neglect of any heat or mass transfer between the countercurrent flows in the hot leg model,

3. Neglect of radial conduction in the split hot leg pipe walls, 
4. Basing the steam generator inlet plenum mixing model on the results of Westinghouse low pressure $1 / 7$ th scale data,

5. No simulation of total loop circulation since the calculations did not predict loop seal clearing, although other studies (discussed in Appendix A) have indicated conditions under which it may occur, including the possibility of a pump seal leak,

6. Inability to calculate hydrogen stratification within the RCS, and

7. Neglect of fission product transport through the coolant loops .

Similarly, the uncertainties associated with the COMMIX analysis can be grouped in terms of the same parameters. The uncertainties associated with vessel modeling which determined the inlet vapor temperature to the hot leg are:

1. Decay heat transient,

2. Oxidation simulation which increased the decay heat energy by only $30 \%$,

3. Inability to model hydrogen production during oxidation,

4. Neglect of fission product transport, and

5. Capability to model single phase vapor only.

The COMMIX hot leg countercurrent flow modeling uncertainties which determined the circulation flow rate and piping temperatures are:

1. Assumption of no heat transfer to the secondary side of the steam generator, which may impact the calculated circulation flow rate,

2. Benchmarking the code to only low pressure, steady state Westinghouse data, and

3. Inability to model fission product transport in the coolant loops.

The major Westinghouse low pressure data limitations discussed in detail in section 6 , upon which both the COMMIX and SCDAP/RELAP5 models were based, are:

1. Low pressure tests did not match pertinent fluid scaling parameters such as flow rates, temperatures, mixing rates, etc., which are crucial to overall system behavior, 
2. Mostly steady state tests were performed, not typical of the TMLB' scenario, and

3. The steam generators were totally non-prototypic.

In an attempt to quantify the relative importance of the analysis uncertainties noted during this review, the sensitivity of the failure location and timing to these parameters was examined using simplified methods. This will enable the sensitivity of key parameters used in the SCDAP/RELAP5 analysis to be assessed. Two methods have been used and will be described in the following sections.

In the first technique, the MELCOR computer code was used to model the Surry primary system natural circulation loop in less detail than the SCDAP/RELAP5 mode1. MELCOR was chosen as the calculational tool for this assessment effort because it (1) contains built-in modeling features to calculate coupled heat/mass transfer phenomena between fluids and structures, (2) is designed to easily model nuclear power plant components, and ( 3 ) has an extensive sensitivity study capability for examining several of the uncertainties summarized above. The MELCOR model developed for this study is described in Section 8 .

Sensitivity studies using MELCOR described in Section 9 were performed to examine the following issues determined to be major contributors to uncertainties associated with the SCDAP/RELAP5 analysis:

1. Decay heat magnitude,

2. Oxidation heating magnitude,

3. Circulation rate,

4. Modeling radial conduction on the split hot leg pipe, and

5. Modeling heat and mass transfer between the hot/cold countercurrent flows in the hot leg.

In addition, a pump seal leak simulation was completed with MELCOR. The results of this analysis are discussed in section 11.

The second method involved modeling the steam generator as a locally 1-D thermosyphon. The intent of the thermosyphon mode 1 was to provide an independent estimate of the circulation and heat transfer rate in the steam generator, and thereby provide a way to resolve the discrepancy between the predictions given by the SCDAP/RELAP5 and COMMIX models. In addition, sensitivity studies could be performed to examine the chosen steam generator inlet plenum mixing fraction as well as the proportion of steam generator tubes carrying hot versus cold fluid. These parameters were entirely based on low pressure Westinghouse data in the SCDAP/RELAP5 analyses. The results of these calculations are discussed in Section 10. 


\subsection{Surry Natural Circulation MELCOR Model Development}

The MELCOR code [23] was used to model the natural circulation phenomena in the Surry nuclear power plant reactor coolant system during the TMLB' accident scenario. MELCOR is a fully integrated, engineering-level computer code that models the progression of severe accidents in light water reactor nuclear power plants. MELCOR is being developed at Sandia National Laboratories for the U.S. Nuclear Regulatory Commission (USNRC) as a second-generation plant risk assessment tool and the successor to the Source Term Code Package [24]. The spectrum of severe accident phenomena, including reactor coolanc system and containment thermal-hydraulic response, core heatup, degradation and relocation, and fission product release and transport, is treated in MELCOR in a unified framework for both boiling water reactors and pressurized water reactors. MELCOR has been especially designed to facilitate sensitivity and uncertainty analyses.

The thermal/hydraulic calculational method in MELCOR uses a control volume/flow path approach similar to SCDAP/RELAP5. However, the same models are used for all volumes and junctions, unlike SCDAP/RELAP5, which contains various separate volume/flow junction models to represent pipe, annuli, and branches or valve, pump, and turbine components. MELCOR does not have the capability to model multidimensional flows within control volumes, while simple approximations a 110 SCDAP/RELAP5 to simulate 2 -dimensional vesse1 natural circulation flows. (See Section 4.2.) One dimensional heat structure modeling is available to simulate all internal and RCS piping, similar to the capabilities of SCDAP/RELAPS.

The major difference in model sophistication for the objectives of this study lies in the core heatup, degradation, and relocation models. For this MELCOR assessment, a deliberate decision was made not to attempt to assess the core relocation and degradation models of SCDAP/RELAP5. Rather, determination of the hot leg inlet vapor temperature, which results from the events taking place in the core, was the focus of interest for examining the loop natural circulation phenomena. Therefore, core degradation and relocation modeling was not attempted, although MELCOR possesses the capability to do so.

To ensure consistency between the SCDP/RELAP5 and MELCOR calculations, a basecase MELCOR calculation should match the important parameters (mass flow rates, hot leg vapor temperatures and RCS piping temperatures) as closely as possible with 'Sensitivity Case 1' of the SCDAP/RELAP5 analyses [2]. 'Sensitivity Case 1' was the basecase of the SCDAP/RELAP5 sensitivity calculations.

\subsection{MELCOR Model and Nodalization}

The MELCOR model nodalization for the Surry natural circulation calculation is shown in Figure 8.1.1. The Surry RCS consists of three coolant loops. However, for this calculation, all three loops were lumped into a single equivalent loop. Combining the three loops was 
reasonable because all the SCDAP/RELAP5 results showed only slight differences in the energy transfer to coolant Loop $C$ (containing the pressurizer and surge line) compared to Loops A and B [2].

A MELCOR input decik for the Surry plant was available as a starting point for the development of this natural circulation model. The deck was originally developed by INEL in 1988 from the SCDAP/RELAP5 model and extensively modified so that it would run at reasonable computational speeds at Sandia National Laboratories for the MELCOR PWR plant demonstration calculation performed for the MELCOR Peer Review Committee [25]. These modifications did not alter the plant geometry. Therefore, consistency was assured between the geometric details of the MELCOR and SCDAP/RELAP5 input decks.

\section{SURRY NATURAL CIRCULATION MELCOR MODEL}

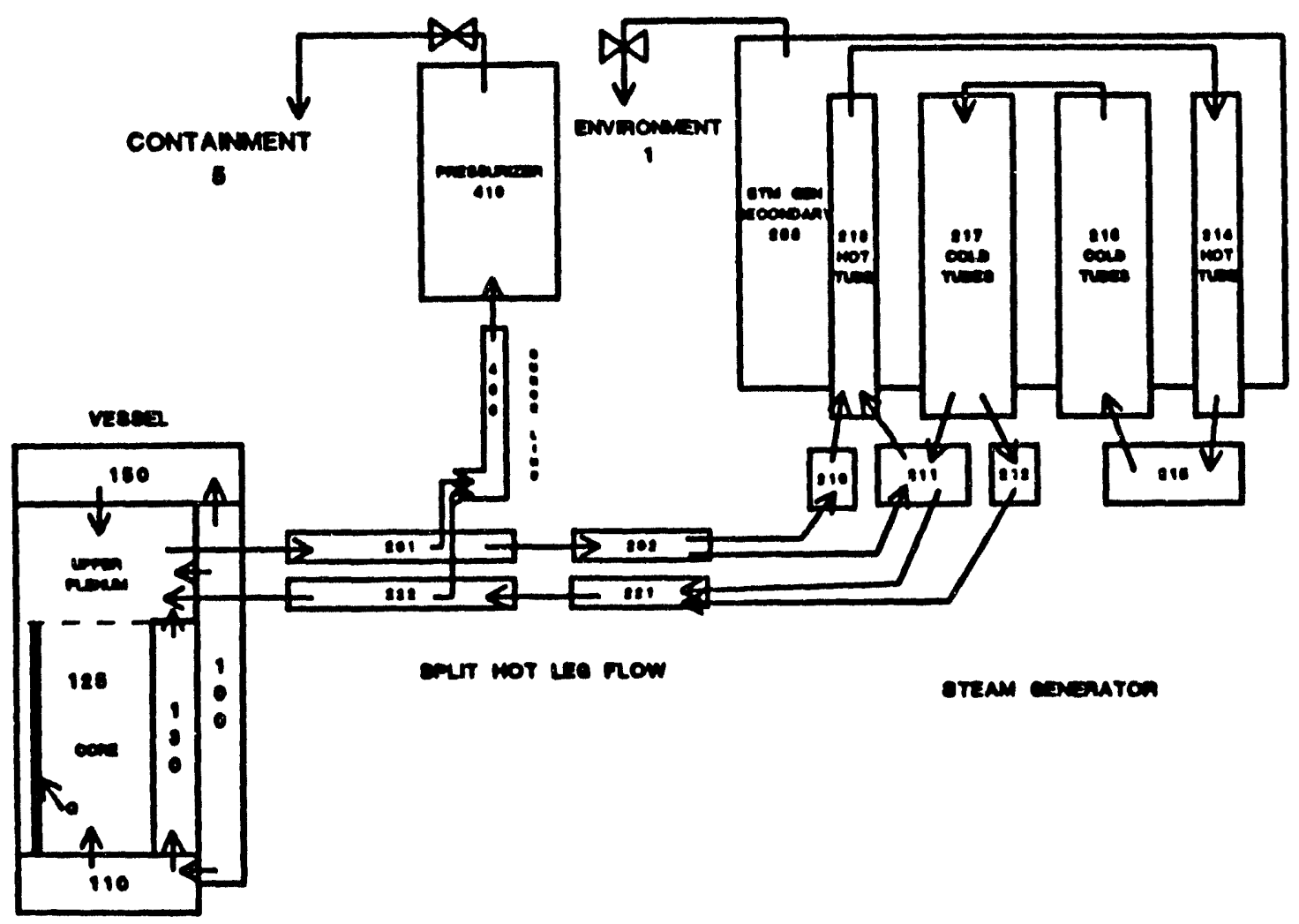

Figure 8.1.1 Nodalization of the reactor coolant system for the Surry MELCOR calculations with hot leg natural circulation. 
The MELCOR model for these natural circulation analyses consisted of 22 control volumes, 28 flow paths, and 72 heat structures to mode 1 the primary coolant system.

The reactor vessel was modeled by five control volumes, as shown in Figure 8.1.1, representing the downcomer (CV 100), lower plenum (CV 110), core and upper plenum (CV 125), core bypass (CV 130), and upper head (CV 150). For this calculation the core and upper plenum region were combined into one control volume to model fluid mixing caused by in-vessel natural circulation. This provided the best match to the SCDAP/RELAP5 calculated vapor temperature histories entering the top of the hot leg, which were produced by SCDAP/RELAP5's natural circulation modeling of the core and upper plenum. Several iterations on the core and upper plenum MELCOR nodalization were performed before this one was chosen. The detall of the model was increased, at one extreme, resulting in five control volumes to model the core region and decreased, at the other extreme, by combining both the core and upper plenum into a single control volume. The desired results were achieved with the simplified nodalization of the combined core and upper plenum.

As mentioned previously, detalled core structure modeling using MELCOR's Core Package was not included in this nodalization. Instead, the core fuel rods were modeled as $1-D$ heat structures. The decay heat energy was added as a heat structure internal power source. oxidation was simulated by adding energy to the core steam as an energy source. The associated hydrogen production during oxidation is discussed in Section 9.2.

A11 other vessel structures (vessel. walls, thermal shield, core baffle, core barrel, support plates, CRD housings, lower plenum, upper head, and upper plenum internal structures) were modeled as 1-D heat structures, similar to the SCDAP/RELAP5 heat structures model. Convective heat transfer between the fluid and structures was code calculated. The outer vessel walls were assumed to be adiabatic, consistent with the SCDAP/RELAP5 analysis.

The coolant loop model shown in Figure 8.1 .1 was based on the SCDAP/RELAP5 sensitivity case 1 nodalization [2] shown in Figure 8.1.2. The hot $1 \mathrm{eg}$ is split into two equal area pipes. CV 201 and CV 222 represent the split hot leg segment to the surge 1 ine and CV 202 and CV 221 represent the segments to the steam generator inlet plenum. The top pipe carries the hot vapor leaving the upper plenum and the bottom half carries the cooler vapor back to the upper plenum. The steam generator inlet plenum is split into 3 control volumes to simulate the steam generator inlet plenum mixing. The SCDAP/RELAP5 calculations based the volume flow areas on the results of the COMMIX analysis. The same areas were used in the MELCOR model. CV 210 represents the unmixed hot flow entering the plenum from the top hot $1 \mathrm{eg}, \mathrm{CV} 211$ represents the mixing volume, and CV 212 represents the unmixed cold flow returning from the cold steam generator tubes and flowing toward the vessel via the lower portion of the hot leg. This model assumes a mixing fraction in the inlet plenum of $90 \%$. The 


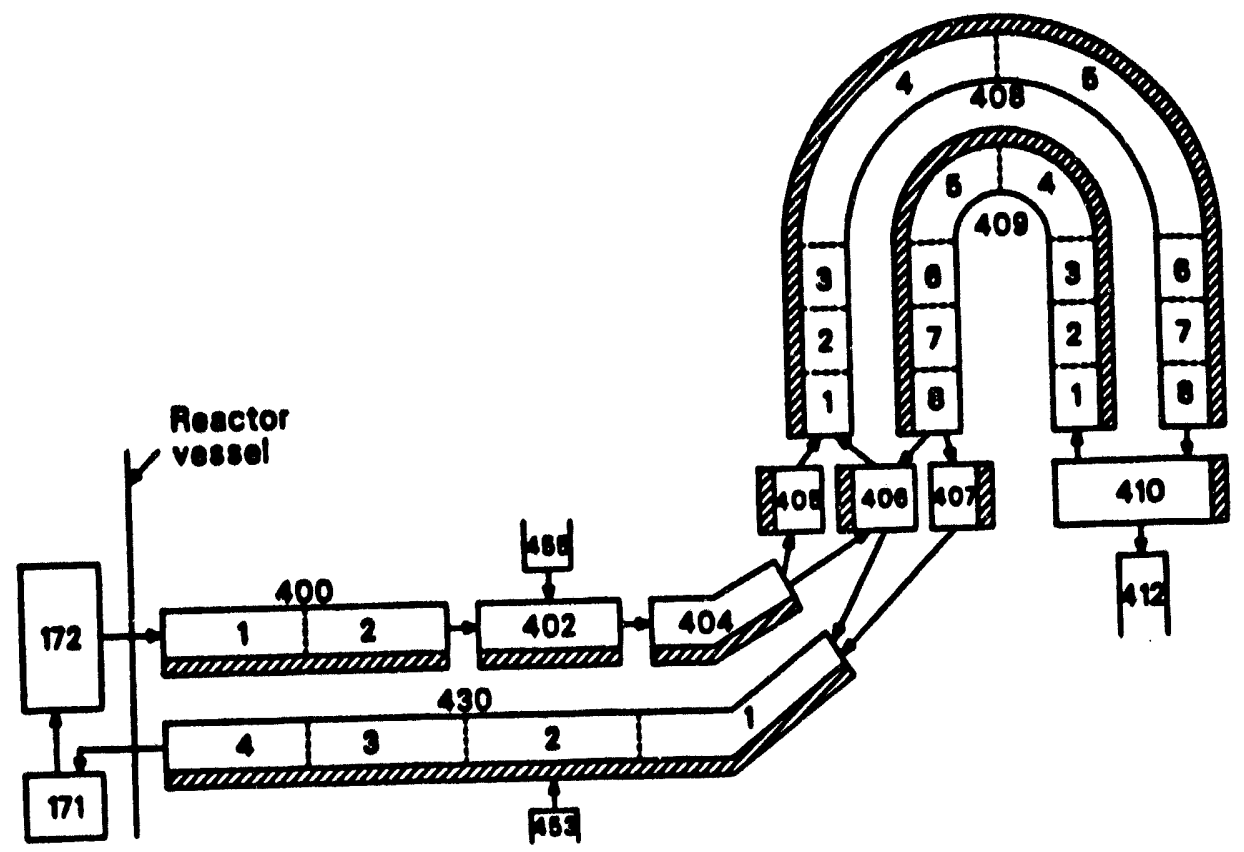

Figure 8.1.2 Nodalization of the hot $1 \mathrm{eg}$ and steam generator for the Surry SCDAP/RELAP5 calculations with hot leg natural circulation.

unmixed volumes (CV 210 and CV 212) each carry 5\% of the total inlet plenum flow. The natural circulation steam generator tube flow nodalization assumes $35 \%$ of the total tubes (CV 213 and CV 214) carry the hot fluid to the steam generator outlet plenum (CV 215) and the other $65 \%$ of the tubes (CV 216 and CV 217) carry the cooler fluid back to the inlet plenum where it mixes with the incoming hot flow before returning to the vessel. The SCDAP/RELAP5 model based these parameters on the Westinghouse low pressure natural circulation experiments [4].

The loop piping loss coefficients were taken from the SCDAP/RELAP5 calculation. These values were very large, approximately an order of magnitude larger than physically reasonable for modeling this kind of piping system. However, Bayless [2] chose these coefficients for the SCDAP/RELAP5 mode1 to match the COMMIX calculated heat transfer to the steam generator tubes and hot leg piping for a given hot leg inlet temperature. In Section 10, the adequacy of this choice will be examined.

In this nodalization, the cold leg portion of the RCS loop was not included. In a later calculation, discussed in Section 11, in which the pump seal leak scenario is simulated, the cold leg and pump suction sections were added. 
The surge line was modeled by one control volume (CV 400). This differed from the SCDAP/RELAP5 model in which the surge line was split into two separate volumes, a top half and bottom half, each connected separately to the top and bottom halves, respectively, of the hot leg. The pressurizer (CV 410), was also modeled as a single control volume with the two PORV's modeled as a single valve with twice the rated capacity of one PORV. The PORV open and close setpoints were 16.20 and $15.72 \mathrm{MPa}$, respectively.

The secondary side of the steam generator was modeled as one control volume (CV 255). A more detailed two volume model was used in some initial calculations, but had an insignificant effect on the results. The relief valve set points were 7.24 and $6.89 \mathrm{MPa}$, respectively.

A11 piping components were modeled as 1-D heat structures. Convection to the fluid was code calculated and the outer walls of all components, except the steam generator tubes, were assumed to be adiabatic. The outside of the steam generator tubes were allowed to transfer energy via convection (natural or forced) to the fluid in the steam generator secondary.

\subsection{MELCOR Basecase Mode1 Results}

The initial conditions for the MELCOR calculation were based on SCDAP/RELAP5 'Sensitivity Case $1 '$ ' [2]. The calculation began at 160 minutes into the TMLB' transient. This corresponded to the time at which the core began to uncover and heat up. The entire system was at saturated conditions. The pressure of the RCS system was $16.2 \mathrm{MPa}$, and the initial temperature of the vapor and structures was assumed to be $625 \mathrm{~K}$. This temperature was a few degrees above the saturation temperature and the initial temperatures used in the SCDAP/RELAP5 analyses, but was used to eliminate small amounts of condensation which tend to form during the initial MELCOR startup transient. The core was initially $75 \%$ full of saturated water. To simplify the MELCOR calculations, the pressurizer was assumed to contain only vapor. The SCDAP/RELAP5 calculations showed that the pressurizer was approximately $70 \%$ full of water and continually drained throughout the transient. The secondary side of the steam generator contained superheated steam at a pressure of $7.07 \mathrm{MPa}$ and vapor temperature of $625 \mathrm{~K}$.

The core decay power history was taken from Table A-4 in Reference 2 and is shown in Figure 8.2.1. This is the same power history used in the SCDAP/RELAP5 'Sensitivity Case 1 ' calculation in Reference 2 and was calculated from ORIGEN2 [26]. It should be noted that this decay heat history was approximately $9 \%$ lower than the one used in the initial SCDAP/RELAP5 scoping calculations which were based on the ANS 5.1 [27] standard (which is known to be conservative with respect to power leve1s). The basecase SCDAP/RELAP5 axial power profile was used in the MELCOR model as well. 
As previously noted, the oxidation energy was not mechanistically calculated in these MELCOR analyses. However, the effect of oxidation was simulated by adding an appropriate amount of energy to the core and upper plenum fluid (CV 125). The amount chosen is shown in Figure 8.2.1 and came from SCDAP/RELAP5 'Sensitivity Case 3' results. Though this case considered the effect of reduced inlet plenum mixing, it was the only oxidation energy history shown in Reference 2 and was used since the 'Sensitivity Case 1 ' values could not be obtained for a timely completion of the analysis. This accelerated oxidation rate was larger than the value predicted by the SCDAP/RELAP5 'Sensitivity Case 1'. The results of a sensitivity study on oxidation heating will be discussed in Section 9.2.

The resulting fraction of core input energy (decay heat plus oxidation energy) that had been removed by the steam coolant at any time is shown in Figure 8.2.2. The core heat removal remained near $72 \%$ for most of the calculation. This compared well with the SCDAP/RELAP5 result of $75 \%$ [2].

Figure 8.2.3 presents the system pressures during the MELCOR calculation. The RCS pressure uscillates between the PORV pressure setpoints as the vapor is continually heated by the decay heat generated in the fuel rods. The secondary side of the steam generator also contains superheated steam. The steam was gradually heated and pressurized as energy was transferred through the steam generator tubes. The pressure was relieved through the secondary side relief valves. Figures 8.2 .4 and 8.2 .5 show the mass flow rate of steam through the pressurizer PORV valves and steam generator secondary valves, respectively. The containment pressure (Figure 8.2.3) slowly increased as steam was released from the primary system through the PORVs.

The collapsed liquid level in the reactor vessel is shown in Figure 8.2.6. In the MELCOR calculation, despite the simple core simulation used, the core liquid coolant level dropped below the core within 1 to 2 minutes of the SCDAP/RELAP5 prediction.

The RCS upper hot leg coolant flow rate predicted by MELCOR is compared with the SCDAP/RELAP5 and COMMIX results in Figure 8.2.7. Since all three coolant loops were combined in the MELCOR model, the mass flow rate shown was that of an average coolant loop, assuming the flow in all three loops were equal. The flow rate between periods when the PORV valves are open (the spikes in the curves) compares very well with the SCDAP/RELAP5 calculated flow rate for coolant Loop C (which contains the surge line and pressurizer) while the PORV valves are closed. Note that the two curves showing the SCDAP/RELAP5 results represent the bounding values when the PORV is closed (lower curve) compared to when the PORV is open (the higher curve). The actual flow rate was oscillatory in nature, similar to the MELCOR results, but bounded by these two curves. The COMMIX calculated flow rate when the PORV valves are closed is also shown for comparison. 


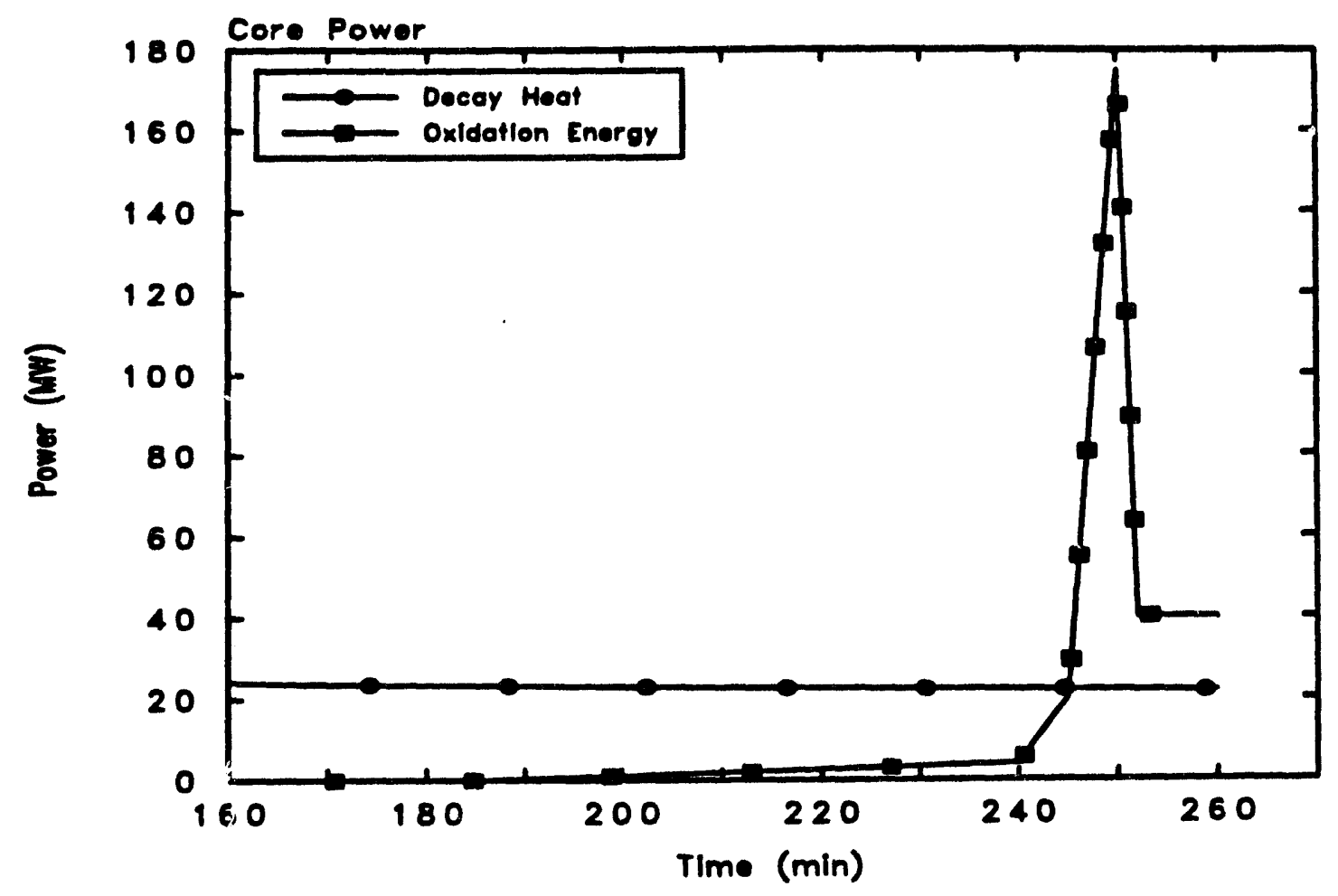

Figure 8.2.1 Core decay heat and oxidation energy used in the MELCOR basecase calculation.

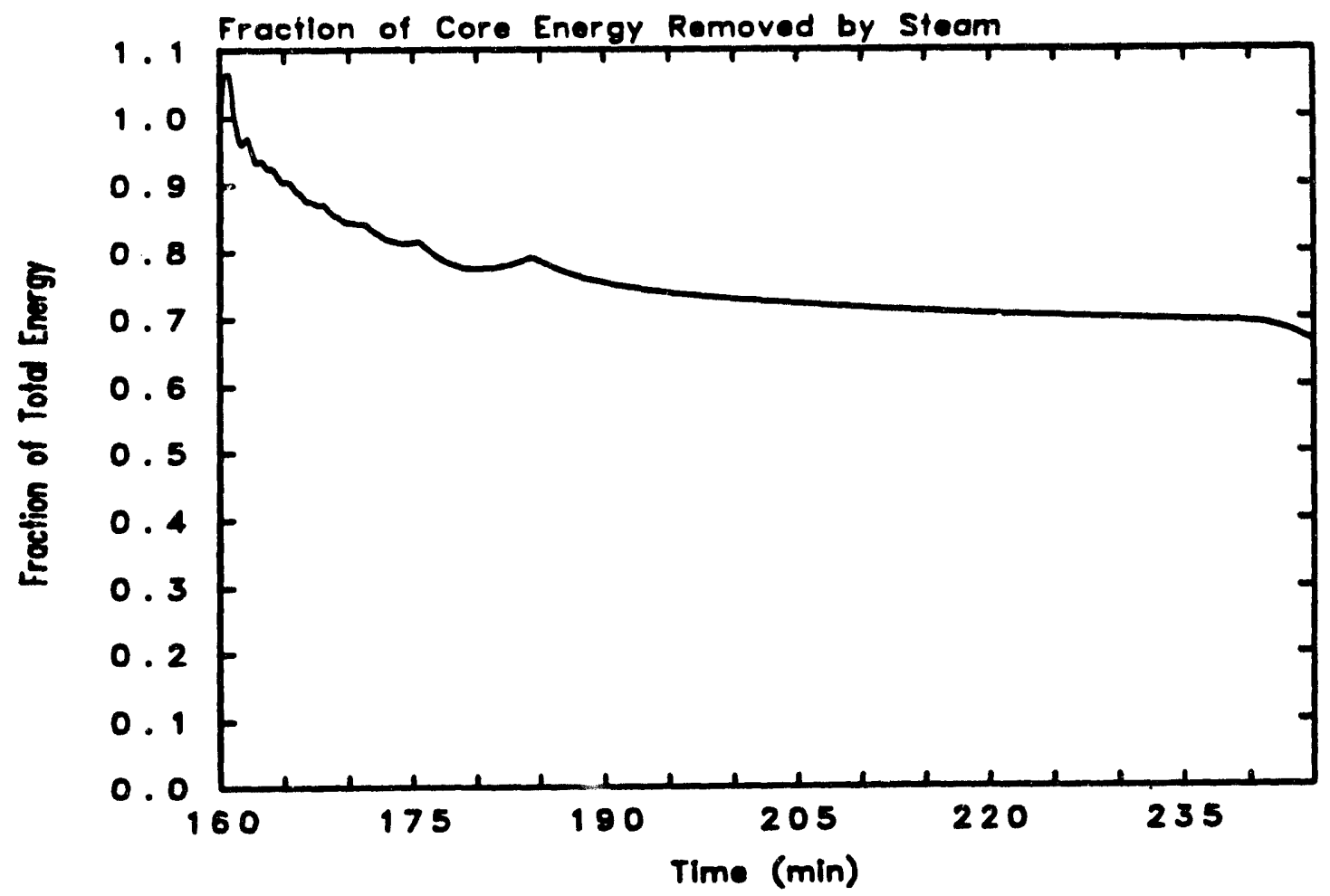

Figure 8.2.2 Fraction of core input energy removed by the coolant in the MELCOR basecase calculation. 


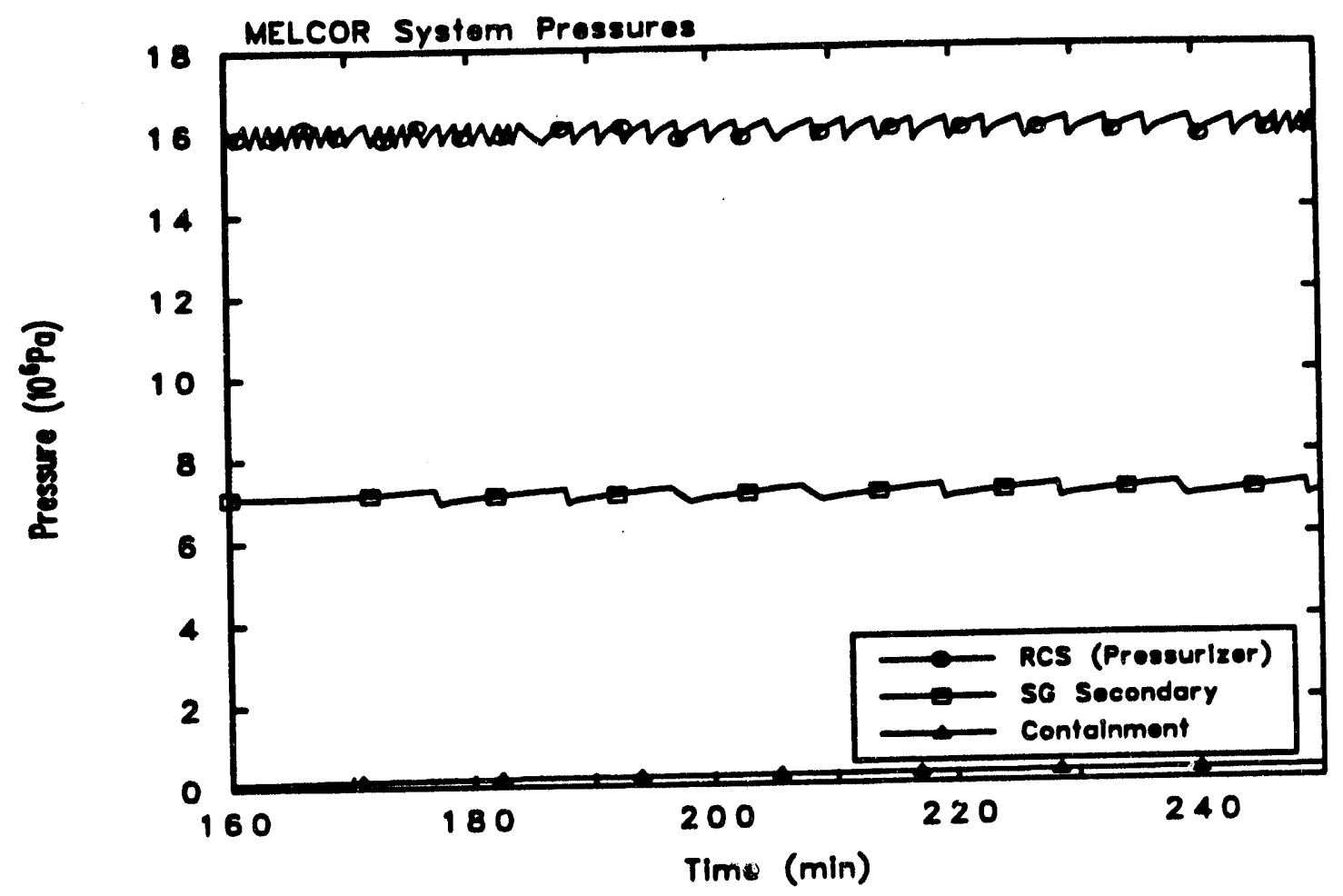

Figure 8.2.3 System pressures of the MELCOR basecase calculation.

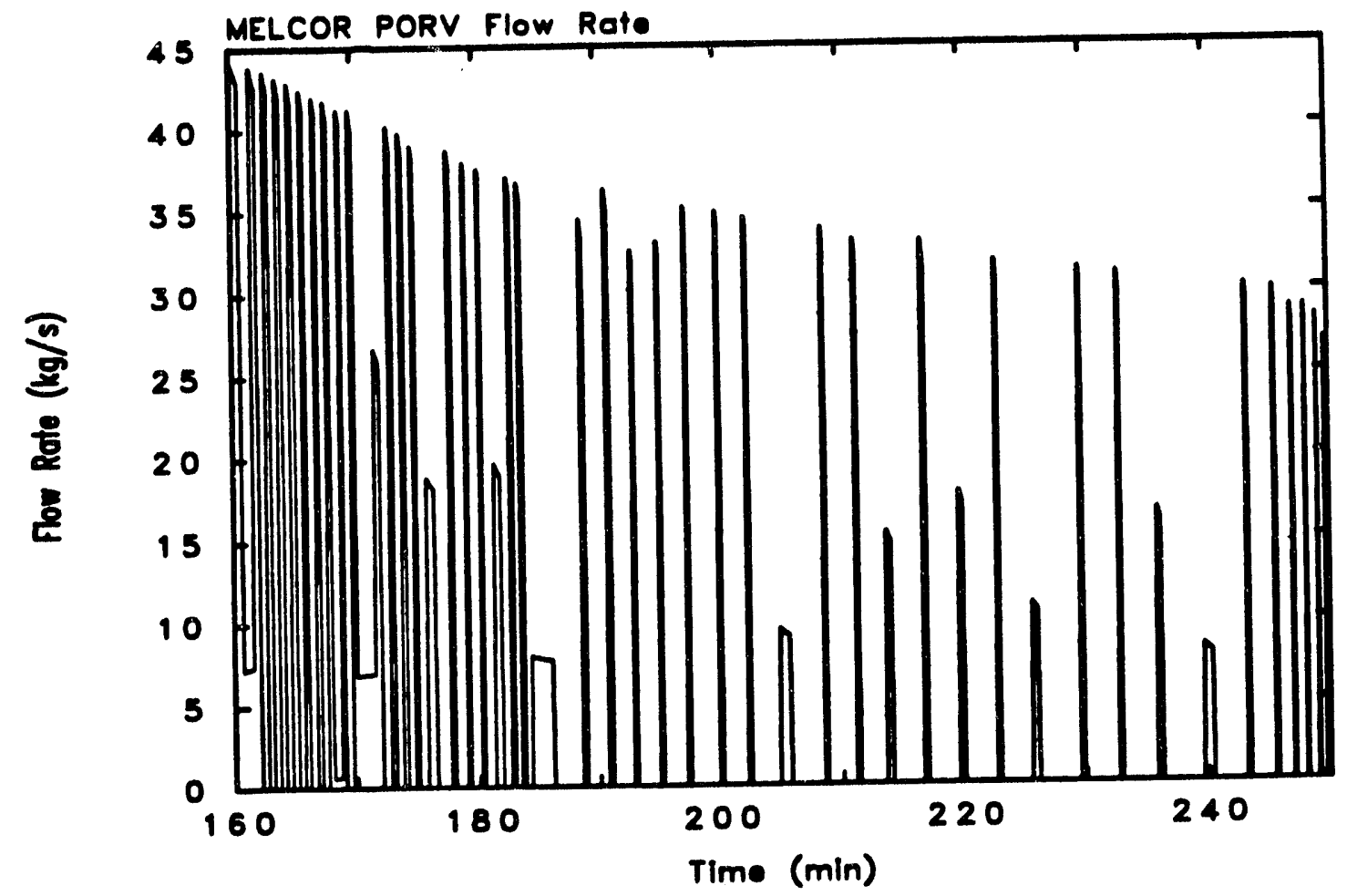

Figure 8.2.4 Mass flow rate of steam through the PORV valves in the MELCOR basecase calculation. 


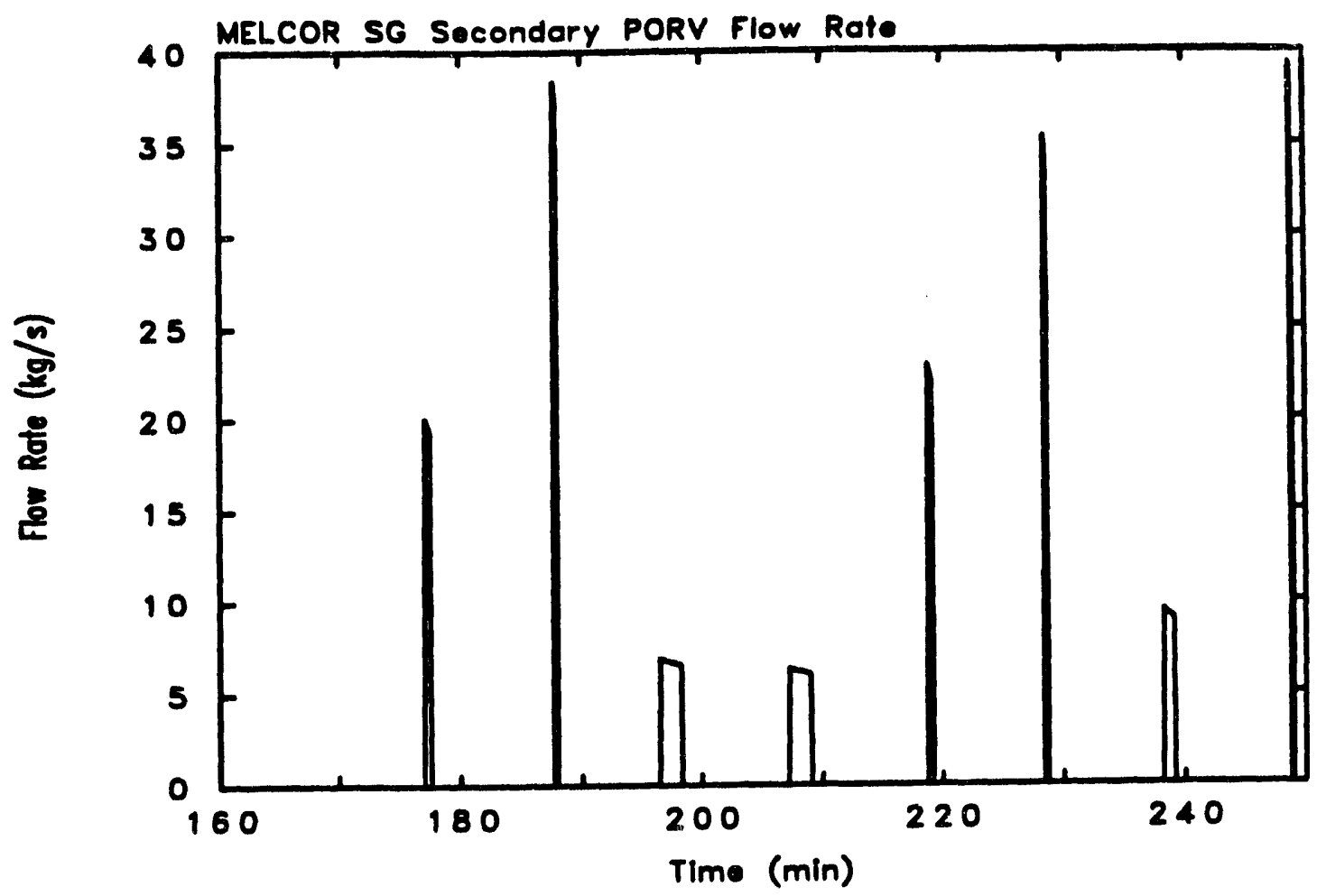

Figure 8.2.5 Mass flow rate of steam through the steam generator secondary PORV valves in the MELCOR basecase calculation.

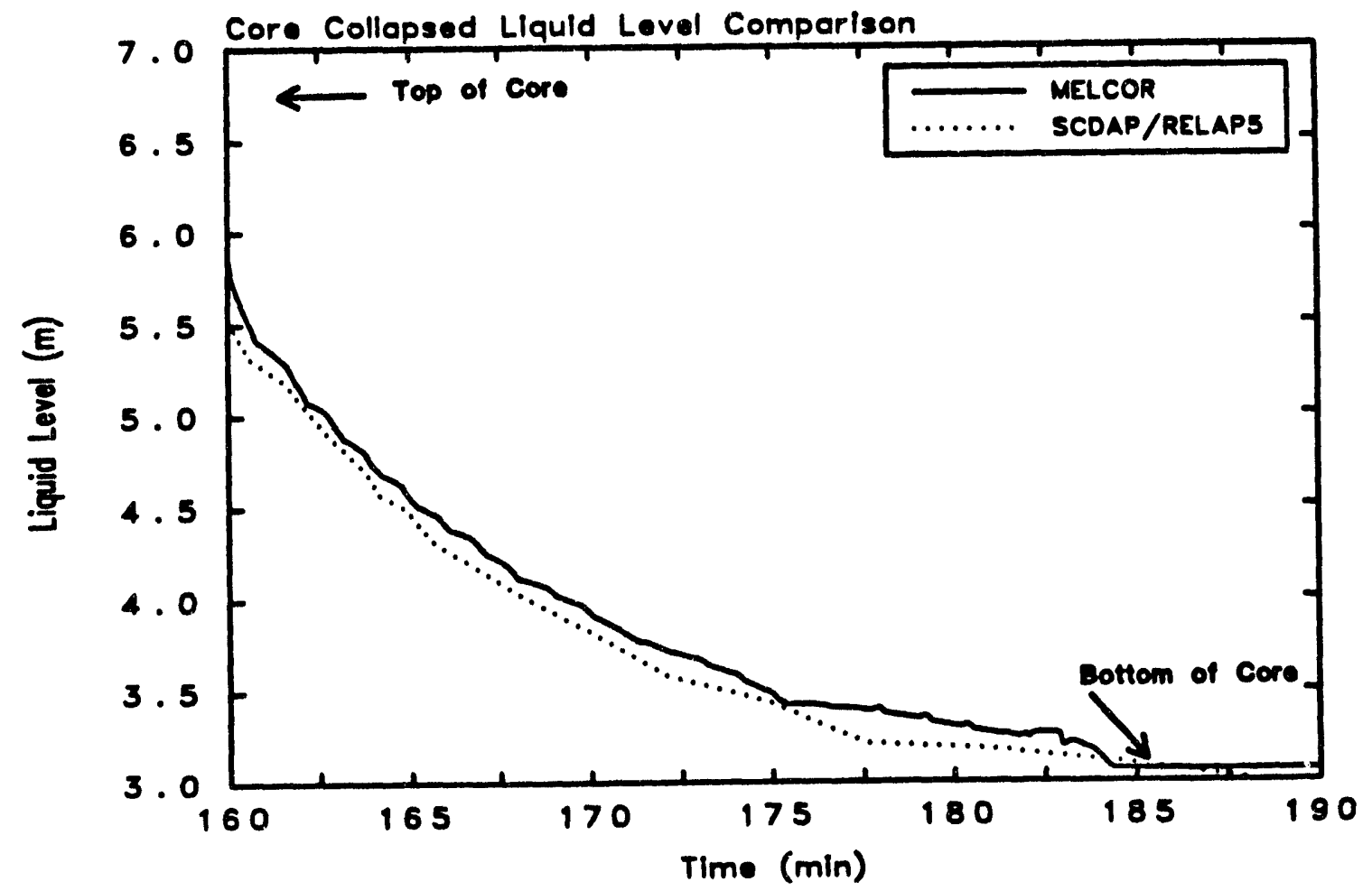

Figure 8.2.6 Comparison of the MELCOR basecase core collapsed liquid level history with the SCDAP/RELAP5 Sensitivity Case 1 results. 


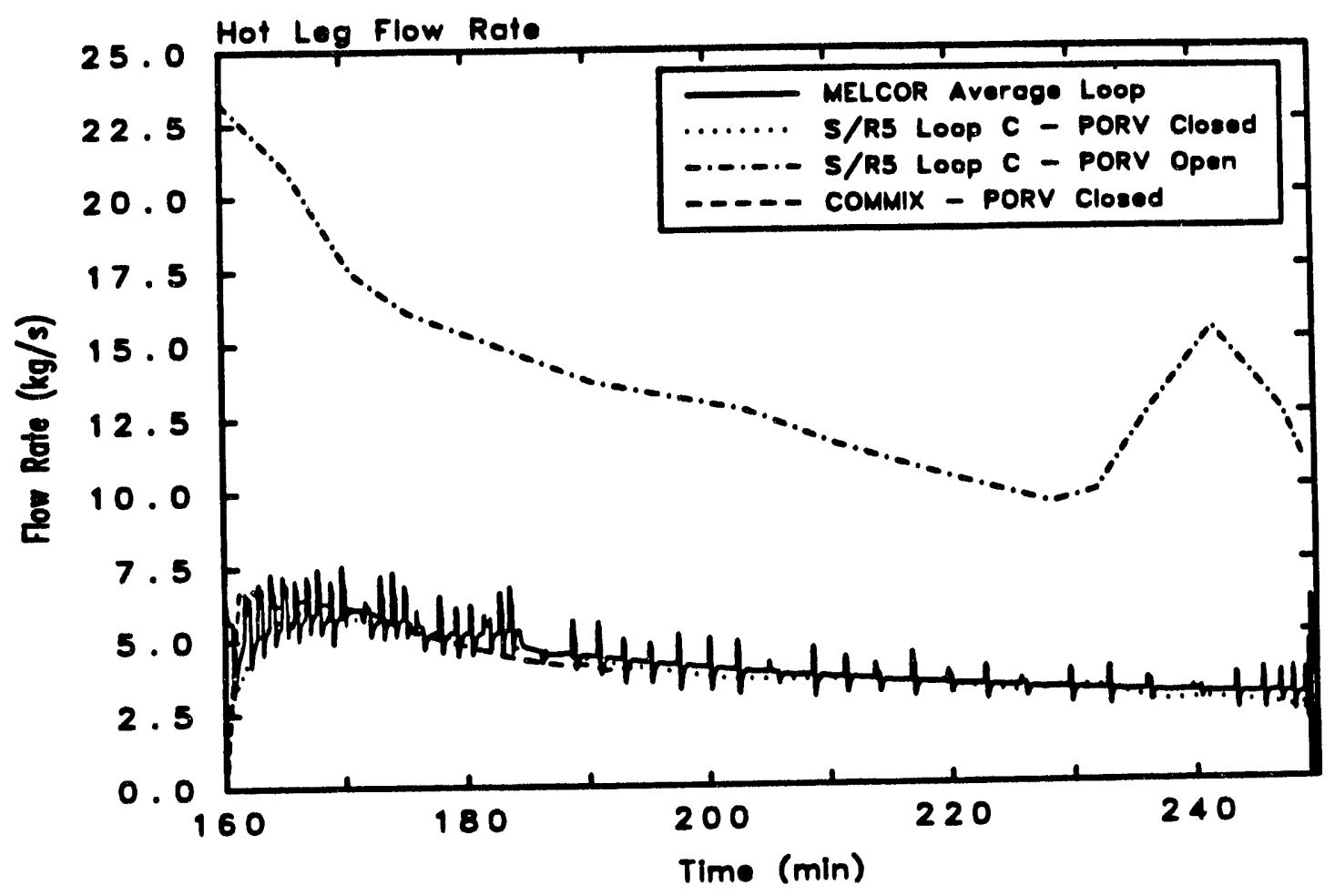

Figure 8.2.7 Comparison of the hot leg mass flow rate between the MELCOR basecase, SCDAP/RELAP5, and COMMIX results.

Due to mixing in the inlet plena of the steam generators, the mass flow rate through the steam generator tubes and through the hot leg may be different. The SCDAP/RELAP5 basecase results predicted a mass flow rate through the Loop $C$ steam generator tubes to be approximately $120 \%$ larger than the flow rate through the hot legs. The results of the MELCOR steam generator versus hot leg mass flow rates are shown in Figure 8.2.8. The MELCOR calculation also predicted a $120 \%$ increase in flow rate through the steam generator tubes after 190 minutes. Note that the SCDAP/RELAP5 (abbreviated as S/R5 in the figure) steam generator tube flow rate plotted in the figure is $120 \%$ greater than the $S / R 5$ hot leg flow rate for the entire transient. The actual time history of the flow rate through the steam generator was never presented in NUREG/CR-5214 [2] Therefore, the discrepancy shown at the beginning of the transient between MELCOR and SCDAP/RELAP5 may not be real. Later in the transient, however, consistent results of circulation flow rates are shown between the two codes.

The COMMIX flow rate results are also shown in Figure 8.2.8. Note that the steam generator flow rate was only $25 \%$ larger than the hot leg flow rate, indicating one of the inconsistencies between the SCDAP/RELAP5 and COMMIX results. 


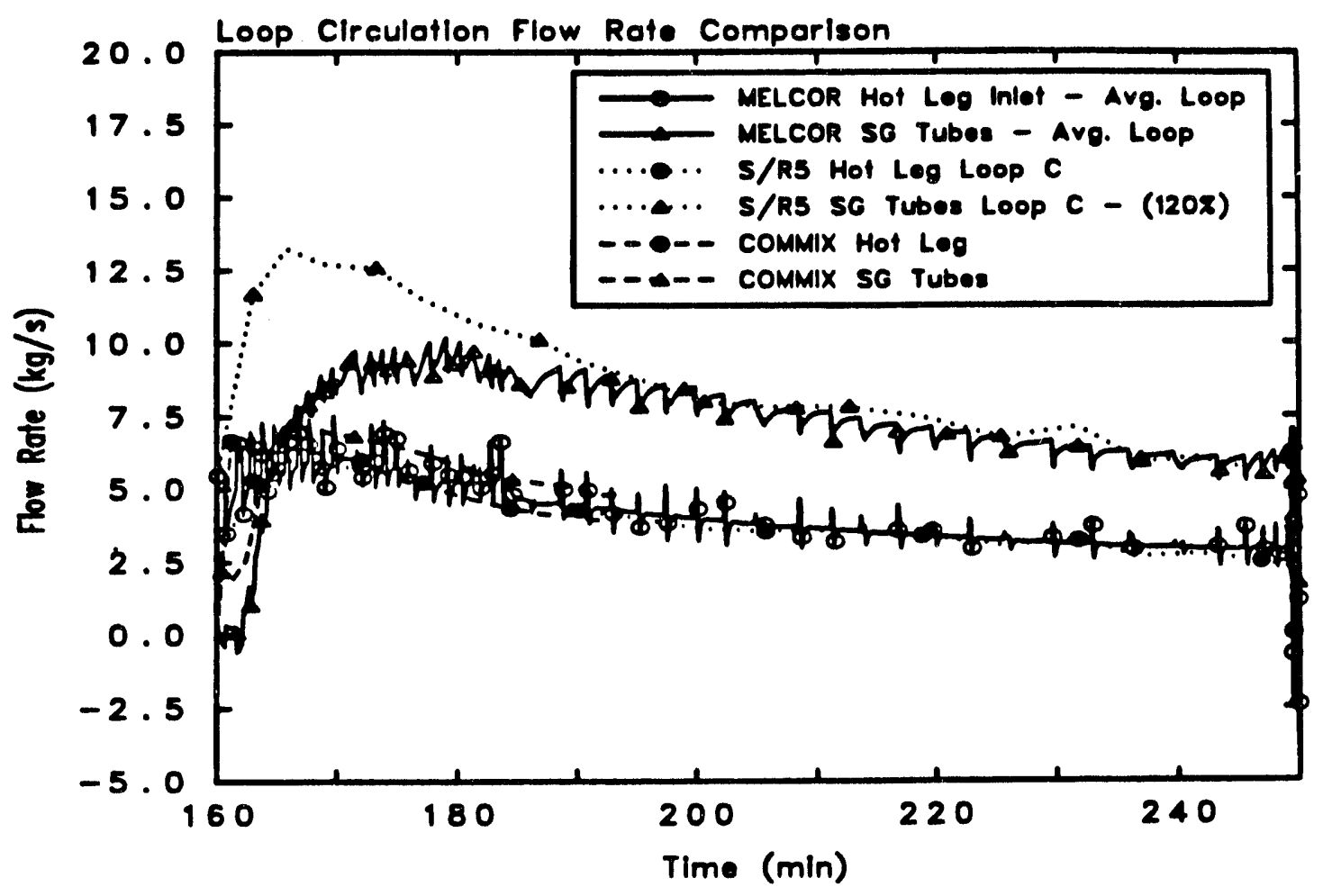

Figure 8.2.8 Comparison of the hot leg and steam generator mass flow rates between the MELCOR basecase, SCDAP/RELAP5, and COMMIX results.

The MELCOR vapor temperatures predicted at various locations in the RCS are shown in Figure 8.2.9. The core and upper plenum temperatures were the highest, being heated by decay and oxidation energy from the fuel rods. The large increase in temperature, beginning at approximately 245 minutes, was due to the accelerated oxidation energy addition to the core. The hot leg inlet temperature was slightly cooler than the upper plenum temperature because of heat transfer to the piping. The surge line vapor temperature was very sensitive to the opening/closing of the PORV valves. The hot and cold steam generator tube vapor remained fairly cool because of the large heat losses through the tubes to the secondary and extensive mixing in the steam generator inlet plena. The bottom hot leg vapor temperature of the flow returning back to the vessel was slightly hotter than the vapor temperature of the flow exiting the tubes since this vapor was reheated in the inlet plena where mixing of the hot and cold flows occurred. 


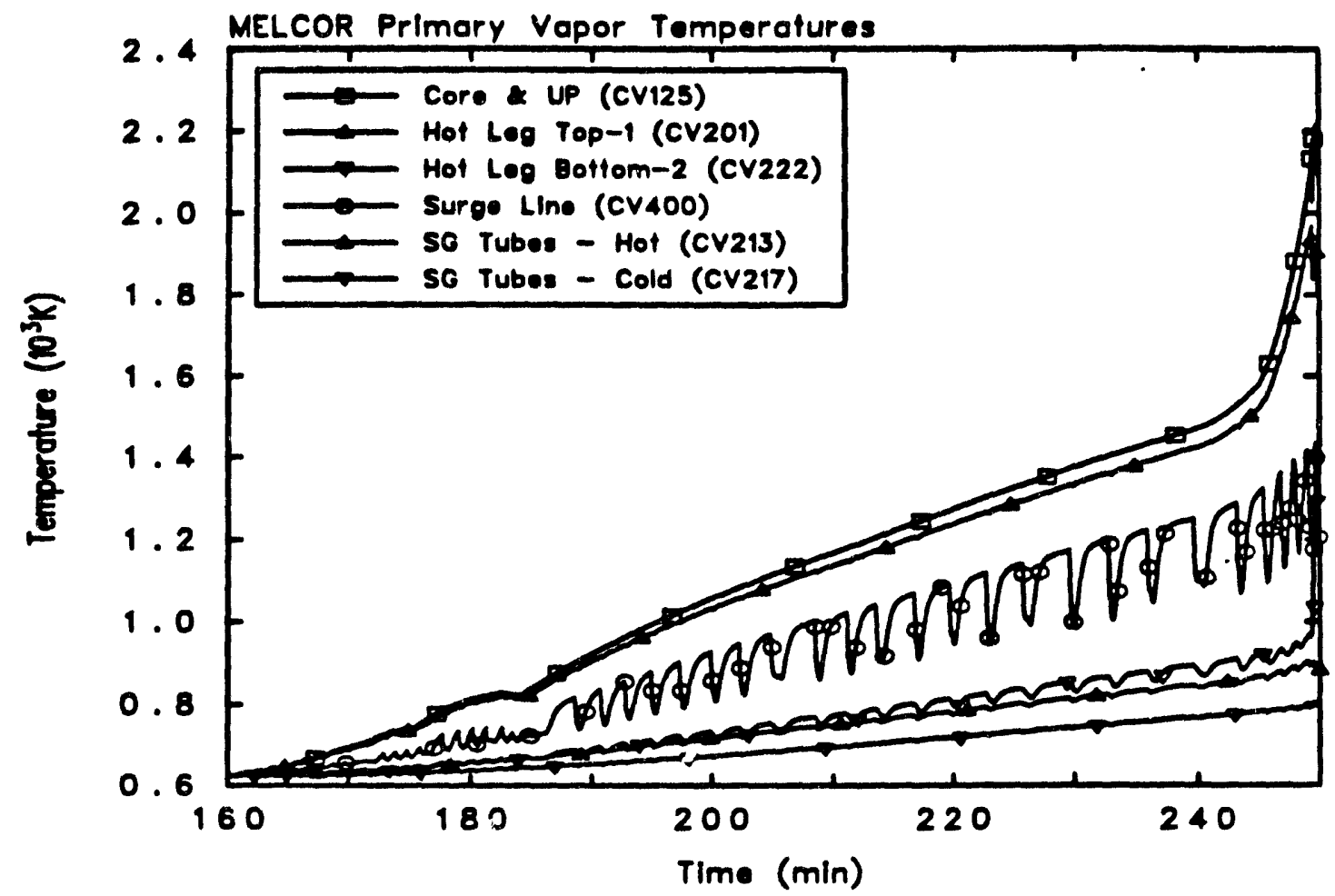

Figure 8.2.9 Reactor coolant system vapor temperatures for the MELCOR basecase calculation.

Figure 8.2.10 presents a comparison of the MELCOR and SCDAP/RELAP5 calculated hot leg top and bottom vapor temperature histories. The MELCOR vapor temperatures were approximately $100 \mathrm{~K}$ larger than the SCDAP/RELAP5 vapor temperatures after 200 minutes. This was in part due to the MELCOR vessel model simplifications. The upper plenum and core fluid completely mixed, whereas the SCDAP/RELAP5 model divided the core and upper plenum into several radial and axial subvolumes to simulate natural circulation flow patterns. In addition, draining of the pressurizer was not simulated in the MELCOR calculation. The SCDAP/RELAP5 analysis showed constant draining of the pressurizer water into the hot leg until it emptied at approximately 225 minutes. This slow addition of saturated liquid to the hot leg tended to cool vapor. This helps explain why the MELCOR predicted hot leg top vapor temperature rise shown in Figure 8.2.10 was larger during the beginning of the transient, matching the SCDAP/RELAP5 temperature rise rate after 220 minutes, and why differences in the inlet vapor temperature were expected. The temperature difference between the top and bottom not leg countercurrent flows, however, was consistent with the SCDAP/RELAP5 results showing consistency in the heat transfer characteristics of the system.

The vapor temperature history of the secondary side of the steam generator is shown in Figure 8.2.11. The temperature rise of the secondary indicated the amount of decay heat energy transferred from the primary system through the steam generator tubes. 


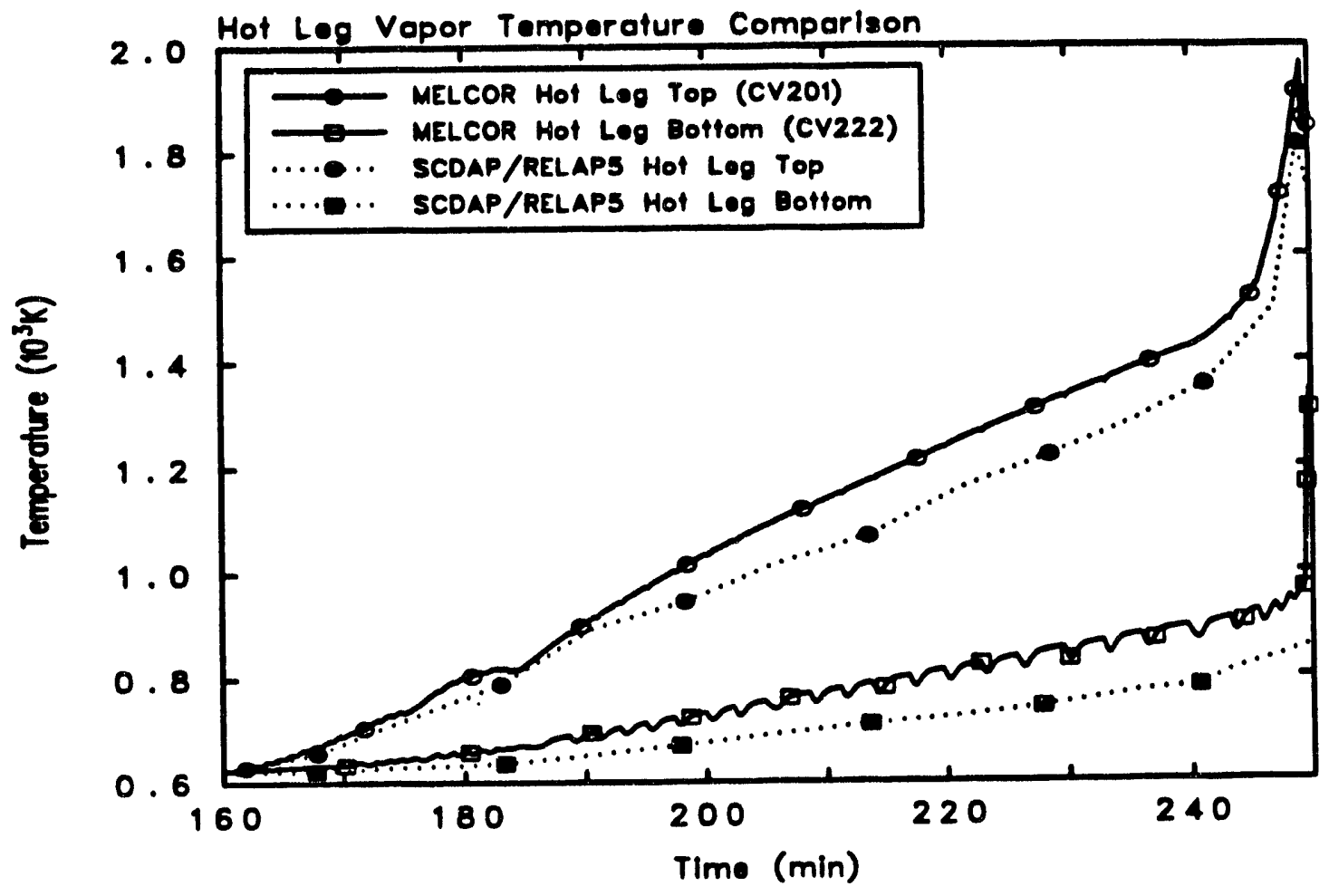

Figure 8.2.10 Comparison of the MELCOR basecase hot leg top and bottom vapor temperature histories with the SCDAP/RELAP5 Sensitivity Case 1 results.

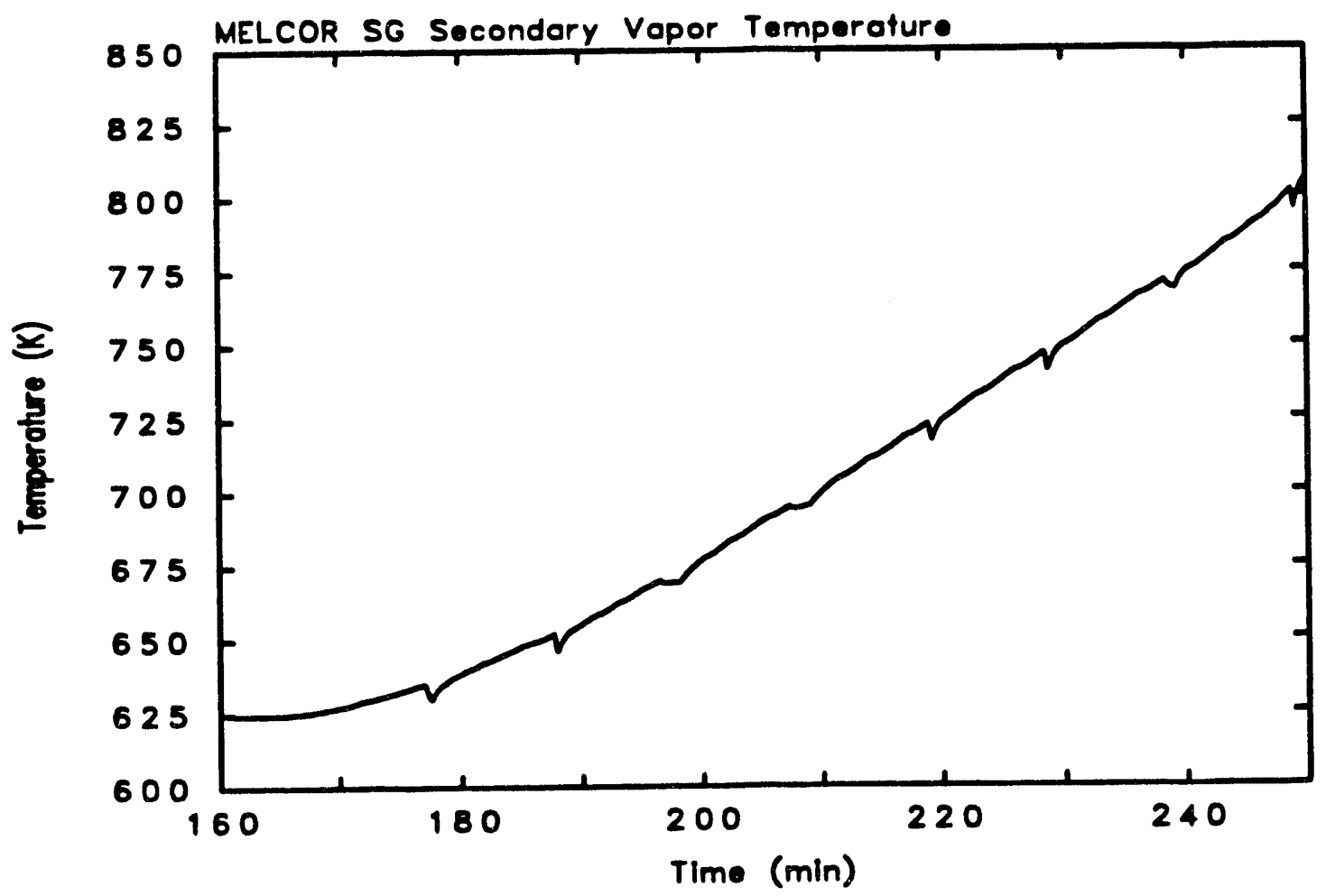

Figure 8.2.11 Steam generator secondary side vapor temperature history for the MELCOR basecase calculation. 
Figures 8.2.12 through 8.2.16 present comparisons of the MELCOR structure temperature histories with the SCDAP/RELAP5 results. Since the hot leg inlet vapor temperature calculated by MELCOR was higher than calculated by SCDAP/RELAP5, and the heat transfer to the piping was similar, the predicted structure temperatures were also consistently higher than the SCDAP/RELAP5 basecase results.

The upper plenum structure temperatures predicted by MELCOR and SCDAP/RELAP5 are shown in Figure 8.2.12. All internal upper plenum structures were combined and modeled as a single heat structure. The CRD housings were considered separate structures and are higher in temperature because they are thinner. The SCDAP/RELAP5 results showed a gradient produced by modeling in-vessel core and upper plenum natural circulation between structures in the center, middle, and outer radial positions within the upper plenum. The calculated CRD housing temperatures were much higher. Reference 2 did not present the CRD temperature history results but stated that the CRD housings reached a temperature of $1803 \mathrm{~K}$ at 250 minutes into the transient. The MELCOR results agreed with these trends.

The temperatures reached by these upper plenum structures were well above the temperature at which oxidation of stainless steel could occur. However, oxidation of stainless steel was not calculated in either of these analyses.

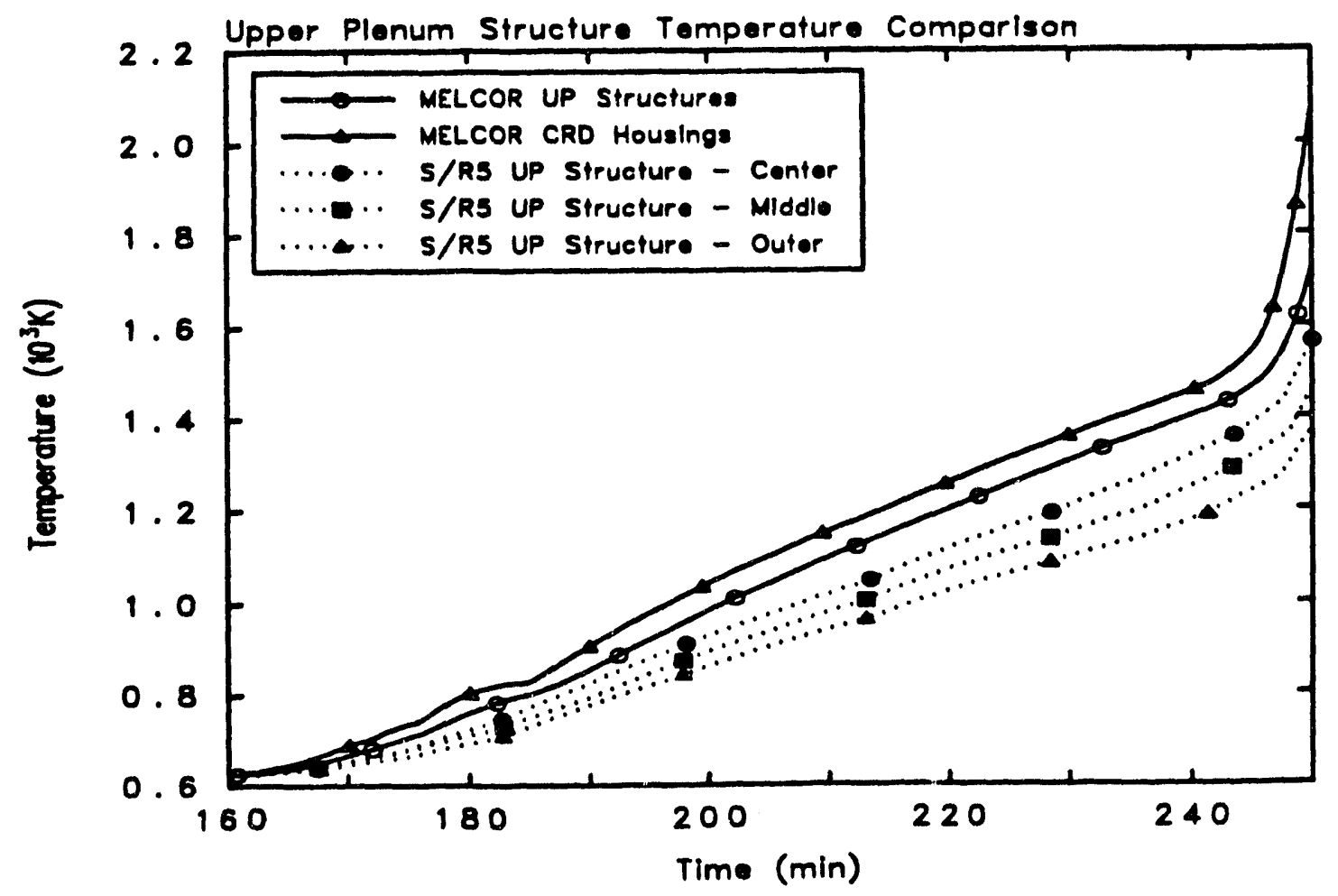

Figure 8.2.12 Comparison of the MELCOR basecase upper plenum structure temperatures with the SCDAP/RELAP5 Sensitivity Case 1 results. 
Figure 8.2.13 presents the hot leg piping temperature comparisons. The top hot leg piping temperature was hotter than the SCDAP/RELAP5 basecase but exhibits the same temperature rise rate. The bottom pipe temperature also increased similarly to the SCDAP/RELAP5 results, though much closer in temperature due to the fact that the return hot leg flow rate is slightly smaller than the top hot leg flow rate, resulting in lower heat transfer to the pipe.

The MELCOR calculated surge line piping temperature is shown with the top and bottom pipe temperatures resulting from the SCDAP/RELAP5 calculation in Figure 8.2.14. Since the MELCOR model contained only a single heat structure to model the surge line it is reasonable that the MELCOR predicted temperature should lie between these two values, as an average pipe temperature. It is, however, slightly higher than the average temperature because the vapor is not cooled by draining liquid water from the pressurizer as was noted in the SCDAP/RELAP5 calculation. Note that the surge line pipe temperature was sensitive to the PORV cycling whereas the hot leg pipe temperature was not. This was due to the large increase in flow rate through the surge line from stagnant conditions when the PORV opened. In addition, the surge line pipe is only one-third the thickness of the hot leg.

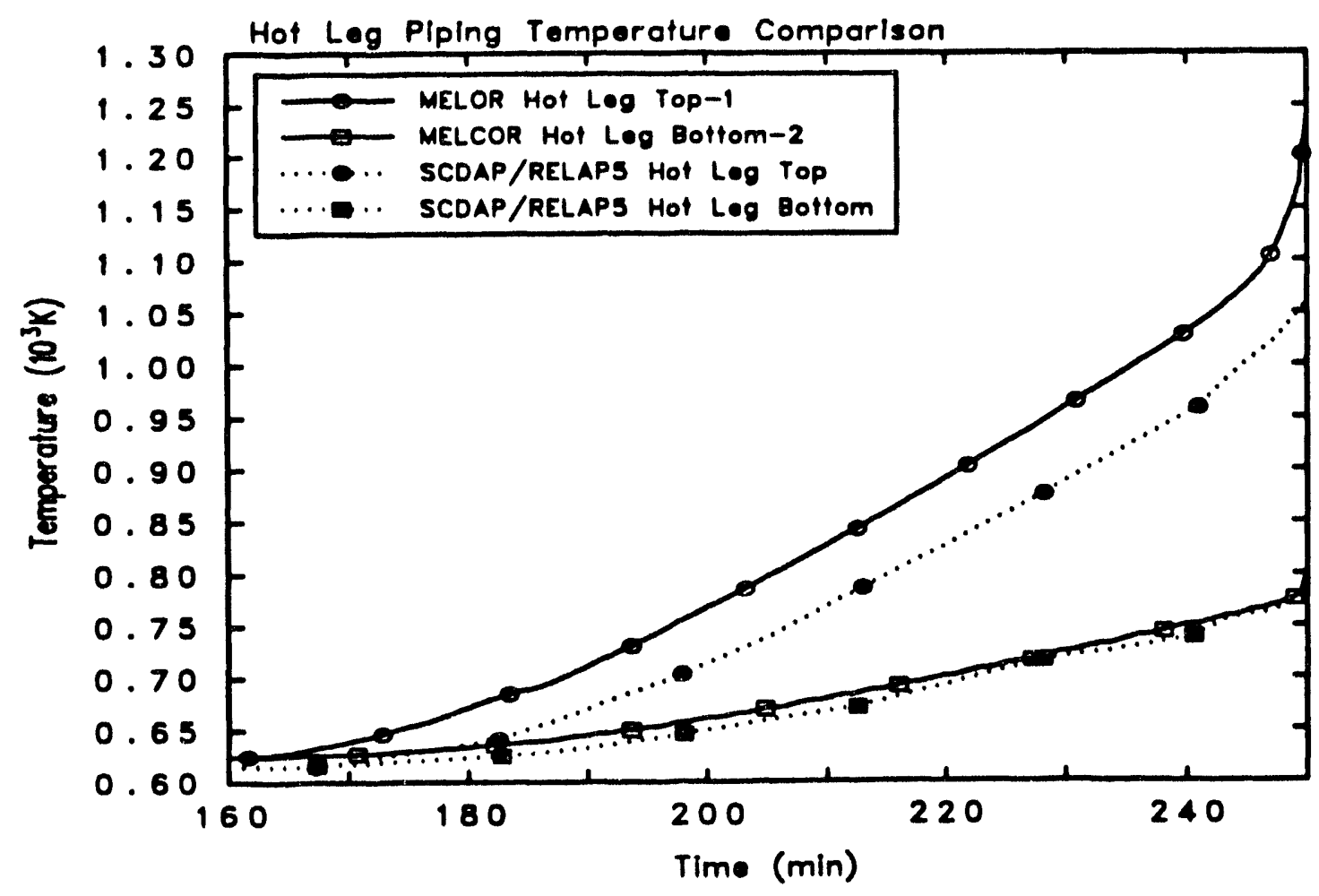

Figure 8.2.13 Comparison of the MELCOR basecase hot leg pipe temperatures with the SCDAP/RELAPS Sensitivity Case 1 results. 


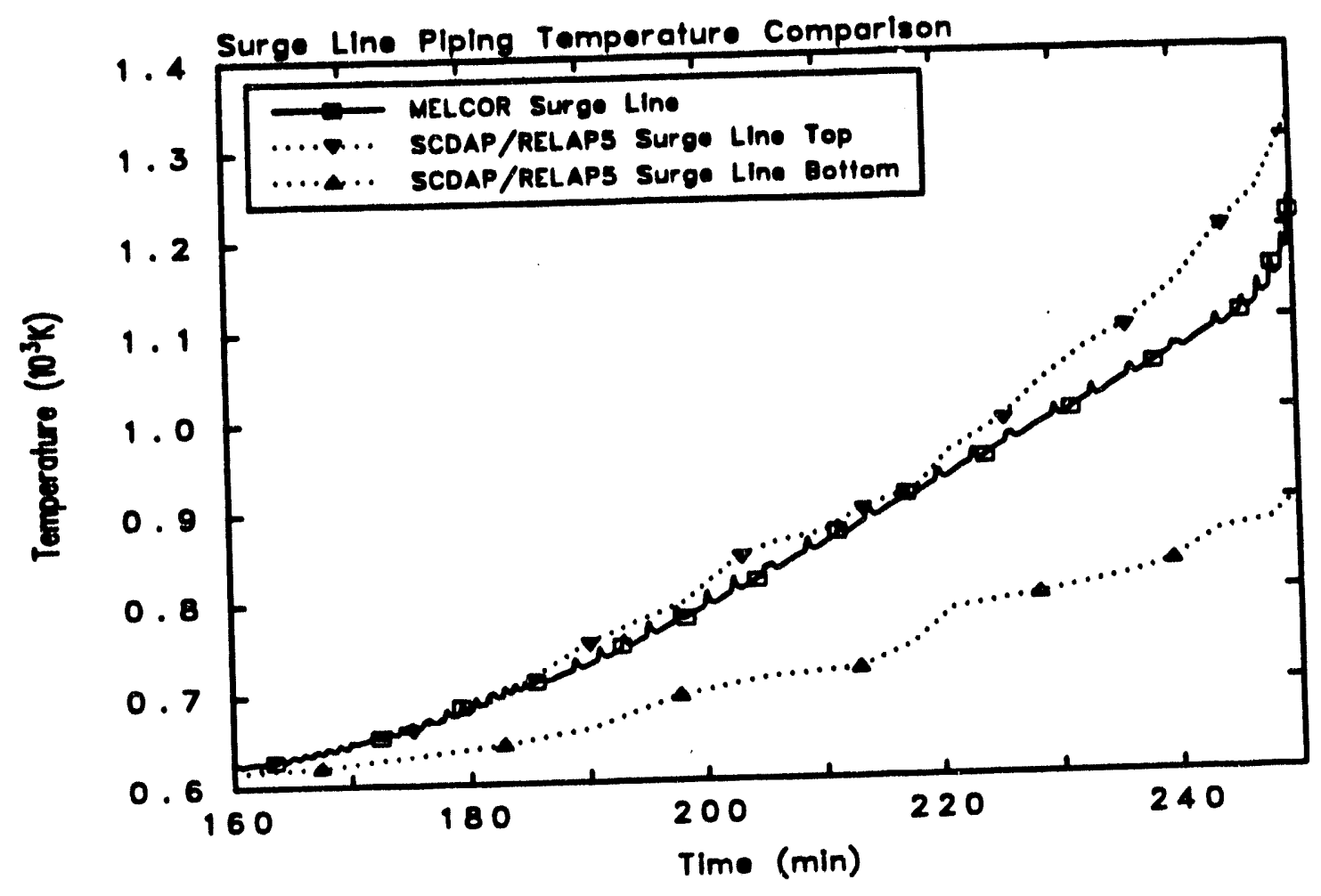

Figure 8.2.14 Comparison of the MELCOR basecase surge line pipe temperature with the SCDAP/RELAP5 Sensitivity Case 1 results.

Finally, the steam generator tube temperature comparison is presented in Figure 8.2.15. Again, because of the slightly higher vapor temperatures predicted around the 10op, the MELCOR tube temperature was also larger. The similar temperature rise rate showed that the heat transfer to the secondary side was similar to the SCDAP/RELAP5 results.

Figure 8.2.16 summarizes the hot leg, surge line, and steam generator tube temperature histories as compared with the SCDAP/RELAP5 analysis. The trends were similar: the surge line remained hotter than the hot $\mathrm{leg}$ and the steam generator tubes remained a lot cooler. Due to the different modeling choice for the surge line described in Section 8.1, the MELCOR calculation did not show as large of a temperature difference between the surge line and hot $\mathrm{leg}$ as was shown by the SCDAP/RELAP5 results. In fact, as the cladding oxidation escalated, around 245 minutes, the hot leg and surge line temperatures were almost identical.

The SCDAP/RELAP5 calculation predicted creep rupture failure of the surge line to occur at 246.3 minutes when the top of the surge line was approximately $1219 \mathrm{~K}$. MELCOR cannot perform stress calculations to predict pipe failure. However, making the same failure temperature assumption, the "average" surge line pipe wall would reach $1219 \mathrm{~K}$ at approximately 249.7 minutes. The delayed failure time was probably due to modeling the entire pipe as one structure in MELCOR. The hot leg pipe at this time reached a temperature of $1212 \mathrm{~K}$, very close to 


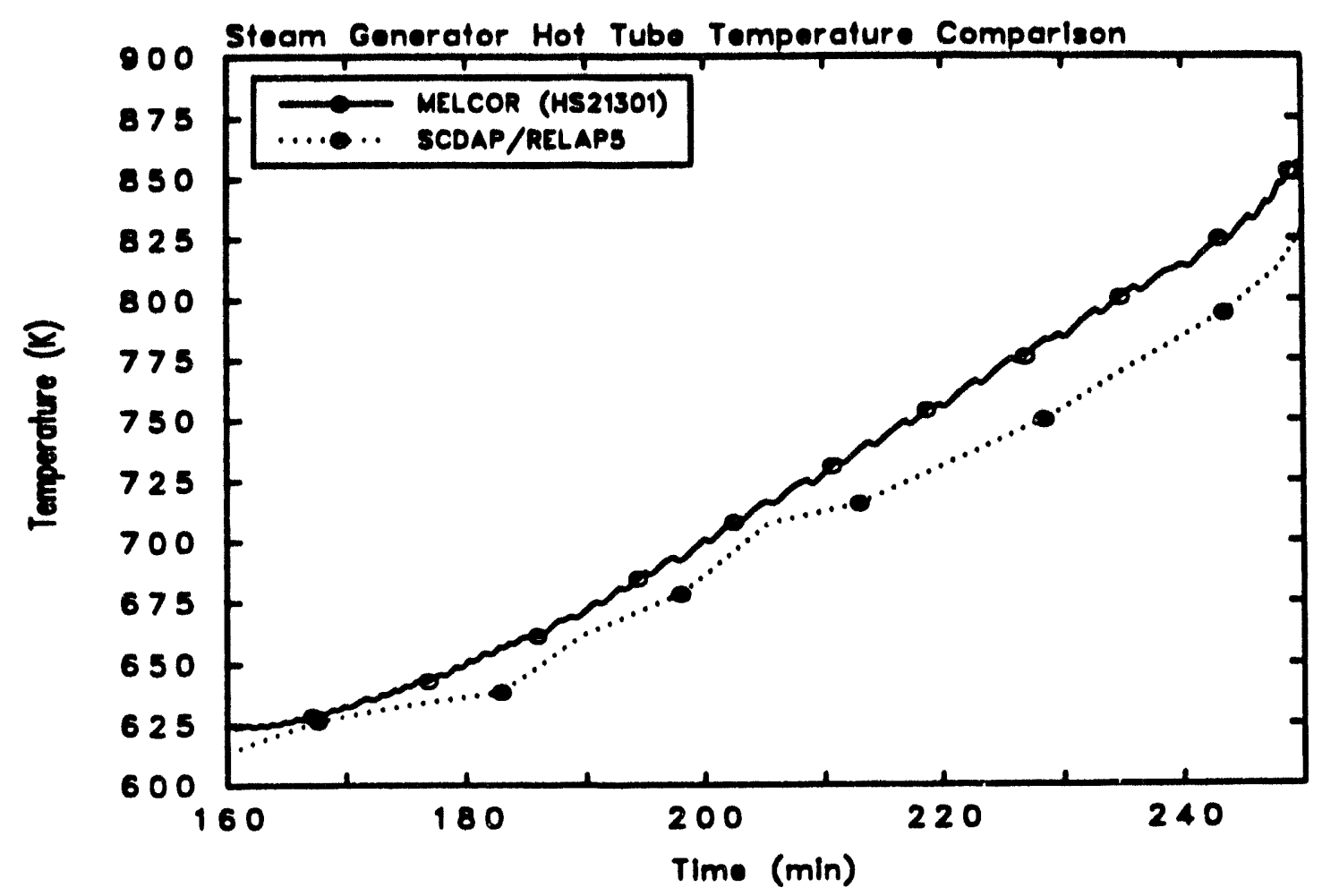

Figure 8.2.15 Comparison of the MELCOR basecase steam generator tube temperature histories with the SCDAP/RELAP5 Sensitivity Case 1 result.

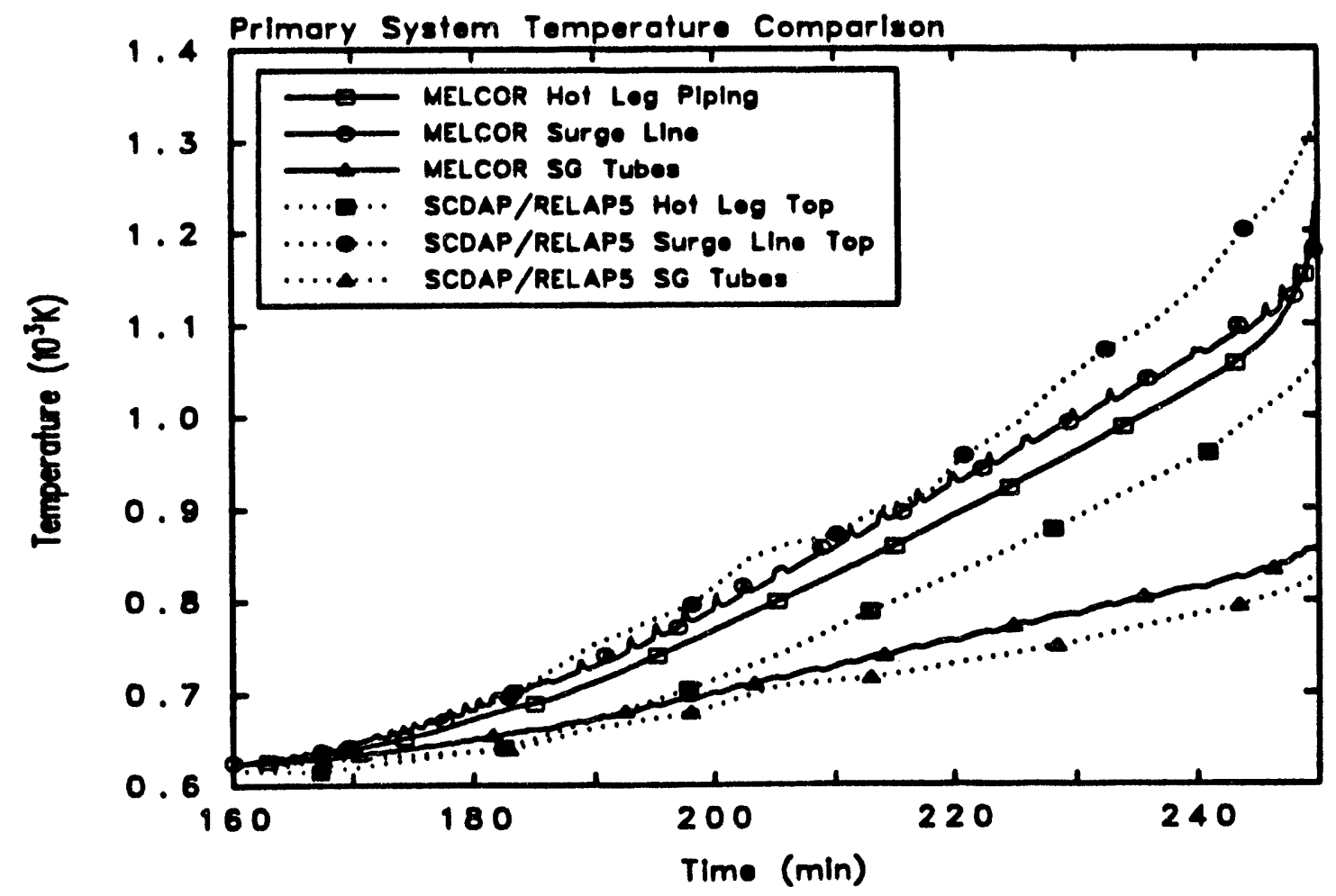

Figure 8.2.16 Comparison of the MELCOR basecase critical component temperature histories with the SCDAP/RELAP5 Sensitivity Case 1 results. 
its failure temperature. The steam generator tubes have only reached $855 \mathrm{~K}$ at this time and were the least likely components to fail. The fallure temperature of the tubes, however, should be lower than the failure of the hot leg and, surge line if defective tubes are taken into account as discussed in support of the NUREG-1150 study [28].

Table 8.2.1 compares the fraction of core input energy (decay heat plus oxidation energy) transferred to the various components of the RCS. The comparisons are shown at 246.3 minutes to be consistent with the SCDAP/RELAP5 calculation since the energy quantities were integrated from the beginning of the calculation. The hot 1 eg and surge line piping values compared fairly well considering the oxidation heating used in the MELCOR calculation was larger. The amount of energy transferred to the steam generator tubes was lower. However, the value shown for MELCOR was based on subtracting the energy convected from the tubes to the steam generator secondary side (12\%) from the energy convected from the primary side steam generator tube vapor to the tubes $(24.2 \%)$. Information was not available from the SCDAP/RELAP5 results concerning the energy transferred to the upper plenum structures and pressurizer.

\section{TABLE 8.2.1 RCS Energy Distribution Comparison (at 246.3 minutes)}

\section{COMPONENT}

Steam Generator Tubes

\& Tube Sheets

Hot Leg Piping

Surge Line Piping

Steam Generator

Inlet Plena

Pressurizer

Upper Plenum Internals

All Upper Plenum

Structures (Internals

plus CRD Housings)

FRACTION OF CORE INPUT ENERGY (\%)

SCDAP/RELAP 5

MELCOR

17.4

3.6

0.6

1.43

$-$

$\cdot$
12.2

4.4

0.8

0.9

2.1

7. 3

13.3 
The timing statistics for the MELCOR calculation for the period from 160 to 250 minutes are shown in Figures 8.2.17 and 8.2.18. The warp factor plotted in Figure 8.2.17 was defined as the ratio of problem time to CPU time. This 90 minute calculation ran approximately at real time on a VAX 8700 computer. A maximum time step of one second was used for the calculation. The code cut this time step intermittently to 0.85 second during the last 10 minutes of the calculation. Figure 8.2.18 shows the actual CPU time used for the calculation. The Heat Structure package used the largest proportion of CPU time due to the large number of heat structures modeled.

The comparisons of vapor temperatures, flow rates, and component temperatures for the basecase show that the MELCOR model provides consistent results with the SCDAP/RELAP5 calculations. Therefore, the MELCOR model can now be applied to investigate sensitivities to various modeling uncertainties.

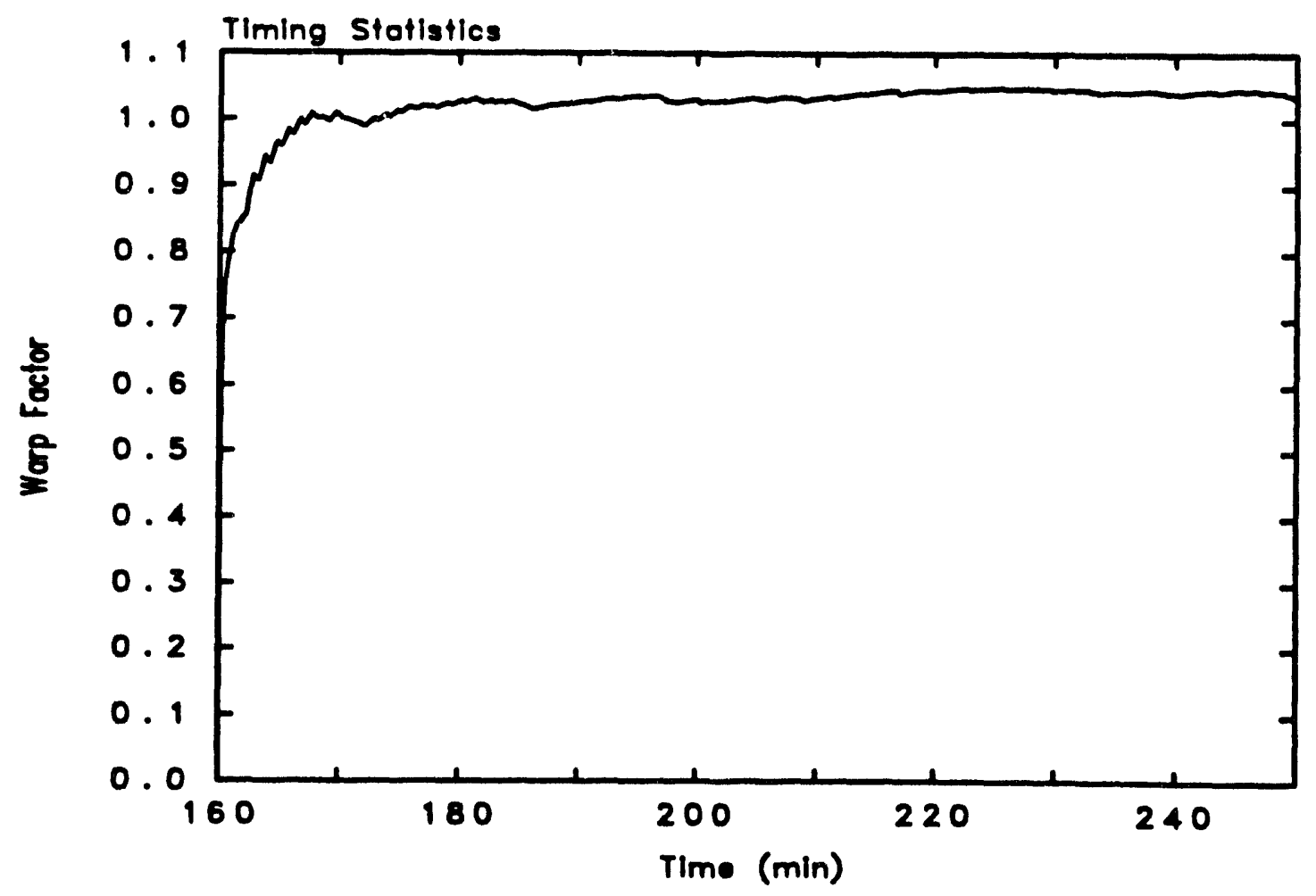

Figure 8.2.17 Warp factor (ratio of problem time to CPU time) for the MELCOR basecase calculation. 


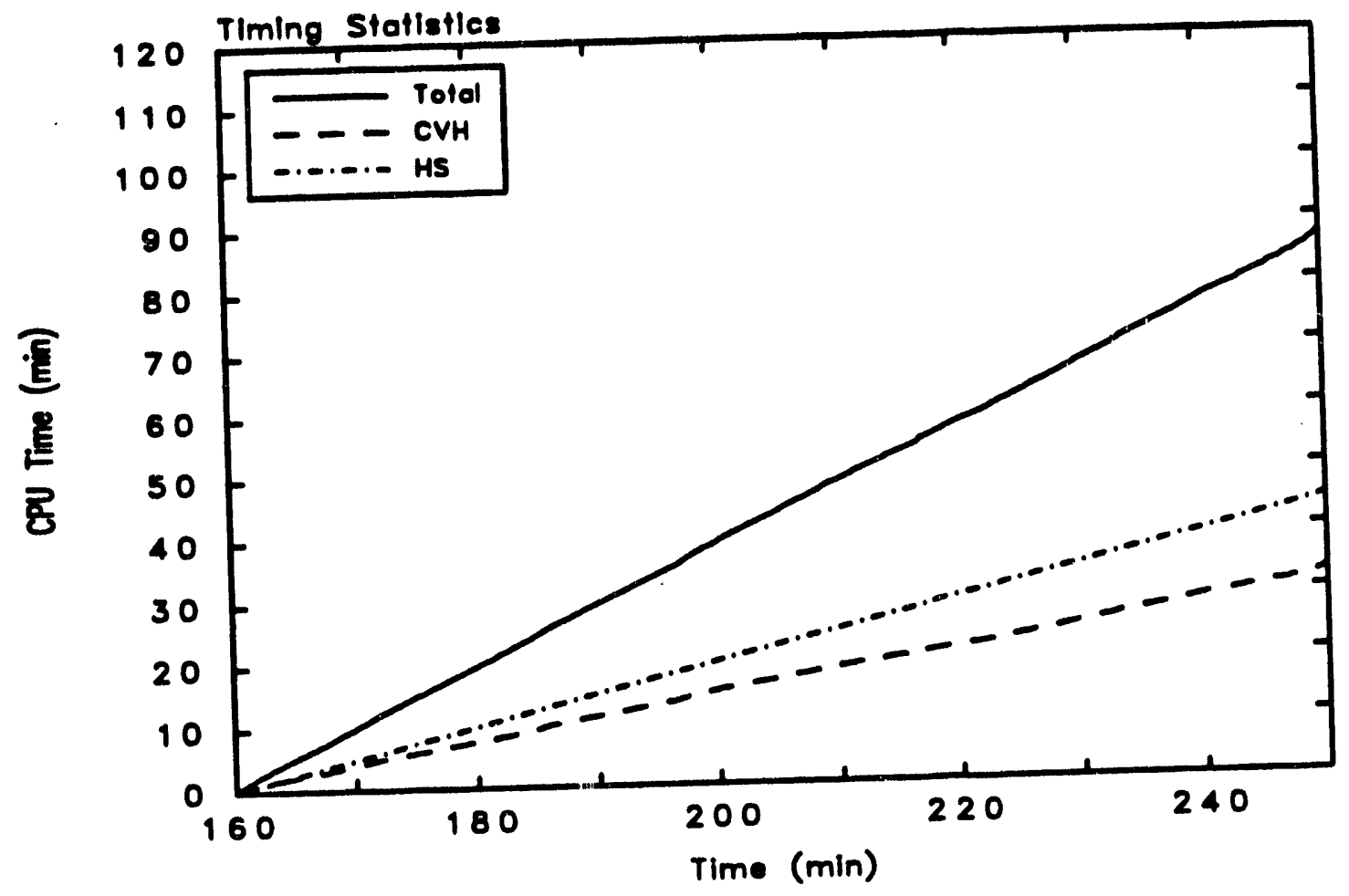

Figure 8.2.18 CPU time used in the MELCOR basecase calculation. 


\subsection{Results of the MELCOR Sensitivity Studies}

Sensitivity studies were performed to investigate the effect of: (1) decay heat variation including the oxidation reaction energy transient coupled to the decay heat transient; (2) the magnitude of the oxidation energy contribution and also the presence of hydrogen; (3) steam circulation rate in the hot leg/steam generator assembly; (4) radial conduction effects in the hot leg piping; and (5) heat/mass transfer between hot and cold countercurrent flows in the hot leg. All of the studies were begun 160 minutes into a TMLB' accident as the core began to uncover and heat up. The initial conditions for this time were obtained from the SCDAP/RELAP5 [2] results.

The criterion for failure in these MELCOR sensitivity studies was also based on the SCDAP/RELAP5 study. In the SCDAP/RELAP5 basecase calculation, the surge line failed at a temperature of $1219 \mathrm{~K}$ at a time 246 minutes into the simulation. The only two regions of the RCS pressure boundary that failed in the SCDAP/RELAP5 sensitivity studies [2] were the surge line pipe and the hot leg pipe. Since the MELCOR model created for these sensitivity studies did not include a detailed core model or account for the physics of creep failure of heat structures acting as pipes, the criterion for failure in these sensitivity studies was determined to occur when any one of the critical components in the RCS reached $1219 \mathrm{~K}$. As in the SCDAP/RELAP5 study, two of these critical components were the surge line and the hot leg pipes. For high flow rates the thin steam generator tubes may also reach failure temperatures, so the tube assembly was designated to be a critical component as well.

As in the basecase calculation discussed in the previous section, the model used for the sensitivity studies contained only one flow loop, not three. However, for comparison purposes, the flow rates presented have been divided by three to show representative flow rates as compared to three-loop systems. One change was inadvertently made in the input for the sensitivity study basecase model as compared to the model described in the previous section and nrt discovered until several were run. Several heat structures in the hot leg region and two in the surge line were given different characteristic lengths than in the original basecase and slightly affected the lieat transfer calculations. This resulted in slightly lower temperatures for the surge line and hot leg, especially late in the simulation after oxidation energy becomes significant, in this case at about 245 minutes. This also caused the temperatures of the hot 1 eg and surge line pipes to be closer together than in the original basecase MELCOR calculation and in the SCDAP/RELAP5 basecase. These calculations were not rerun since the objective of the sensitivity analyses was to determine relative differences between cases in which (ideally) only one parameter was changed. 


\subsection{Decay Heat Sensitivity Study}

As pointed out in Reference 2, a parameter which can greatly affect the timing of events and the onset of RCS pressure boundary failure is the magnitude of the decay heat. This sensitivity study was carried out in two parts. First, four cases were run in which the decay heat was varied $-10 \%$ and $-25 \%$ from the basecase value. Although it is instructive to examine the results of these four cases, the physics were not fully accurate. Because the core in this model was modeled empirically, the decay heat and oxidation energy were decoupled whereas in actuality they are highly coupled. This coupling results from the decay heat causing the uncovering of the core, upon which the resultant exposure to hot steam would cause oxidation. A higher decay heat rate would cause quicker core uncovering, a quicker onset of oxidation, and a faster failure time. The inverse will be true for lower decay heat rates. To account for the decay heat/oxidation energy coupling in the core, another series of four runs were then made with the decay heat again varied $10 \%$ and $25 \%$ from the basecase. In addition, however, the oxidation energy release was shifted in time. The time shift was obtained from data gained from the first decay heat sensitivity series. The heat-up delay/acceleration in heat structures representing the rods for each run as compared to the basecase was measured. This time offset was then applied to the oxidation energy which was represented as a volumetric heat source versus time. This heat source was located in the core control volume (CV 125). Table 9.1.1 summarizes the runs made for the decay heat sensitivity study. Figure 8.2.1 shows the basecase curve of oxidation energy versus time obtained from [2] as described in section 8.2.

Figures 9.1.1 through 9.1.3 show the temperatures of the three critical components in which only the decay heat was varied. The temperatures of each of the critical components (the hot leg pipe, the surge line, and the steam generator tubes) for the basecase and each of the four decay heat runs are compared in Figures 9.1.4 through 9.1.7. The corresponding failure times relative to the basecase are summarized in Table 9.1.1. Overall trends were not changed from those of the basecase. Thai is, if the surge line remained the hottest critical component throughout the basecase run, then the same was true for each of the decay heat sensitivity runs, although a slight effect in the difference between the surge line and hot leg failure time was found. When the decay heat was decreased, for example, by $25 \%$, the hot leg temperature lagged the surge line temperature (compared to the basecase) by a few more minutes. Conversely, as the decay heat was increased to $+25 \%$, the hot 1 eg and surge 1 ine temperatures were very close, suggesting the possibility of simultaneous failure.

Changing the decay heat by $-10 \%$ had a minimal effect on temperatures; the temperatures in the critical components differed by less than $45 \mathrm{~K}$ from the basecase and changed the failure time by only $-1-2$ minutes. Changing the decay heat by $-25 \%$ made a somewhat larger difference. In Figure 9.1.7, for example, the temperature of the hot leg pipe for the $+25 \%$ decay heat run was $136 \mathrm{~K}$ higher as compared to the basecase at a time of 250 minutes. With the $+25 \%$ higher decay heat, the failure time 


\begin{tabular}{|c|c|c|c|}
\hline$\overline{\overline{\text { TABLE }}}$ & DECAY HEAT & IVITY STUDY RESULTS & \\
\hline Case & Description & $\begin{array}{l}\text { Failure Time (min) } \\
\text { Relative to Basecase }\end{array}$ & $\begin{array}{l}\text { Fallure } \\
\text { Location }\end{array}$ \\
\hline 1 & $-25 \%$ Decay Heat & +5.2 & Surge Line \\
\hline 2 & $-10 \%$ Decay Heat & +2.0 & Surge Line \\
\hline 3 & $+10 \%$ Decay Heat & -1.2 & Surge Line \\
\hline 4 & $+25 \%$ Decay Heat & -4.2 & Surge Line \\
\hline 5 & $\begin{array}{l}-25 \% \text { Decay Heat with } \\
\text { Oxidation Offset }\end{array}$ & +23.5 & Surge Line \\
\hline 6 & $\begin{array}{l}-10 \% \text { Decay Heat with } \\
\text { Oxidation Offset }\end{array}$ & +9.1 & Surge Line \\
\hline 7 & $\begin{array}{l}+10 \% \text { Decay Heat with } \\
\text { Oxidation Offset }\end{array}$ & -8.0 & Surge Line \\
\hline 8 & $\begin{array}{l}+25 \% \text { Decay Heat with } \\
\text { Oxidation Offset }\end{array}$ & -20.4 & Surge Line \\
\hline
\end{tabular}

occurred 5.2 minutes faster than in the basecase. Conversely, the hot leg temperature for the $-25 \%$ decay heat run was $129 \mathrm{~K}$ cooler as compared to the basecase and the failure time was delayed 4.2 minutes.

The results from the decay heat sensitivity runs with the time offset delaying or accelerating the onset of oxidation are shown in Figures 9.1.8 through 9.1.10. These figures show the temperatures in each of the critical components for each of the four sensitivity runs and the basecase. Again, overall trends remained unchanged. However, the combination of the higher/lower decay heat and the corresponding acceleration/deceleration of the rod oxidation dramatically changed the temperature profiles and failure times of the three critical components compared to the previous decay heat sensitivity runs. Table 9.1.1 again summarizes the failure times for these runs. Changing the decay heat by $-25 \%$ with an oxidation offset delayed the failure times by 23.5 minutes, while raising the decay heat by $+25 \%$ with the oxidation offset accelerated the failure time by 20.4 minutes. 


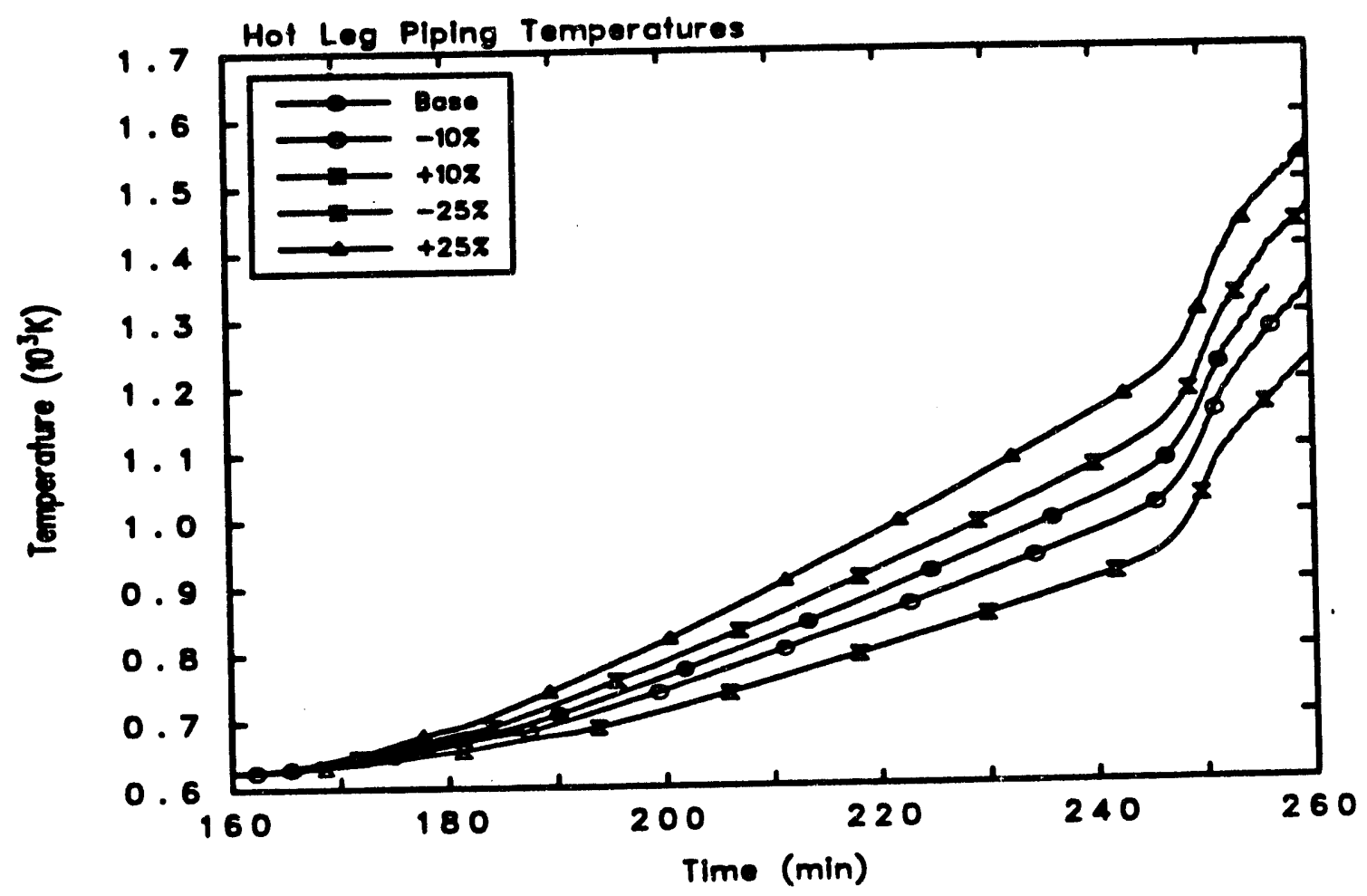

Figure 9.1.1 Comparison of the hot leg piping temperature of the MELCOR basecase with the MELCOR sensitivity study which varied the decay heat by $\pm 10 \%$ and $\pm 25 \%$.

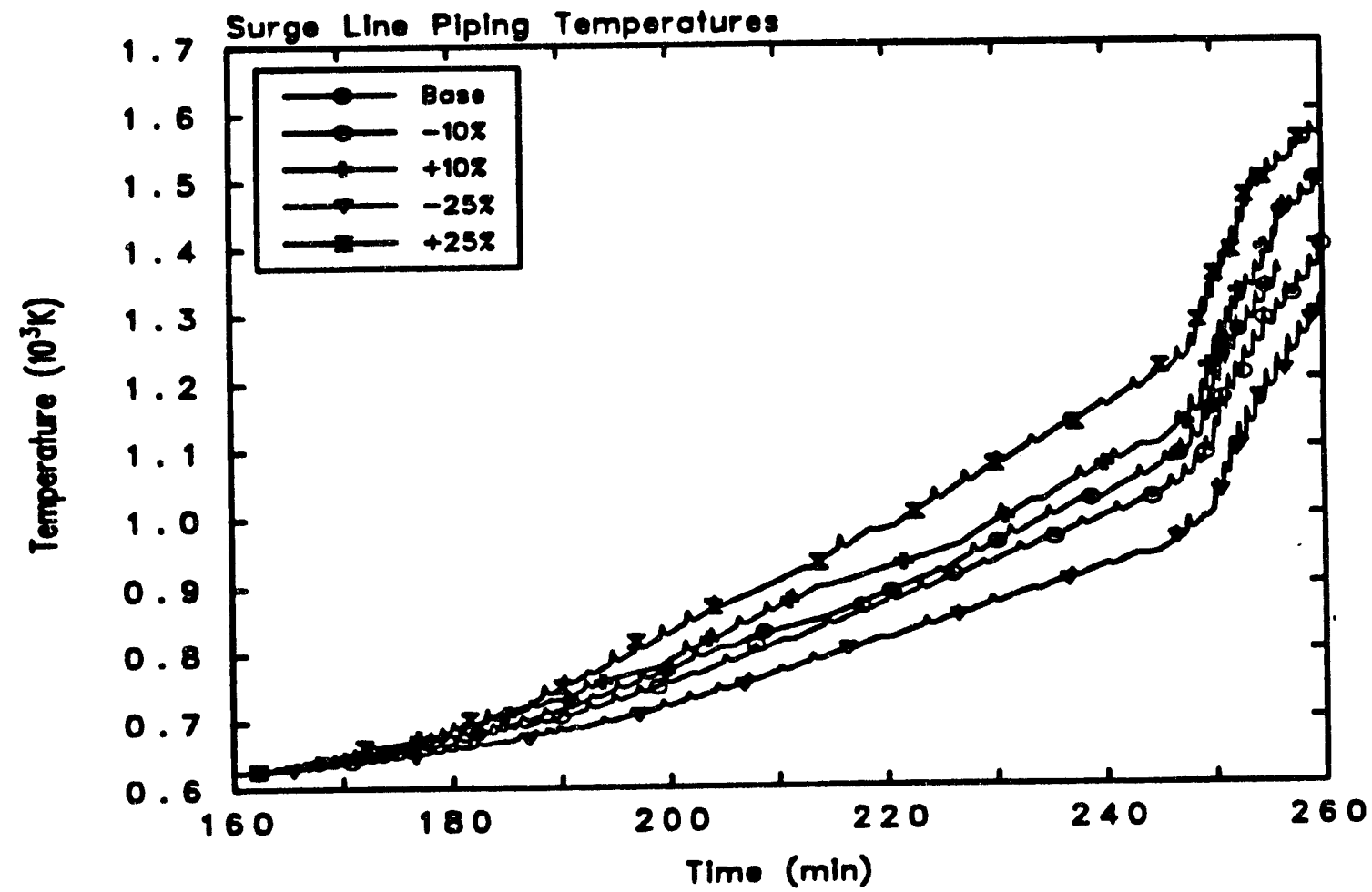

Figure 9.1.2 Comparison of the surge line piping temperature of the MELCOR basecase with the MELCOR sensitivity study which varied the decay heat by $\pm 10 \%$ and $\pm 25 \%$. 


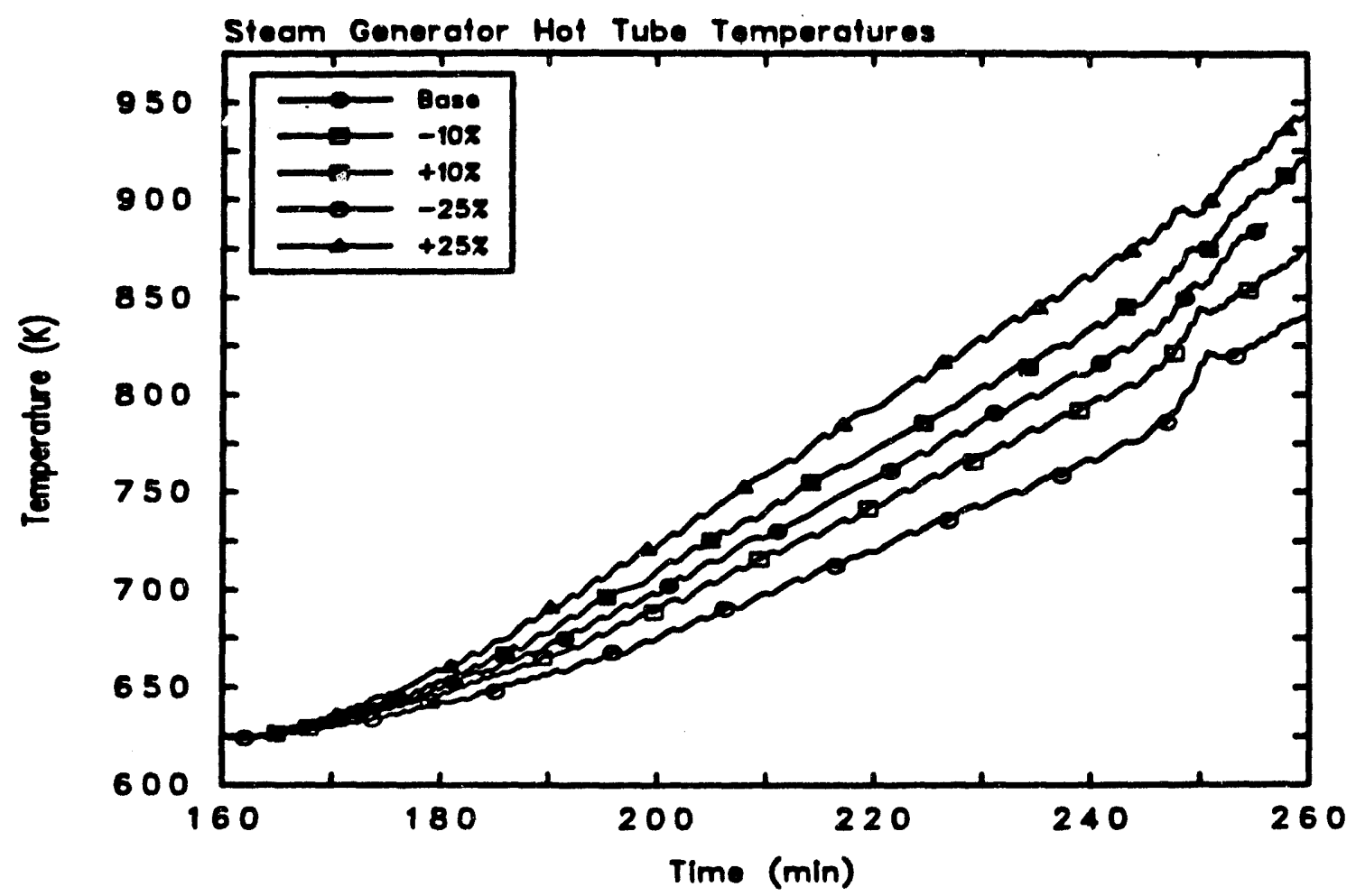

Figure 9.1.3 Comparison of the steam generator hot tube temperature of the MELCOR basecase with the MELCOR sensitivity study which varied the decay heat by $\pm 10 \%$ and $\pm 25 \%$.

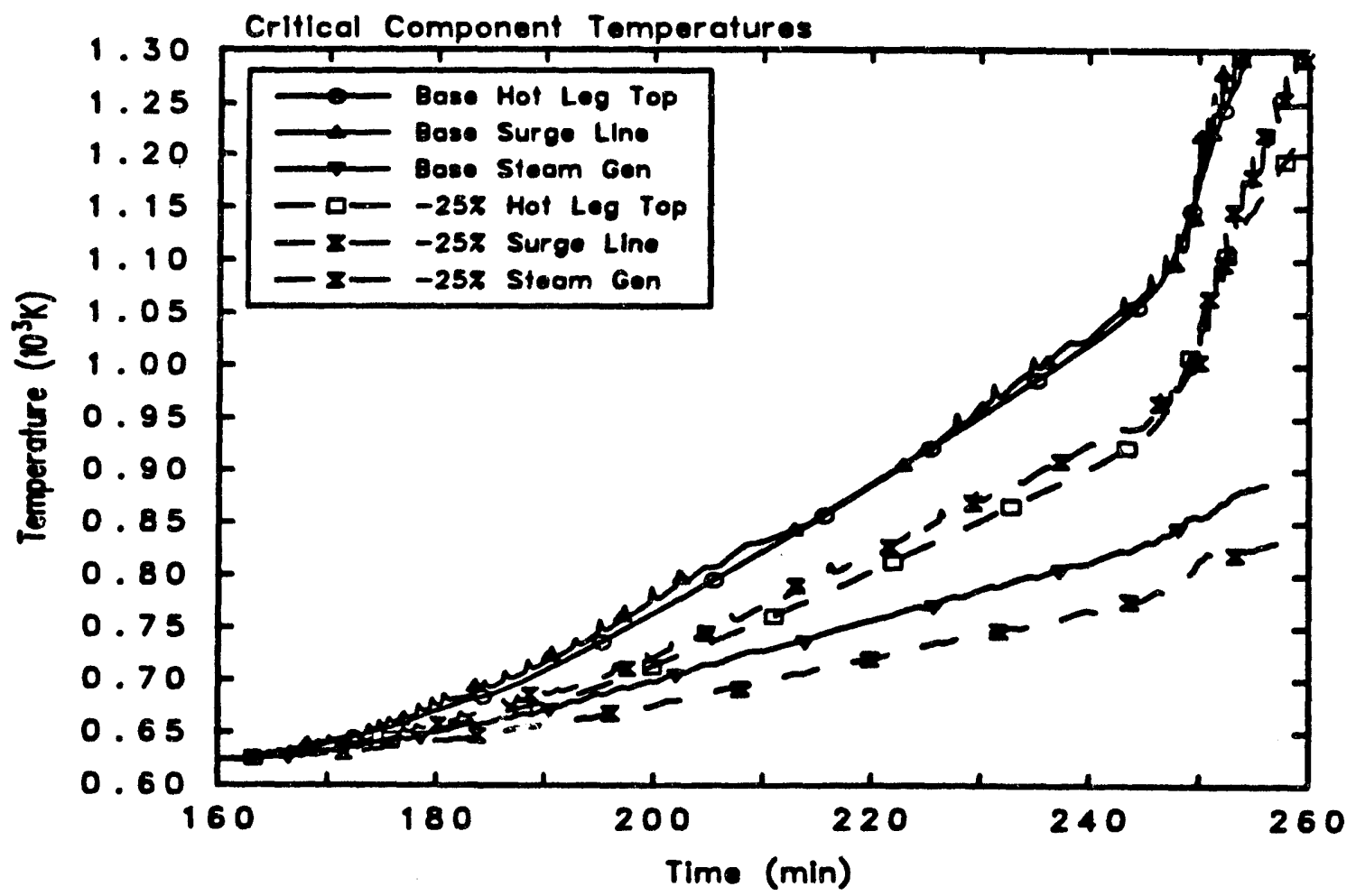

Figure 9.1.4 Comparison of the critical component (hot leg piping, surge line piping, steam generator hot tube) temperatures of the MELCOR basecase with the MELCOR case at $-25 \%$ decay heat. 


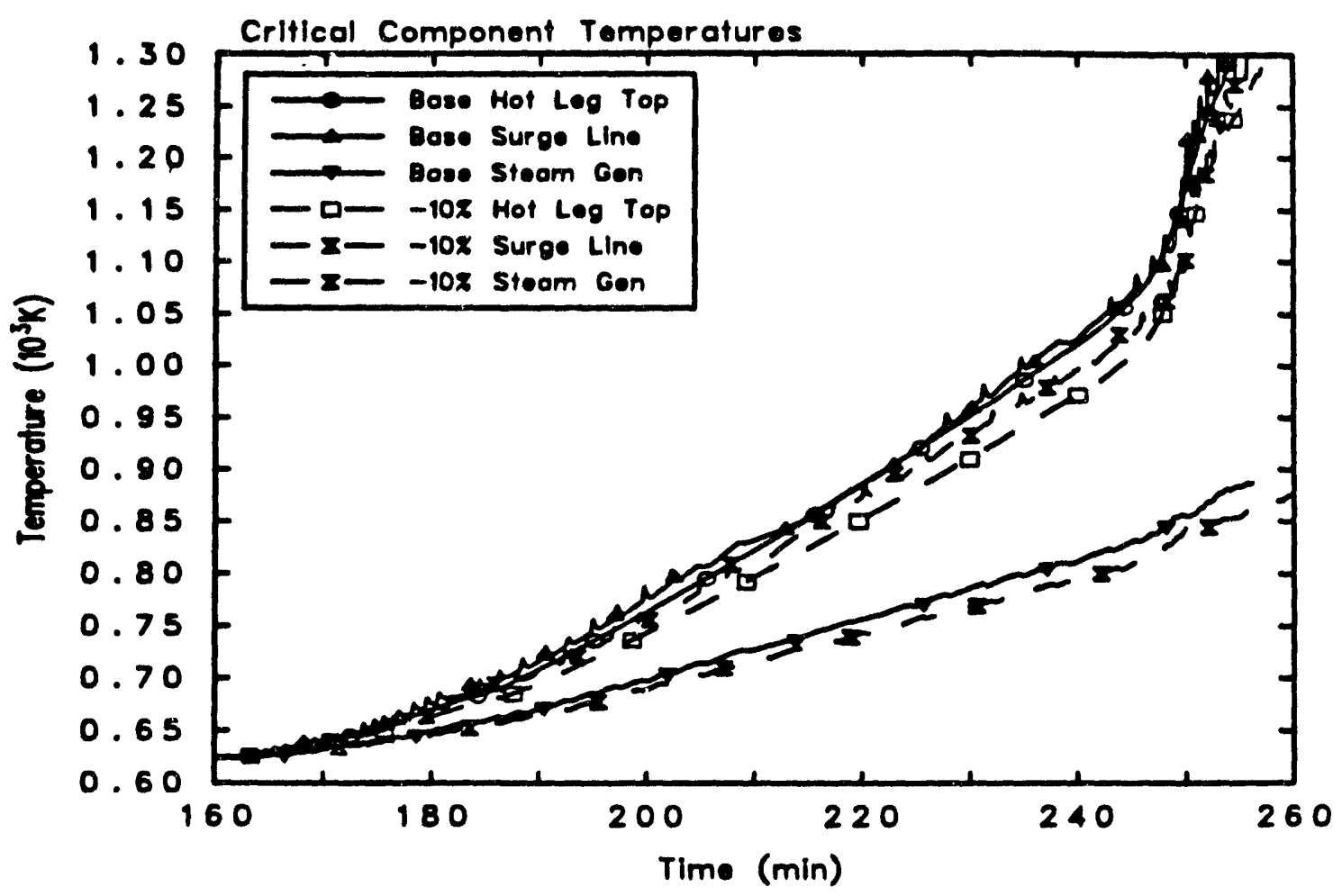

Figure 9.1.5 Comparison of the critical component (hot leg piping, surge line piping, steam generator hot tube) temperatures of the MELCOR basecase with the MELCOR case at $-10 \%$ decay heat.

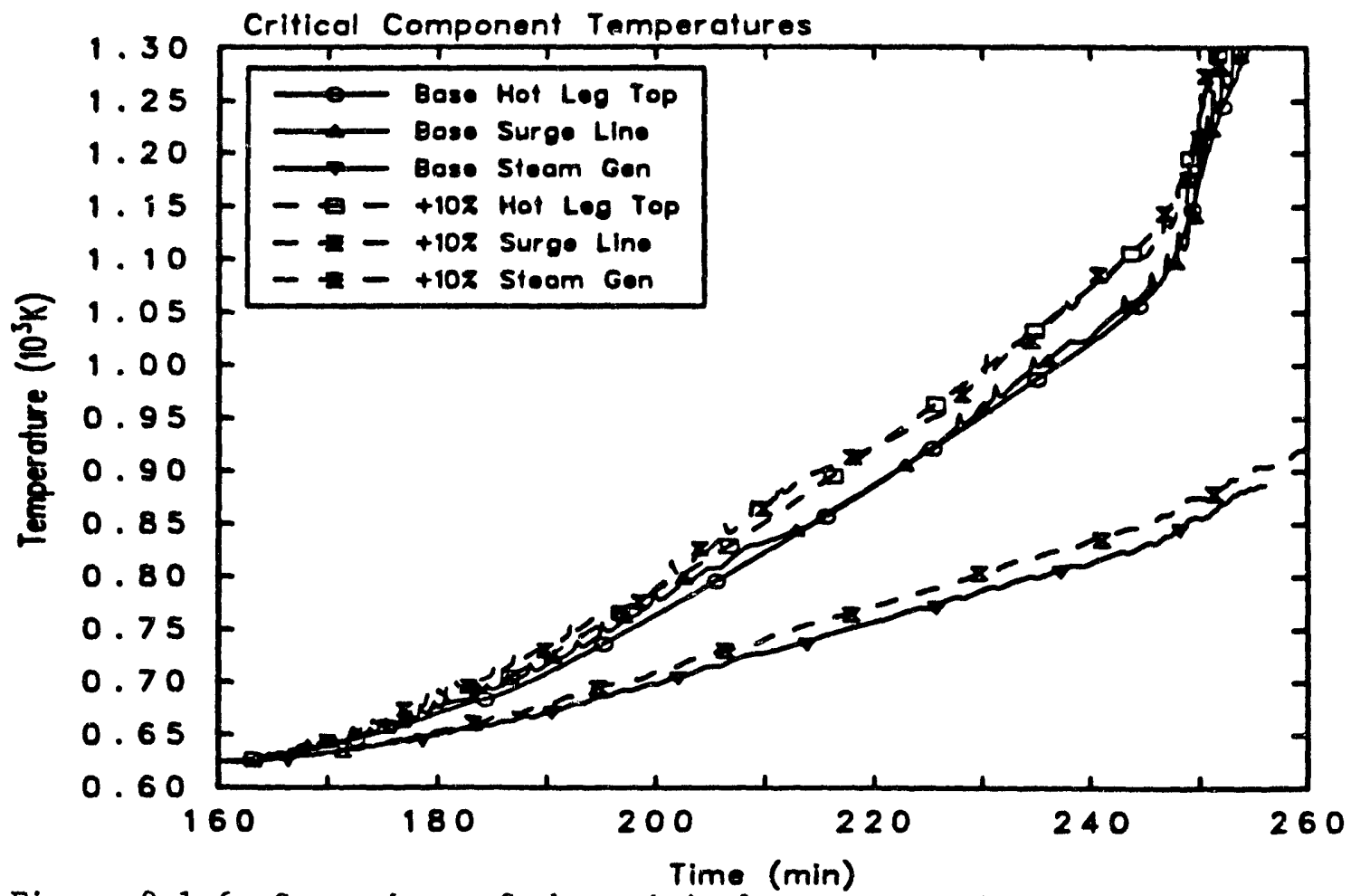

Figure 9.1.6 Comparison of the critical component (hot leg piping, surge line piping, steam generator hot tube) temperatures of the MELCOR basecase with the MELCOR case at $+10 \%$ decay heat. 


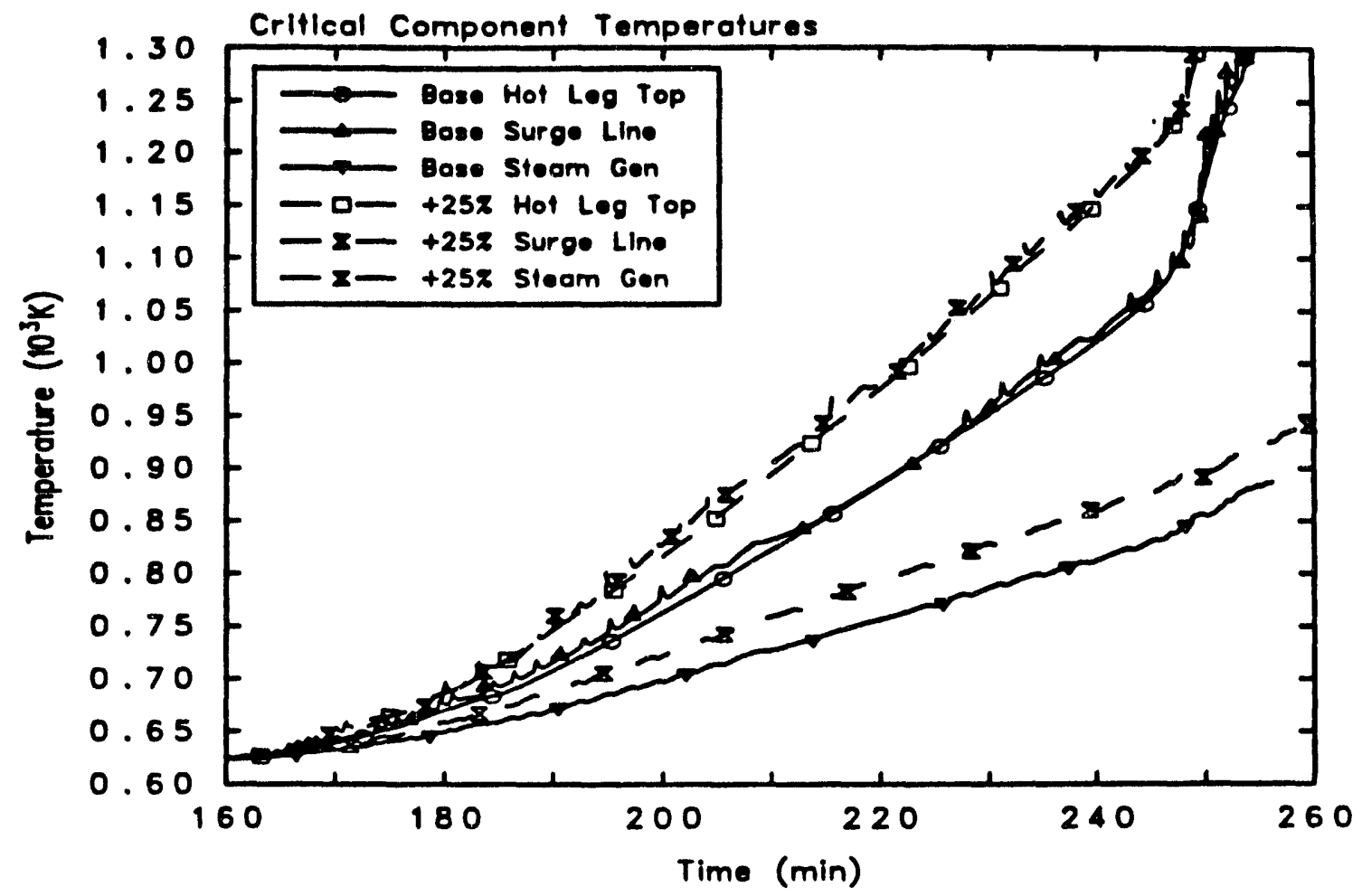

Figure 9.1.7 Comparison of the critical component (hot leg piping, surge line piping, steam generator hot tube) temperatures of the MELCOR basecase with the MELCOR case at $+25 \%$ decay heat.

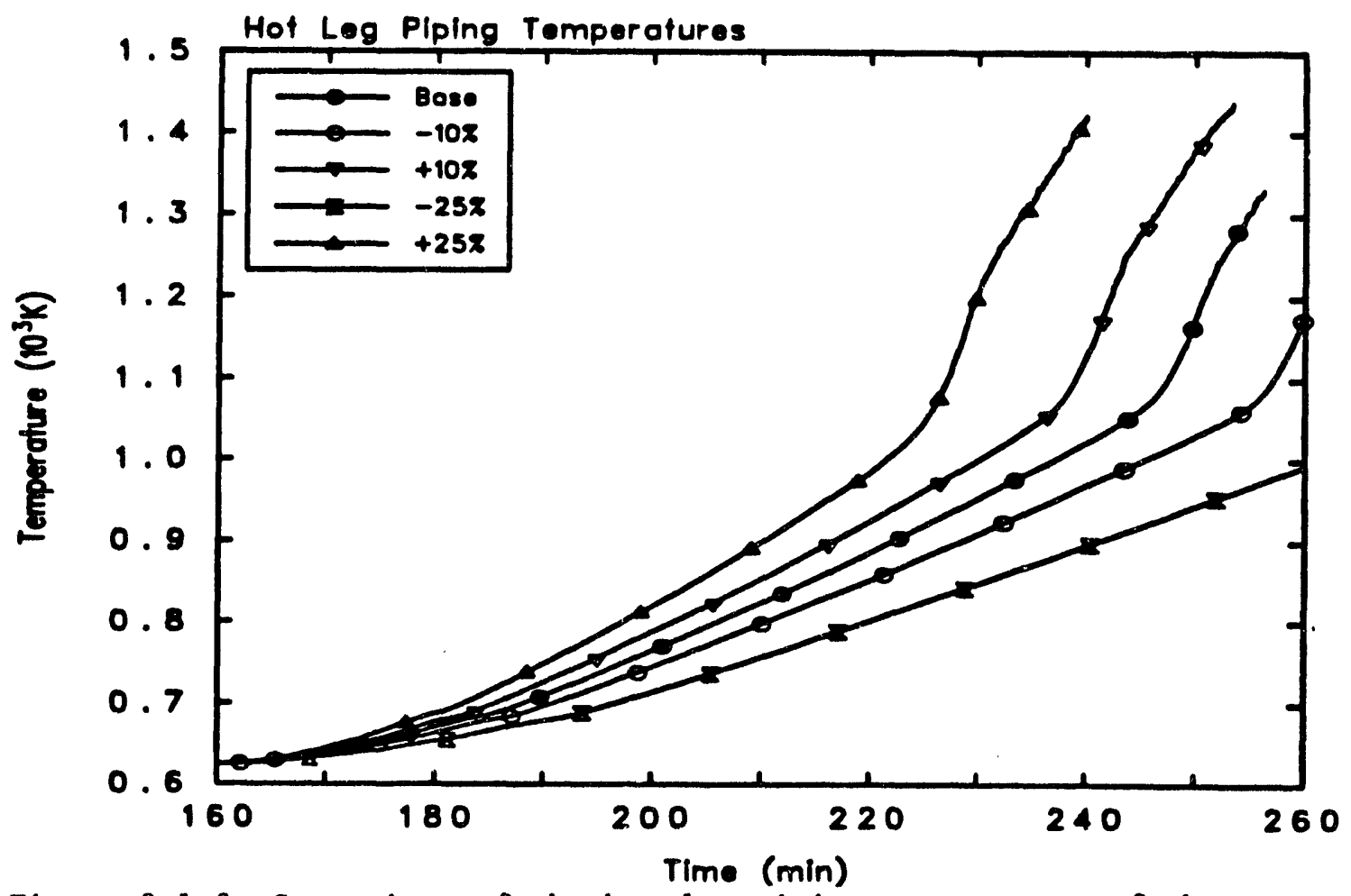

Figure 9.1.8 Comparison of the hot leg piping temperature of the MELCOR basecase with the MELCOR sensitivity study which varied the decay heat by $\pm 10 \%$ and $\pm 25 \%$, including zircaloy oxidation time advance or delay. 


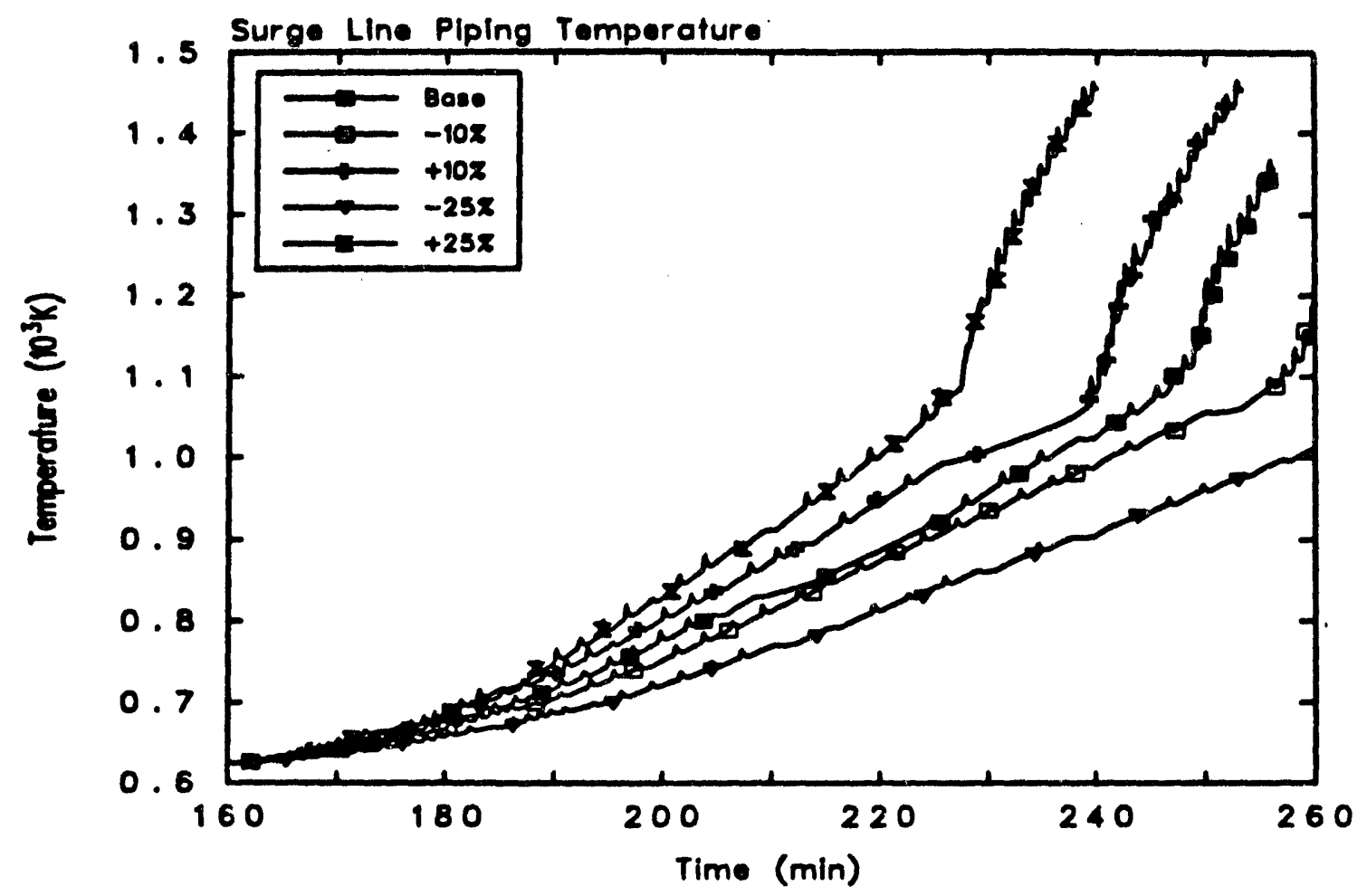

Figure 9.1.9 Comparison of the surge line piping temperature of the MELCOR basecase with the MELCOR sensitivity study which varied the decay heat by $\pm 10 \%$ and $\pm 25 \%$, including zircaloy oxidation time advance or delay.

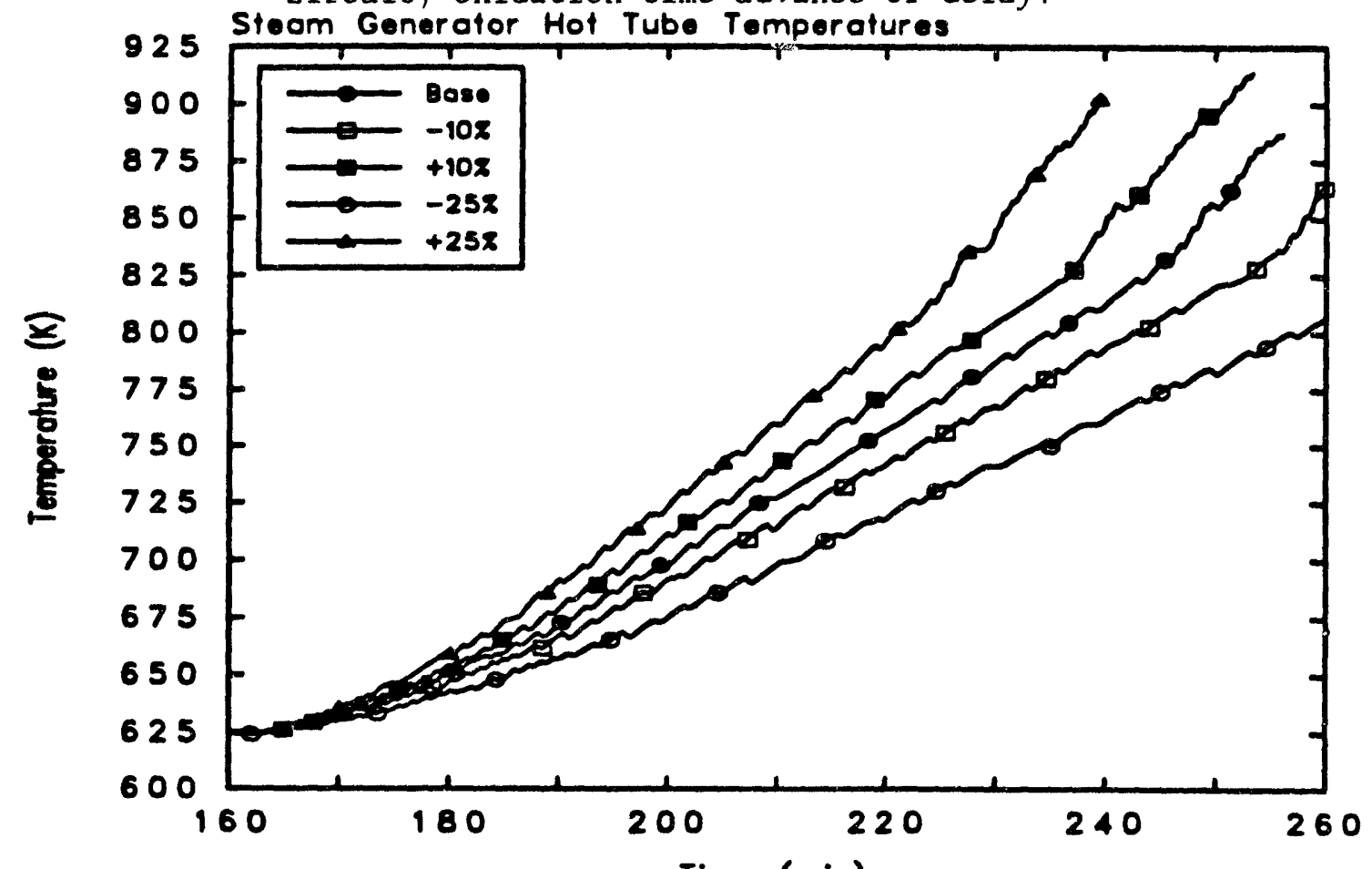

Figure 9.1.10 Comparison of the steam generator hot tube temperature of the MELCOR basecase with the MELCOR sensitivity study which varied the decay heat by $\pm 10 \%$ and $\pm 25 \%$, including zircaloy oxidation time advance or delay. 
The effect of the oxidation offset coupled with a decay heat change compared to just changing the decay heat is shown in Figures 9.1.11 and 9.1.12. Hot $\mathrm{leg}$ and the surge line piping temperatures for five cases are displayed: (1) basecase, (2) $-25 \%$ decay heat; ( 3 ) $-25 \%$ decay heat with oxidation offset; (4) $+25 \%$ decay heat; and (5) $+25 \%$ decay heat with oxidation offset. In Figure 9.1.11, the "break off point" indicating the onset of oxidation occurred about 1342 seconds earlier in the the $+25 \%$ case with the oxidation offset than in the $+25 \%$ case without the offset. This corresponded very well with the input oxidation offset time of 1295 seconds. Similar results are observed in Figure 9.1.12 for the surge line.

In Reference 2, one of the major differences between the basecase scoping calculation with the countercurrent flow loop present in the geometry, and the basecase for the sensitivity studies was a difference in the calculated decay heat of $9 \%$ due to the use of the ANS 5.1 Standard [27] for the scoping calculations and ORIGEN2 [26] for the sensitivity calculations. Thus, there is uncertainty in the magnitude of the decay heat which should be used. Sensitivity studies on decay heat as conducted here serve to bound the uncertainty in the basecase value. The state of core degradation at the later time of RCS failure, indicated by the $-25 \%$ decay heat case should also be investigated.

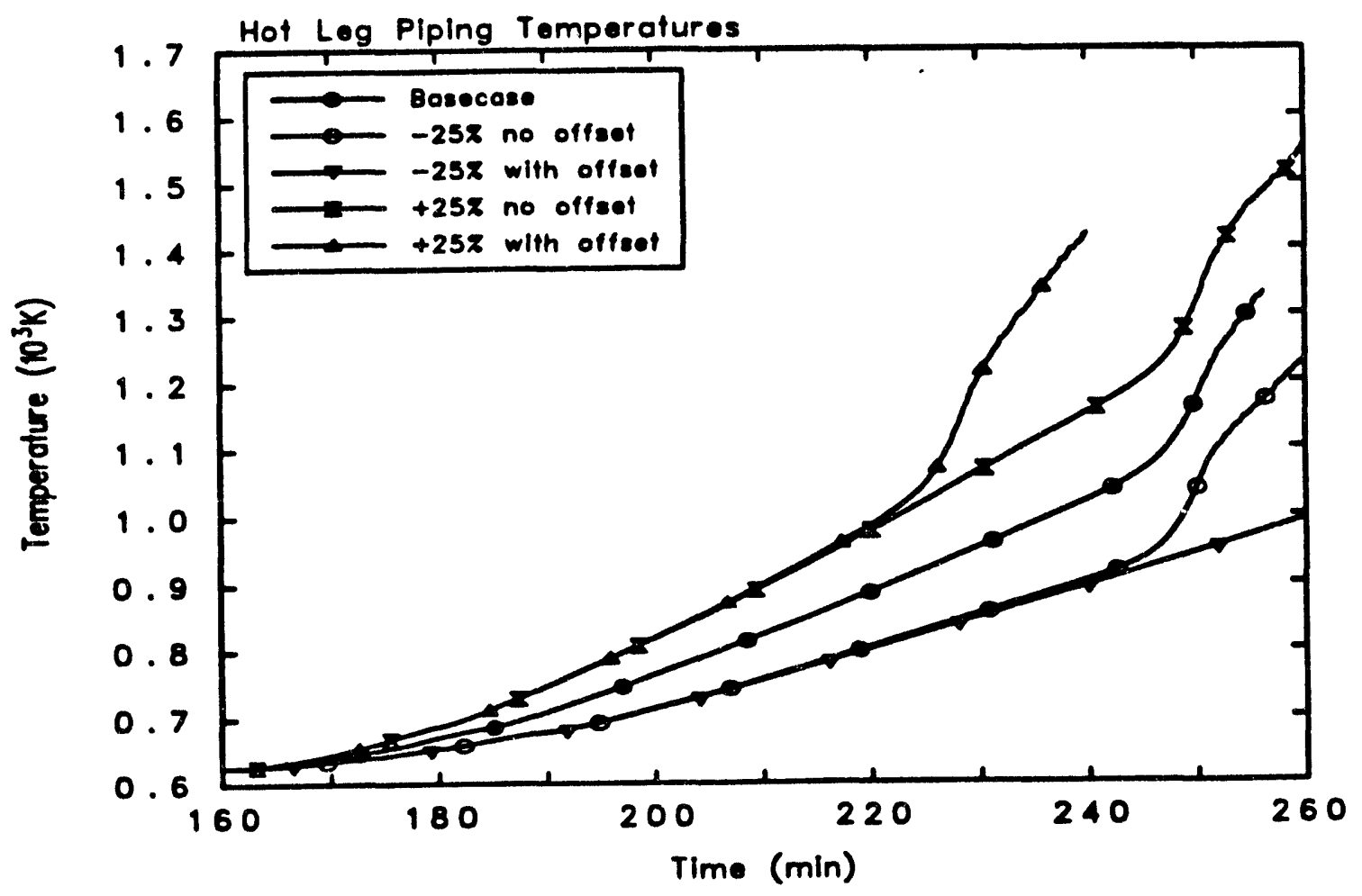

Figure 9.1.11 Comparison of the hot leg piping temperature of the MELCOR basecase with the MELCOR sensitivity study which varied the decay heat by $\pm 25 \%$, and the MELCOR sensitivity study which varied the decay by $\pm 25 \%$ including zircaloy oxidation time advance or delay. 


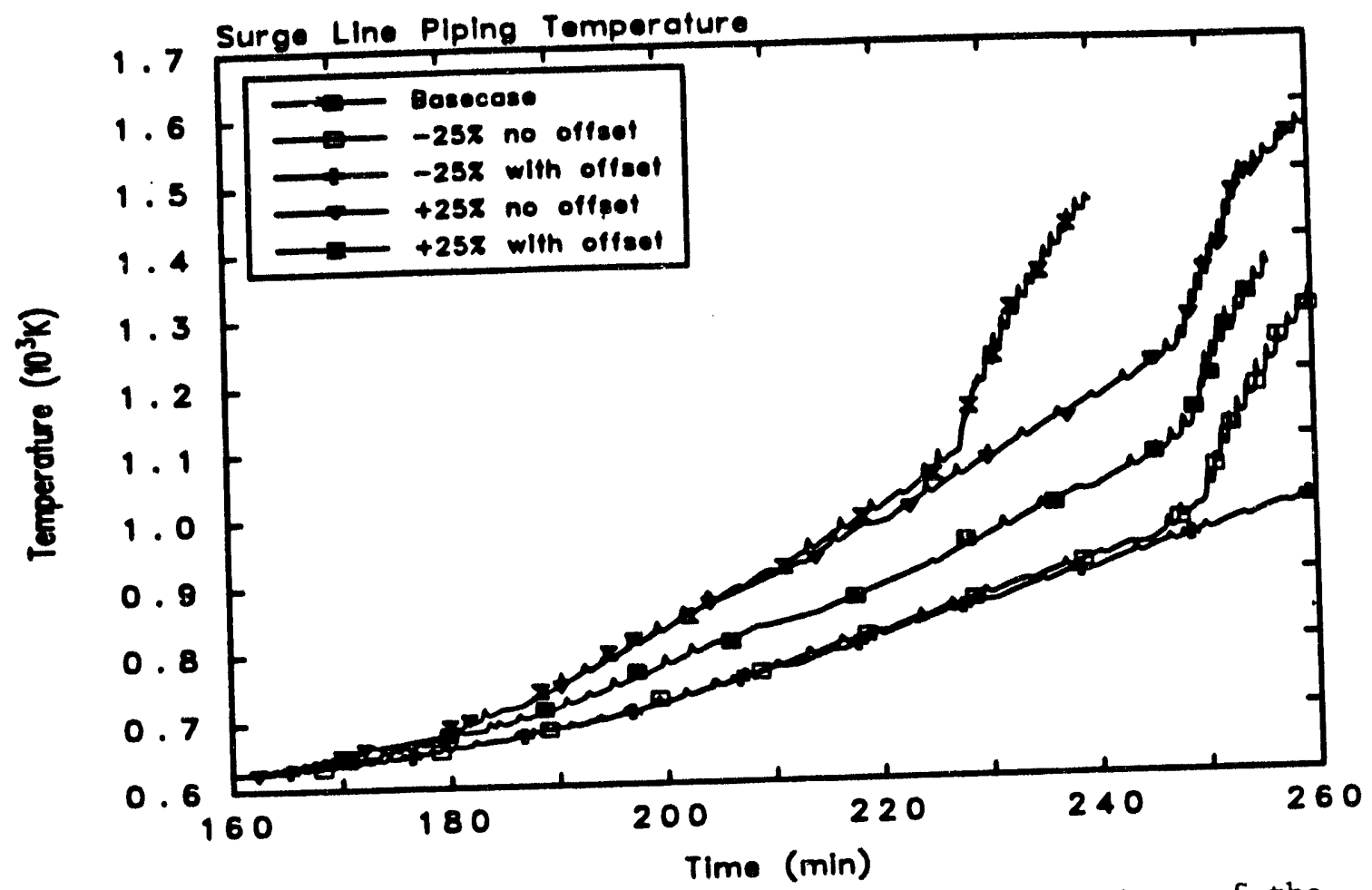

Figure 9.1.12 Comparison of the surge line piping temperature of the MELCOR basecase with the MELCOR sensitivity study which varied the decay heat by $\pm 25 \%$, and the MELCOR sensitivity study which varied the decay by $\pm 25 \%$ including zircaloy oxidation time advance or delay.

\subsection{Zircaloy Oxidation Heating Sensitivity Study}

In this study, the effect of the magnitude of the oxidation heating was examined. In one case, oxidation heating was eliminated to establish the possible effect of grid spacer interactions causing melting of Zirconium-Nickel eutectic mixtures before substantial oxidation can occur. In the second case, the magnitude of oxidation heating at any instant in time was doubled from that of the basecase to simulate additional oxidation of steel upper plenum structures which are near oxidation temperatures at this time (Fig. 8.2.12). The results of these two cases are compared with those of the basecase for each of the three critical components in Figures 9.2.1 through 9.2.3. In the case with no oxidation heating, the failure location changed from the surge line to the hot leg pipe. The reason this occurred is as follows. Oxidation heating occurred at a late time in the TMLB' scenario. The energy thus provided serves to pressurize the system faster, causing the pressurizer to relieve that pressure more often, which in turn flowed more hot fluid into the surge line. This extra flow heated up the surge line until it failed. With no oxidation, a substantial late-time energy source was removed from the computation, and pressure relief was not required as often as in the basecase. This in turn reduced the flow and thus the temperatures in the surge ine. Instead, the circulation through the hot leg pipe heated up this component and caused failure in this region. In Figures 9.2.1 through 9.2.3 the lack of oxidation caused the temperature curves to be virtually linear in later times, rather than the dramatic upswing 
observed for the two cases in which oxidation was included. This increased the fallure time of the case with no oxidation heating by 28.4 minutes, to 279.6 minutes. As suggested in section 9.1, the state of core degradation which was not considered in the MELCOR calculations should also be examined at this later RCS fallure time.

On the other hand, when the magnitude of the oxidation was doubled, the effect on fallure time was moderate. The higher rate accelerated the time of fallure by about 2.6 minutes, and the component which failed was the surge line.

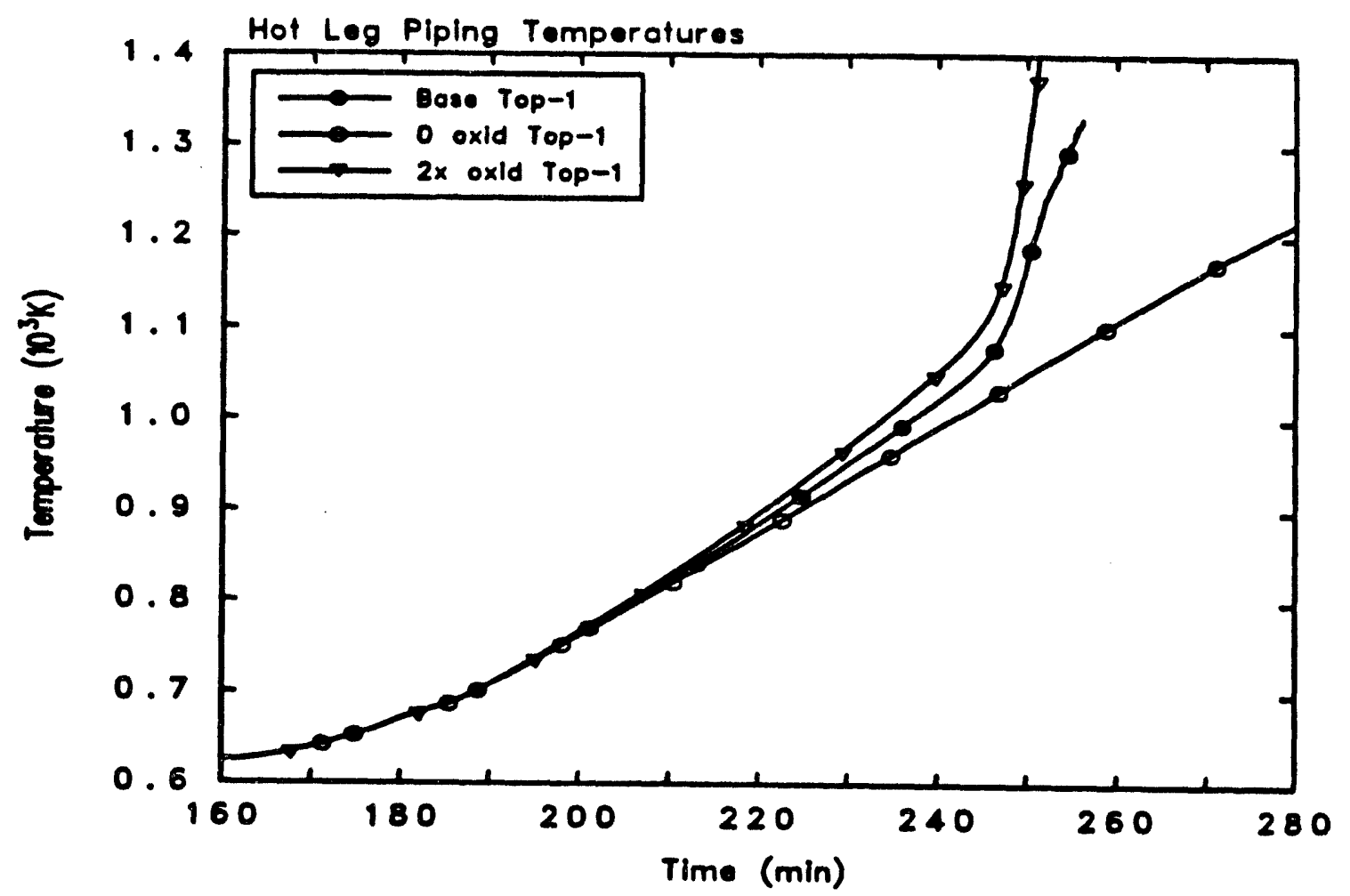

Figure 9.2.1 Comparison of the hot leg piping temperature of the MELCOR basecase with the MELCOR sensitivity study which varied the magnitude of oxidation by zeroing it out and by a factor of two. 


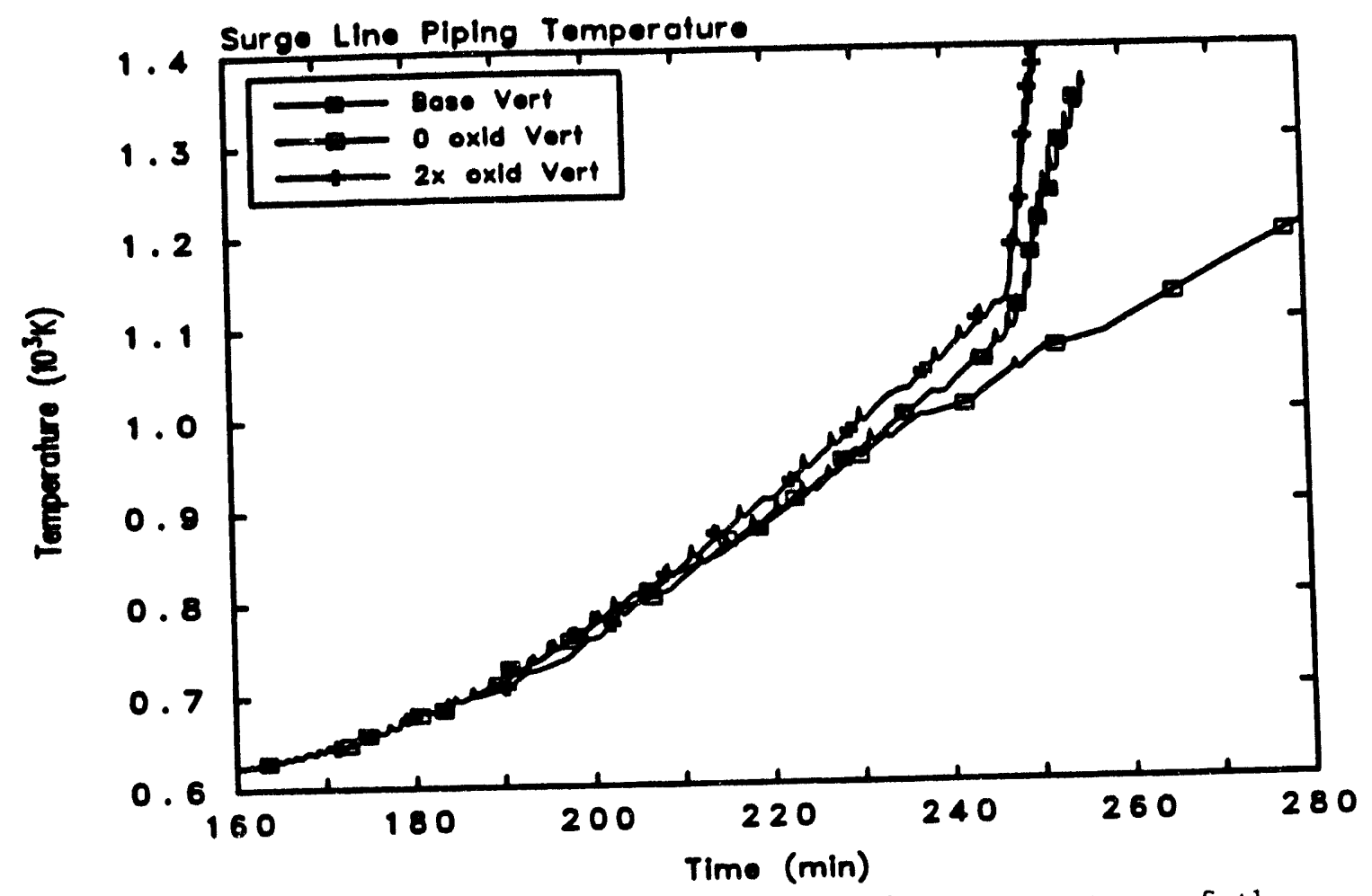

Figure 9.2.2 Comparison of the surge line piping temperature of the MELCOR basecase with the MELCOR sensitivity study which varied the magnitude of oxidation by zeroing it out and by a factor of two.

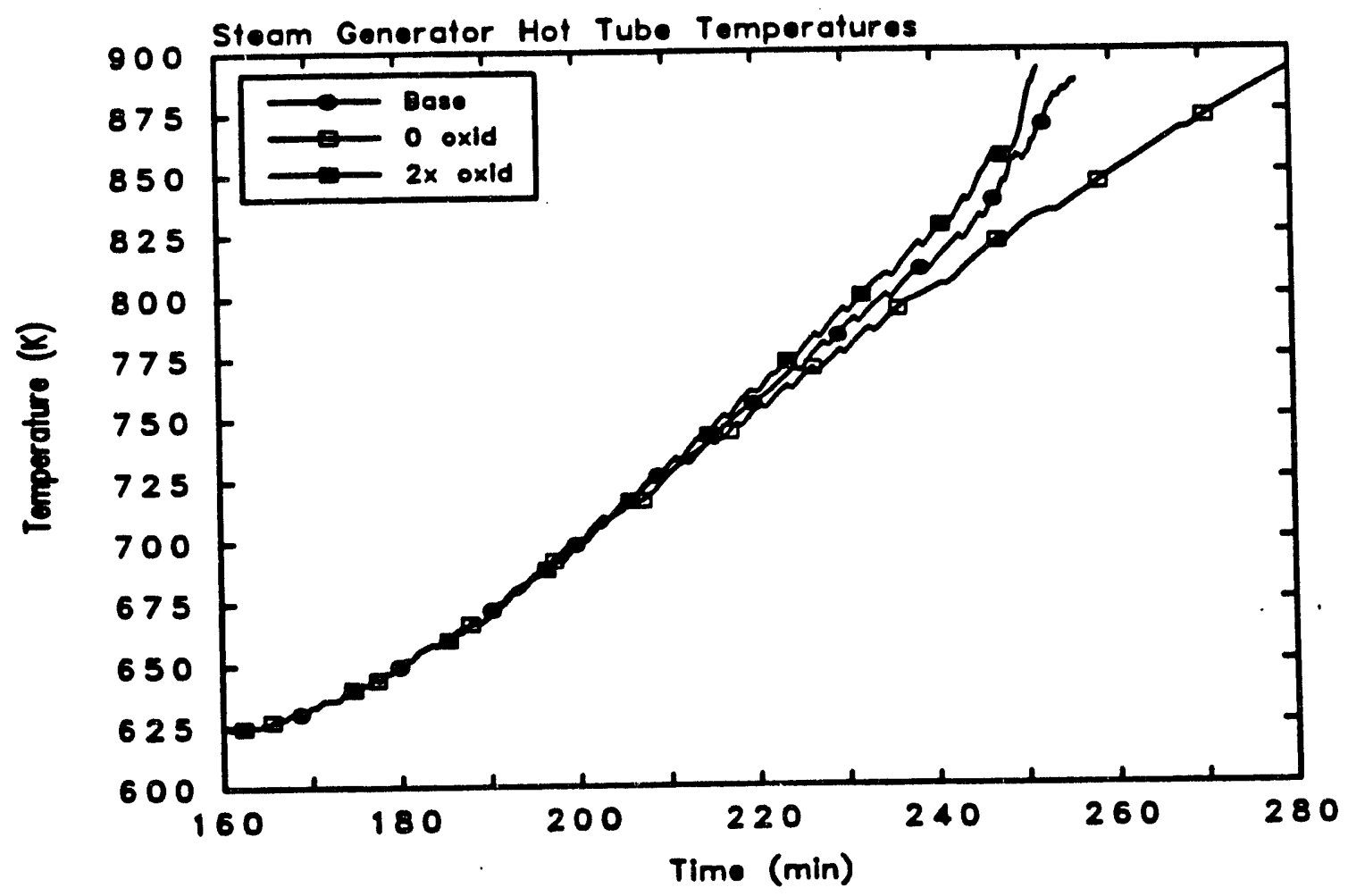

Figure 9.2.3 Comparison of the steam generator hot tube temperature of the MELCOR basecase with the MELCOR sensitivity study which varied the magnitude of oxidation by zeroing it out and by a factor of two. 
The MELCOR basecase computation did not include the effect of hydrogen production in the core due to the Zircaloy oxidation. Hydrogen can migrate to other parts of the system, including the hot leg, surge line and steam generator. The concern is that hydrogen, being much lighter than steam, can rise and fill the critical components of the RCS, acting to greatly reduce the buoyancy driven flow loops. It should be noted that MELCOR, as well as SCDAP/RELAP5, assumes complete mixing of the steam and any non-condensible gases in each control volume. Similarly, gases flowing between volumes are also assumed to be wel1-mixed. Therefore, correct simulation of hydrogen stratification in various region of the RCS, particularly the top of the steam generator tubes, cannot be modeled in either MELCOR or SCDAP/RELAP5. To simulate the creation of hydrogen in the core, the hydrogen generation rate curve from Reference 2 was used as the hydrogen source to the core control volume (CV 125). Since detailed core modeling was not included, the hydrogen was added at the core control volume temperature. In reality, the hydrogen is generated at the cladding temperature which is much larger than the fluid temperature during oxidation. Thus, in this simulation the only effect of hydrogen addition was to determine if a change in fluid properties affected the results. One-fourth of the hydrogen did not remain in the RCS. Instead, it reached the containment control volume after being expelled from the pressurizer. As a result, temperatures of the critical components were not changed significantly, as Figures 9.2.4 through 9.2.6 show. The surge line failed approximately 1.8 minutes earlier when hydrogen production was included as compared to the basecase.

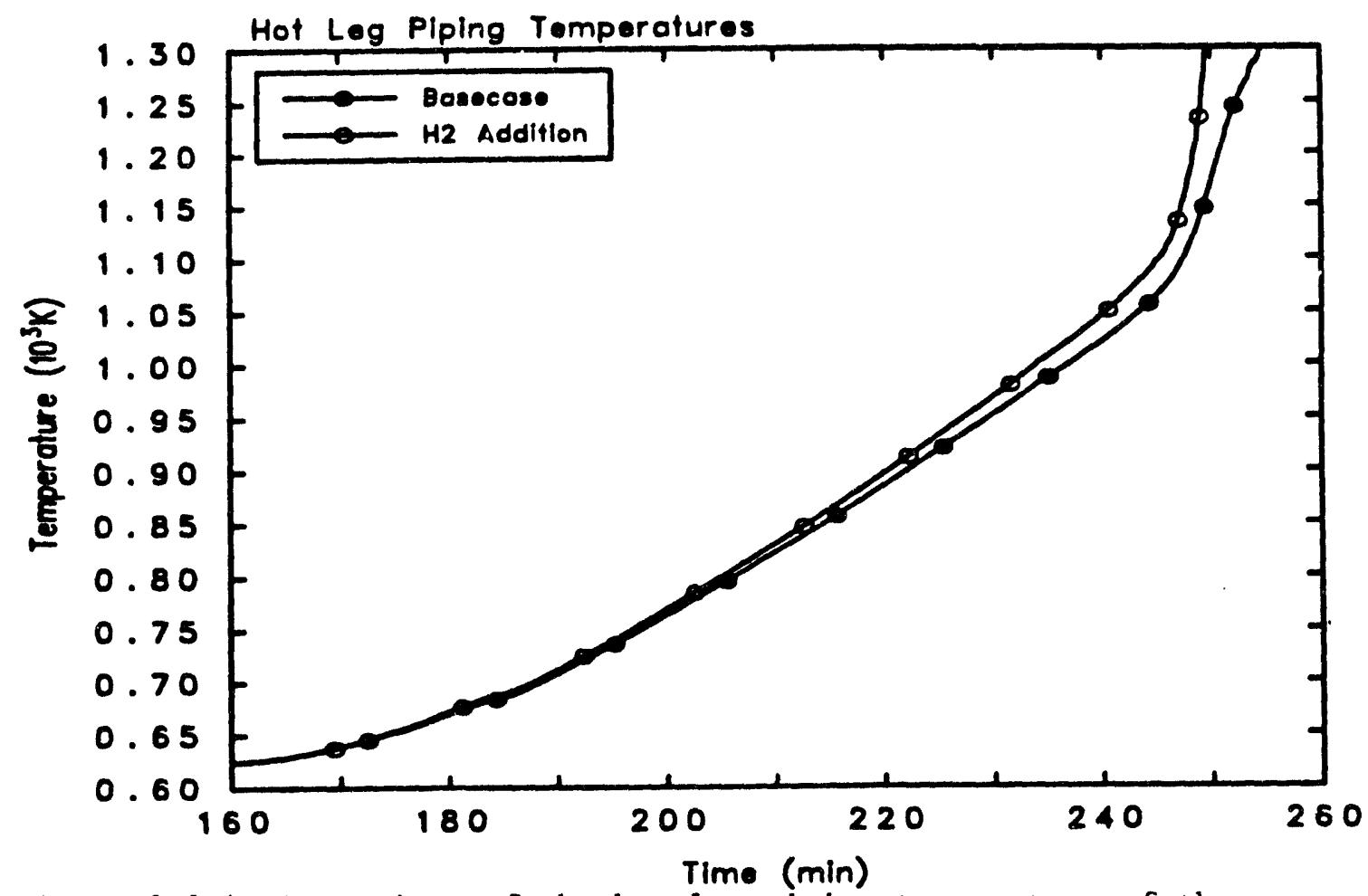

Figure 9.2.4 Comparison of the hot leg piping temperature of the MELCOR basecase with the MELCOR sensitivity study which included hydrogen production. 


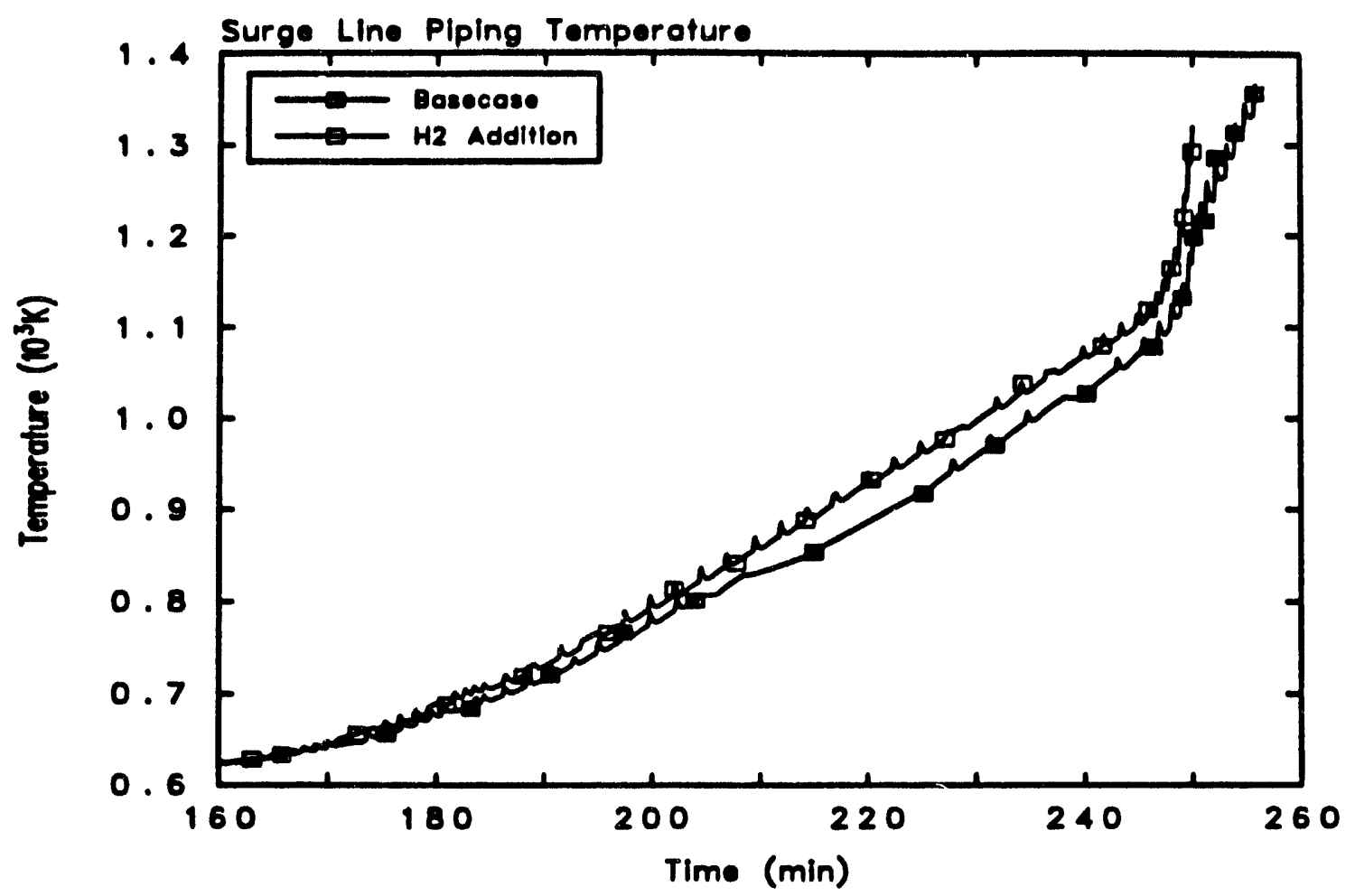

Figure 9.2.5 Comparison of the surge line piping temperature of the MELCOR basecase with the MELCOR sensitivity study which included hydrogen production.

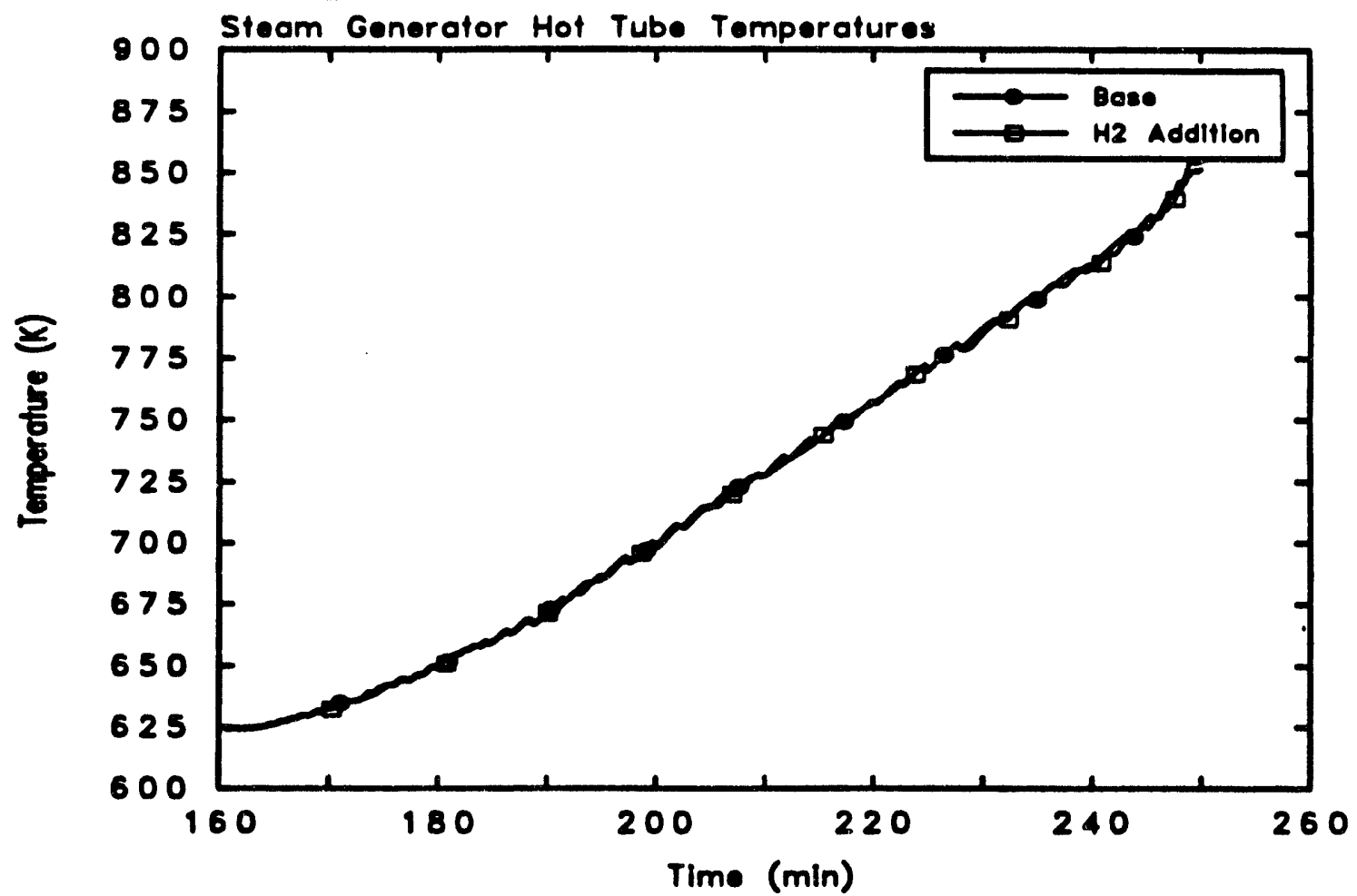

Figure 9.2.6 Comparison of the steam generator hot tube temperature of the MELCOR basecase with the MELCOR sensitivity study which included hydrogen production. 


\section{3 Circulation Rate Sensitivity Study}

The effect of modifying the countercurrent hot leg loop circulation rate was examined in this study, thus addressing concerns of the accuracy of flow rates derived from the Westinghouse experiments and the COMMIX computations. Although not shown specifically, flow rates in the previous sensitivity studies did not change significantly from that of the basecase, and thus did not provide any guidance concerning the importance of this parameter. To examine this issue, the flow loss coefficients in the hot leg/surge line/steam generator assembly were varied over a scale that ranged four orders-of-magnitude. Each order-of-magnitude value constituted a case, so that a total of four cases were run. The basecase values fell between the lowest flow rate case and the next highest flow case, termed the 3 rd highest flow case. The loss coefficient, $K$, was varied in a manner as $K / 10, K, 10 \mathrm{~K}$, and $100 \mathrm{~K}$ at each region of the hot $\mathrm{leg} / \mathrm{steam}$ generator natural circulation loop. Note that a high flow loss coefficient corresponded to a low flow rate, because the "resistance" to flow has been increased. The amount of mixing at the inlet plenum to the steam generators was held fixed for each run because the experimental data to correlate hot leg/steam generator flow rates with inlet plenum mixing was not available.

Results for the four cases as compared to the basecase are shown in Figures 9.3.1 through 9.3.8. Figure 9.3.1 shows that the lower flow rate in the hot $1 \mathrm{eg} / \mathrm{steam}$ generator $\mathrm{fl} p$ results in less energy being extracted from the core. Figu: confirms that changing the pipe loss coefficients did raise or the average flow rate in the hot leg loop. The maximum flowrate $\ldots$ the hot leg varied from a low of about $5.0 \mathrm{~kg} / \mathrm{s}$ to a high of $23.0 \mathrm{~kg} / \mathrm{s}$. The basecase maximum was about $7.5 \mathrm{~kg} / \mathrm{s}$. Flows in the steam generator did not change as drastically (Figure 9.3.3). The maximum flow rate in the low flow case was about $3.5 \mathrm{~kg} / \mathrm{s}$, the maximum flow rate in the high flow case was about $14.0 \mathrm{~kg} / \mathrm{s}$, while the basecas steam generator maximum flow rate was $10.0 \mathrm{~kg} / \mathrm{s}$. Variation of the flow rate in the hot leg loop changed vapor temperatures throughout the system significantly, as shown in Figure 9.3.4 for the vessel vapor temperature. The lowest flow rate resulted in the highest vapor temperature. In this case, heat transfer to the heat structures by natural convection has been suppressed resulting in higher core and steam temperatures. Conversely, the highest flow rate case exhibited the lowest vapor temperatures, evincing the ability of the circulation loop to transfer heat to heat structures and keep the RCS cooler.

Figure 9.3 .5 shows that the steam generator vapor temperature contradicted the above generalities correlating flow and vapor temperature. In this case, a high flow rate resulted in high vapor temperatures, and vice versa. This phenomenon highlights the complex nature of fluid flow/heat transfer in this system. Figure 9.3 .5 plots the temperatures of Control Volume 213 (see Figure 8.1.1). Note that part of the flow from the hot leg passed through a volume that served as the "mixing chamber" between hot and cold fluid at the inlet plenum to the steam generator tubes. The mixinc model, as noted above, was not changed. Therefore, these results may be affected by this assumption. 


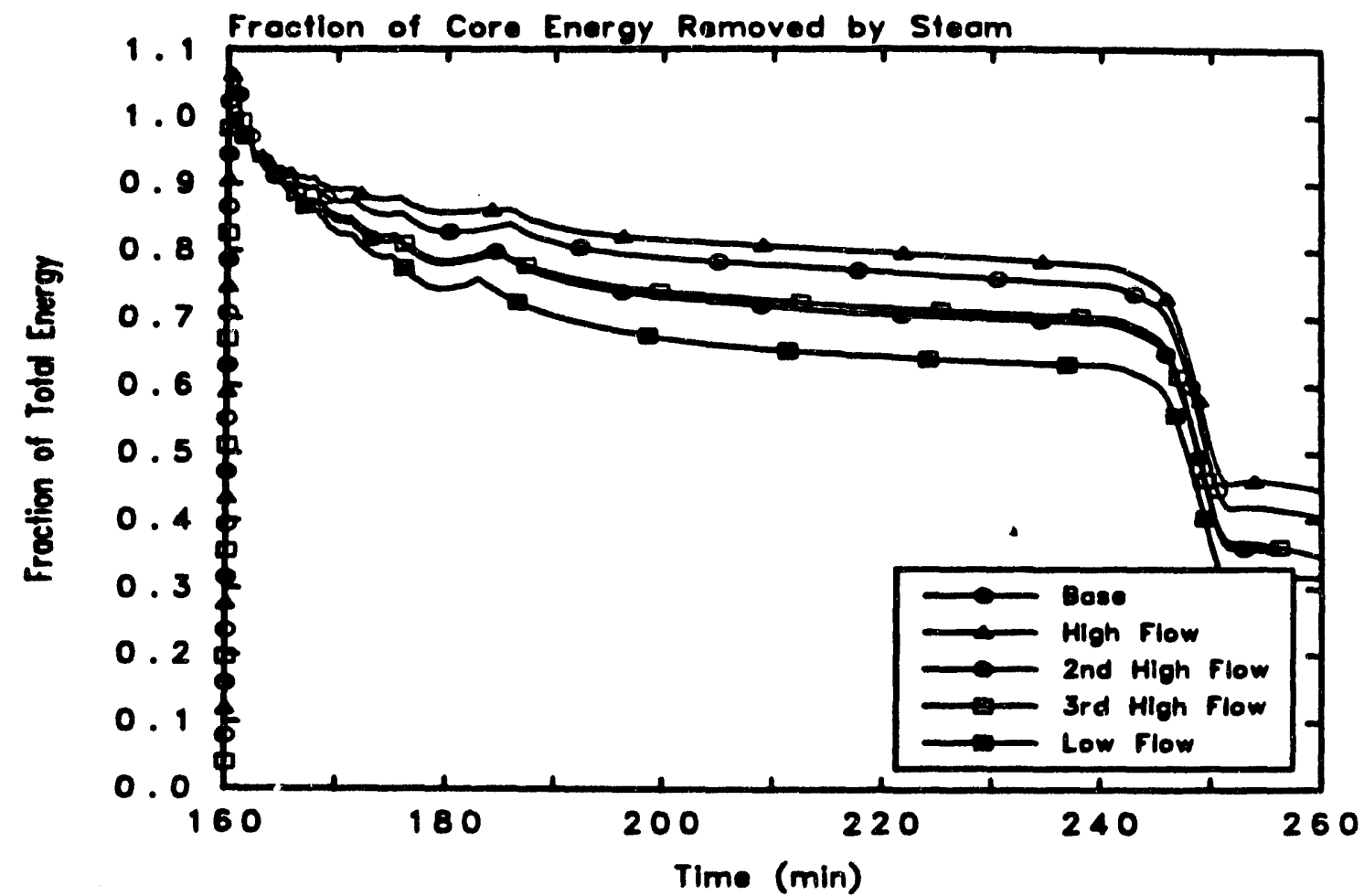

Figure 9.3.1 Comparison of the core energy removed by steam in the MELCOR basecase with the MELCOR sensitivity study which varied the loss coefficients in the hot leg flow loop by four orders of magnitude.

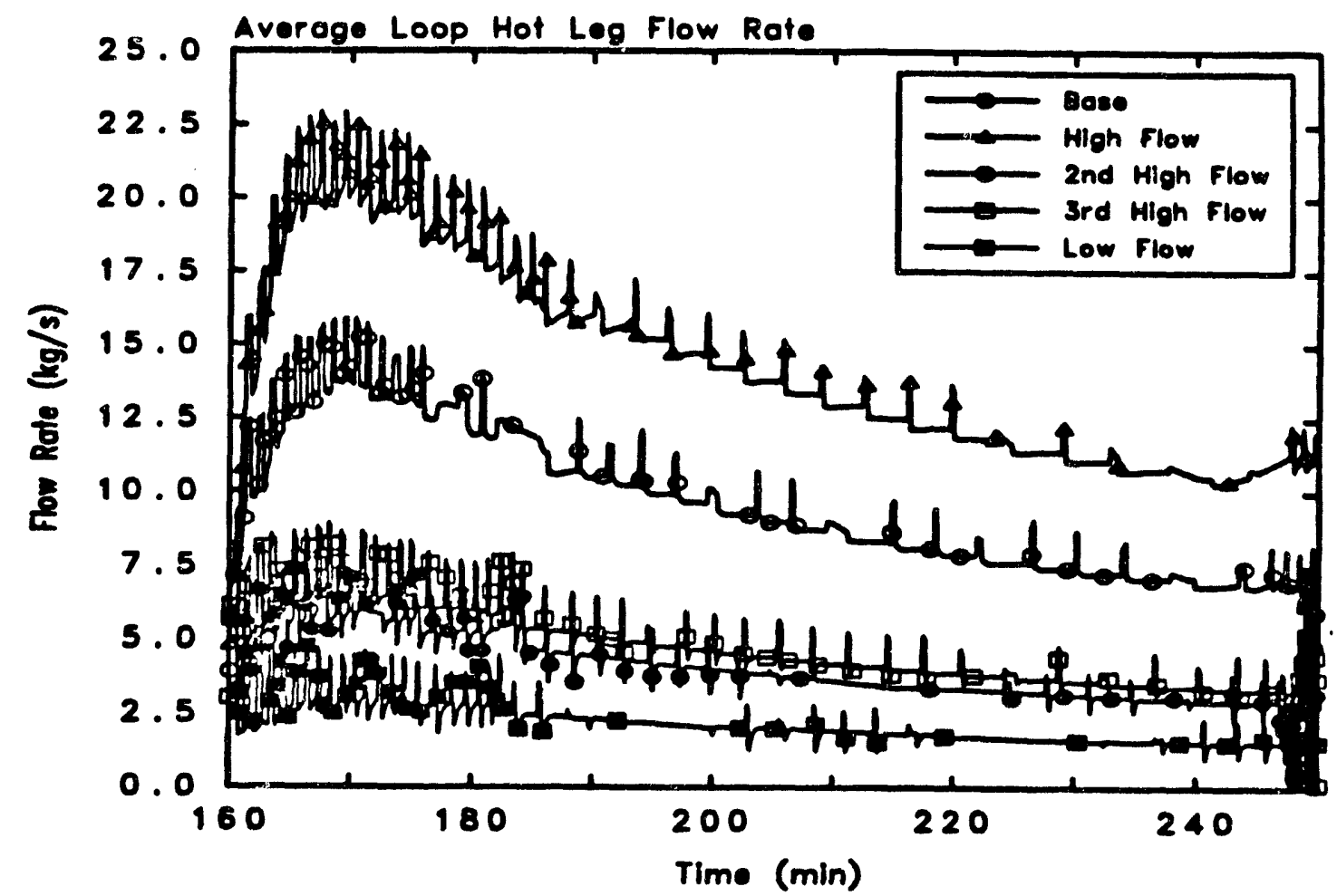

Figure 9.3.2 Comparison of the "average" loop hot flow rate in the MELCOR basecase with the MELCOR sensitivity study which varied the loss coefficients in the hot leg flow loop by four orders of magnitude. 


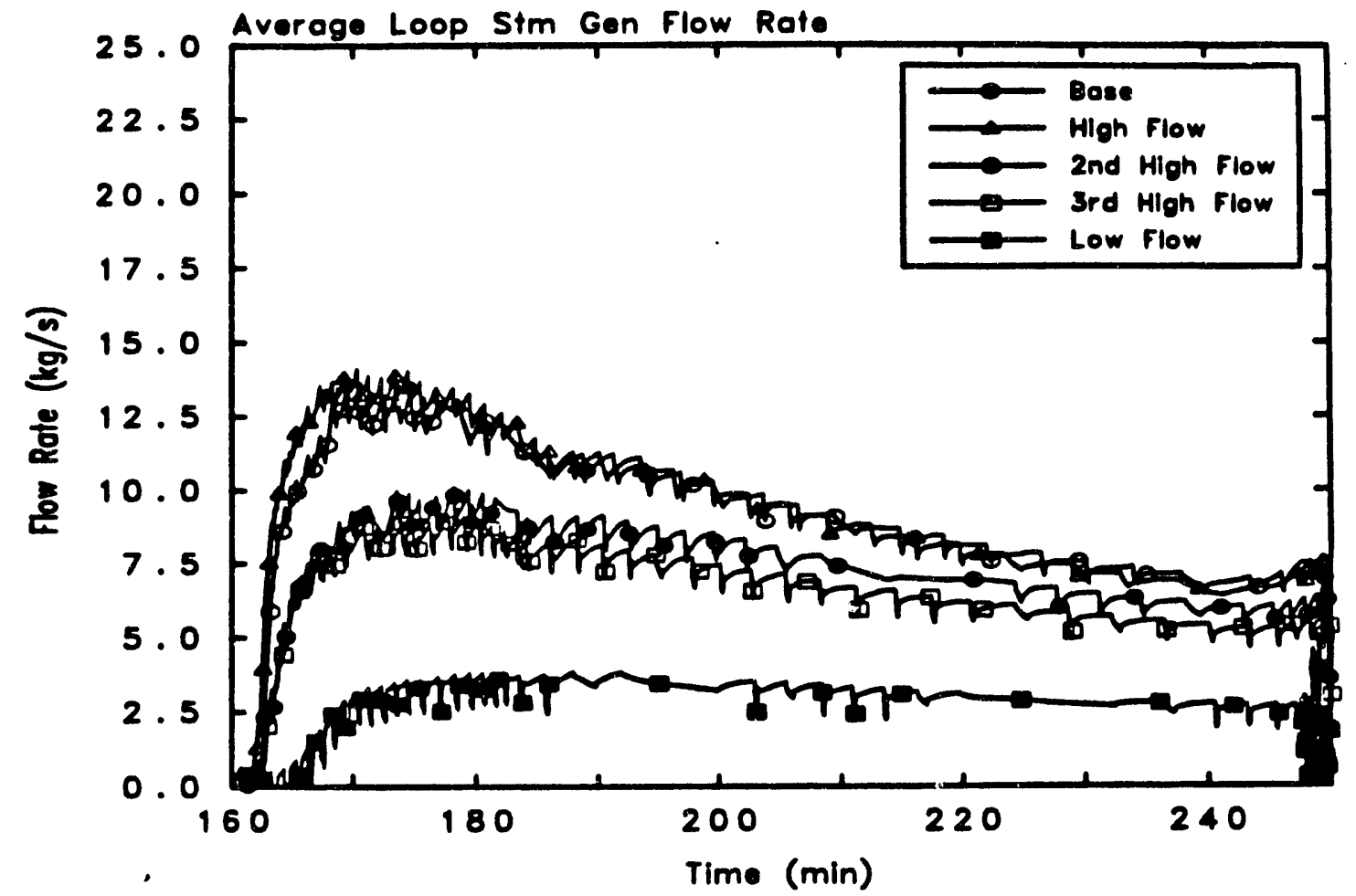

Figure 9.3.3 Comparison of the "average" loop steam generator flow rate in the MELCOR basecase with the MELCOR sensitivity study which varied the loss coefficients in the hot leg flow loop by four orders of magnitude.

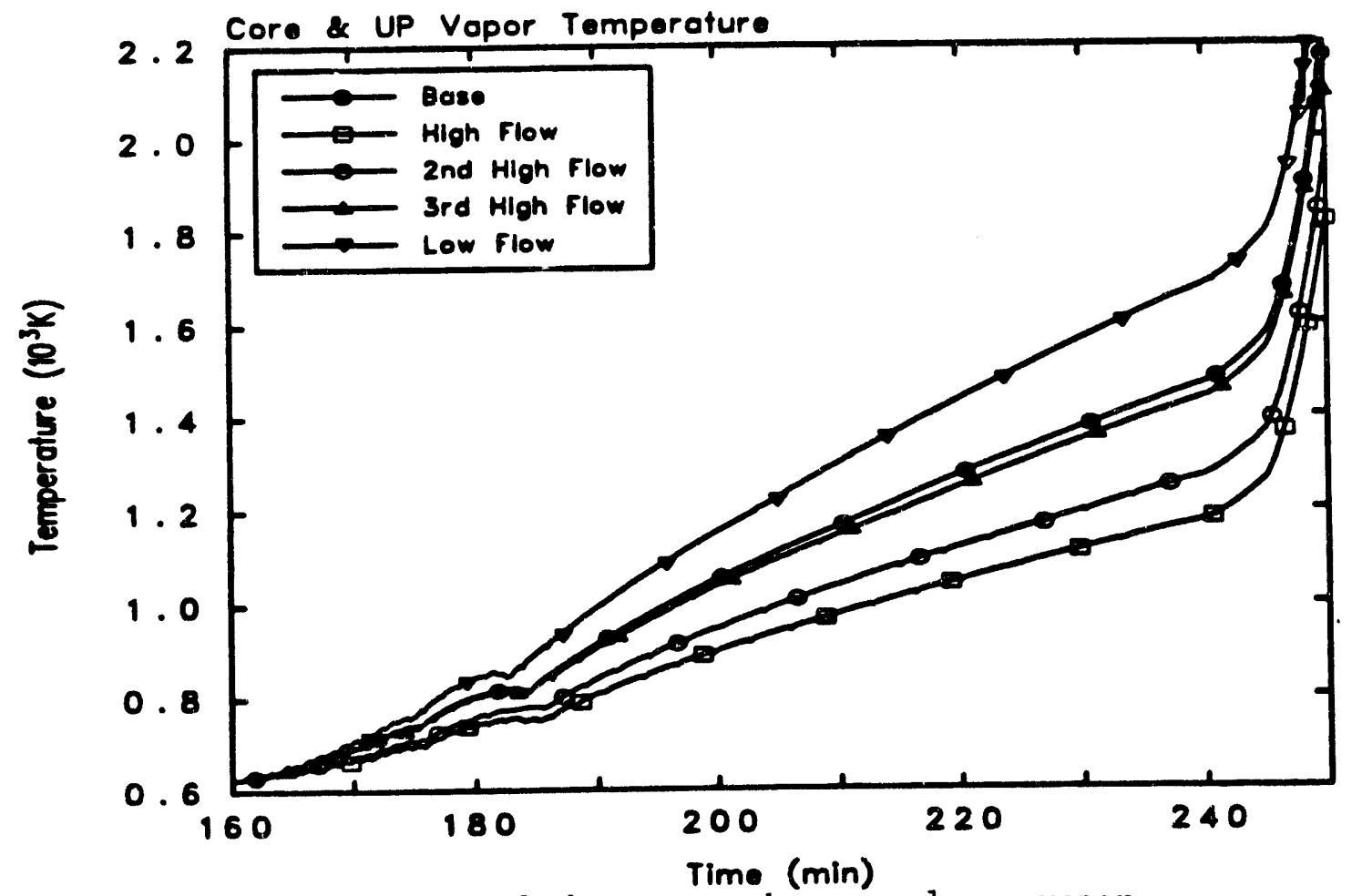

Figure 9.3.4 Comparison of the core and upper plenum vapor temperature in the MELCOR basecase with the MELCOR sensitivity study which varied the loss coefficients in the hot leg flow loop by four orders of magnitude. 


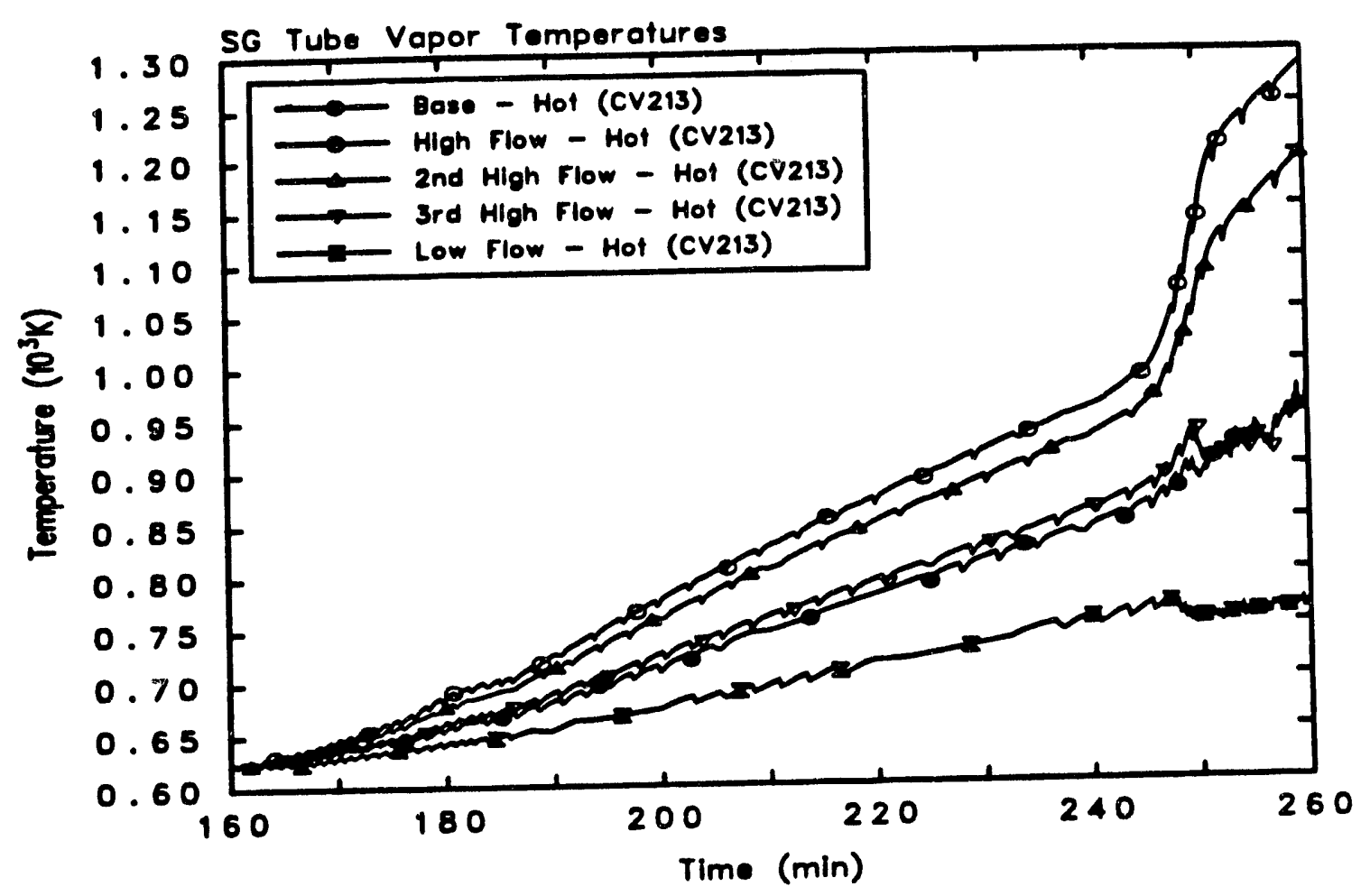

Figure 9.3.5 Comparison of the steam generator vapor temperature in the MELCOR basecase with the MELCOR sensitivity study which varied the loss coefficients in the hot leg flow loop by four orders of magnitude.

The hot leg piping temperatures for the four circulation sensitivity runs are shown in Figure 9.3.6. An interesting fact shown in this figure is that the hot leg piping temperature for the low flow and high flow case were almost identical up to a time of about 245 minutes when oxidation heating became important, while the two intermediate cases exhibited hot leg temperatures substantially cooler. This result stemmed from convective heat transfer, which depends both on the temperature of the convective fluid, and its rate of flow. The high flow case had high flow rates, but low fluid temperatures; the low flow case had low flow rates, but high fluid temperatures. However, as Figure 9.3.6 shows, when the effects were combined, the resultant transfer of heat for the high and low flow cases was nearly identical. Intermediate flow loss coefficient values resulted in an overall lowering of the hot leg piping temperature as compared to the basecase and the high/low flow rate cases. At late times, when the oxidation energy became dominant, the high flow rate case transferred more energy at a faster rate than any of the other cases. Consequently, the hot leg temperature for this case increased at a faster rate than the other cases. 


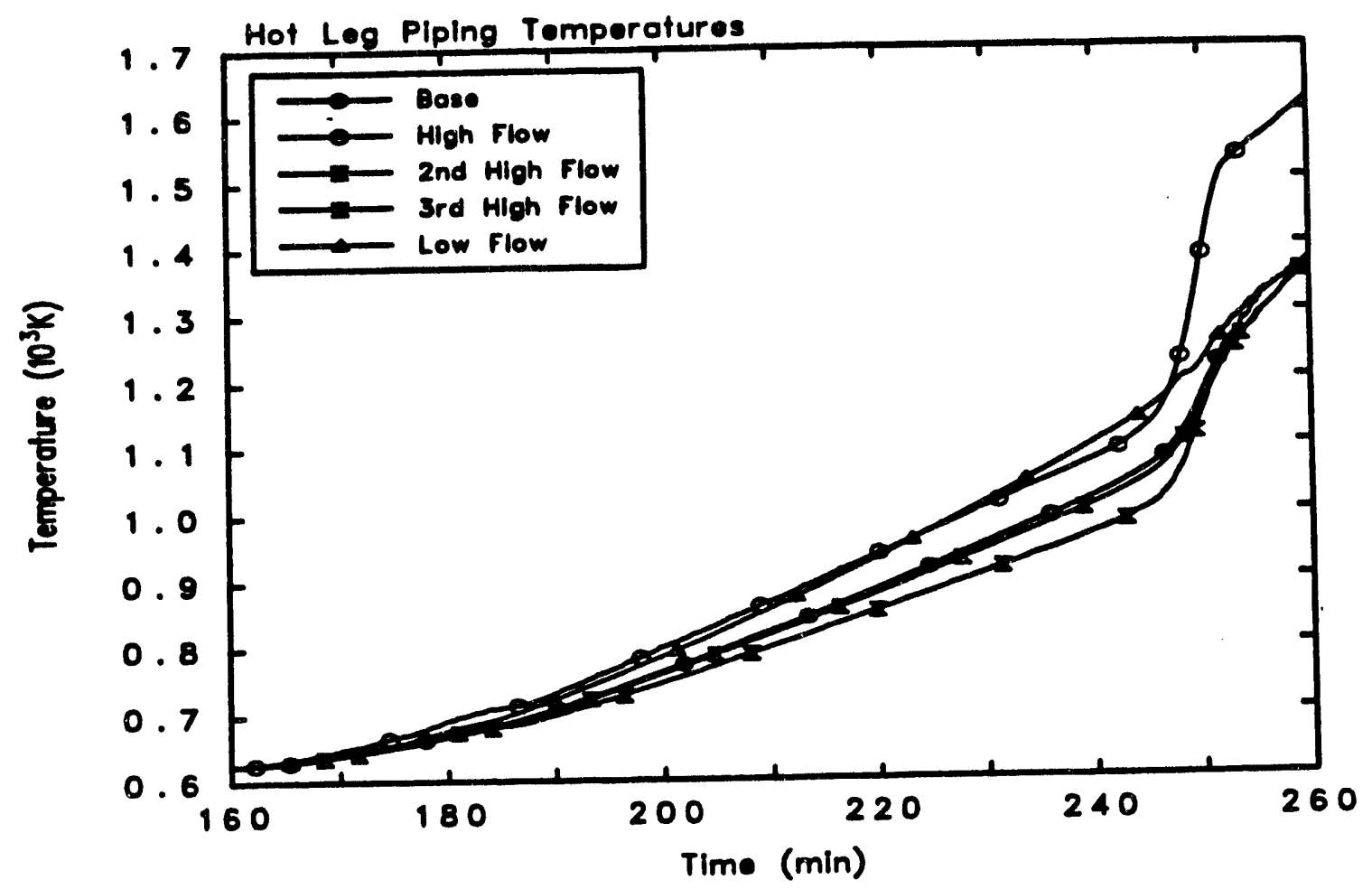

Figure 9.3.6 Comparison of the hot leg piping temperature in the MELCOR basecase with the MELCOR sensitivity study which varied the loss coefficients in the hot leg flow loop by four orders of magnitude.

The surge line piping temperatures for the four circulation runs is shown in Figure 9.3.7. Because the flow rate in the surge line is highly intermittent, the results are different than those observed for the hot leg piping. The low flow case had the hottest surge line pipe temperatures, which was due principally to two phenomena. First, the origin of the surge line fluid was the hot leg, which had the hottest fluid for the low flow case. Second, because not as much heat was being removed from the core in the low flow case, pressure in the system always built up more quickly than in the other cases, so fluid flowed into the surge line in the low flow case more often. This is readily observed in Figure 9.3 .7 at late times when the oxidation energy became important. The surge line piping temperature for the low flow case has more oscillations in it than any other case, indicating the frequent opening of the relief valve. Because the high flow rate case had much cooler hot leg vapor temperatures than the low flow case, it had the coolest surge line pipe temperatures. Also, pressure excursions were much less frequent than the low flow case. Note, however, because the flow loss coefficients in the surge line were smallest for the high flow case, when the relief valve did open, high surge line flow rates led to higher individual peak temperature excursions. For example, at late times, each peak in the low flow case would rise about $40 \mathrm{k}$, while in the high flow case, individual peaks were about $80 \mathrm{~K}$. Intermediate cases lie between these two extremes for surge line piping temperatures. 


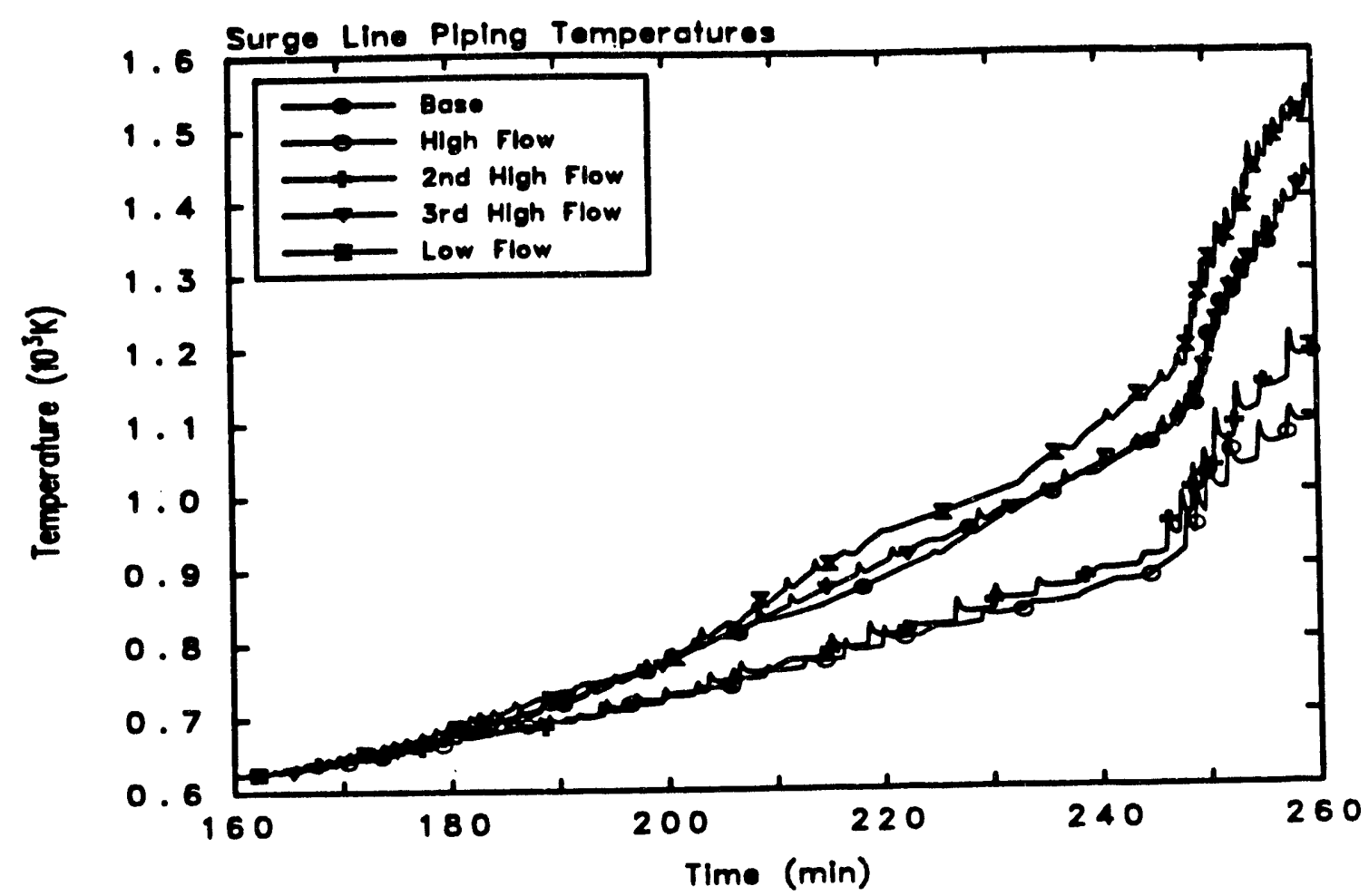

Figure 9.3.7 Comparison of the surge line piping temperature in the MELCOR basecase with the MELCOR sensitivity study which varied the loss coefficients in the hot leg flow loop by four orders of magnitude.

The steam generator tube temperature for each of the four cases is shown in Figure 9.3.8. It has already been noted that flow rate was the dominant heat transfer parameter in this region, and the results bear out this observation. The high flow rate case had the highest steam generator tube temperatures, while the low flow rate case had the lowest temperatures consistent with the tube vapor temperature trends previously noted.

The low temperatures in the surge line for the high flow rate case, and the dramatic temperature increase in the hot leg pipe for this case when oxidation became important combined to make the hot leg pipe the component which failed for this case. Thus, the high flow rate case fails about. 3.7 minutes earlier than the basecase. In the low flow case, the surge line was the component which failed, and again the time was about 2.4 minutes earlier than the basecase. The case labeled 3rd highest flow in Figure 9.3.8 failed in the surge line at a time almost identical to that of the basecase. On the other hand, the case designated as the 2 nd highest failed in the hot leg less than a minute later than the basecase. 


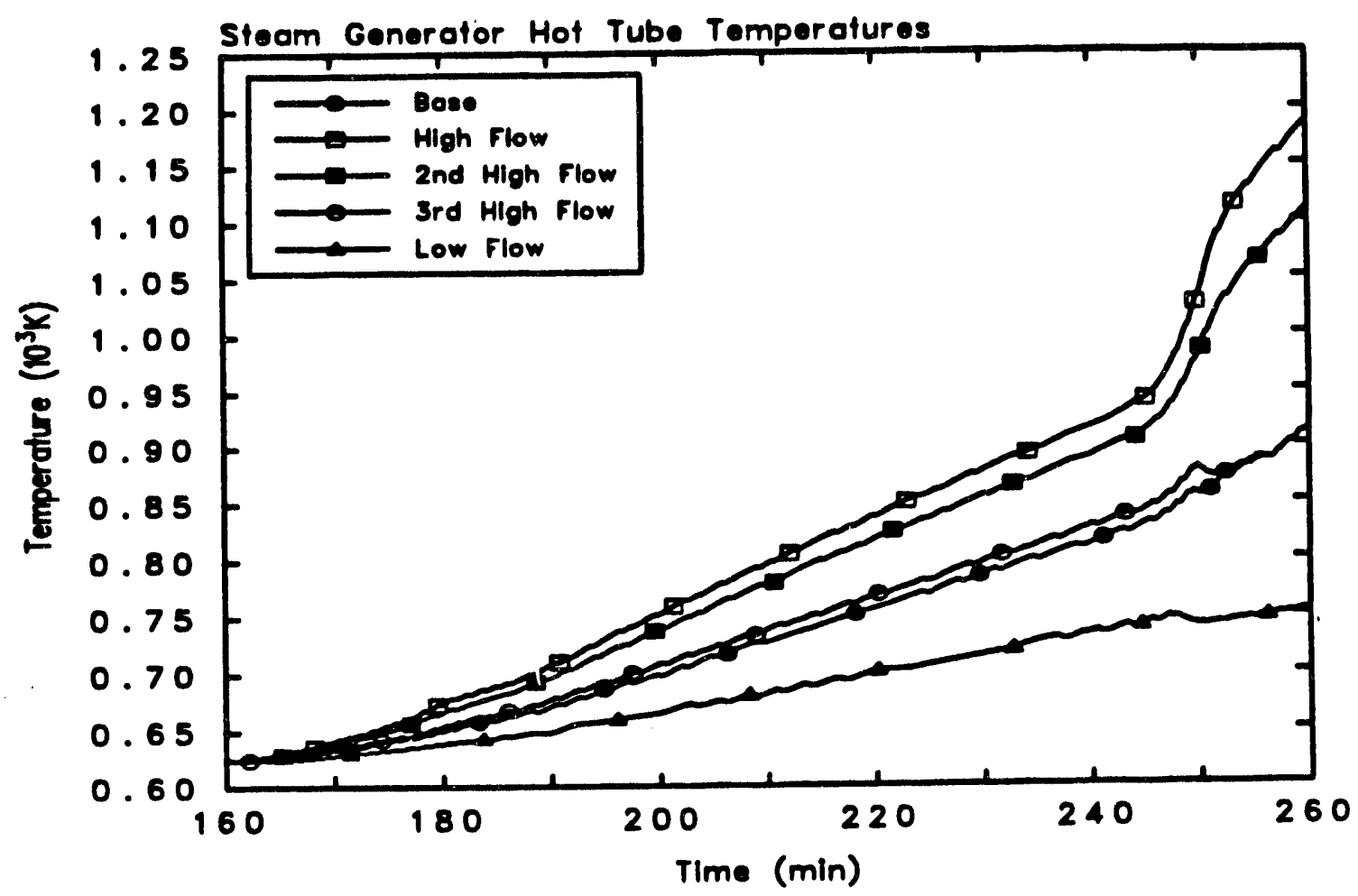

Figure 9.3.8 Comparison of the steam generator hot tube temperature in the MELCOR basecase with the MELCOR sensitivity study which varied the loss coefficients in the hot leg flow loop by four orders of magnitude.

\subsection{Radial Conduction Effects on the Split Hot Leg P1ping Model}

A major SCDAP/RELAP5 model limitation identified in Section 4.2 was the neglect of circumferential heat conduction between the physically separated top and bottom halves of the split hot leg model. A sensitivity study using the MELCOR model simulated this phenomenon.

Radial conduction from the top hot leg pipe heat structures in CV 201 and CV 202 to the bottom hot leg pipe heat structures in CV 222 and CV 221 was simulated by using the control function capability of the MELCOR code. The conductive energy rate, $Q$, was calculated as

$$
Q=K_{\text {eff }}\left(T_{\text {top }}-T_{\text {bot }}\right)
$$

where

$$
K_{\text {eff }}=\left[1 / K_{\text {top }}+1 / K_{\text {bot }}\right]^{-1}
$$

and

$$
K_{\text {top }}=k\left(T_{\text {top }}\right) \cdot A / z, K_{\text {bot }}=k\left(T_{\text {bot }}\right) \cdot A / z \text {. }
$$

$T_{\text {top }}$ and $T_{\text {bot }}$ are the top and bottom hot leg pipe heat structure average temperatures, respectively, $k$ is the stainless steel conductivity evaluated at the top or bottom hot leg pipe temperature, $A$ is the conduction area chosen as the actual contact area between the two pipe halves, and $z$ is the conduction length chosen to be onequarter of the pipe circumference. $A$ and $z$ are equal for both the top and bottom halves of the pipe since the pipe was split into equal 
halves. This energy was removed from the top hot leg pipe structures and added to the bottom hot leg pipe structures as boundary condition power sources in the analysis.

Figures 9.4.1 through 9.4.3 show the results of this analysis compared with the MELCOR basecase calculation. Figure 9.4.1 compares the hot leg top and bottom pipe temperature histories with the basecase. As expected, the top pipe remained slightly cooler and the bottom pipe was hotter when circumferential conduction between the two pipes was modeled. The effect, however, was quite small. The pipe temperatures were less than $15 \mathrm{~K}$ hotter/colder than the basecase temperatures during most of the transient. Figure 9.4.2 explains why the effect is $s$, minor. The conduction energy, on the order of kilowatts, was minimal compared to the convective energy, on the order of megawatts.

Figure 9.4 .3 shows the comparison of all critical component temperatures with the basecase. Again, only the hot leg pipe temperature was affected. The figure shows that the surge line and steam generator tube temperatures are not affected at all by this change. The temperature of the steam flowing through the loop, which drives the heat transfer to the piping components was also unchanged. Therefore, the predicted failure location remains in the surge line and would occur at the same time as predicted for the basecase, 249.7 minutes. However, the maximum hot leg temperature at this time was $1188 \mathrm{~K}, 24 \mathrm{~K}$ lower than the basecase.

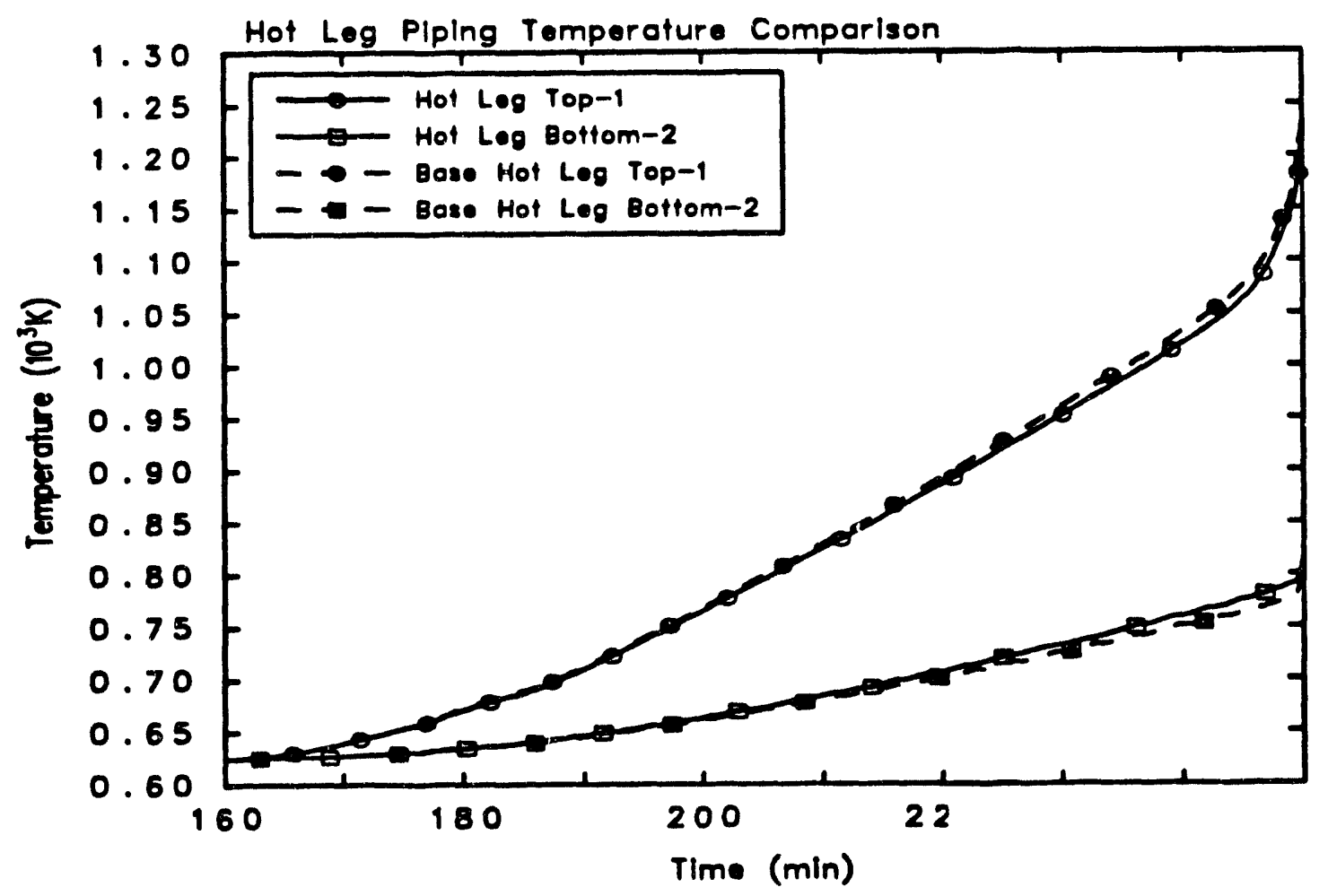

Figure 9.4.1. Hot leg pipe radial nonduction effects on the hot leg piping temperatures. 


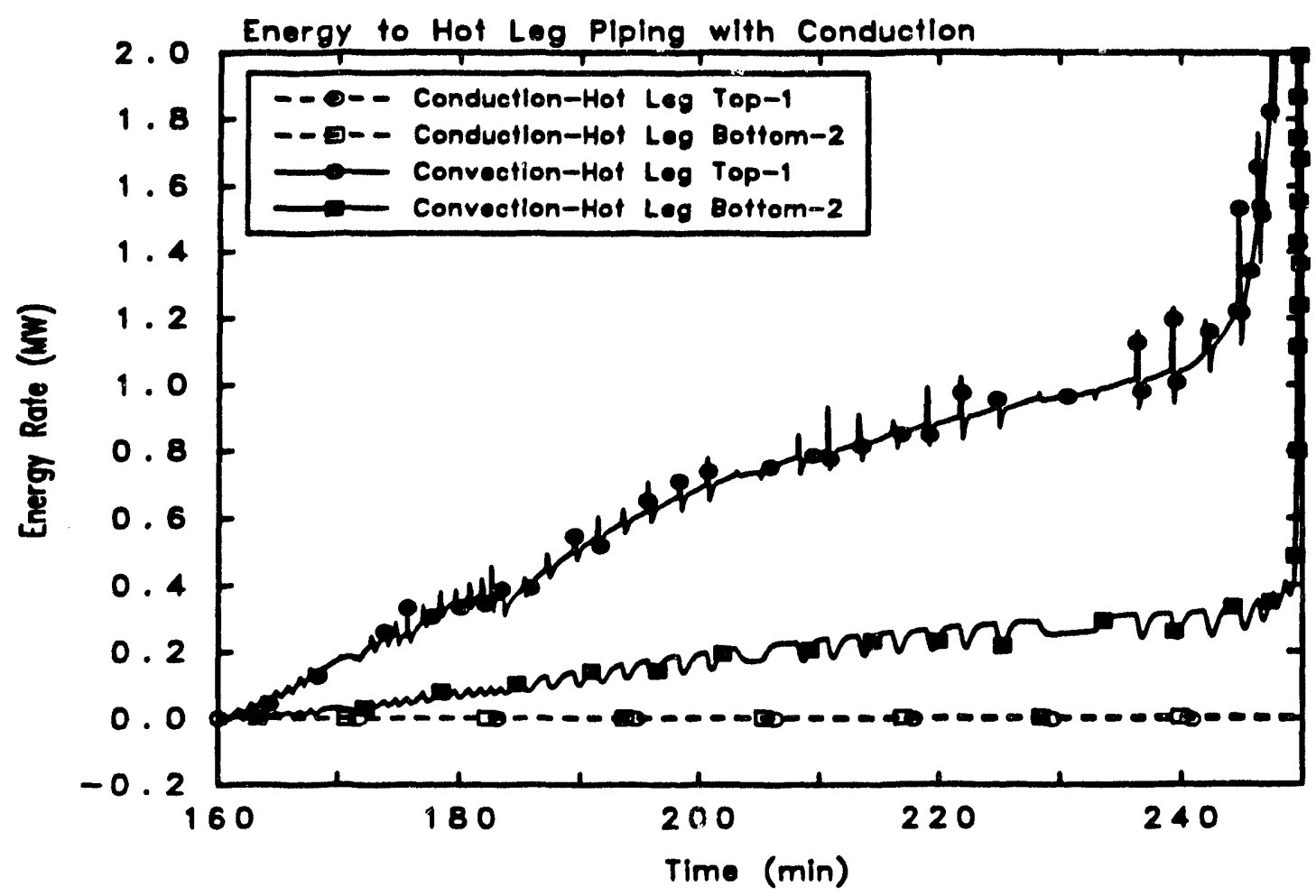

Figure 9.4.2 Conduction versus convection energy rates to the hot leg piping with radial conduction modeled.

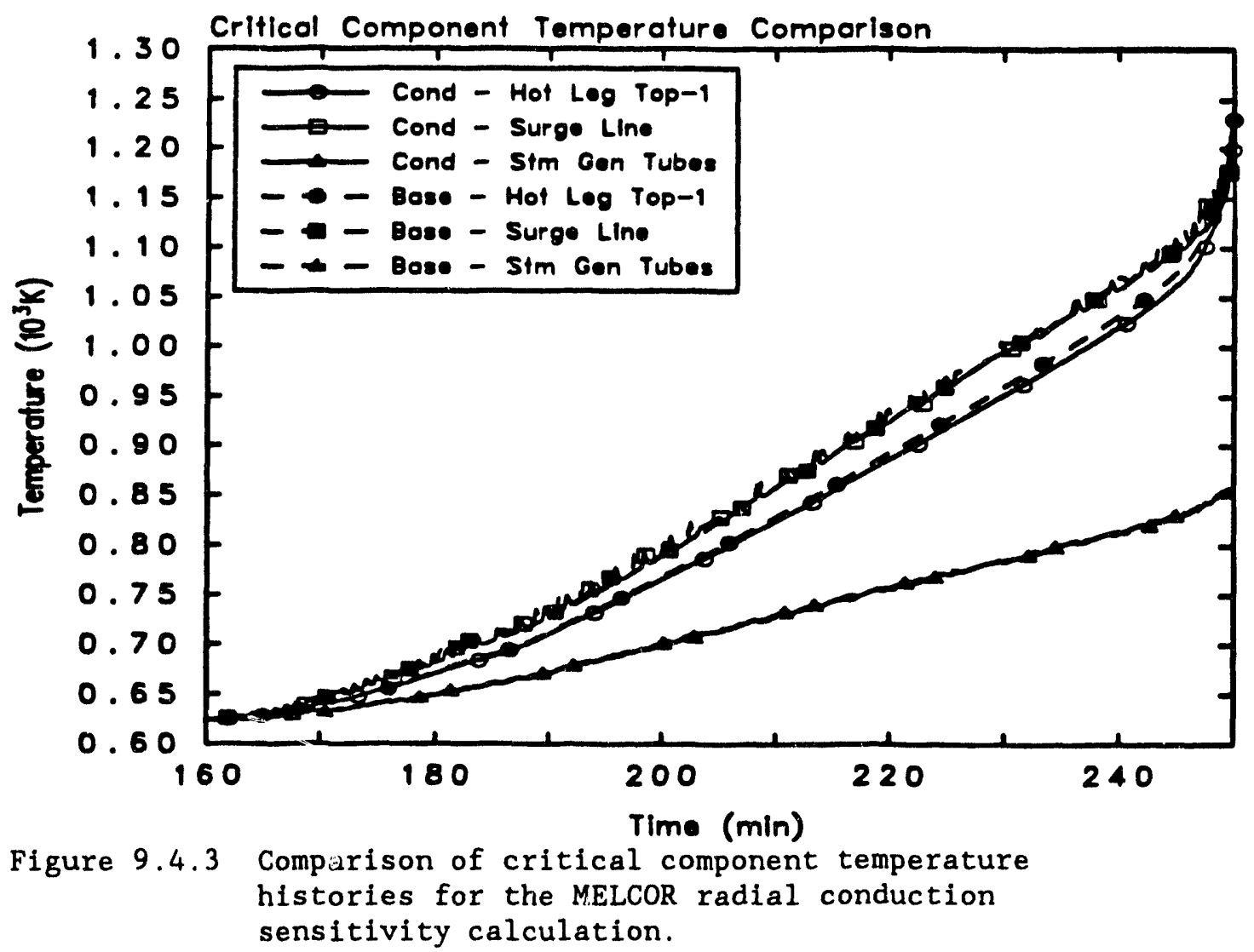


This analysis has shown that convection from the steam to the piping is the dominant heat transfer mechanism. Therefore, neglect of circumferential conduction between the split hot leg pipes was a reasonable assumption in the SCDAP/RELAP5 analysis.

\subsection{Effect of Heat/Mass Transfer Between Hot Leg Hot/Cold Flows}

Another SCDAP/RELAP5 code limitation concerning the split hot leg modeling approach was the inability to model the effect of heat and mass transfer, or mixing, between the hot and cold countercurrent fluid streams. In addition, settling of fission products was not simulated. Two approaches were taken to attempt to simulate the heat and mass transfer effects which are discussed below. The effect of fission product transport was not examined in this study, although MELCOR does have the capability to model this phenomenon.

The first calculation involved simulating heat transfer between the hot and cold countercurrent flow streams by adding a heat structure of very small thermal capacitance and relatively large conductivity (on the order of stainless steel) between the hot and cold fluid volumes. The assumed contact area was the pipe inner diameter multiplied by the pipe length.

The effect of heat transfer between the hot and cold countercurrent flow streams was very small. The temperature difference between the top and bottom fluids was lowered slightly, by less than $20 \mathrm{~K}$ due to heat transfer between the countercurrent flows. This resulted in only a slight decrease/increase in hot leg top/bottom pipe temperatures. A comparison of the critical component temperature histories with the basecase is presented in figure 9.5.1. This plot shows that all components were only minimally affected. The predicted failure location was the surge line. The failure time is a few seconds later than the basecase and was predicted to occur at 249.9 minutes in the surge line. The hot leg, however, was within a few degrees of the surge line pipe and could be predicted to fail at approximately the same time.

The second approach involved simulating mixing between the hot/cold countercurrent flow streams. This was attempted in MELCOR by including a flow path between CV 201 and CV 222 (FL 500) as well as between CV 202 and CV 221 (FL 501) as shown in Figure 9.5.2. Three cases of varying degrees of mixing were considered to bound the simulation. The first case assumed very high mixing between the two flow streams. The flow areas of these flow paths were defined as the actual interface areas between the split hot leg pipe segments (the pipe diameter times the pipe length). Very extensive mixing was predicted for this case and it is considered as the upper bound calculation. The second case was denoted as a medium mixing simulatin, probably much more realistic than the upper bound. For this sjmulation, the flow area was modeled as $10 \%$ of the total interface area. Finally, the third case simulated a very small amount of mixing. The flow area was defined as less than $0.1 \%$ of the actual 


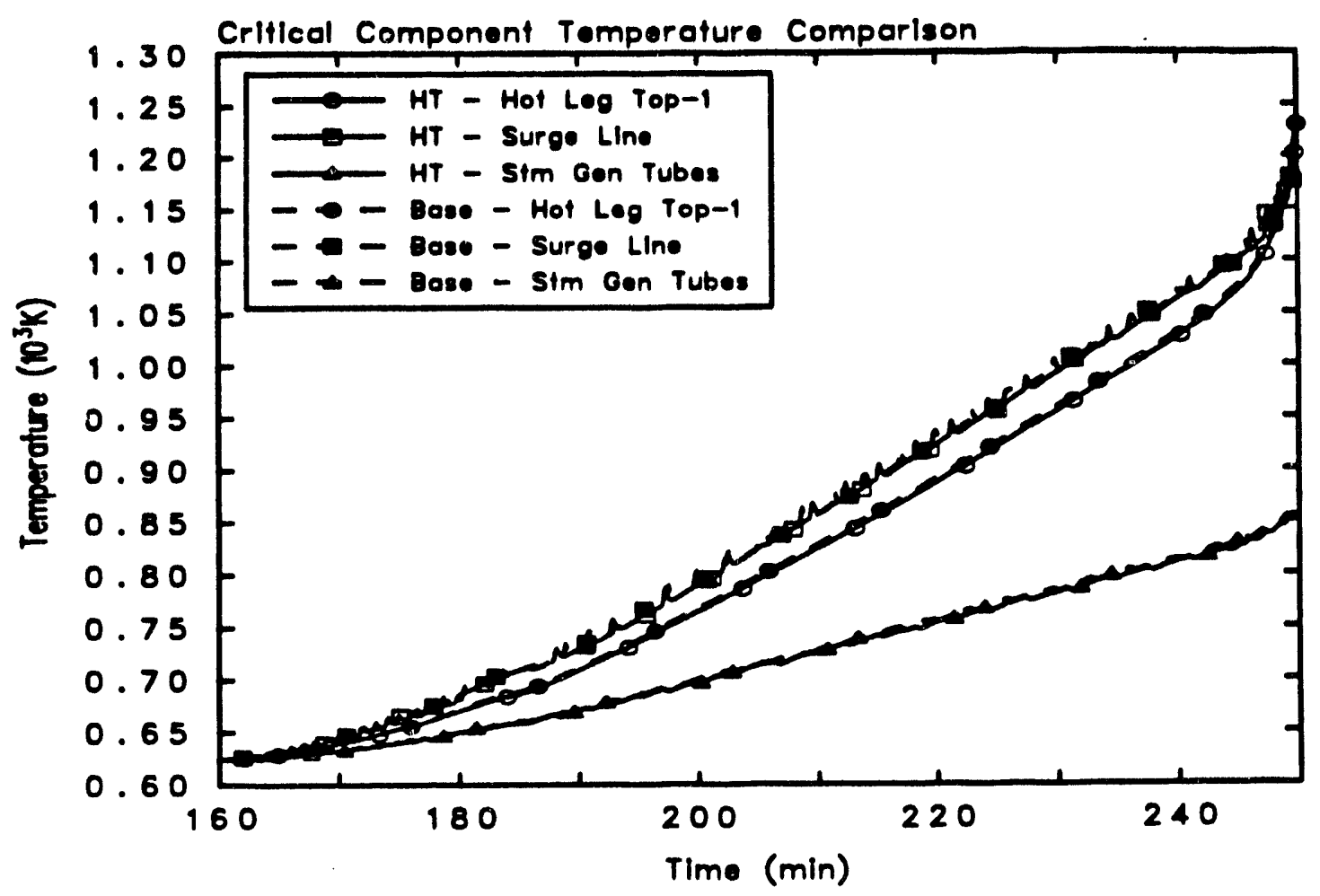

Figure 9.5.1 Comparison of critical component temperature histories for the MELCOR sensitivity calculation including heat transfer between hot leg hot/cold flows.

MIXING BETWEEN HOT/COLD COUNTERCURRENT FLOW STREAMS TO SURGE LINE

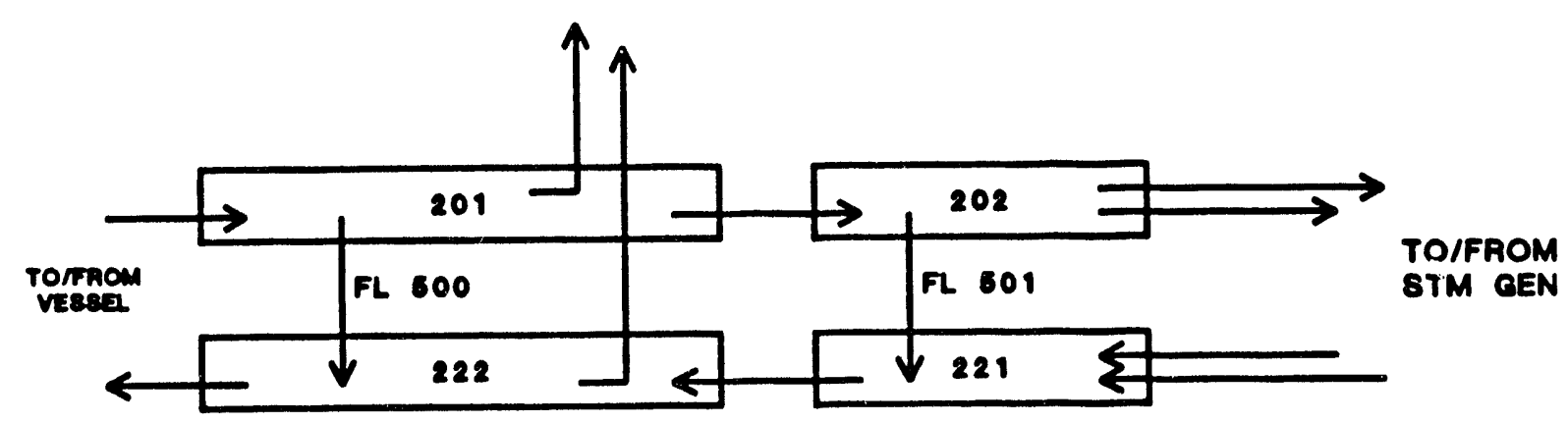

BPLIT HOT LEG FLOW

Figure 9.5.2 Schematic of the split hot leg MELCOR nodalization for the mixing simulation calculations. 
interface area. The results of this calculation were indistinguishable from the basecase, however, and will not be shown in the following discussion. Figures 9.5.3 through 9.5.7 show the results of these mixing calculations. Simulating mixing increased the average hot leg flow rate as shown in Figure 9.5.3. It might be postulated that this was caused by an artificial recirculation loop set up between the control volumes due to this particular nodalization choice. The flow rate between the top and bottom halves of the split hot leg are shown in Figure 9.5 .4 and are significant. The high mixing case showed a mixing flow rate on the order of one-half of the hot leg flow rate. The medium mixing case is lower, approximately one-third of the hot leg flow rate.

The effect of hot/cold countercurrent hot leg flow mixing on the steam generator flow rate was minimal. The flow rate in the steam generator was dominated by the heat transfer to the tubes.

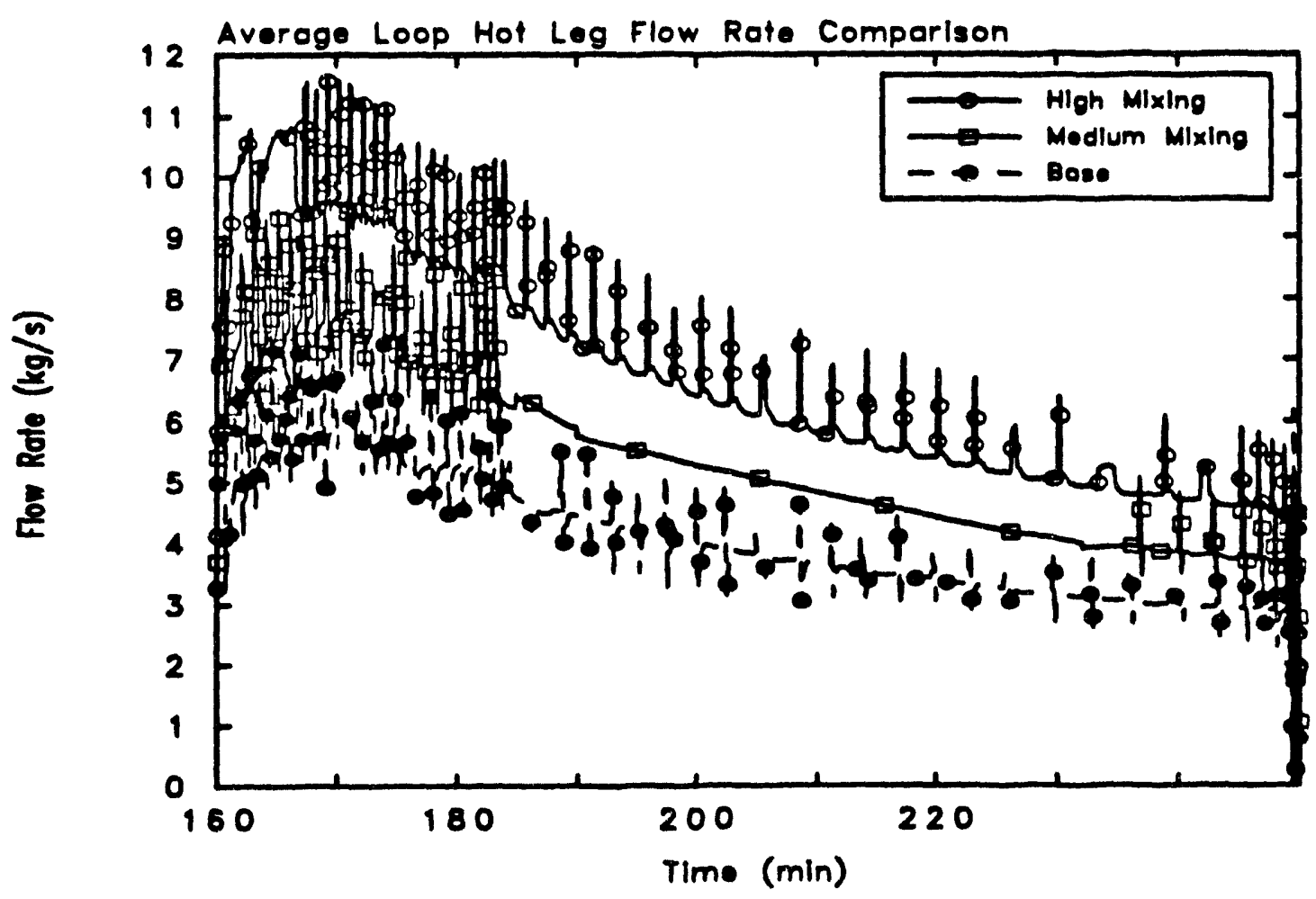

Figure 9.5.3 Effect of mixing between the hot leg hot/cold flows on the hot leg flow rate. 


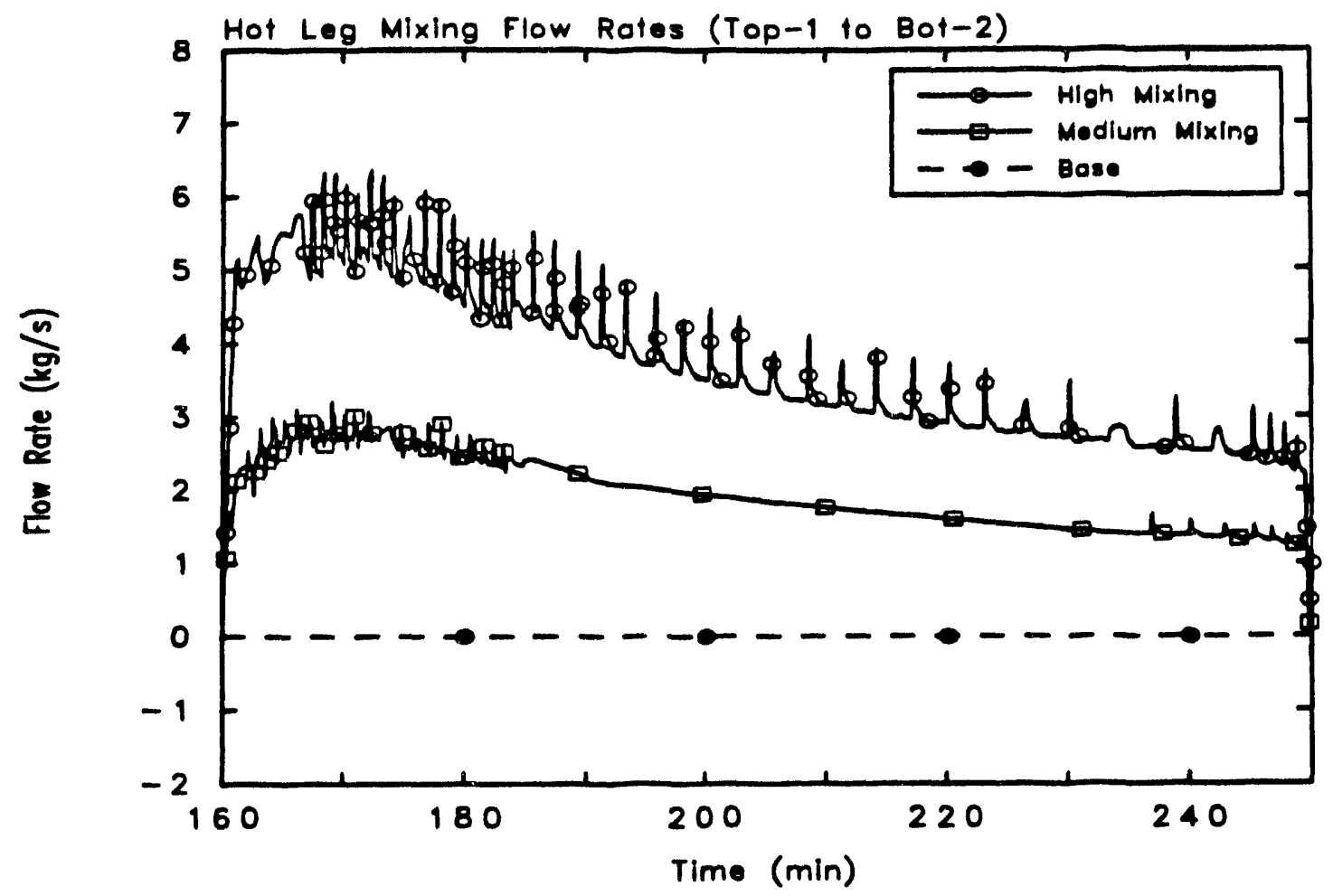

Figure 9.5.4 Mass flow rates between the hot leg hot/cold flows for high, medium, and no (basecase) mixing.

The comparisons between the vapor temperatures in the hot leg and steam generator tubes are shown in Figures 9.5.5 and 9.5.6, respectively, for the high, medium, and no mixing (base) cases. With mixing, the top hot leg temperature history was only slightly affected (Figure 9.5.5). The bottom hot leg temperature, however, increased. With considerable mixing the temperature gradient between the top and bottom hot leg flows was cut in half. Recall that this large temperature difference predicted by the COMMIX [3] and SCDAP/RELAPS [2] codes was listed as a major uncertainty in Sections 4 and 5 . The surge line vapor temperature history was not affected. Figure 9.5.6 shows the steam generator tube vapor temperatures. Note that the heat transferred to the tubes as the fluid flowed around the circuit did not significantly change, but the temperature magnitudes were decreased with enhanced mixing. The fluid entering the steam generator inlet plenum was cooler because more heat was transferred from the faster flowing fluid to the hot leg piping.

A comparison of the critical component temperature histories with the basecase is presented in Figure 9.5.7. As indicated, the hot leg was most significantly affected. Even the medium mixing case showed increased hot leg top and bottom pipe temperatures by 80 to $100 \mathrm{~K}$. The pipe temperatures were higher by $250 \mathrm{~K}$ in the high mixing simulation. The increased hot leg flow rate, if realistic, enhances the heat transfer to the hot leg pipe. Since the surge line vapor temperatures were not significantly affected by mixing in the hot leg, the surge line pipe temperatures increased by less than $30 \mathrm{~K}$ for the highest mixing case. The steam generator tubes are 30 to $50 \mathrm{~K}$ cooler with mixing simulated since the steam generator vapor temperatures are also cooler, as previously discussed. 


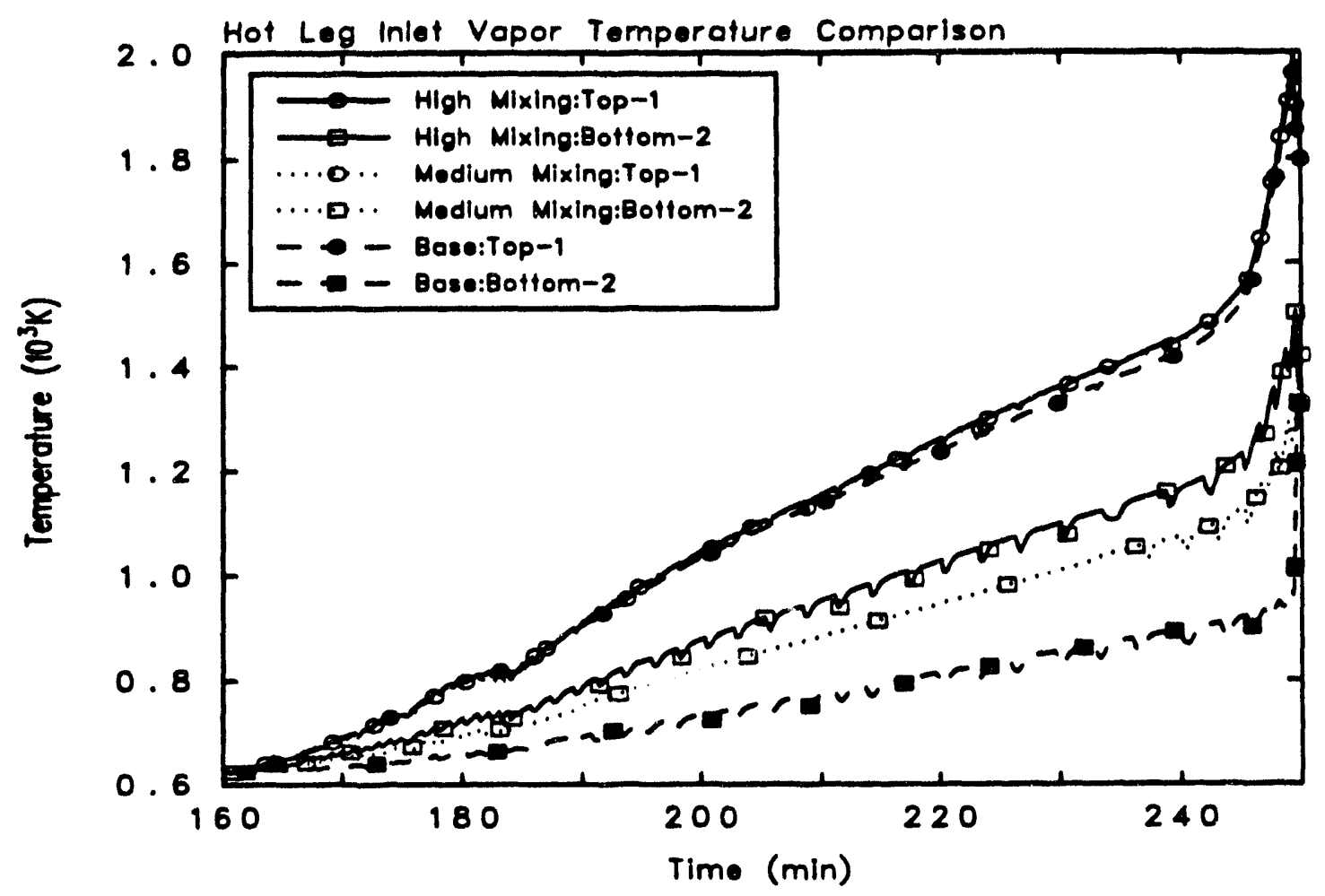

Figure 9.5.5 Effect of mixing between the hot leg hot/cold flows on the hot leg inlet vapor temperature history.

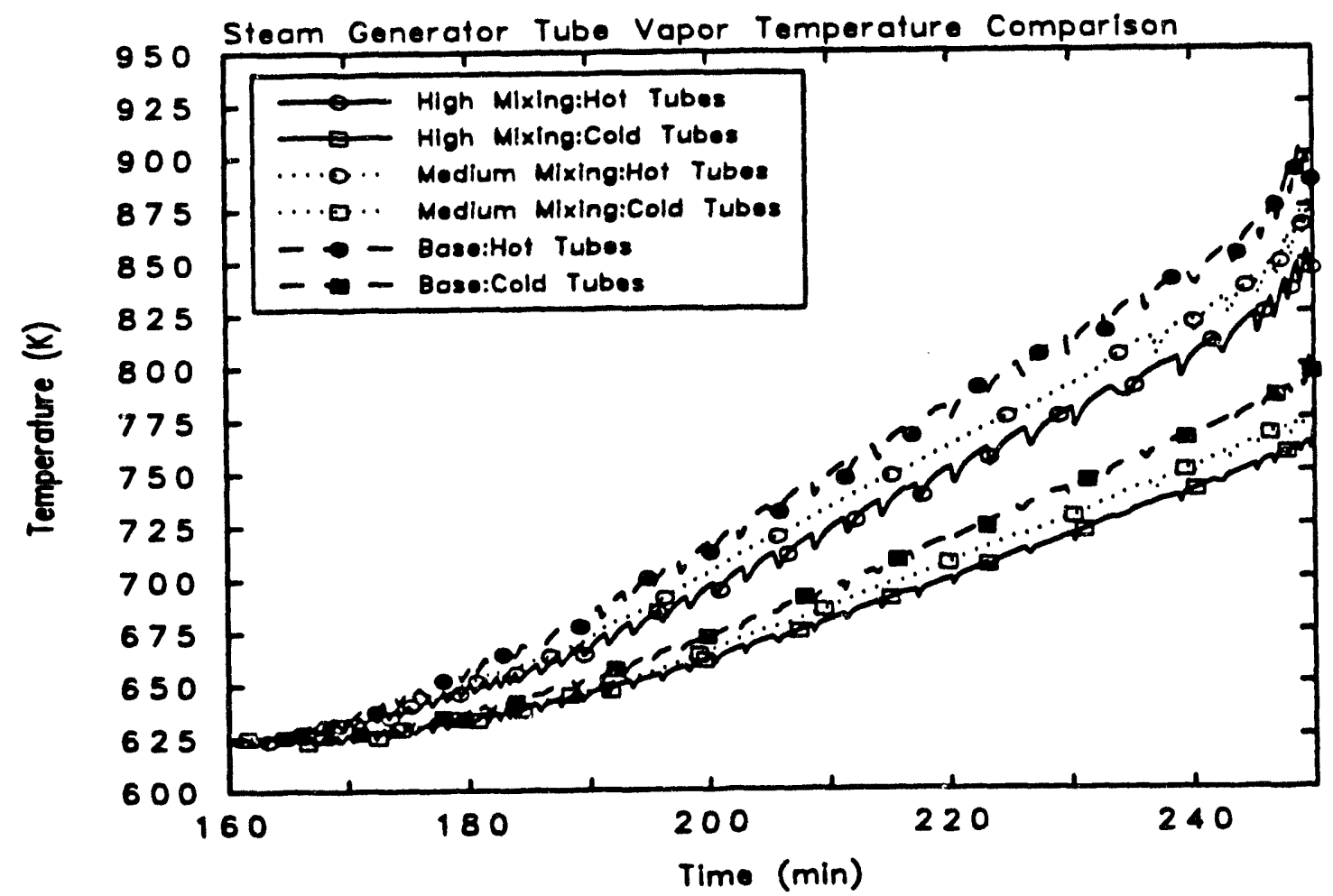

Figure 9.5.6 Effect of mixing between the hot leg hot/cold flows on the steam generator tube vapor temperature history. 


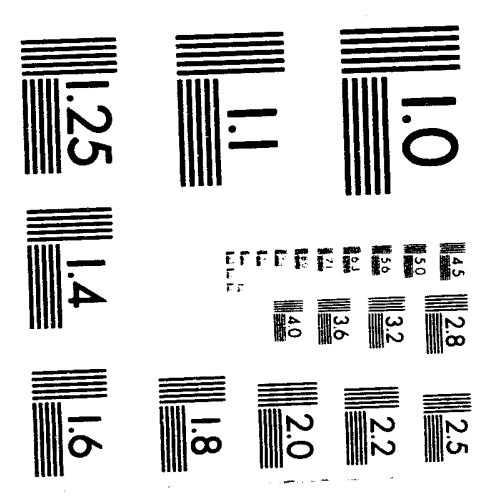



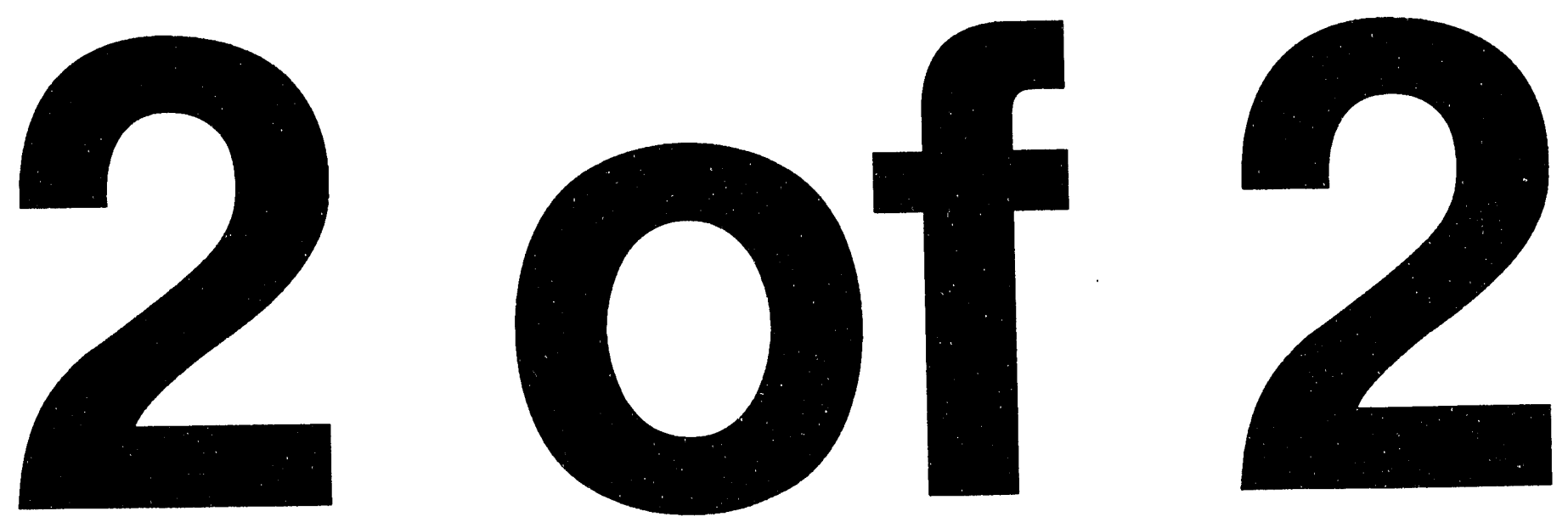


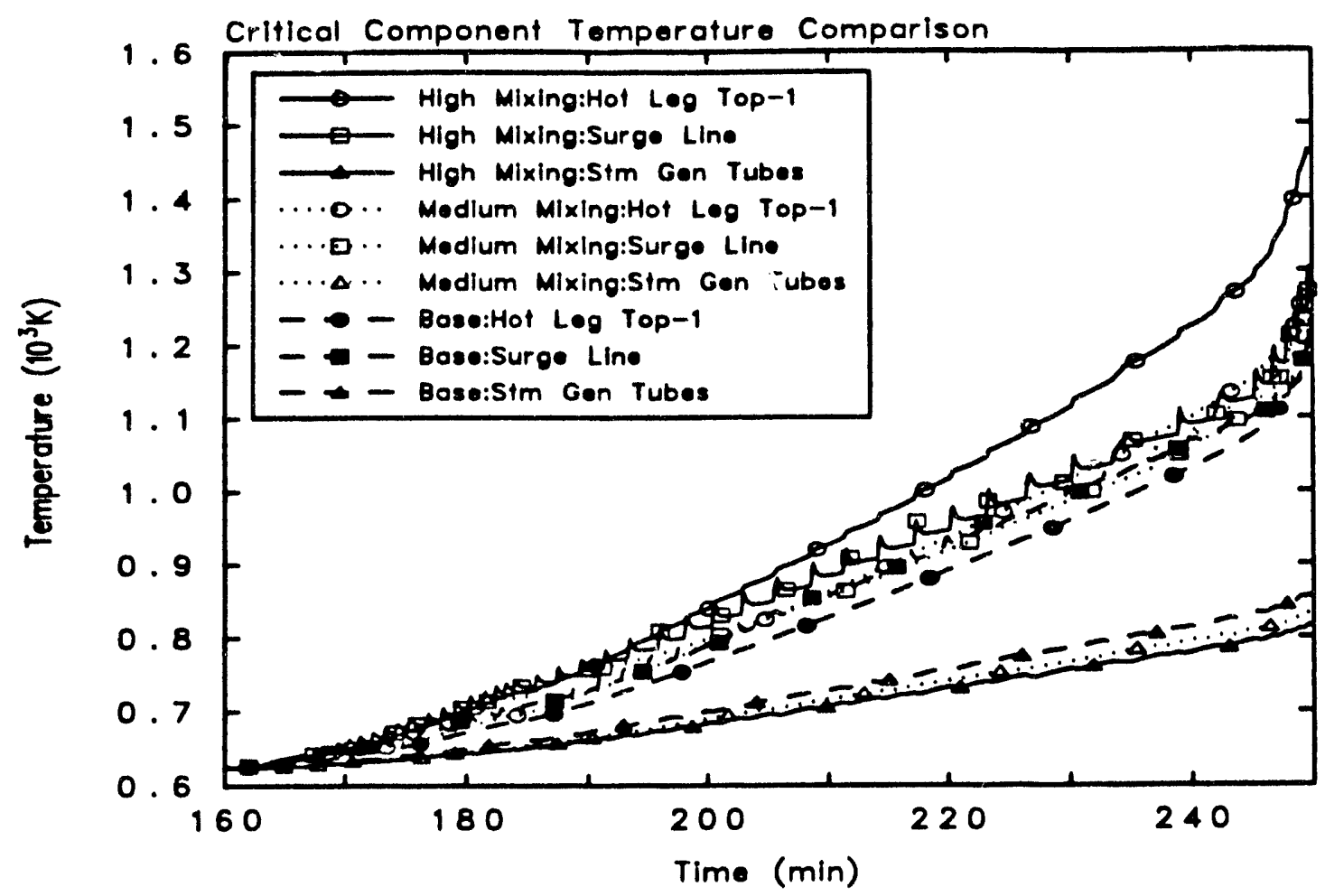

Figure 9.5.7 Comparison of critical component temperature histories for the MELCOR sensitivity calculation including mixing between the hot leg hot/cold flows.

This study showed that for both the high and medium mixing cases, the hot leg would be the component most likely to fail compared to the base case with no mixing. Table 9.5.1 compares the failure times predicted by these calculations.

TABLE 9.5.1 TOP/BOTTOM COUNTERCURRENT FLOW MIXING FAILURE TIMES

Case

Base - no mixing

Medium mixing

High mixing

\section{PREDICTED FAILURE TIME (min) Hot Leg \\ Surge IIne}

249.8

248.0

239.3
249.7

249.1

248.9

The high mixing case predicted hot leg failure (at $1219 \mathrm{~K}$ ) almost 10 minutes prior to the surge line failure time of the basecase. This mixing was extreme and judged to be an upper bound, and far from realistic. The medium case, which could also be more severe than might actually occur, showed a difference in failure time of less than two minutes. This indicated that including mixing between the countercurrent hot leg flows, though it affected vapor temperature differences between the countercurrent flows, did not significantly change the outcome of the analysis. To re-emphasize, however, very crude modeling attempts were assumed for this simulation and more detailed analyses and information from high pressure transient experiments is required to fully investigate this phenomenon. 


\subsection{Simplified Steam Generator Model Calculations}

In this section an analysis of thermosyphoning in a steam generator is presented. The motivation for developing the thermosyphon model was twofold: (1) to provide an independent investigation of the relation between steam temperatures in the inlet plenum and the steam generator circulation rate, and (2) to provide a computationally efficient model to study the effects of variation of key parameters affecting the circulation rate. The first item was itself motivated by the disagreement in the steam generator circulation rates predicted by SCDAP/RELAP5 and COMMIX.

A prominent feature in the simulation of the TMLB' accident scenario is the postulated development of natural circulation of superheated steam in the steam generators once the core has been uncovered. Because the return cold leg remains blocked by water, a natural circulation pattern is assumed to develop in which steam enters the top of the hot leg from the vessel, flows along the top of the hot leg to the inlet plenum where it mixes, flows through some fraction of the steam generator tubing to the outlet plenum, returns to the inlet plenum via the remaining tubes and returns to the vessel through the lower half of the hot leg. An important aspect of simulating these phenomena is proper modeling of the circulation rate and the heat transfer rates in the steam generator, since heat removal in the steam generator is the source of bouyancy driving the natural circulation phenomena.

A more detailed buoyant flow model than those available in either SCDAP/RELAP5 or MELCOR was developed to simulate thermosyphoning in a steam generator representative of one of three such generators in a 3 Loop Westinghouse Pressurized Water Reactor (PWR). The resulting model was much less CPU intensive than the systems codes and sensitivity studies could be performed in a much more cost effective manner. Only the thermosyphoning phenomena was considered in this model. The vessel and hot and cold legs which comprise the primary components in a PWR were not modeled explicitly. Their effect in producing and transporting steam vapor to the steam generator was modeled by specifying the heating rate of gases entering the inlet plenum from the top of the hot leg. Heating rate values were varied about values predicted with the SCDAP/RELAP5 and COMMIX codes which have been employed to model the entire PWR under the TMLB' transient.

\subsection{Thermosyphoning Mode1 Description}

In this work, the buoyancy-driven flow in the steam generator tubing was modeled in detail. Mixing of gases in the plena and the countercurrent flow in the hot leg were modeled empirically by use of a thermodynamic mixing model developed by stewart et al. [4] which contained various mixing parameters whose influence was to be determined. The objective of this study was to develop a model which contains the essential mechanisms which generate the circulation in the steam generator, not to resolve in detail the complex flow that arises in the plena. 
The governing equations which model the thermosyhoning phenomena in the steam generator were developed from a mass, momentum and energy balance on the system. Momentum conservation included a balance of the rate of change of momentum with buoyancy and viscous forces in a typical tube. The buoyancy was treated via the Boussinesq approximation. The pressure drop over forward- and backward-flowing tubes was eliminated by an appropriate summation of these respective equations. The energy balances included storage, convection and heat exchange between the flowing vapor and the tubing. Heat exchange to the secondary side of the steam generator was modeled by treating the secondary side steam as a lumped volume. The resulting coupled system of equations was solved numerically for the steam generator circulation rate, the vapor and tubing temperature distributions along the length of U-tubes, and the secondary side steam temperature.

The resulting equations governing the thermosyphoning phenomena are given in Appendix B, which also includes a complete description of the model. There are several assumptions and approximations that were invoked in developing the steam generator model; these are enumerated below:

1. Temperature and velocity are assumed to depend only on distance along tubes, $x$, and on time, $t, i . e .$, equations are area-averaged.

2. The Boussinesq approximation is invoked.

3. Streamwise heat conduction is small compared to convection and is not included in gas energy balance.

4. Heat conduction is also neglected in piping. This invokes the small Biot number assumption since the pipe walls are thin.

5. Pipe bend is neglected.

6. Tube sheet is not modeled.

7. Temperature dependent properties are based on average temperatures, $T_{\mathbf{g}}=\left(T_{\mathbf{g}}(0, t)+T_{\mathbf{g}}(2 L, t)\right) / 2$, and $T_{\mathrm{p}}=$ $\left(T_{\mathrm{p}}(0, t)+T_{\mathrm{p}}(2 L, t)\right) / 2$, where $T_{\mathrm{g}}$ denotes the vapor temperature and $T_{\mathrm{p}}$ is the steam generator tube temperature.

8. The steam on the secondary side of the steam generator is modeled as a lumped volume.

A schematic of the steam generator is shown in Figure 10.1.1. This schematic shows only one forward and one backward flowing tube, however, the steam generator modeled included a total of 3388 inverted 


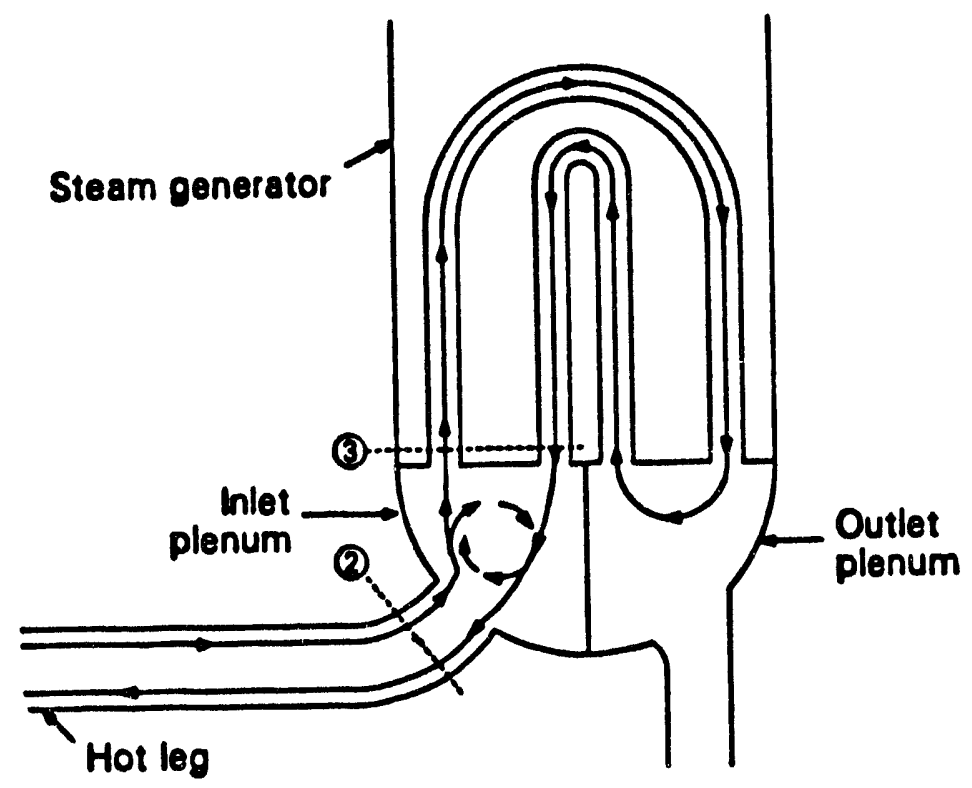

Figure 10.1.1 Schematic of the steam generator model.

U-shaped tubes. It was assumed that $n_{f}$ tubes carry steam from the inlet plenum to the outlet plenum, and that the remaining $n_{b}$ tubes carry the same total mass flow from outlet plenum back to the inlet plenum. The mass and momentum equations governing the buoyancy-driven flow in the steam generator are shown in Appendix $B$.

The initial condition for the system was that the temperature and pressure were uniform at $620 \mathrm{~K}$ and $16 \mathrm{MPa}$, respectively. This corresponded to conditions after 160 minutes into the transient. The boundary condition for the thermosyphon equations was specification of the heating rate of gases entering the inlet plenum through the top of the hot leg, $T_{h}$. This temperature was coupled with the steam temperatures entering $\left(T_{B}(0)\right)$ and exiting $\left(T_{B}(2 L)\right)$ the steam generator tubing through the plenum mixing model (see Appendix $B$ ).

The numerical treatment of the model equations was validated by comparison with an analytical solution to a partial set of the equations. This exercise also included a mesh refinement study to show the mesh resolution required for acceptable agreement with the known solution. Numerical solution of the heat transfer equations, (B.3)-(B.5), was verified by comparing with the analytical solution for constant velocity and step-jump in inlet temperature given in Carslaw and Jaeger [29]. It was determined that 80 finite difference 
volumes were sufficient to obtain better than $5 \%$ agreement with the analytical solution. In addition, the steady system of thermosyphon equations was applied to the steady experimental data for liquid flow given in Reference 4. The comparison was done assuming a constant temperature for the secondary side volume, as compared to the constant flux condition imposed in the experiment. Using the measured flow rate data and some limited temperature measurements, the estimate for the temperature drop across the steam generator given by the model was in fair agreement $(12.7 \mathrm{~K}$ ) with the measurements (about $10 \mathrm{~K}$ ).

Further details on the model development, numerical solution of the governing equations and the thermophysical properties and dimensions used, can be found in Appendix B.

\subsection{Discussion of Results}

The major parameters considered in the study included the heating rate, $r$, the mixing fraction $f_{\mathrm{mix}}$, the ratio of forward-running to backward-running tubes in the steam generator, $n_{\mathrm{r}}=n_{\mathrm{f}} / n_{\mathrm{b}}$, and the ratio of mass flow rate in the hot leg to the steam generator, $m_{\mathrm{r}}=m_{\mathrm{HL}} / m_{\mathrm{SG}}$. Appendix $B$ explains the meaning of these parameters ir more detail. The parameter set will be referred to collectively as the vector $P=$ $\left(r, f_{\mathrm{mix}}, n_{\mathrm{r}}, m_{\mathrm{r}}\right)$. The base set was chosen as $(8.85,0.9,0.54,0.5)$. This heating rate, expressed in Kelvins/min, mixing fraction, tube ratio and mass flow ratio all match the results of Reference 2 .

\section{Base case results}

Figure 10.2.1 shows the temperature history for the base case over an 80 min (elapsed time) simulation period. The steam and piping temperature histories at various locations in the system are shown on this and subsequent figures. $T_{h}$ is the steam temperature entering the inlet plenum from the hot leg, which in this model was a result of the heating rate (see Equation B.9 in Appendix B). $T_{c}$ is the steam temperature after circulating in the steam generator, returning to the inlet plenum, mixing, and re-entering the lower half of the hot leg. $T_{g}(0)$ and $T_{p}(0)$ are the steam and tubing temperatures, respectively, at the inlet to the steam generator tubing from the inlet plenum, and $T_{\mathrm{g}}(2 L)$ and $T_{\mathrm{p}}(2 L)$ are the exiting values after circulating in the steam generator. $T_{\mathrm{ht}}$ and $T_{\mathrm{ct}}$ are the steam temperatures entering and leaving the steam generator tubing computed by Reference 3 using COMMIX. The incoming steam temperature to the steam generator (SG) compared well with that computed by Reference 3, however, the exiting temperature computed here was higher. The mass flow rate in the SG is shown in Figure 10.2.2 for various values of $m_{r}$. The history computed with COMMIX is also shown for comparison and the figure shows the flow rate computed here was substantially higher (almost double). This 
could explain the increased temperatures of gases exiting the $S G$ in this calculation as compared to COMMIX. It is also emphasized that the simulations using COMMIX [3] assumed completely insulated SG tubing.

The steam generator flow rate history shown in Figure 10.2.2 for $m_{r}=0.5$ is similar to that reported in Reference 2 for the SCDAP/RELAP5 calculations. (Note that the mass flow rate in the SG was not shown, but reported to be about $120 \%$ higher than in the hot 1 eg, which is shown.) However, the heat transfer rate to the secondary side computed here appears to be vastly different from that predicted by SCDAP/RELAP5 [2]. This was inferred from the histories of vapor temperatures in the hot leg reported in Reference 2 showing a temperature difference of roughly $\left(T_{\mathrm{h}}-T_{\mathrm{c}}\right)=580 \mathrm{~K}$ at 240 minutes. Vapor temperatures across the $S G$ were not reported, however calculations of this problem with MELCOR show the temperature difference across the hot leg to be much smaller than that across the SG. Under quasi-steady conditions, this latter difference multiplied by the heat capacity is the amount of heat being transferred to the secondary side. Figure 10.2.1 shows a temperature difference $\left(T_{\mathrm{h}}\right.$ $T_{c}$ ) of about $130 \mathrm{~K}$ at 240 minutes. Thus, the present model, when compared to the calculation with SCDAP/RELAP5, predicted a similar mass flow rate for the SG but much lower temperature drop across the SG.

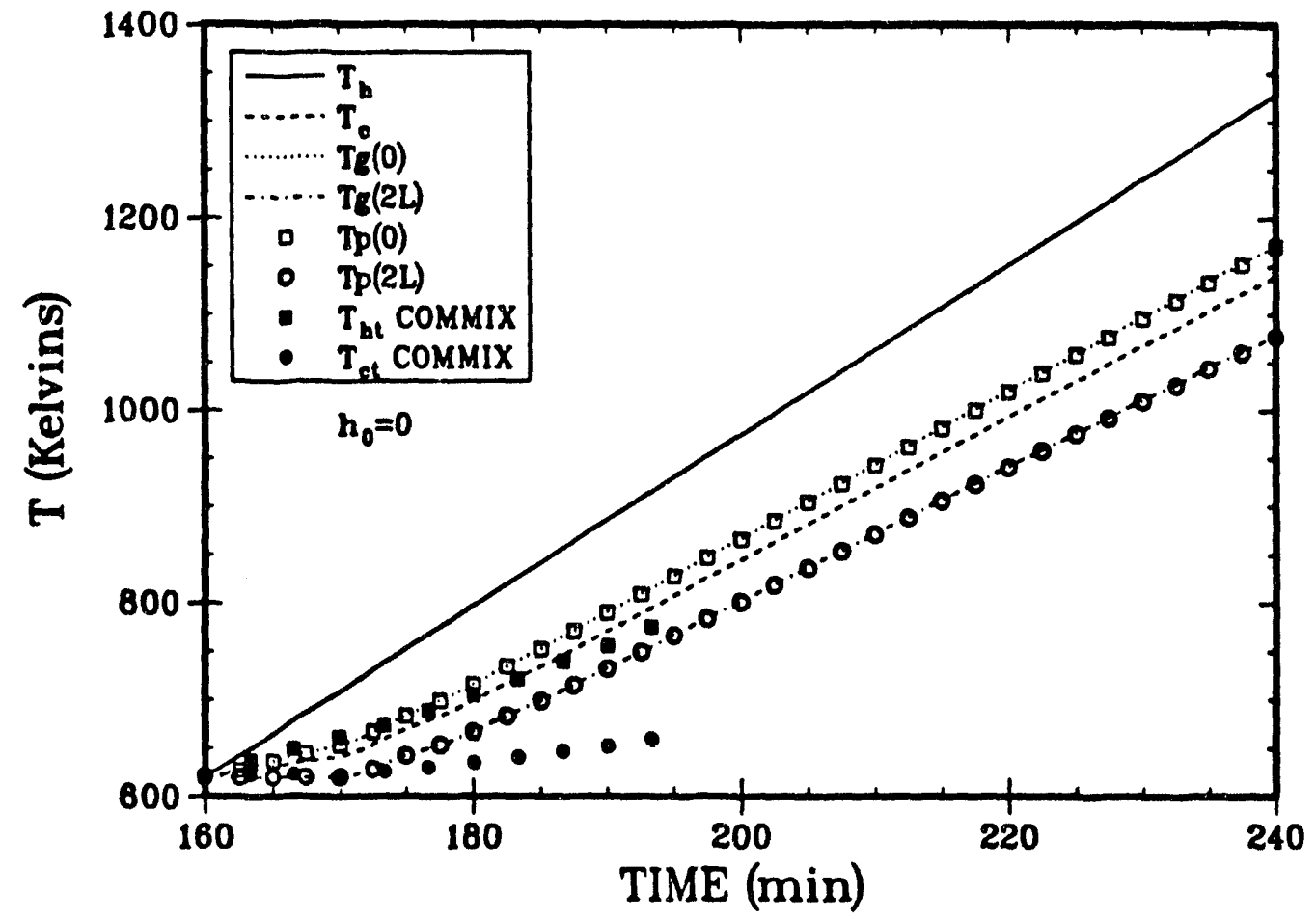

Figure 10.2.1 Temperature history for the basecase, $\mathrm{P}=(8.85,0.9,0.54,0.5)$. 


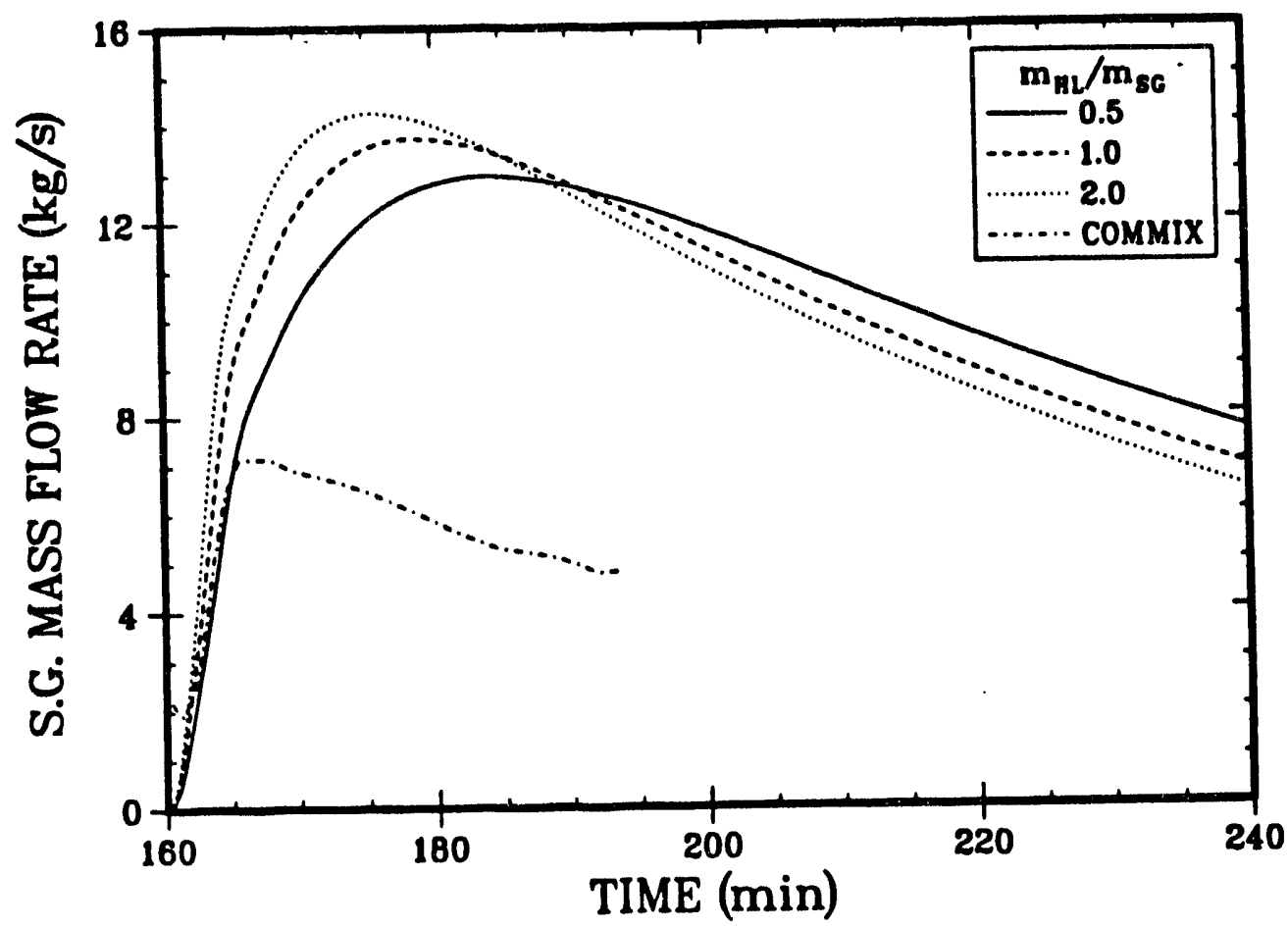

Figure 10.2.2 Steam generator mass flow rate variation with mass flow ratio, $m_{\mathrm{HL}} / m_{\mathrm{SG}}$, for $\mathrm{P}=(8.85,0.9,0.54$, var $)$.

\section{Heating rate variation}

Figures 10.2.3 through 10.2.5 show the temperature histories for various values of heating rate. The mass flow ratio is unity for these figures. Beyond the obvious increase in temperatures with heating rate, the figures also show that the difference between inlet and outlet SG temperatures increases with $r$. At $t=240 \mathrm{~min}$, these temperature differences were roughly 90,160 and $330 \mathrm{~K}$ for heating rates of $5.5,8.85$, and 16.2 kelvins/min, respectively. The temperature difference was about proportional to the heating rate.

The variation in SG mass flow rate with heating rate is shown in Figure 10.2.6. The maximum mass flow rate increased with heating rate, however, the mass flow rate decreased more rapidly with time for larger heating rates. This effect was due to the temperature dependent steam properties, in particular, the decrease of steam density and increase in steam viscosity with temperature. Generally, as the heating rate was increased, the average steam temperatures also increased. Hence, higher $r$ initially increased the flow rate in the early transient, but as the entire gas volume was hotter, and therefore more viscous, the flow rate decreased as the drag increased with viscosity and the vapor density decreased with temperature. This is the reason for the flow rate decrease with time that is apparent in all mass flow rate histories 


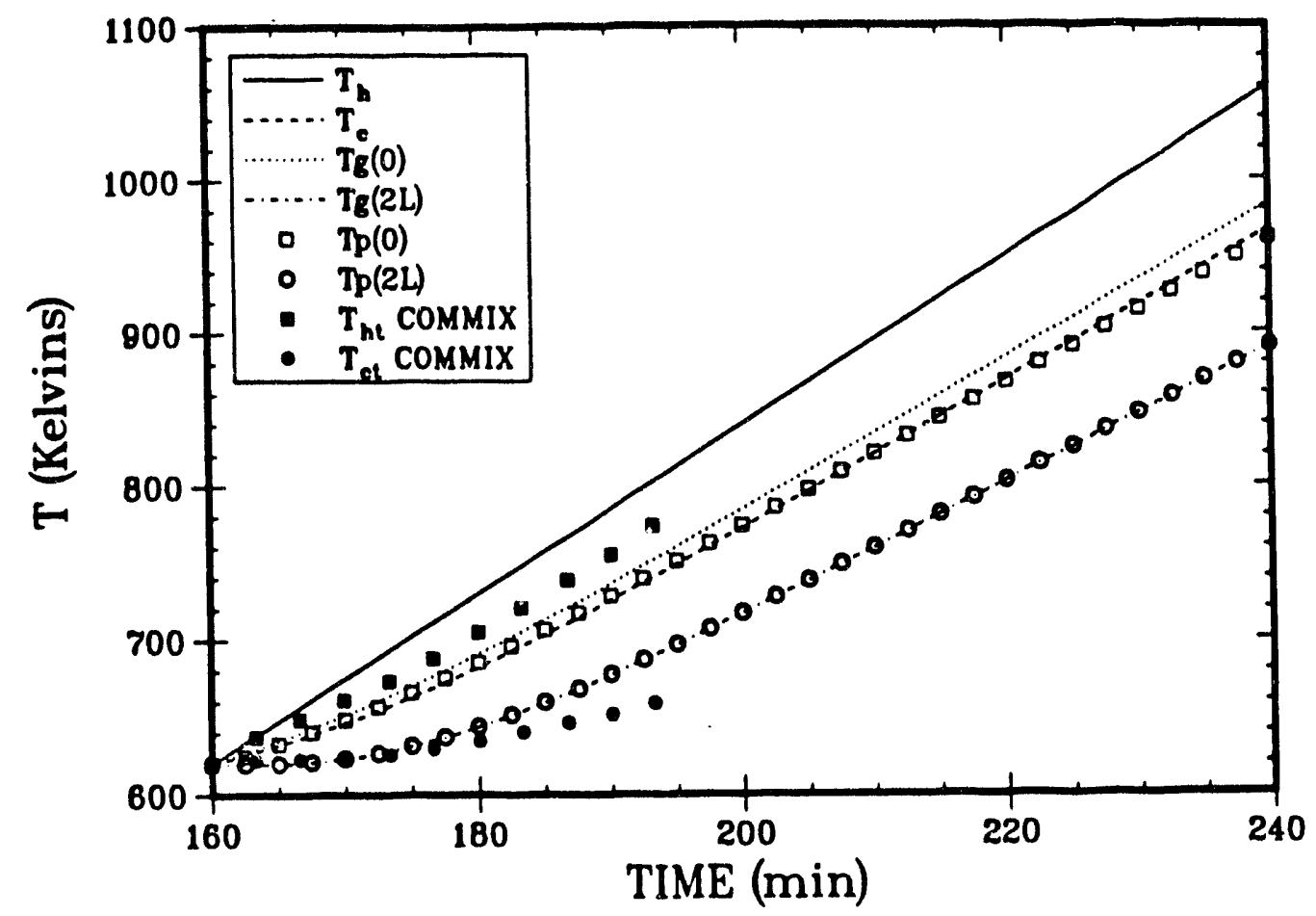

Figure 10.2.3 Temperature history for $r=5.5 \mathrm{Kelvin} / \mathrm{min}$, $\mathrm{P}=(5.5,0.9,0.54,1.0)$.

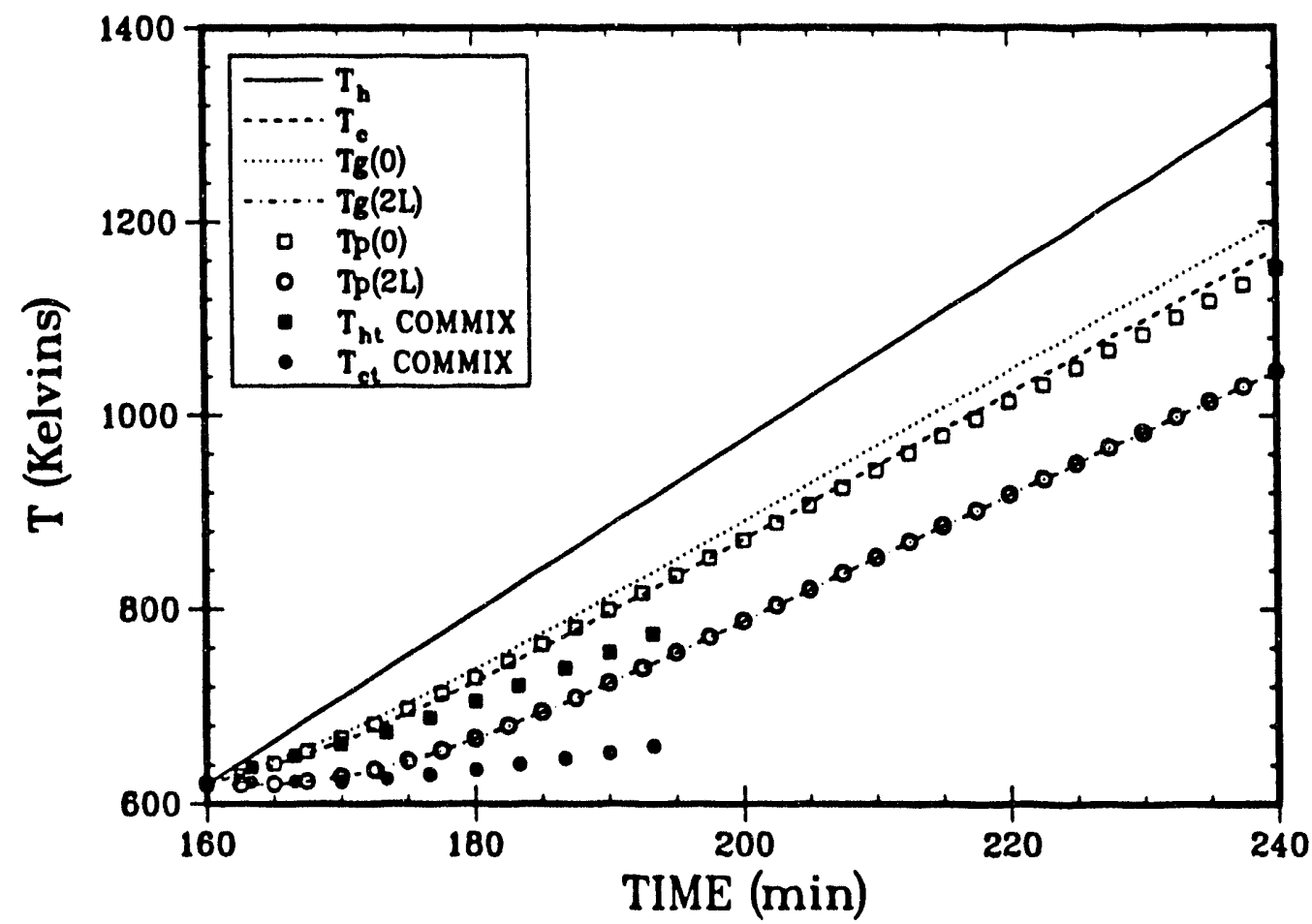

Figure 10.2.4 Temperature history for $r=8.85 \mathrm{Kelvin} / \mathrm{min}$, $\mathrm{P}=(8.85,0.9,0.54,1.0)$. 


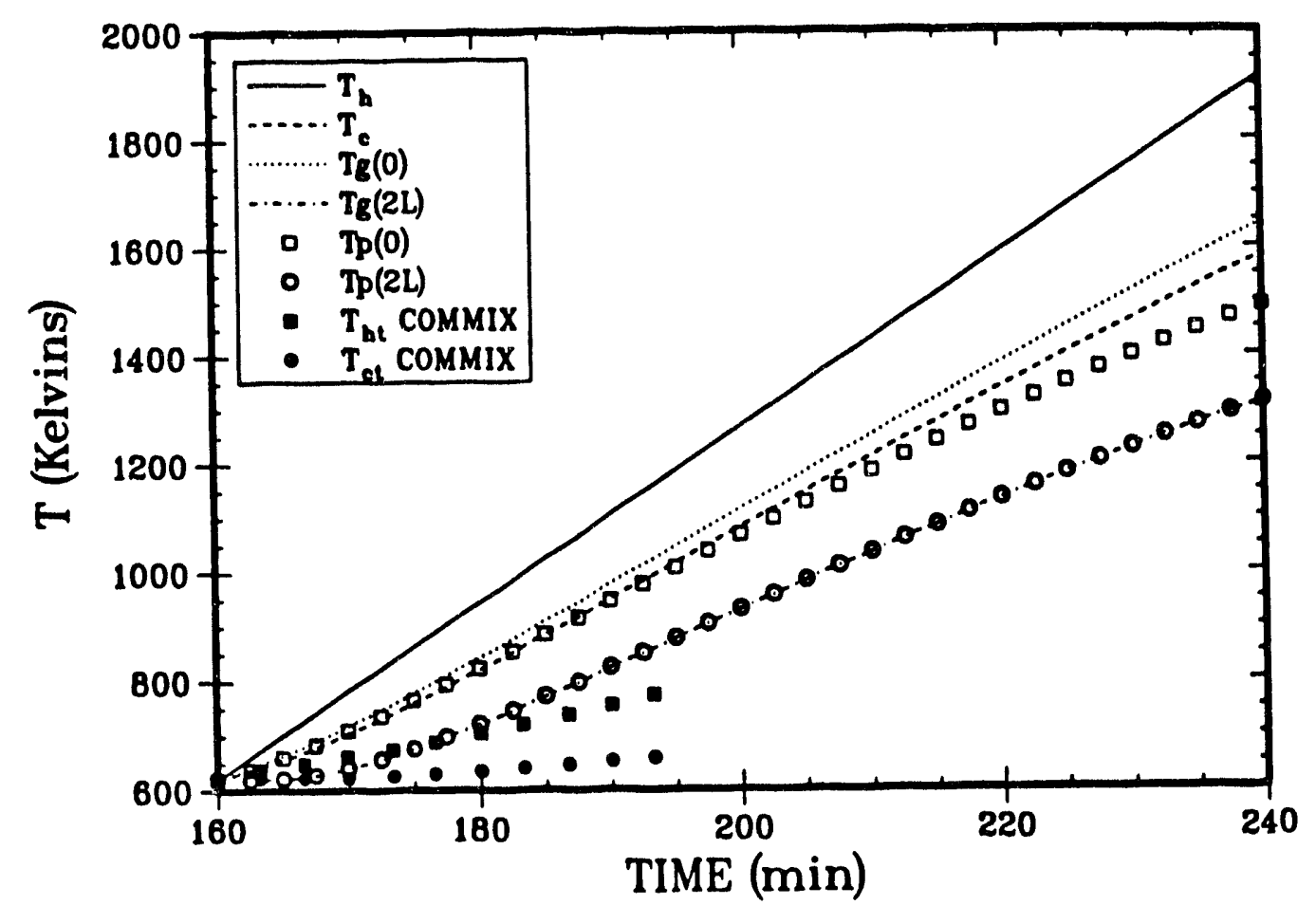

Figure 10.2.5 Temperature history for $r=16.2$ Kelvin/min, $\mathrm{P}=(16.2,0.9,0.54,1.0)$.

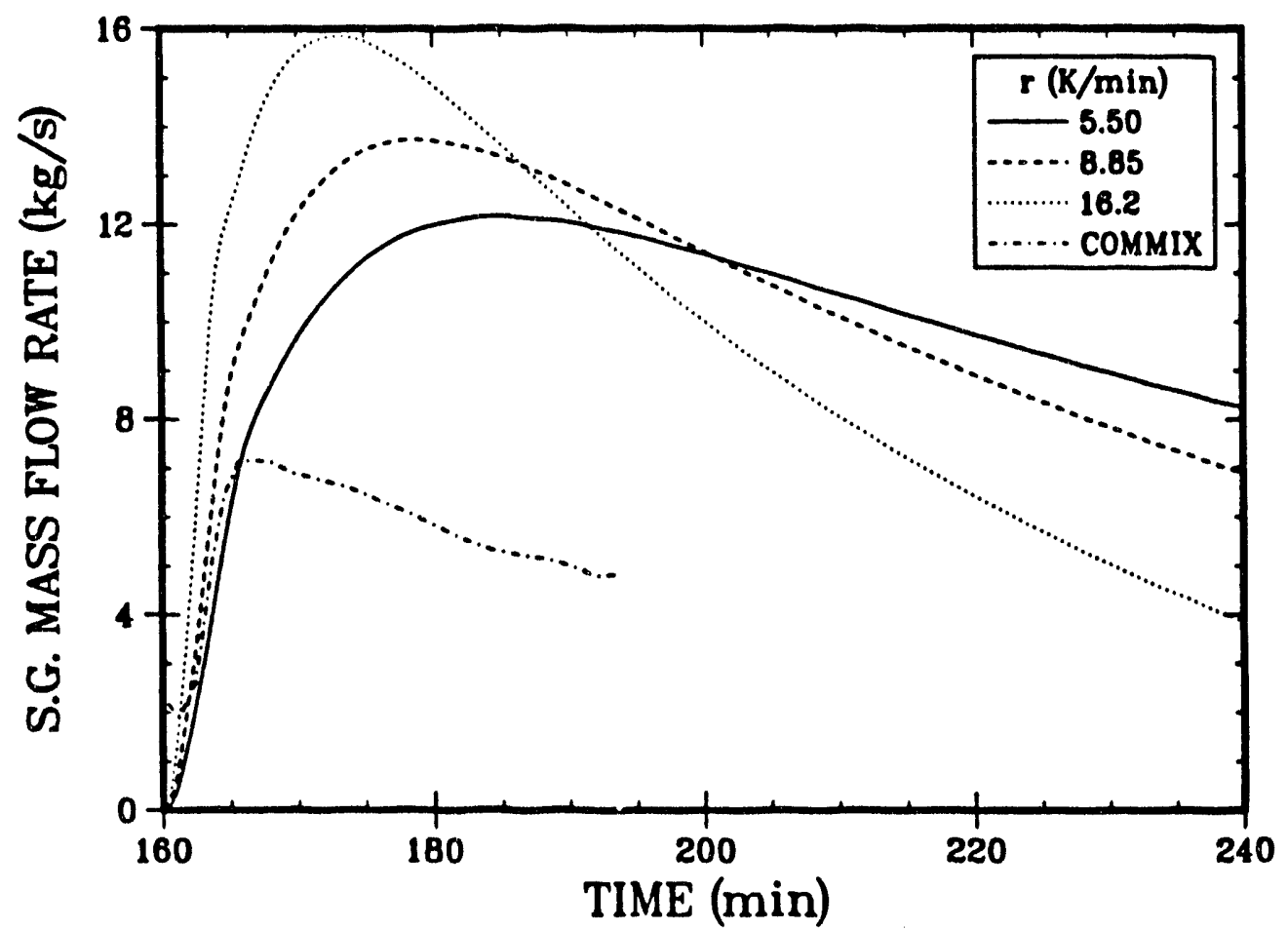

Figure 10.2.6 Steam generator flow rate variation with heating rate, $P=(\operatorname{var}, 0.9,0.54,1.0)$. 
The temperature history of the secondary side steam volume is shown in Figure 10.2.7 for various values of heating rate. The secondary side temperature increased in proportion to the heating rate.

Profiles of steam temperature variation with distance along the tubes for $t=240 \mathrm{~min}$ are shown in Figure 10.2.8 The figure shows that the secondary side cooling rate was high enough to cool the gas to a uniform value in the rising leg of the forward-running tubes $(x=11 \mathrm{~m})$. The temperature is uniform thereafter. Also, the temperature gradient was more localized to the entrance region as the heating rate increased. All plots show $T_{g}(2 L)=T_{p}(2 L)$.

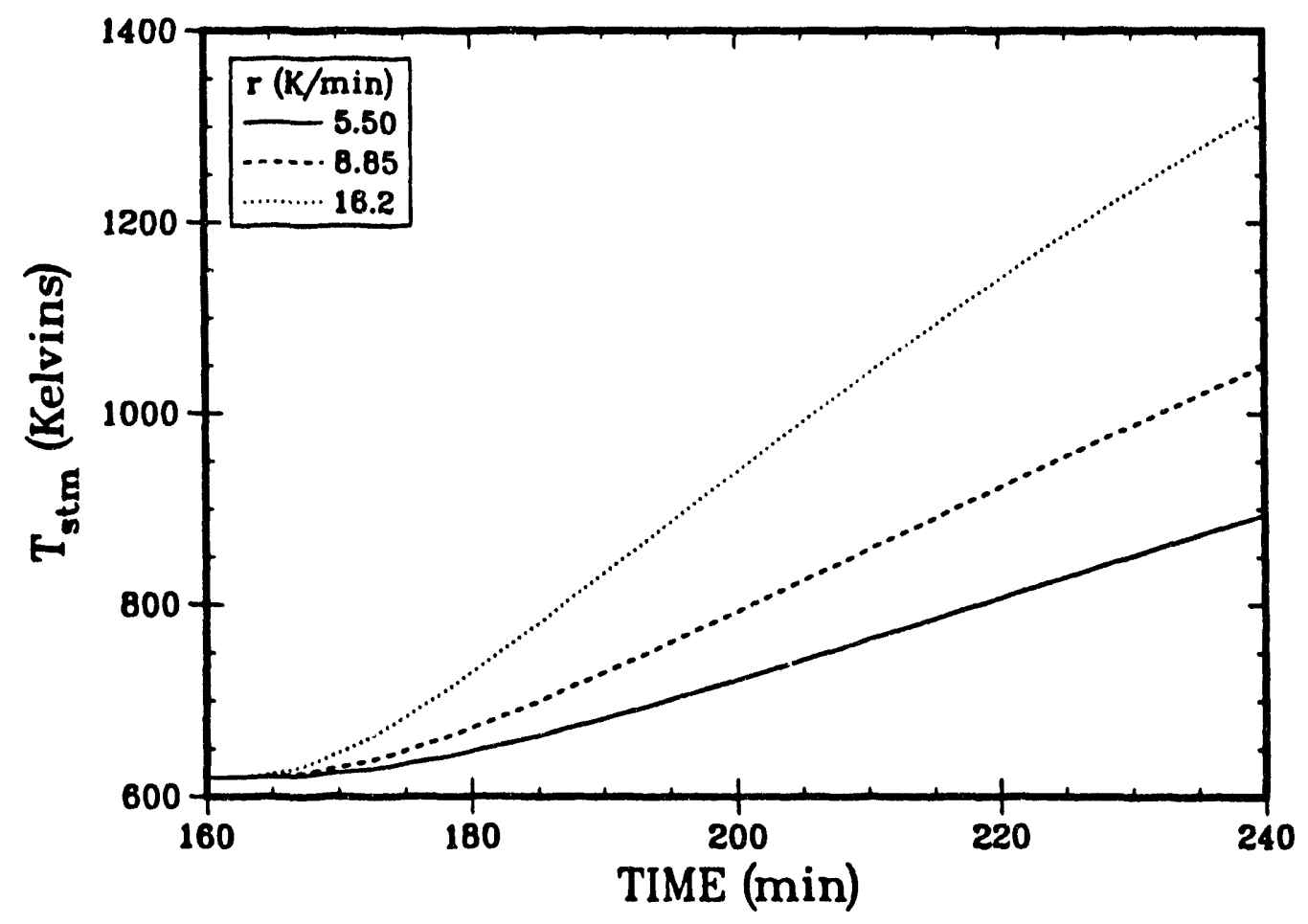

Figure 10.2.7 Secondary side steam temperature history for various heating rates, $\mathrm{P}=(\operatorname{var}, 0.9,0.54,1.0)$. 


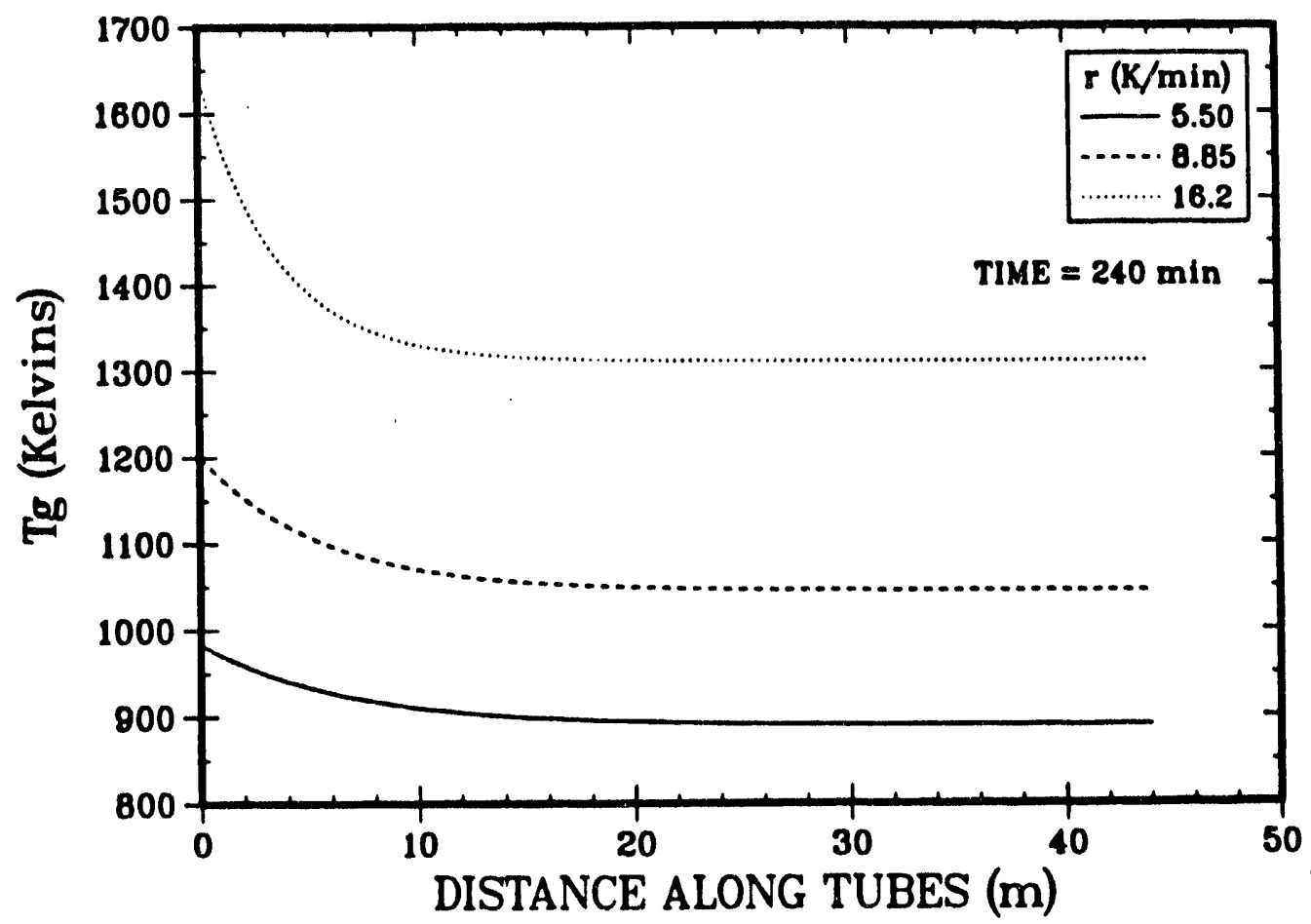

Figure 10.2.8 Profiles of steam temperature for various heating rates, $\mathrm{P}=(\operatorname{var}, 0.9,0.54,1.0)$.

\section{Mixing fraction variation}

The variation of $S G$ mass flow rate with mixing fraction, $f_{\mathrm{mix}}$, is shown in Figure 10.2.9. The SG thermosyphoning rate was not sensitive to the mixing fraction, for this set of parameters.

\section{Tube ratio variation}

The variation in the SG mass flow rate with the ratio of the number of forward flowing tubes to backward flowing tubes is shown in Figure 10.2 .10 for $n_{r}=0.25, .54$ and 0.75 , and for $m_{r}=0.5$. Only values of $n_{r}<1$ were considered since all experiments have reported this range. This was also expected since the forward flowing tubes provided most of the bouyant head as shown in Figure 10.2.8, and thus less forward flowing tubes than backward flowing tubes are required. Figure 10.2.10 shows that the tube ratio was not significant until $n_{r}$ is approximately 0.25 , i.e., the variation in flow rate between $n_{x}=0.75$ and 0.54 is much less than between 0.54 and 0.25 . 


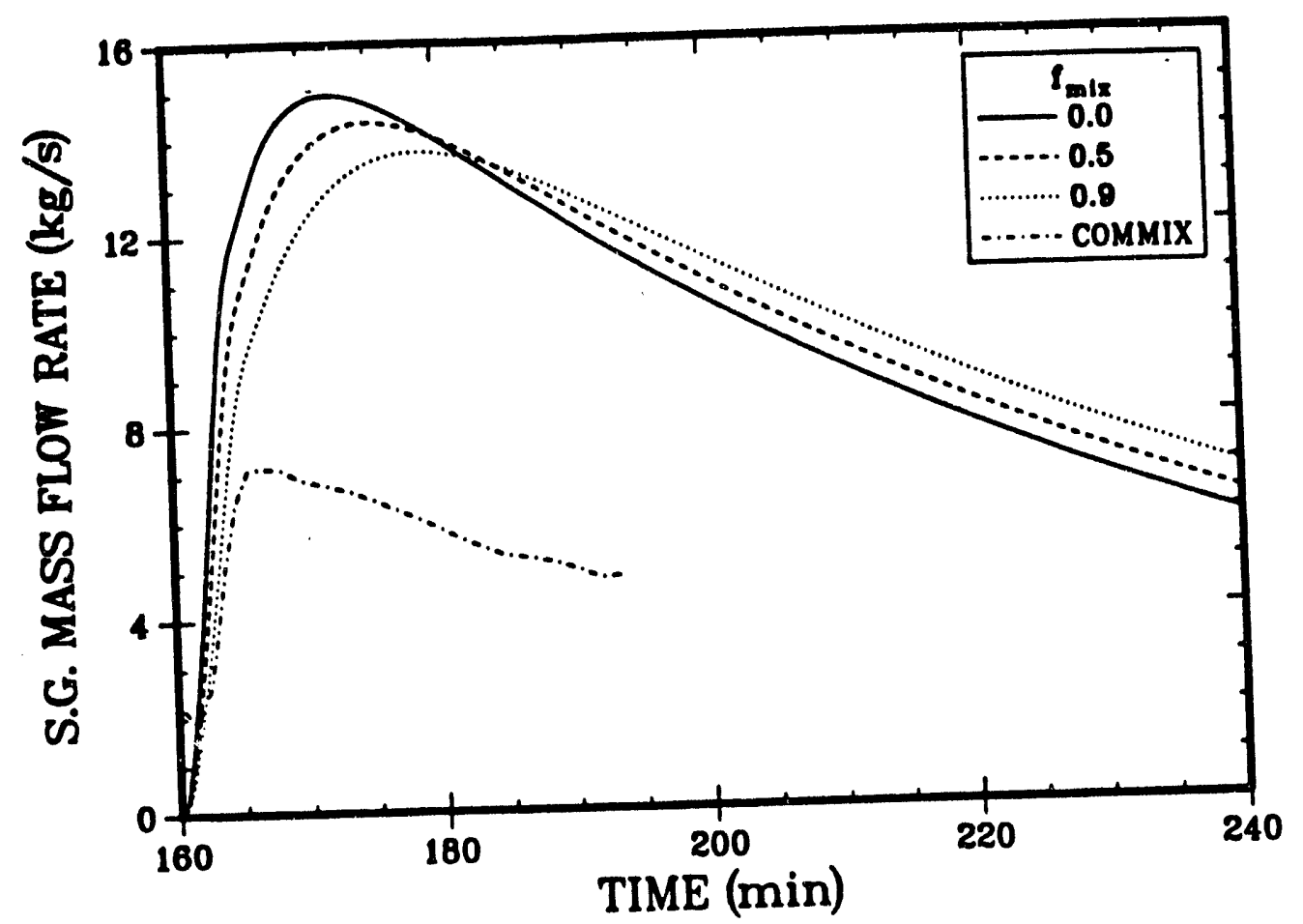

Figure 10.2.9 Variation of steam generator mass flow rate history with mixing fraction, $\mathrm{P}=(8.85$, var $, 0.54,1.0)$.

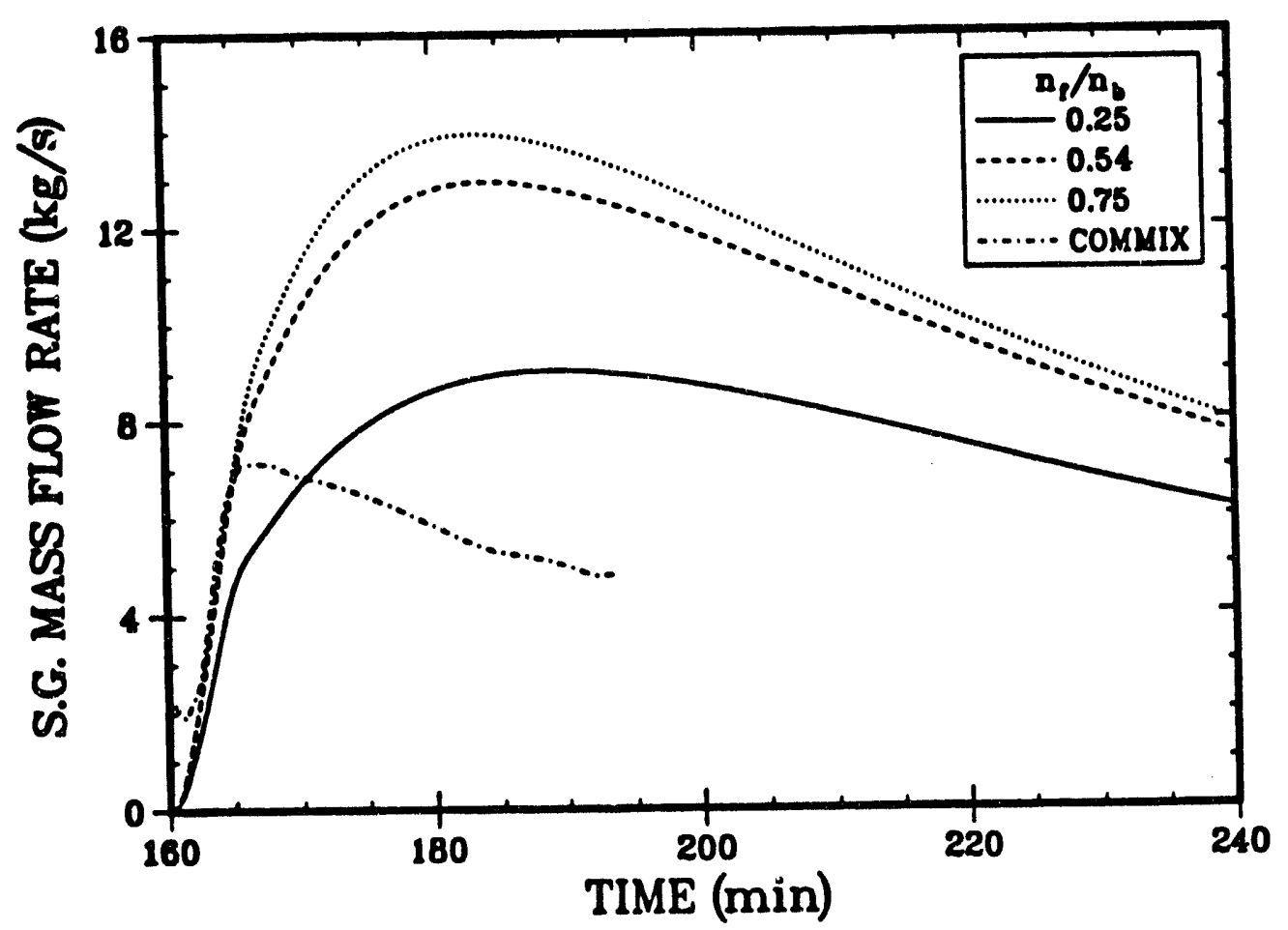

Figure 10.2.10 Variation of steam generator mass flow rate history with $n_{r}=n_{f} / n_{b}, P=(8.85,0.9$, var, 0.5$)$. 


\section{Mass flow ratio variation}

Figure 10.2.11 shows the temperature history for $P=(8.85,0.9,0.54,2)$. A comparison of Figures 10.2.1 and 10.2.4, shows that steam temperatures increased with increasing mass flow ratio. This is because more hot gases are cycled through the inlet plenum, thereby raising the average temperature therein. Values obtained with $m_{r}=0.5$ match best with the values computed with COMMIX. One might expect $m_{r}$ $<1$ since SG thermosyphoning should be the driving force to general recirculation.

The circulation rate in the $S G$ was shown earlier in Figure 10.2.2. The figure showed moderate variation with $m_{r}$. The maximum flow rate increased with increasing $m_{r}$, however, the reverse was true at $t=240$ min. This latter effect was due to viscosity variations with temperature as discussed earlier.

\section{Influence of loss coefficients}

The analysis using SCDAP/RELAP5 [2] specified a large loss coefficient for the hot leg and steam generator piping. Apparently, this was done to match the heat transfer rates reported in Reference 3 using COMMIX. It is also of interest here to determine the possible influence of such a specification in the present model. As we stated earlier, the thermosyphon model predicted a similar flow rate history in the SG to that calculated by SCDAP/RELAP5. These flow rates were substantially higher than produced by the simulation of the TMLB' scenario using COMMIX, the simulation of which was used by Bayless [2] to calibrate his model.

The loss coefficient $(K)$ was included in the present model by adding an appropriate term to the original friction factor. Figure 10.2.12 shows the temperature history using a value of $K=20$. This value was used in MELCOR simulations of the TMLB' scenario discussed in Section 8. Comparing with Figure 10.2.1 for the same parameter set but without a loss coefficient, the steam temperature exiting the SG is closer to the COMMIX values with a loss coefficient. Furthermore, while the overall steam temperatures were reduced with the loss coefficient specified, the temperature difference between incoming and exiting $S G$ steam was only slightly larger than without a loss coefficient, about $135 \mathrm{~K}$ in Figure 10.2.12.

The mass flow rate in the SG is compared in Figure 10.2.13 with and without a loss coefficient specified. As might be expected, the loss coefficient reduced the mass flow rate. The reduction amount depended on time, but was roughly $10-25 \%$ less with $K=20$. 


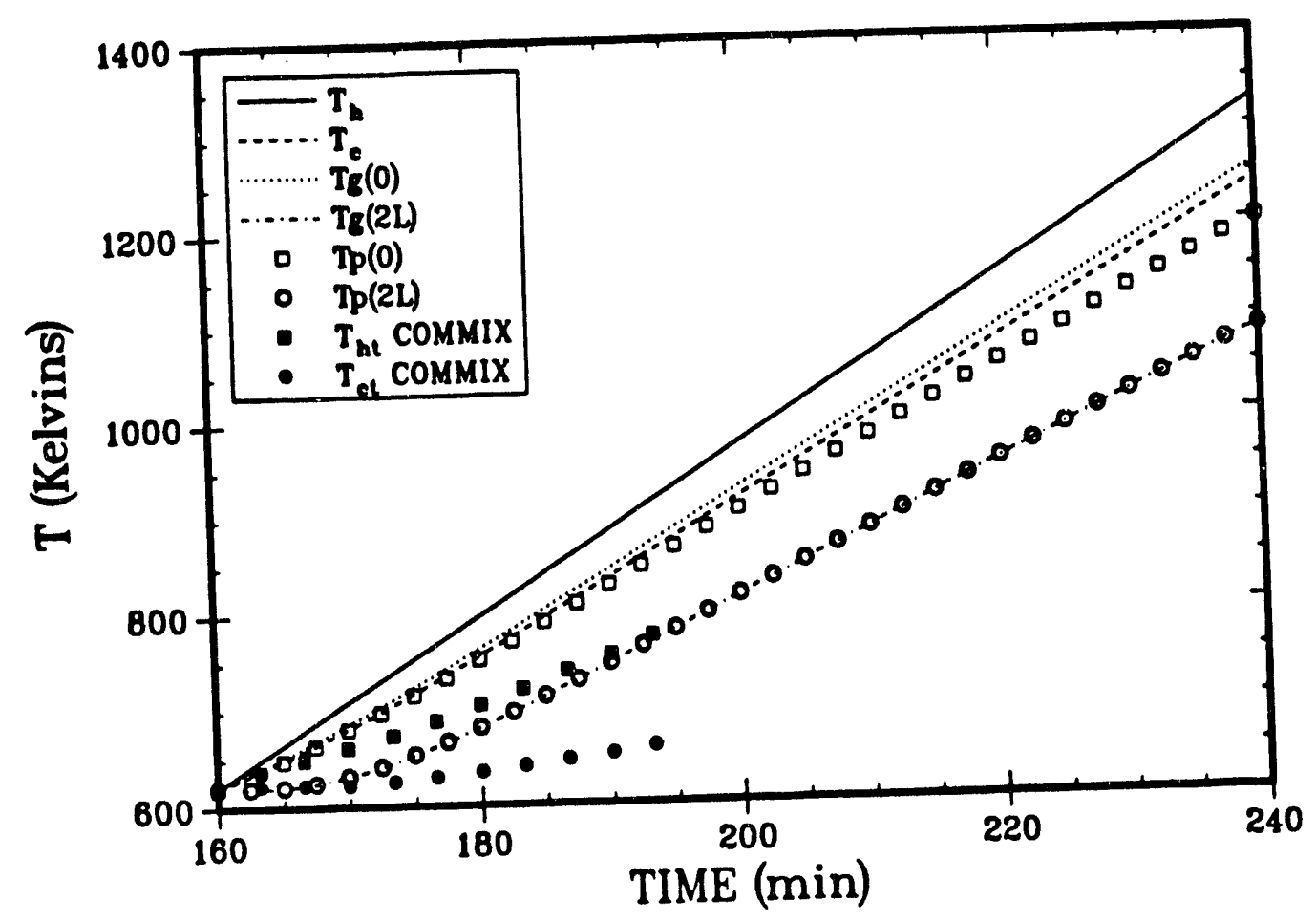

Figure 10.2.11 Temperature history for $\mathrm{m}_{\mathrm{HL}} / \mathrm{m}_{\mathrm{SG}}=2, \quad P=(8.85,0.9,0.54,2)$.

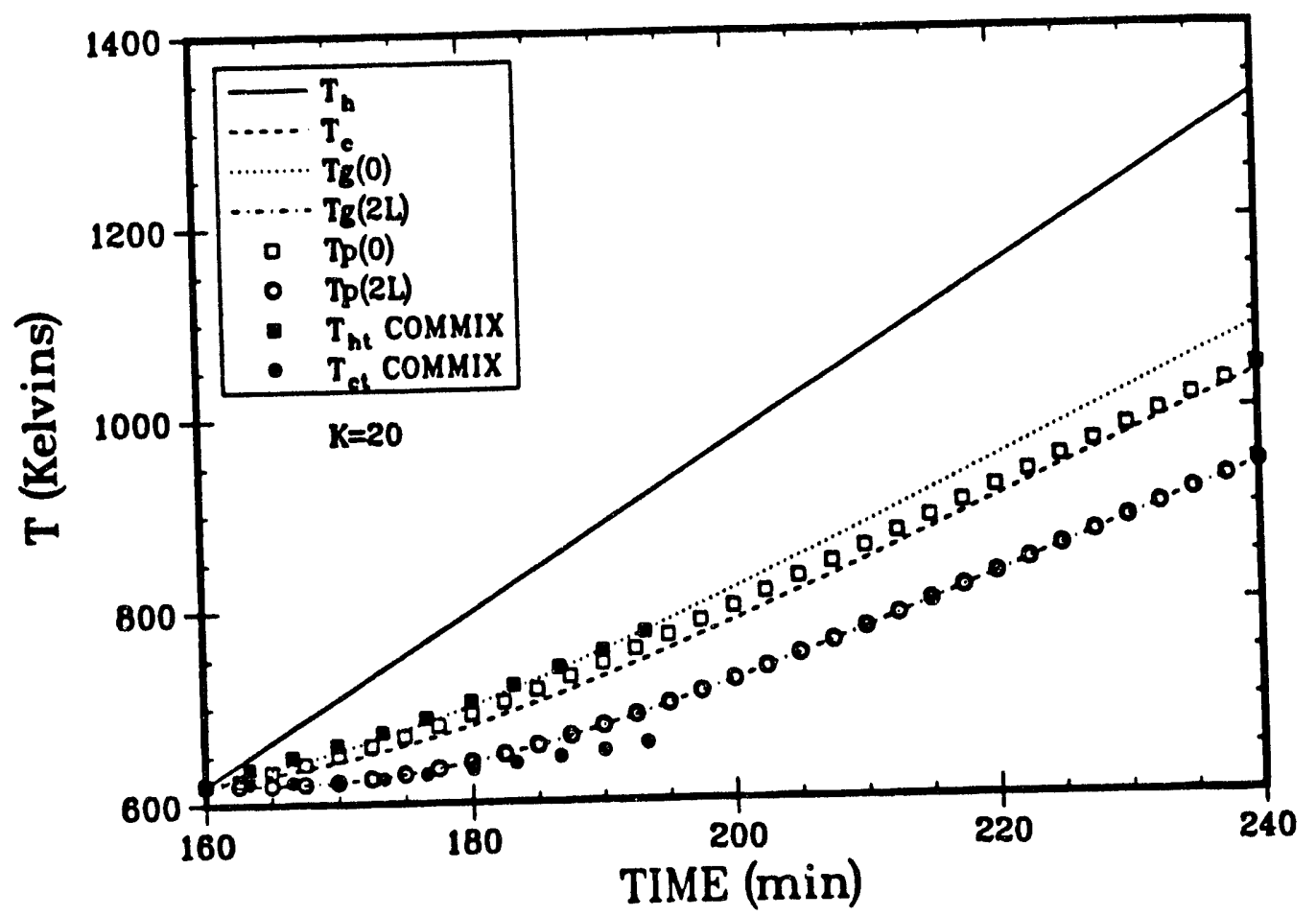

Figure 10.2.12 Temperature history for $K=20, P=(8.85,0.9,0.54,0.5)$. 


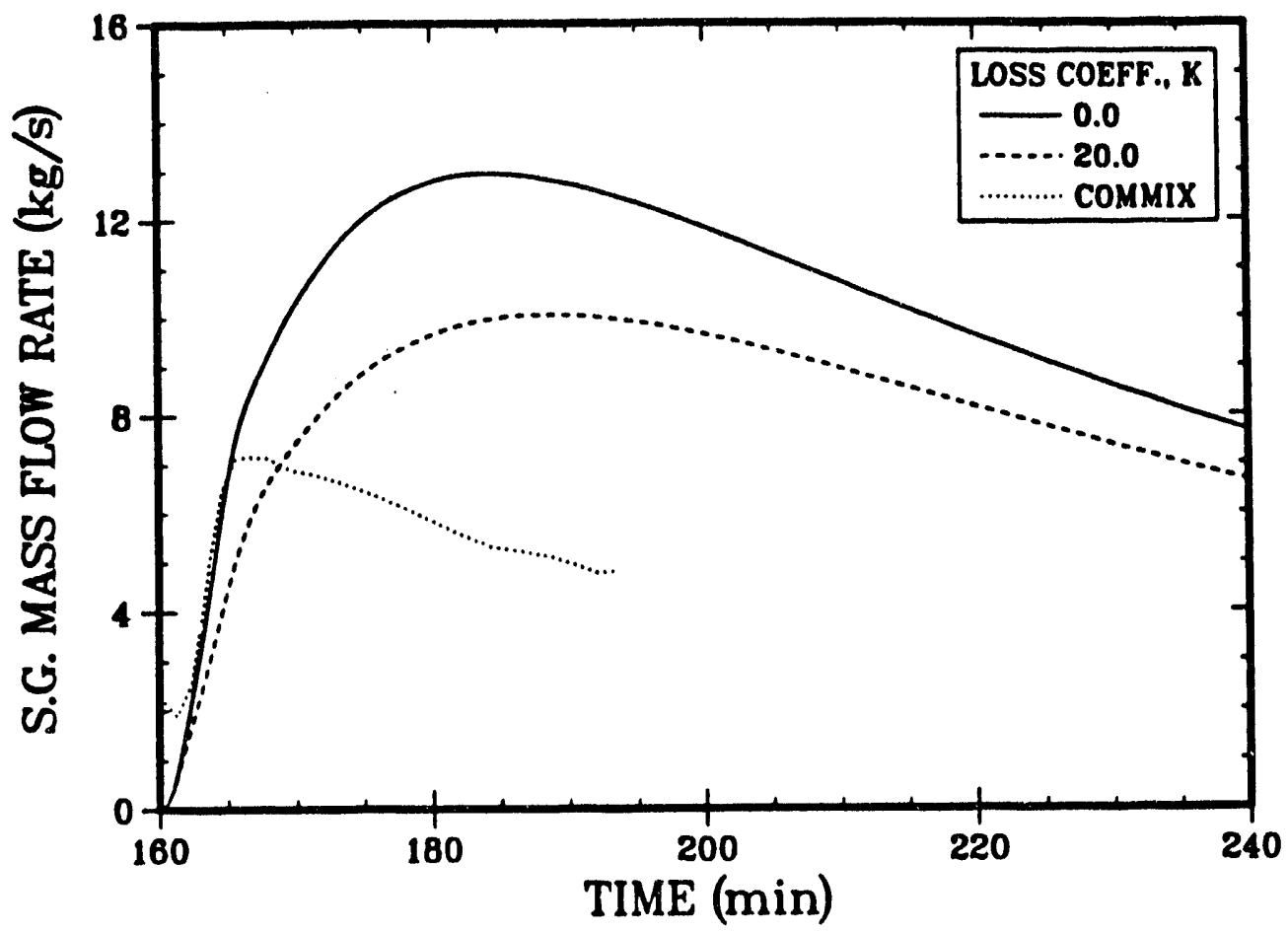

Figure 10.2.13 Effect of loss coefficient on steam generator flow rate, $P=(8.85,0.9,0: 54,0.5)$.

Influence of secondary heat transfer

As noted earlier, the calculations using COMMIX assumed insulated SG tubing. The SCDAP/RELAP5 model was calibrated using this simulation. The specification of insulated SG tubing was also considered in this model in order to investigate its effect. Figure 10.2.14 compares the mass flow rate history with and without secondary side heat transfer in the SG. The latter was accomplished simply by setting the secondary side heat transfer coefficient to zero. Note, however, that the steam still transfers heat to the tubes. The mass flow rate was reduced by roughly $15-20 \%$. The oscillations in the history for insulated tubes denoted the time when the temperature pulse reached the outlet plenum and then the inlet plenum. The mass flow rate with insulated tubes was still considerably higher than COMMIX.

Figure 10.2.15 shows the temperature history with insulated SG tubes. Comparison with Figure 10.2.1 shows that in the absence of secondary side heat exchange, the circulating vapor was hotter overall but the temperature difference across the SG was less, about $100 \mathrm{~K}$ compared to $125 \mathrm{~K}$ with secondary side heat transfer. 


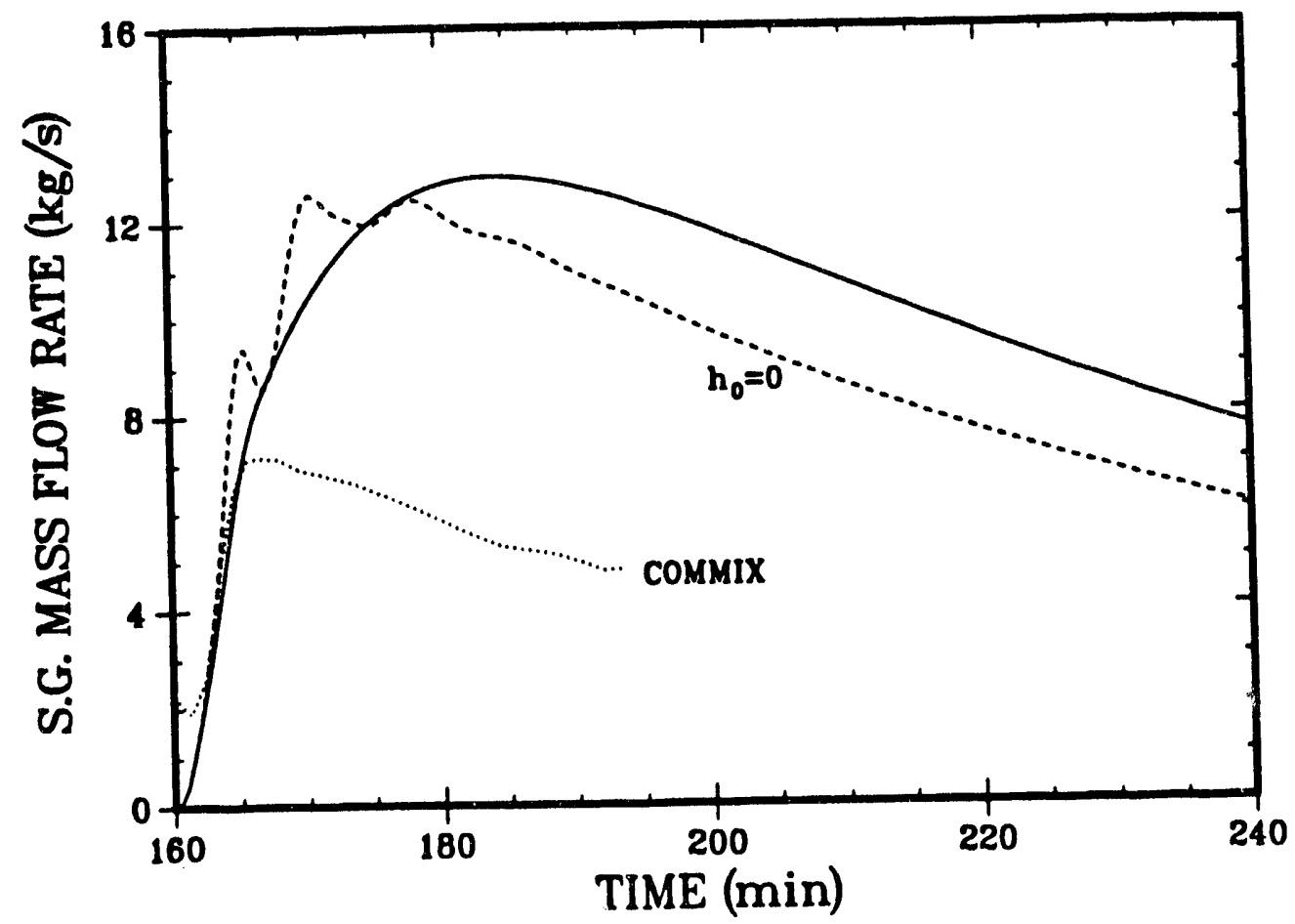

Figure 10.2.14 Effect of secondary side heat transfer on steam generator flow rate, $\mathrm{P}=(8.85,0.9,0.54,0.5)$.

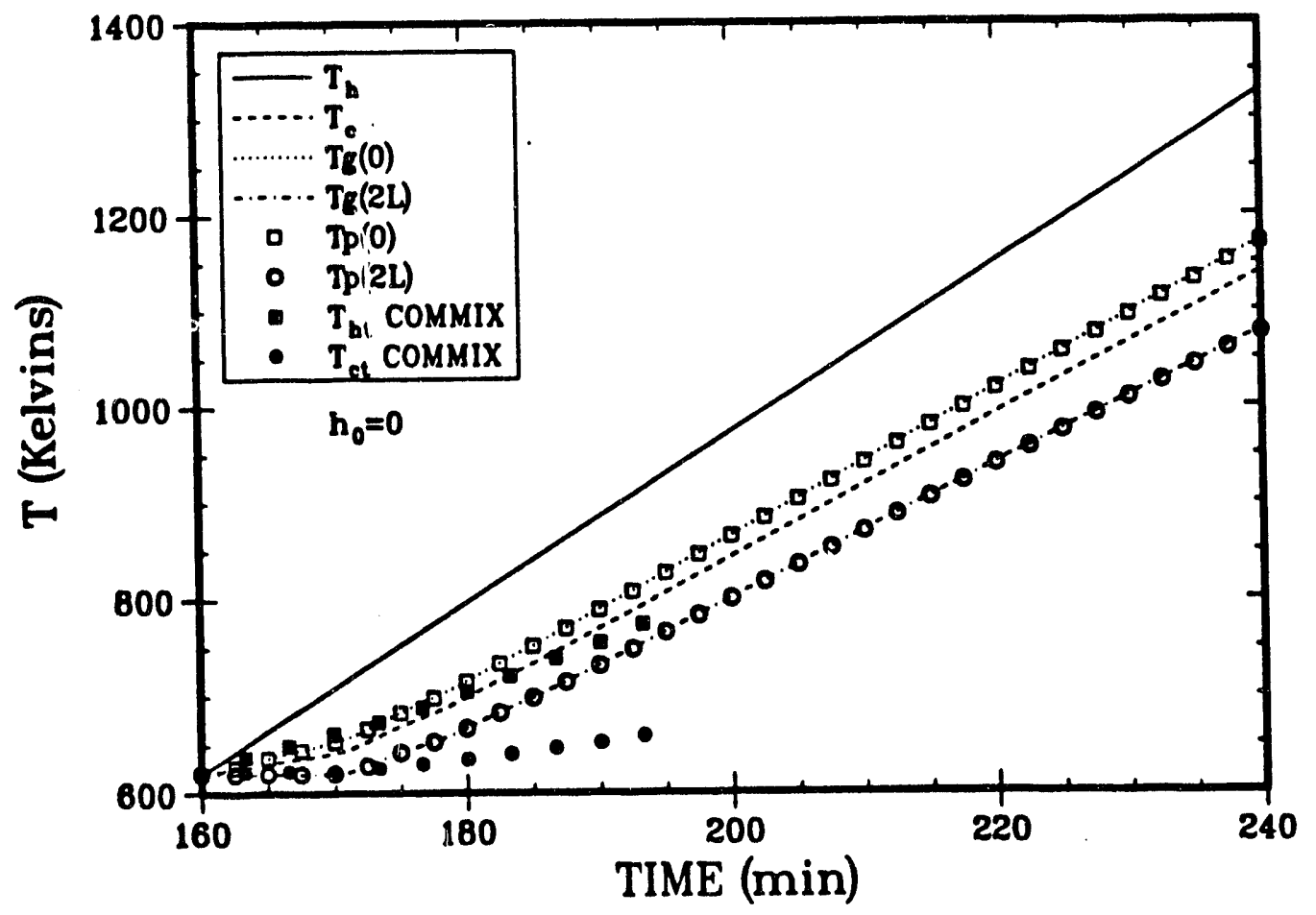

Figure 10.2.15 Temperature history without secondary side heat transfer, $P=(8.85,0.9,0.54,0.5)$. 


\subsection{Conclusions}

In this section, a model of the buoyancy-driven flow in a steam generator was presented for a specified heating rate of gases entering the inlet plenum. The motivation for this analysis was twofold: (1) to provide an independent study of the relation between steam temperatures in the inlet plenum and steam generator circulation rates and (2) to provide a computationally efficient model to study the effects of variation of key parameters affecting the circulation rate. The key parameters include the heating rate of gases entering the inlet plenum, $r$, the fraction of incoming gases which mix in the inlet plenum before entering the steam generator tubes, $f_{\mathrm{mix}}$, the ratio of forward flowing to backward flowing tubes in the steam generator, $n_{r}$, and the hot leg to steam generator mass flow rate, $m_{r}$.

Using the same mixing parameters as SCDAP/RELAP5 $(r=8.85$ Kelvin/min, $f_{\mathrm{mix}}=0.9, n_{\mathrm{r}}=0.54$, and $m_{\mathrm{r}}=.5$ ), a similar mass flow rate history for the steam generator was predicted. However, the heat transfer rate from the circulating steam to the steam on the secondary side was apparently much less than predicted by SCDAP/RELAP 5 . Furthermore, the SCDAP/RELAP5 model predicted these mass flow rates by the specification of artificially large loss coefficients in the hot$1 \mathrm{eg} / \mathrm{steam}$ generator system. Since the problem is buoyancy-driven, the inconsistent heat transfer rate indicates substantial uncertainty in the simulation results. According to Reference 2, these loss coefficients were specified to match heat transfer rates with the COMMIX simulations. This study with loss coefficients did show a modest increase in the temperature difference across the SG. However, the introduction of a loss coefficient resulted in a $10-25 \%$ reduction in mass flow rate. Thus, by increasing the loss coefficient, the circulation rate given by COMMIX could eventually be matched, but not the heat transfer rate. It should be re-emphasized that the COMMIX simulation assumed insulated SG tubing. Hence, it is not surprising that the heat transfer rates should differ.

This was perhaps the same dilemma faced by the SCDAP/RELAP5 modelers, having the ability to match either the mass flow rate or the heat transfer rate of COMMIX, but not both. Given that the COMMIX simulation assumed insulated SG tubing, it is somewhat surprising to choose to match heat transfer rates as opposed to SG circulation rates. Since the thermosyphoning phenomena are buoyancy-driven, the heat and momentum transport are intimately coupled. There would seem to be a significant uncertainty between calculations which are in agreement in either the mass or heat transfer rates, but not both.

As regards the sensitivity of the model to the various parameters, the findings can be summarized as follows: 
- The temperature difference across the SG increased proportionally with the heating rate. The steam was cooled to its exiting temperature over the rising half of the forward flowing tubes, and was uniform in temperature thereafter.

- The mass flow rate in the SG initially increased with heating rate, but ultimately decreased with increasing heating rate.

- The SG mass flow rate was relatively insensitive to either mixing fraction, $f_{\mathrm{mix}}$ or mass flow rate ratio $m_{\mathrm{HL}} / m_{\mathrm{SG}}$. However, both increased mixing and increased flow ratio tended to increase the temperature of the circulating steam. The temperature difference across the steam generator also increased with increasing $m_{\mathrm{r}}$.

- The SG mass flow rate was sensitive to the tube ratio only for $n_{x}$ below 0.54 .

- Application of a loss coefficient $(K=20)$ reduced the flow rate and decreased steam temperatures but only mildly increased the temperature difference between incoming and exiting steam.

- Neglect of secondary side heat exchange reduced the mass flow rate in the $S G$, increased overall vapor temperatures, but decreased the temperature difference across the SG. 


\subsection{MELCOR Simulation of a Pump Seal Leak}

The above analyses have studied the effects of in-vessel and hot leg countercurrent natural circulation flow in the Surry RCS which can occur if the pump loop seals remain blocked by water. The third form of natural circulation flow is complete loop flow and will occur if the loop seals clear of liquid. The SCDAP/RELAP5 analysis [2] and MELCOR analysis for the full plant calculation [25] did not predict loop seal clearing. Instead, the results of such an event occurring in the Surry Power Plant were postulated in Reference 2 from analyses completed for the Babcock and Wilcox Bellefonte plant [14]. Though this analysis was for a plant containing once-through steam generators, it was thought that similar results should be expected for a U-tube steam generator plant like Surry. This analysis showed that complete loop circulation reduced the heatup rate of the core because all of the piping in the RCS was available as a heat sink and thus increased the thermosyphoning flow rate. The pipe temperatures lagged behind the maximum fuel rod cladding temperatures by about $100 \mathrm{~K}$. These high temperatures in the loop structures would probably cause the RCS pressure boundary to fail long before the fuel rods began to relocate. The most likely failure point was predicted to be the steam generator tubes since they are the thinnest structures.

Other independent analyses have shown that the loop seals may clear, but well into the transient after major core relocation has occurred. Reference 30 described an analysis of the Surry plant using the integrated MELPROG/TRAC code. (This analysis is also summarized in Appendix A.) Countercurrent flow in the hot leg was not considered in this analysis. The seal was cleared by a pressure spike produced by hot core debris falling into the water in the lower plenum, thereby establishing loop circulation flow. However, the SCDAP/RELAP5 analyses of hot leg countercurrent flow circulation predicted failure of the RCS piping well before major core relocation occurred, which places skepticism on the probability of loop seal clearing from a pressure pulse.

Whether or not the loop seal may clear due to core relocation, there is another possible accident scenario which was not considered in the SCDAP/RELAP5 [2] analyses. The pump seal leak scenario of a station blackout accident (S3-TMLB') was analyzed using the MELPROG/TRAC code [9]. This analysis assumed the pump seals began to leak when the water in the loop seals reached saturation. The loop flow which developed after the liquid level dropped caused the energy generated in the core to quickly redistribute to the other portions of the RCS and showed a high probability that surge line or hot leg failure would ensue long before vessel failure. 


\subsection{MELCOR Model of the Pump Seal Leak Scenario}

To study the effects of natural circulation flow through the coolant loops (the third scenario), a MELCOR calculation of the pump seal leak accident scenario (S3-TMLB') was performed. The basic MELCOR model, described in detail in section 8 and used as the basecase for the sensitivity studies described in Section 9, was altered to include the cold leg side of the primary coolant system as shown in Figure 11.1.1. Two control volumes were added to represent the cold leg. As before, all three loops were combined. Control volume 230 represents the pump suction section of the cold leg from the outlet plenum of the steam generator. The remainder of the cold leg from the pump suction to the vessel is modeled by control volume 240. All geometrical dimensions agree with the SCDAP/RELAP5 model [2]. Three flow paths were added to join the cold leg control volumes as shown in Figure 11.1.1. Seven heat structures were added to model the cold leg and pump suction piping sections. Insulated outside piping boundary conditions were applied.

\section{SURRY NATURAL CIRCULATION MELCOR MODEL PUMP SEAL LEAK}

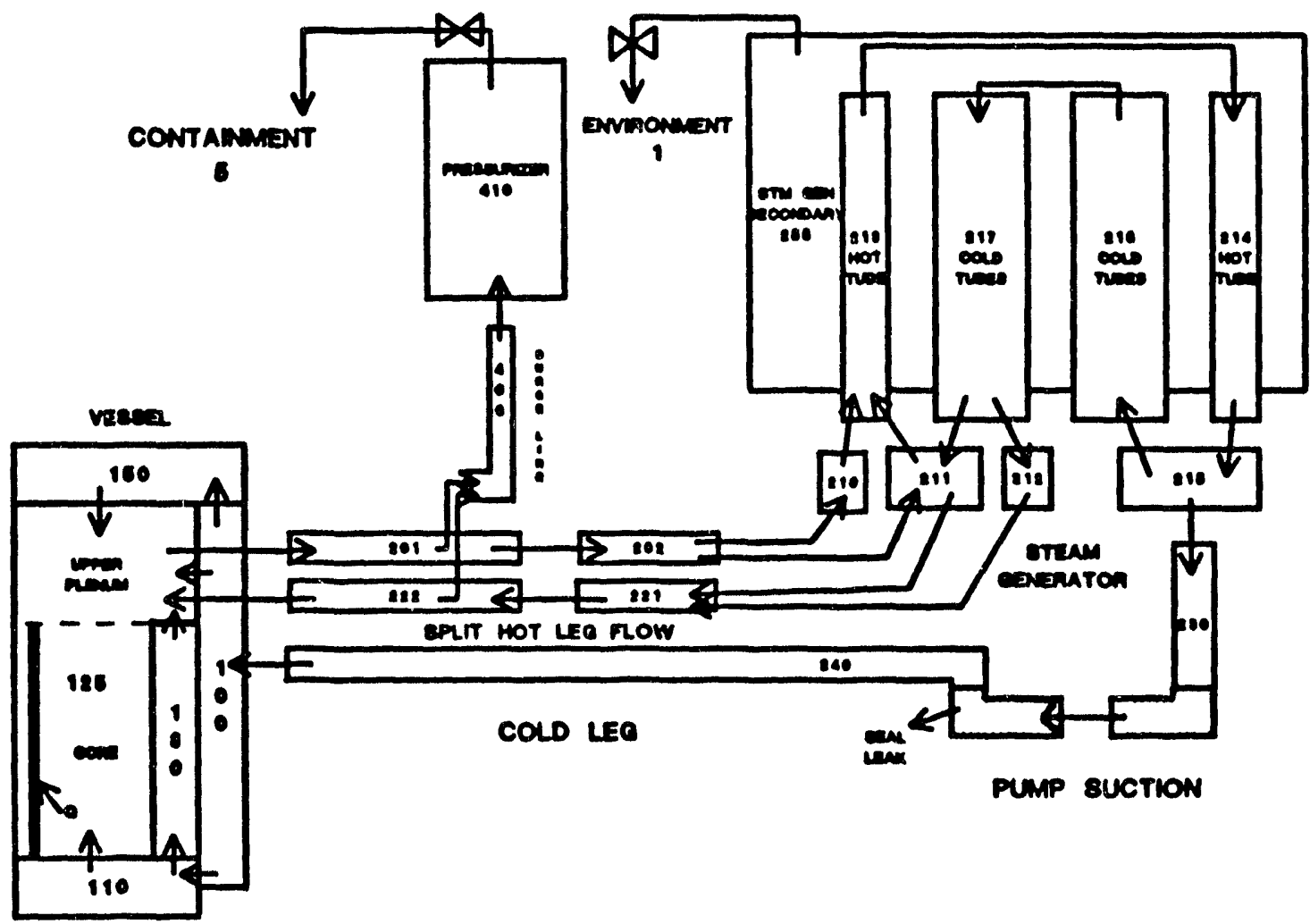

Figure 11.1.1 Nodalization of the reactor coolant system for the Surry MELCOR calculations for the pump seal leak scenario. 
The transient was started at 160 minutes at the same conditions as the basecase calculation. The same decay heat and oxidation energy histories were applied to the core fluid volume. The initial liquid level of water at the pump seals was assumed to be below the elevation of the cold leg piping returning to the vessel, $7.74 \mathrm{~m}$, to inhibit flow of water during the startup of the calculation. The pump seal leak was modeled as a flow path as shown in Figure 11.1.1. The area of the leak was assumed to be $4 \mathrm{~cm}^{2}$ at $2 \mathrm{~m}$ below the center of the cold leg pipe, $6.09 \mathrm{~m}$. These dimensions were taken from the S3-TMLB' analysis with the MELPROG/TRAC code [9] and based on NUREG-1150 [31] expert opinion results. The leak began at 160 minutes when the RCS was at saturation according to the assumptions of Reference 9 which were based on experimental data [32].

The calculation was run initially without a seal leak. This was done to insure that the addition of the cold leg to the model did not adversely affect the previous solutions where the cold leg section of the model was omitted. The results of this calculation were identical to the basecase calculation shown in Section 8 The MELCOR code also did not predict loop seal clearing during the course of this 90 minute transient, which agrees with the SCDAP/RELAP5 analyses.

\subsection{MELCOR Results of the Pump Seal Leak Simulation}

The leak was initiated in the next calculation at 160 minutes. The results of this analysis are presented in Figures 11.2.1 through 11.2.16. The pressure histories in the primary, secondary and containment are shown in Figure 11.2.1. The small pump seal leak caused a slow depressurization of the primary. By 250 minutes, the primary pressure was reduced to the steam generator secondary pressure. Note also that flow through the leak depressurized the system sufficiently such that flow through the PORV valve discontinued at approximately 183 minutes as shown in Figure 11.2.2. The actual pump seal leak flow rate is shown in Figure 11.2.3. Initially the liquid pool above the leak elevation leaked through the broken pump seal at a mass flow rate of $22 \mathrm{~kg} / \mathrm{s}$. After the liquid level in the pump seal section fell below the leak elevation, $6.09 \mathrm{~m}$, (Figure 11.2.4) steam flowed through the seal leak and the primary system began to depressurize more rapidly. The remaining liquid in the cold leg pump suction presented in Figure 11.2 .4 gradually evaporated due to the increased flow of superheated steam in the cold $1 \mathrm{eg}$. 


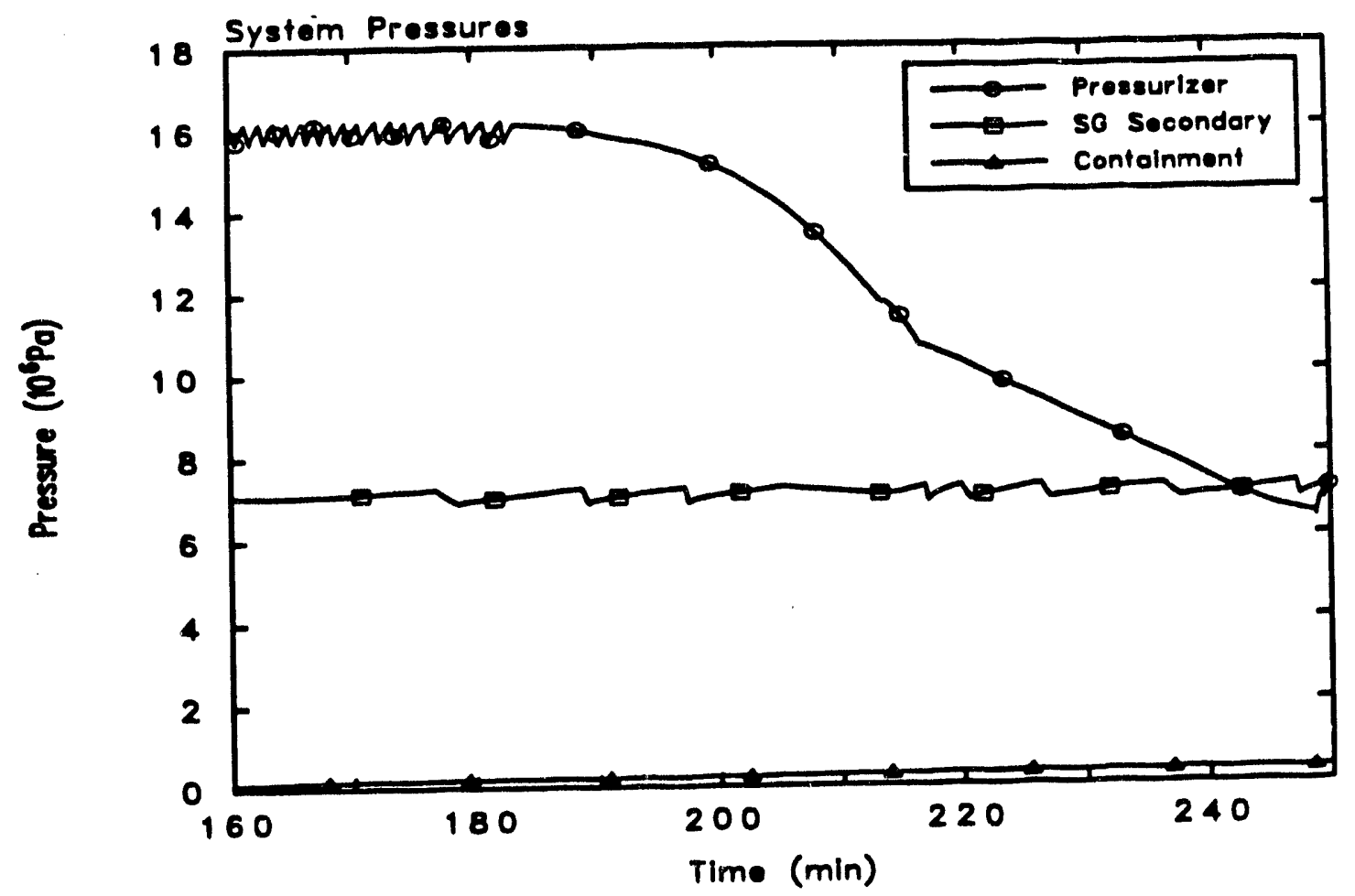

Figure 11.2.1 System pressures for the MELCOR pump seal leak simulation.

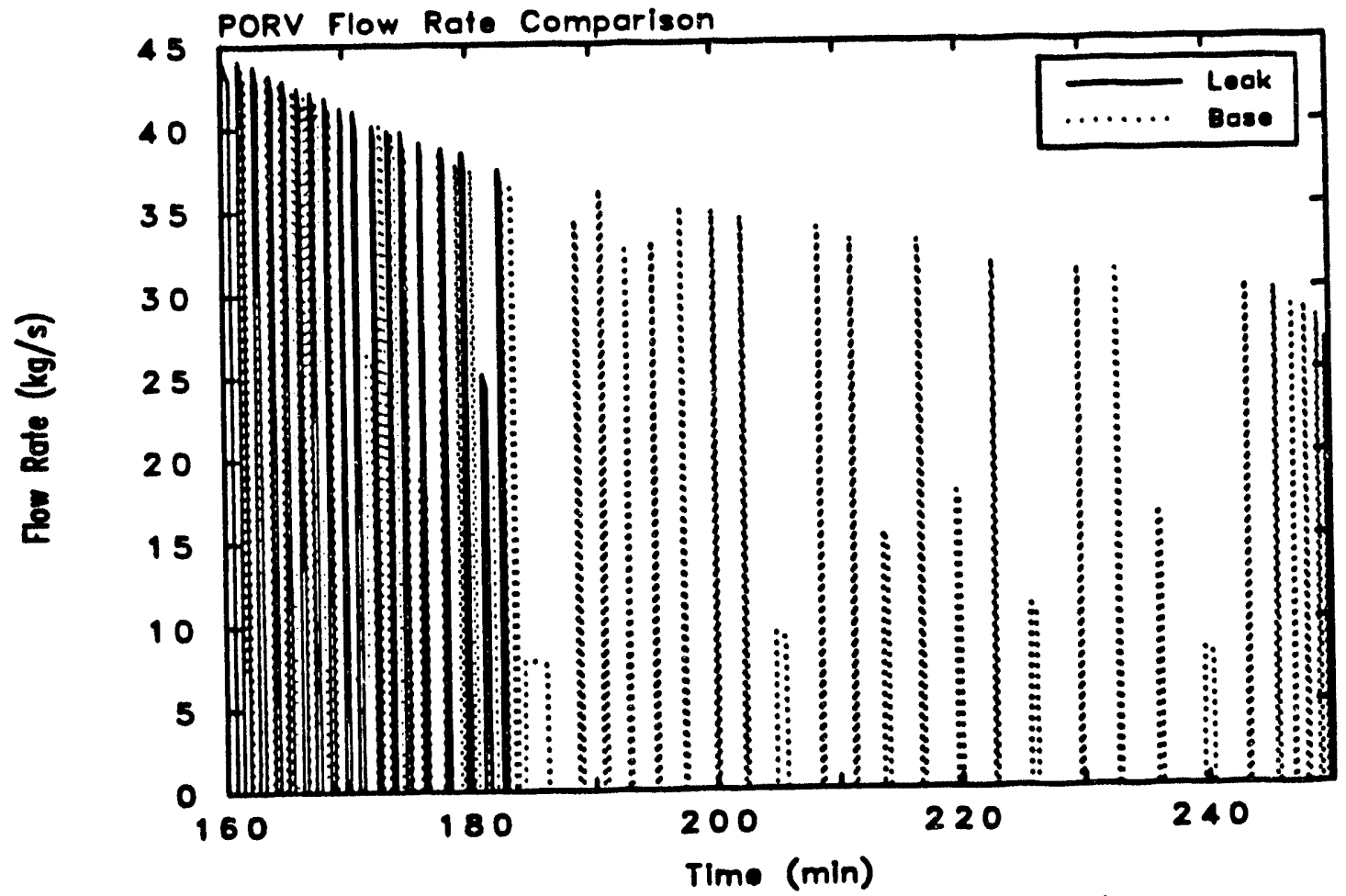

Figure 11.2.2 Effect of the pump seal leak on the PORV flow rate history. 


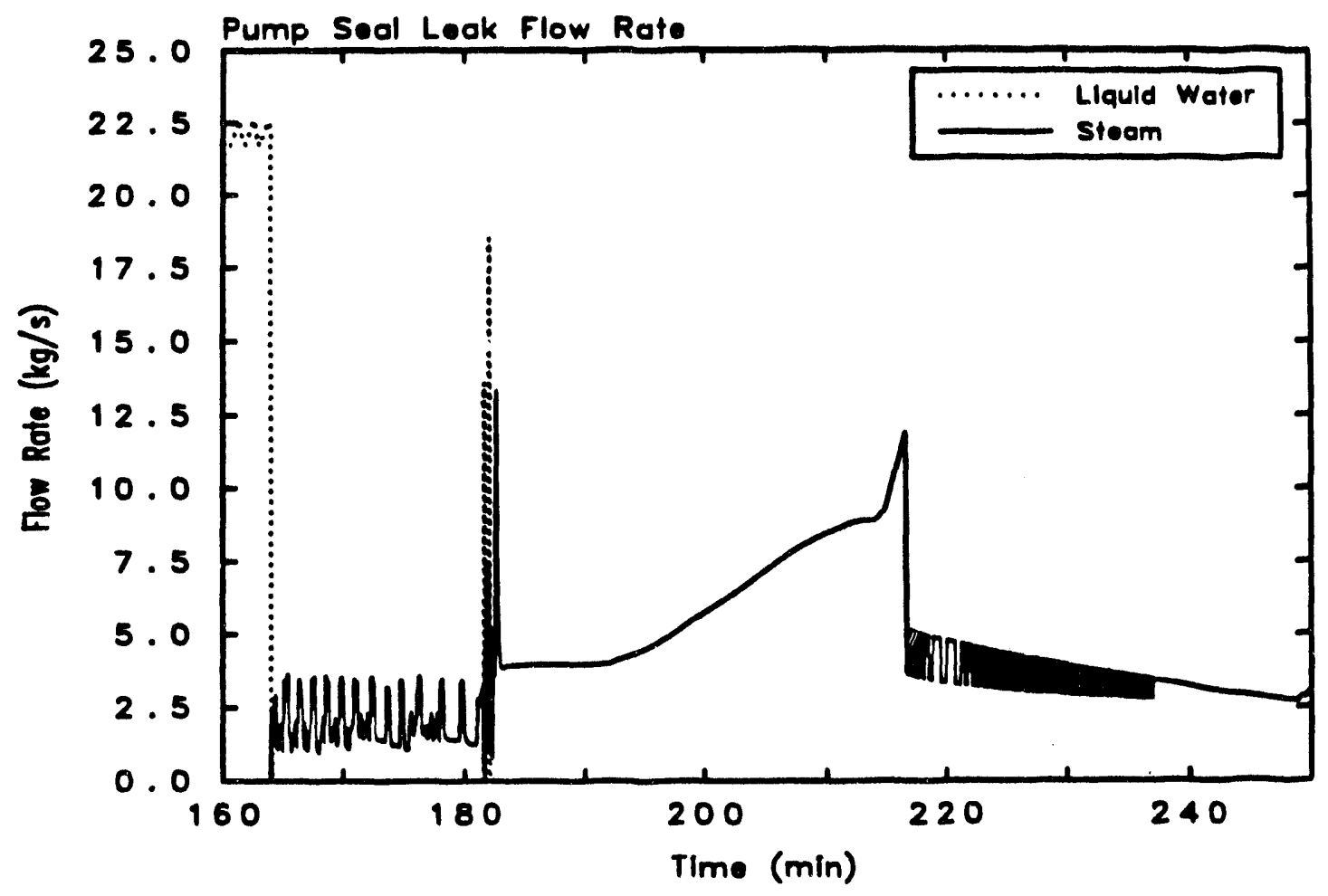

Figure 11.2.3 Pump seal leak flow rate history.

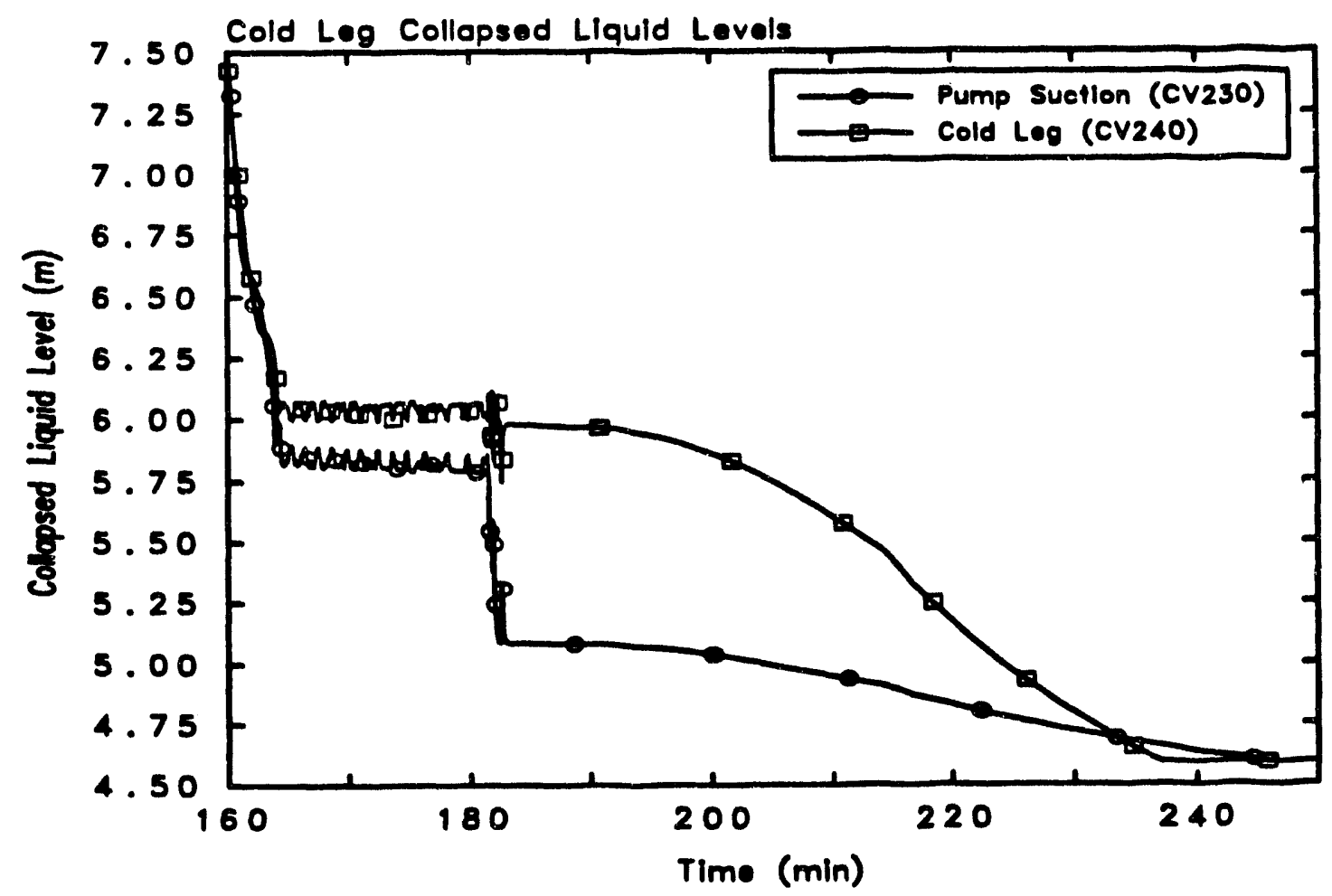

Figure 11.2.4 Cold leg collapsed liquid level history during the pump seal leak MELCOR simulation. 
A comparison of the hot and cold leg flow rate histories is shown in Figure 11.2.5. The hot leg top and bottom flows are countercurrent, similar to the basecase results, until flow began in the cold leg at approximately 185 minutes. At this time the bottom hot leg flow decreased until 215 minutes when full loop circulation flow started in the RCS. This occurred when the liquid water remaining in the bottom of the cold leg pump suction dropped sufficiently to allow complete steam flow throughout the coolant loop. Note that the bottom hot leg flow reversed at this time. That is, both split sections of the hot leg began flowing in the same direction toward the steam generator. Summation of the hot leg top and bottom flow rates is equivalent to the cold leg flow rate returning back to the vessel. Thus full coolant flow through the RCS had been established at approximately 215 minutes into the transient.

Similar flow results are shown in the steam generator tubes (Figure 11.2.6). The countercurrent flow pattern established early in the transient, similar to the basecase, was disrupted as full loop flow developed. At 215 minutes the cold tube flow completely reversed and flow through all the tubes was in the normal RCS coolant flow direction, from the steam generator inlet plenum to the outlet plenum.

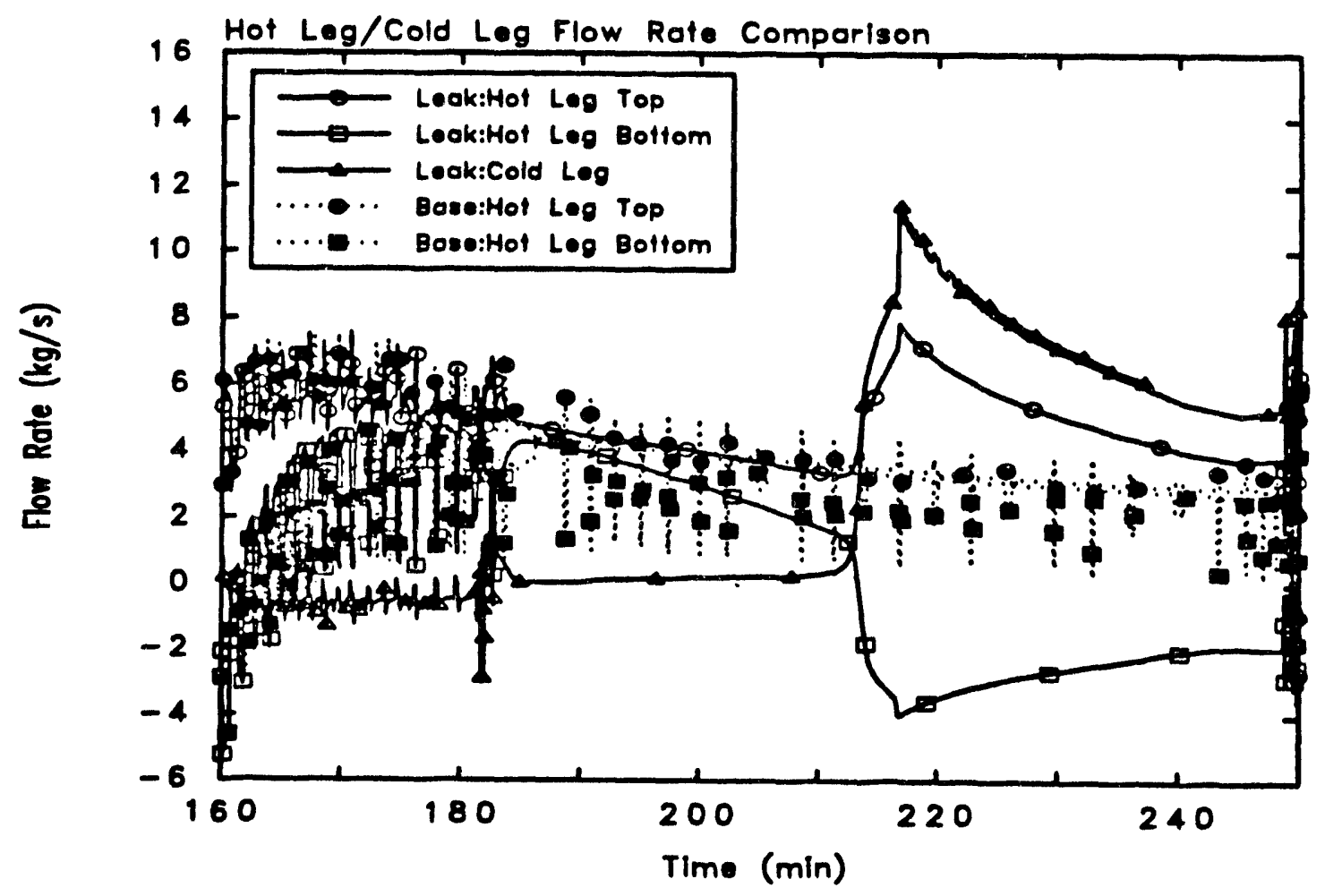

Figure 11.2.5 Effect of the pump seal leak on the hot and cold leg flow rates. 
The effect of the developed full coolant loop flow on the vapor temperatures throughout the RCS are shown compared to the basecase results in Figures 11.2 .7 through 11.2.11. The core and upper plenum vapor temperature (Figure 11.2.7) decreased as full coolant flow was established due to the higher flow rate in the RCS and distribution of more of the energy from the core to the entire piping system of the coolant loop. The hot leg vapor temperatures are shown in Figure 11.2.8. Note that after full flow was established the hot leg top and bottom temperatures reach the same values intermediate between the original separate hot and cold countercurrent flow temperatures of the basecase. The surge line vapor temperature (Figuce 11.2.9) began to diverge from the basecase at approximately 195 minutes since the flow through the surge line diminished as the system began to depressurize. The surge line vapor cooled considerably, almost to saturation, until oxidation energy was added to the primary system. The vapor temperature in the steam generator tubes increased as full coolant flow developed as shown in Figure 11.2.10. The effect of mixing of the cold and hot flows was lost which had kept the steam generator vapor temperatures cooler in the natural circulation basecase. More energy was also transferred to the steam generator secondary via the tubes as shown by the higher secondary temperatures in Figure 11.2.11.

The resultant component temperature histories are presented in Figures 11.2.12 through 11.2.15. The reactor vessel upper plenum structures (Figure 11.2.12) cooled slightly as the full coolant flow developed until oxidation energy began to reheat them. The upper plenum internal structures and CRD housings remained cooler by 200 to $250 \mathrm{~K}$, indicating that oxidation and melting of these structures, not modeled in these calculations, may not be of concern with full loop flow during a pump seal leak station blackout accident scenario. Figure 11.2.13 shows, however, that the hot leg piping temperature increased as full loop flow was established because of the higher flow rate and increased heat transfer to the hot leg piping. The top hot leg temperature increased temporarily as loop flow was established and then followed a similar temperature history as the basecase. The bottom hot leg pipe, however, increased from the beginning of the flow reversal throughout the remainder of the calculation. As expected, with lack of flow through the surge line toward the PORV valves, the surge line pipe temperature cooled considerable as shown in Figure 11.2.14. The surge line would not be a likely candidate for failure in this scenario. Figure 11.2.15, however, shows the increased steam generator tube temperature. The tubes are heated 50 to $100 \mathrm{~K}$ higher than in the natural circulation case due to the enhanced heat transfer of hotter fluid flowing through them. 


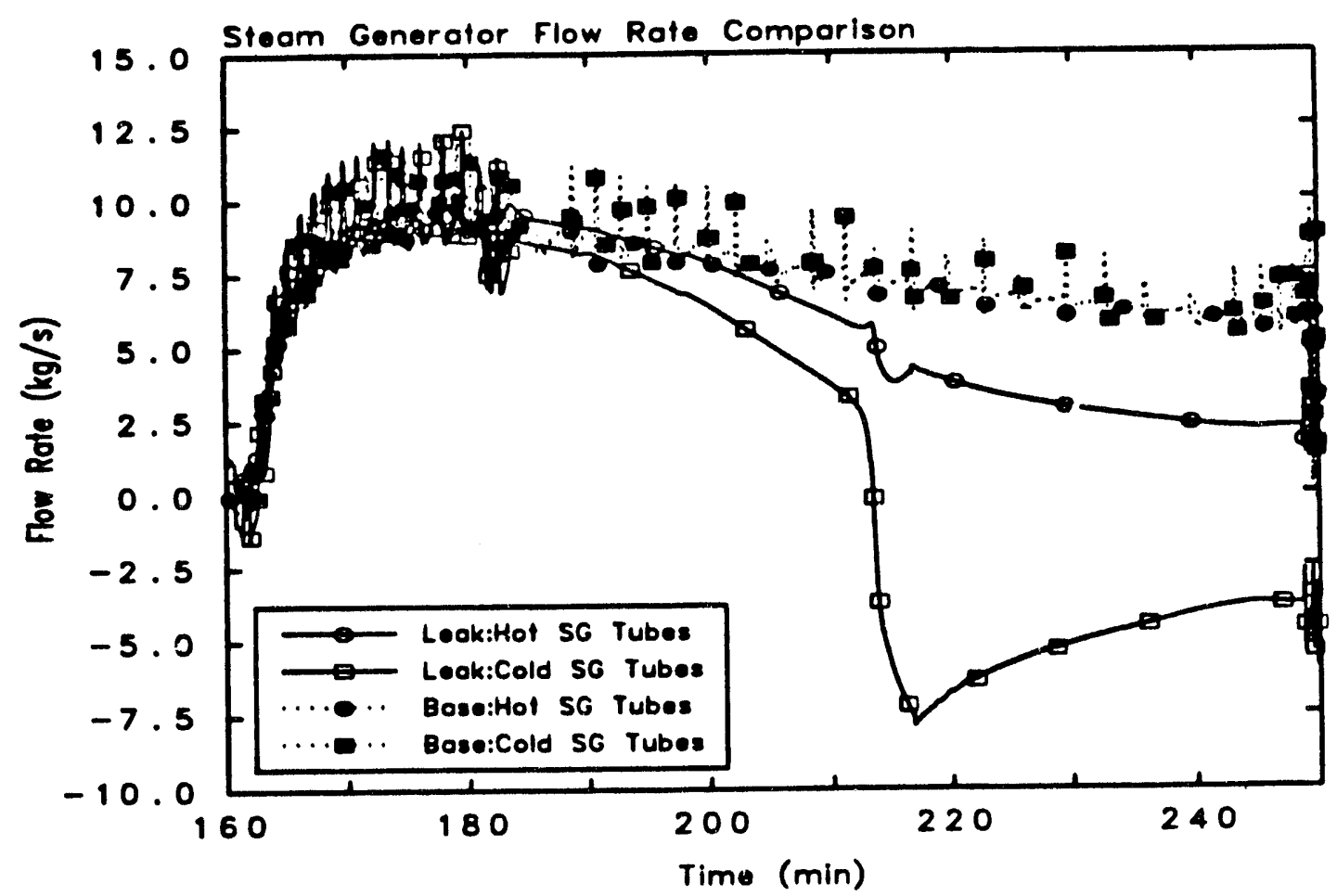

Figure 11.2.6 Effect of the pump seal leak on the steam generator mass flow rates.

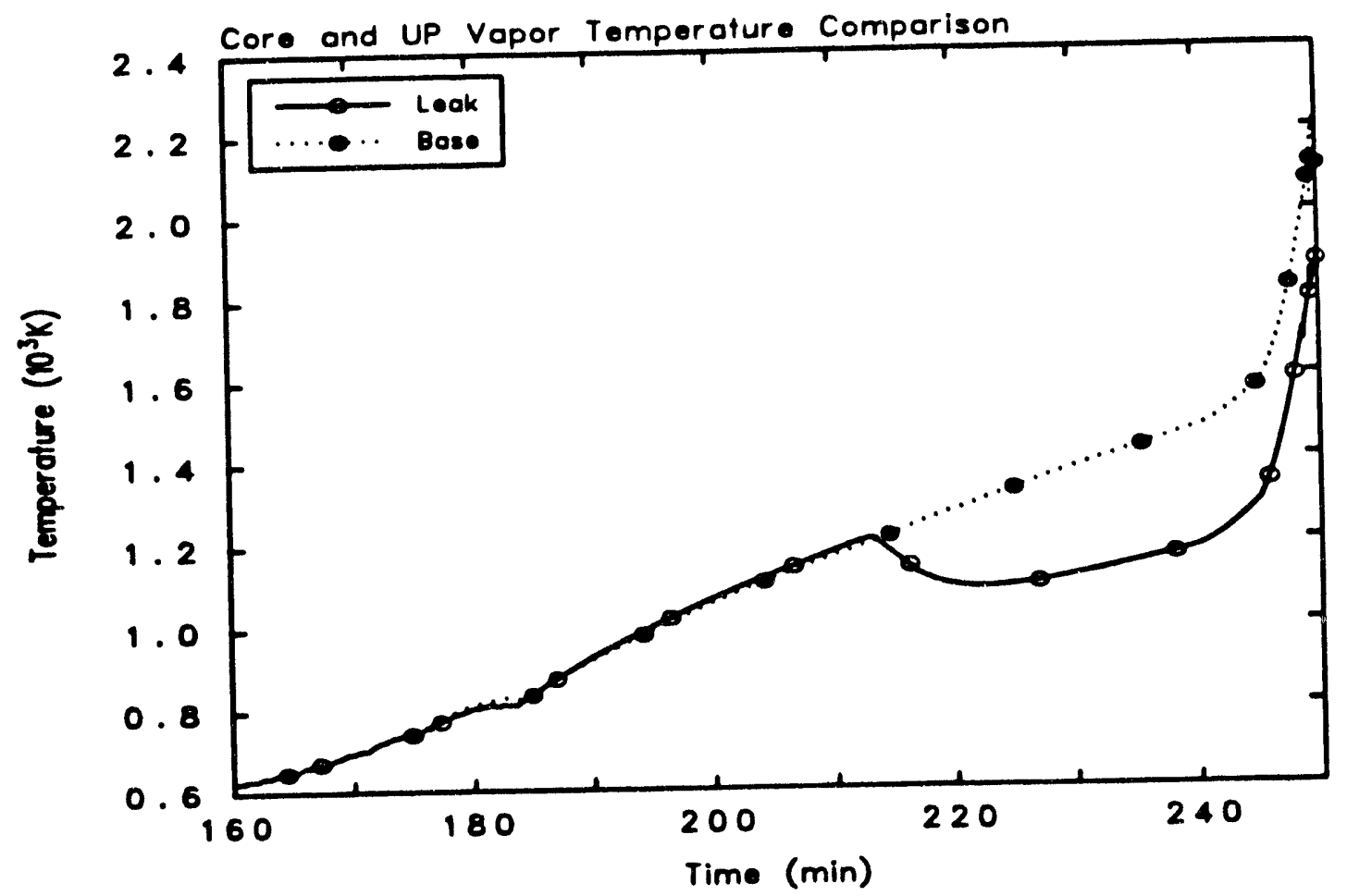

Figure 11.2.7 Effect of the punp seal leak on the core and upper plenum vapor temperature history. 


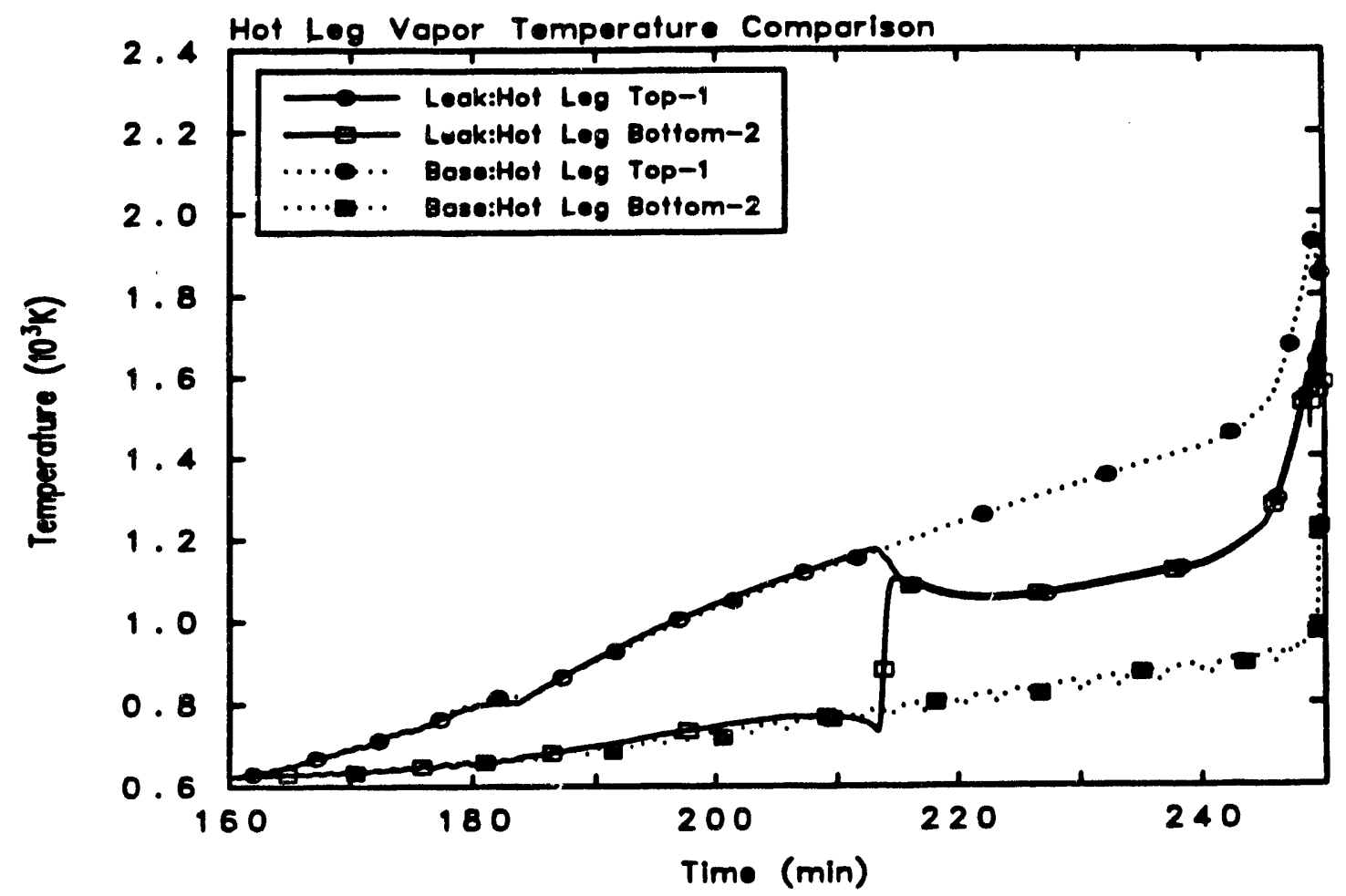

Figure 11.2.8 Effect of the pump seal leak on the hot leg vapor temperature history.

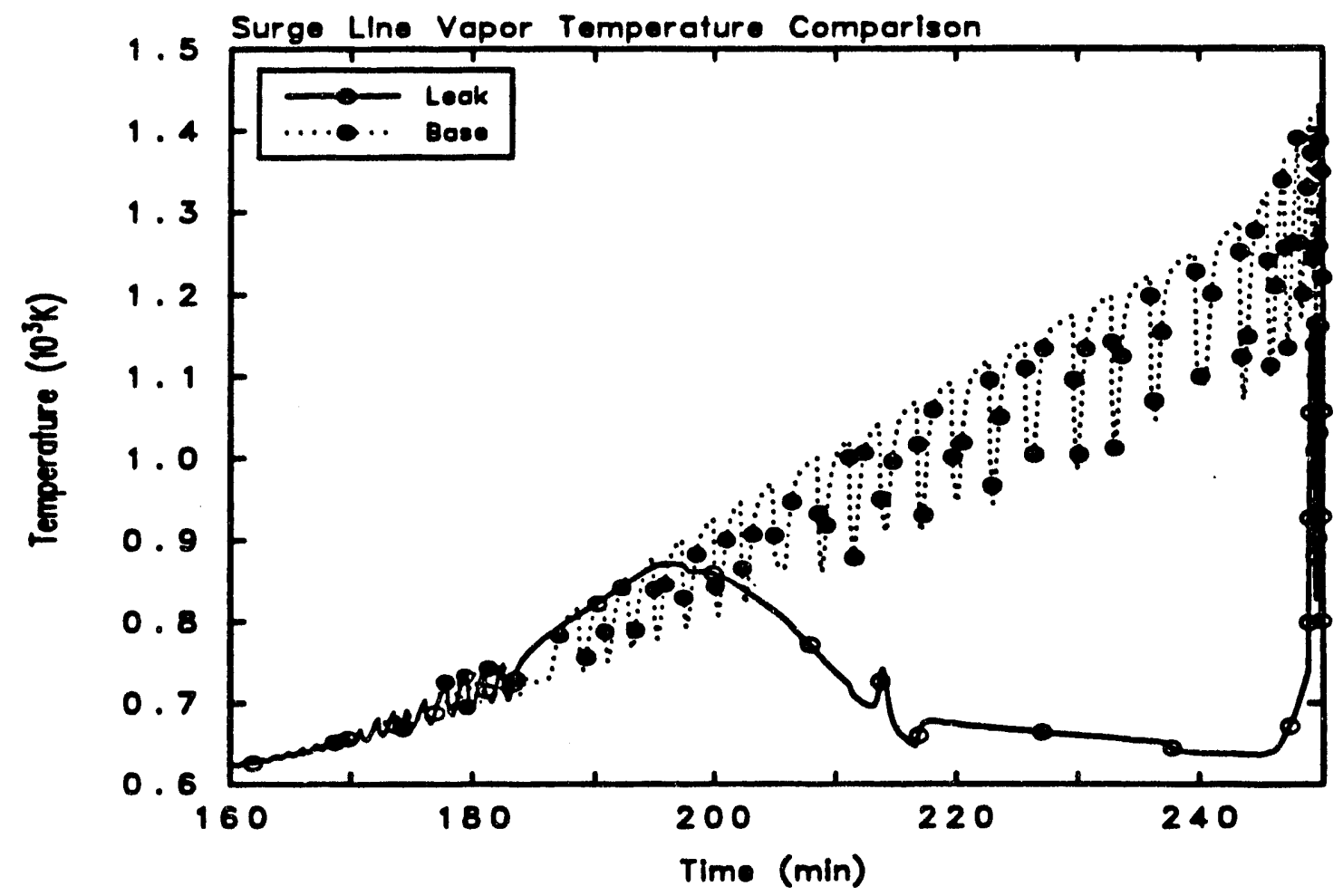

Figure 11.2.9 Effect of the pump seal leak on the surge line vapor temperature history. 


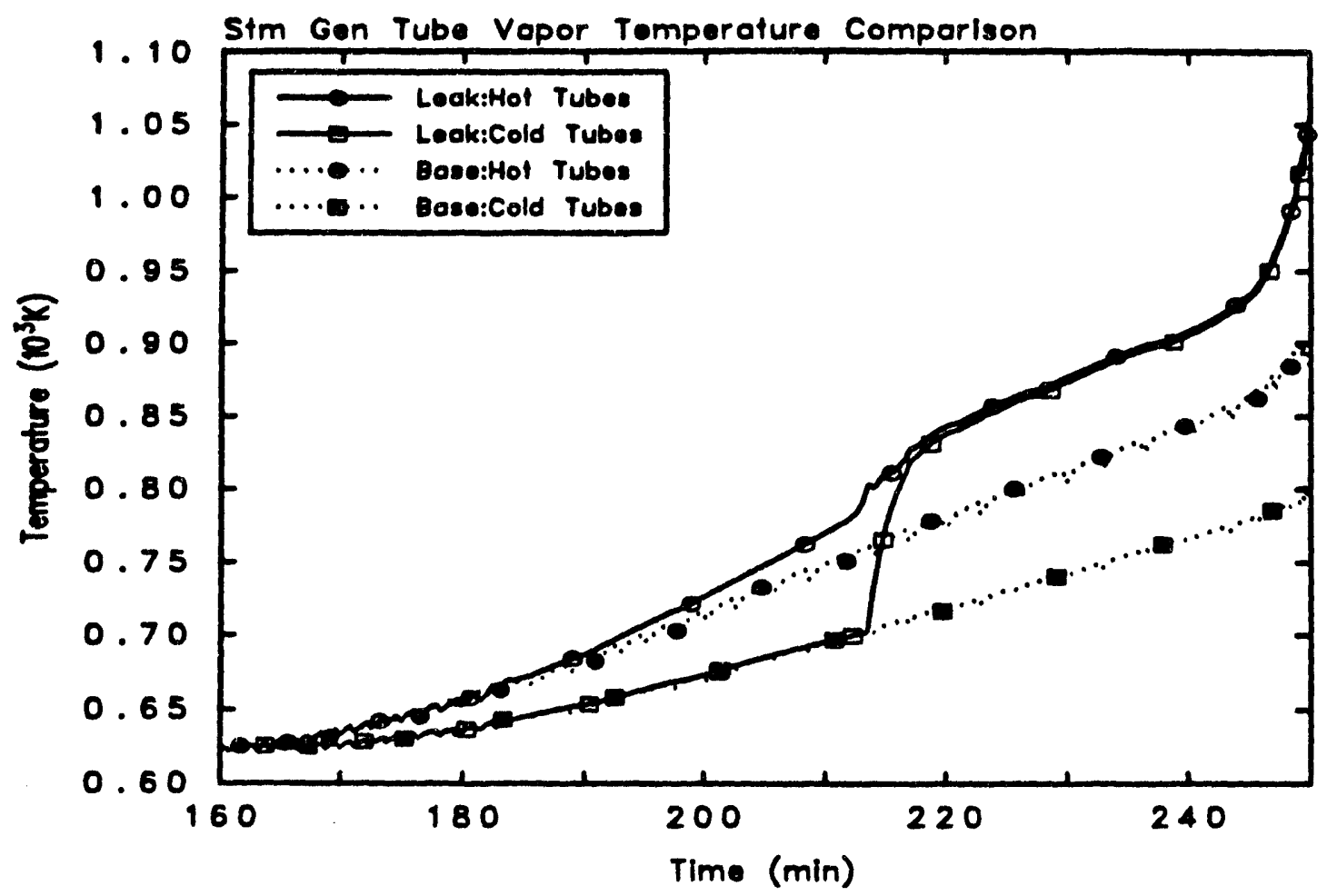

Figure 11.2.10 Effect of the pump seal leak on the steam generator - ube vapor temperature history.

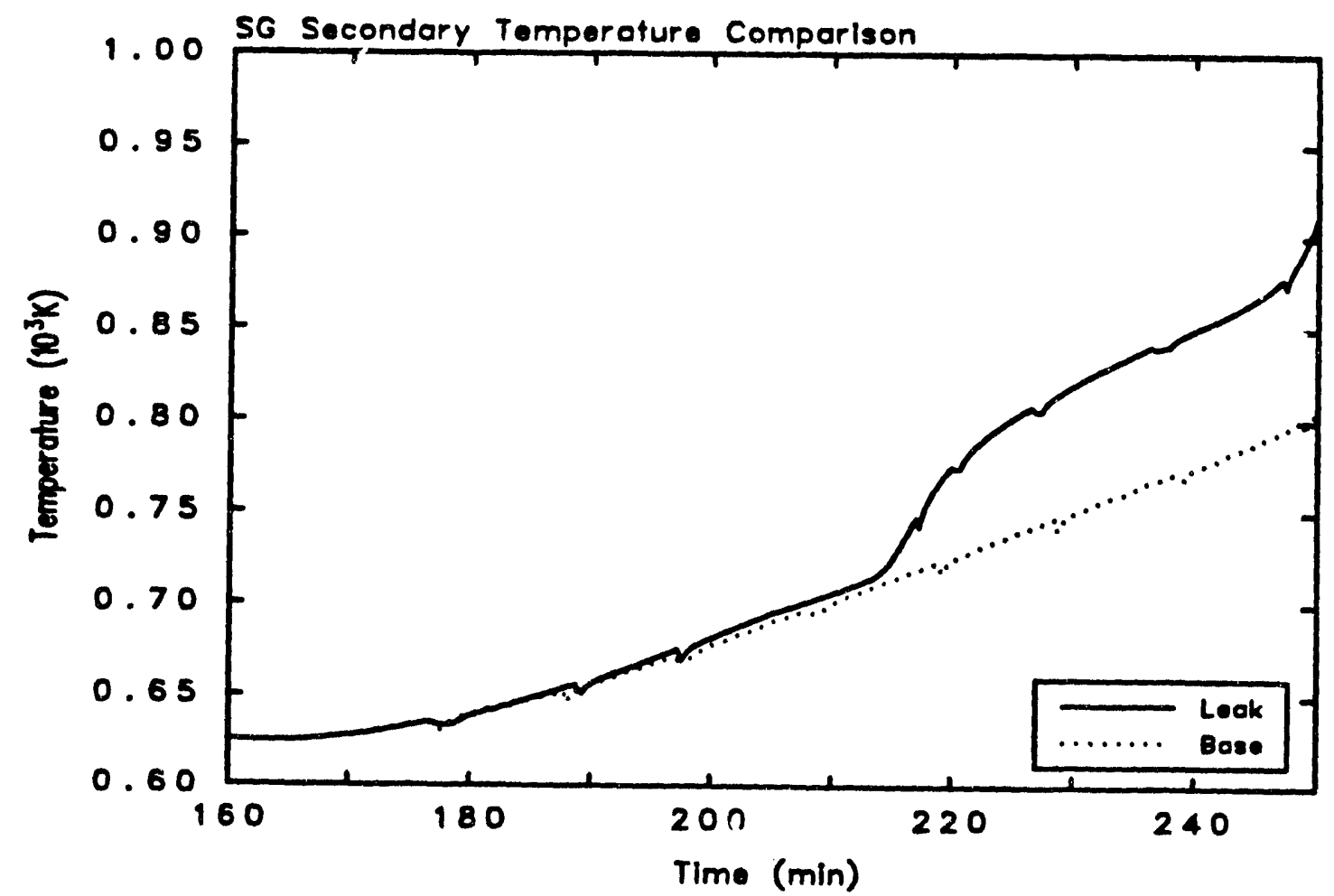

Figure 11.2.11 Effect of the pump seal leak on the steam generator secondary vapor temperature history. 


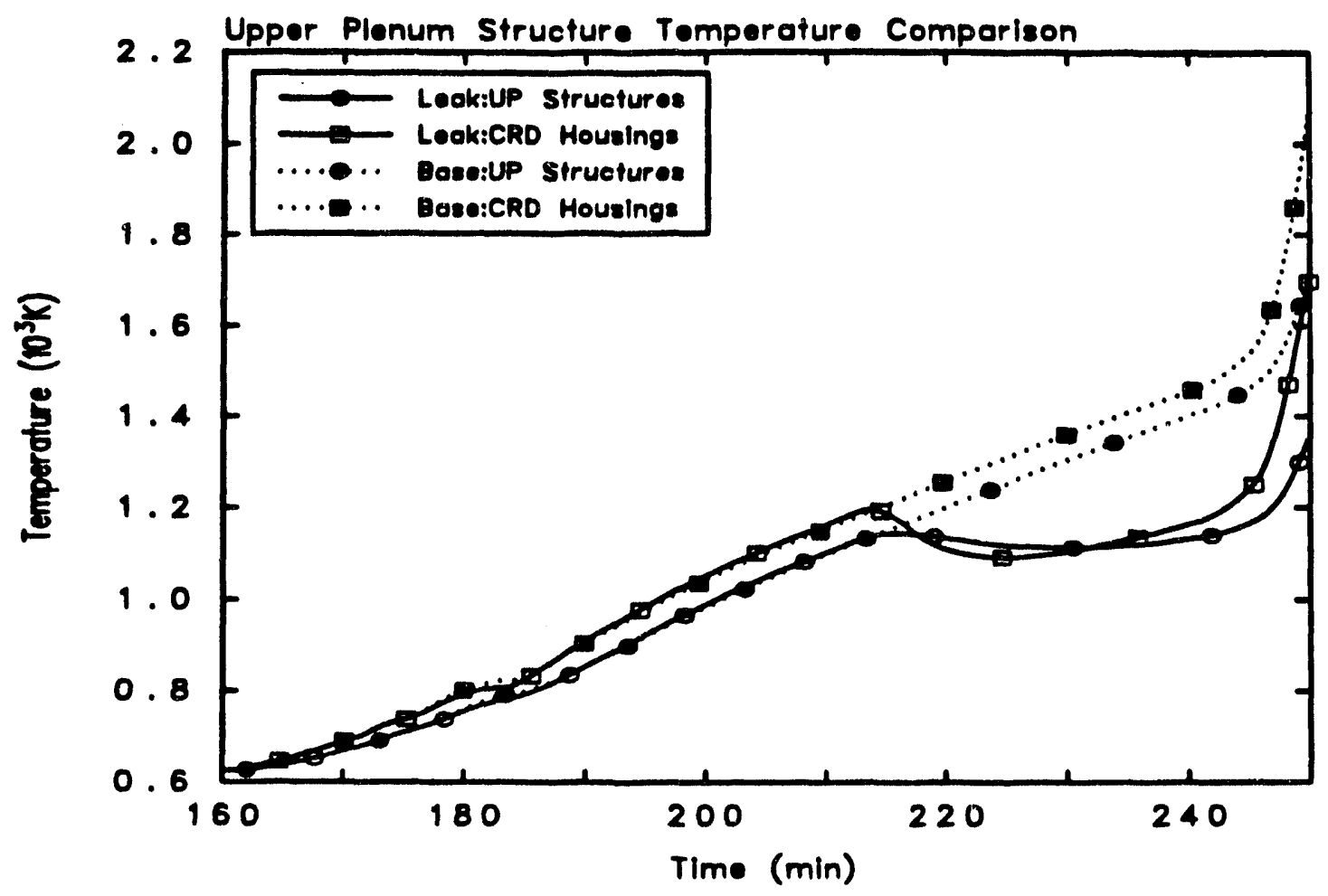

Figure 11.2.12 Effect of the pump seal leak on the upper plenum structure temperatures.

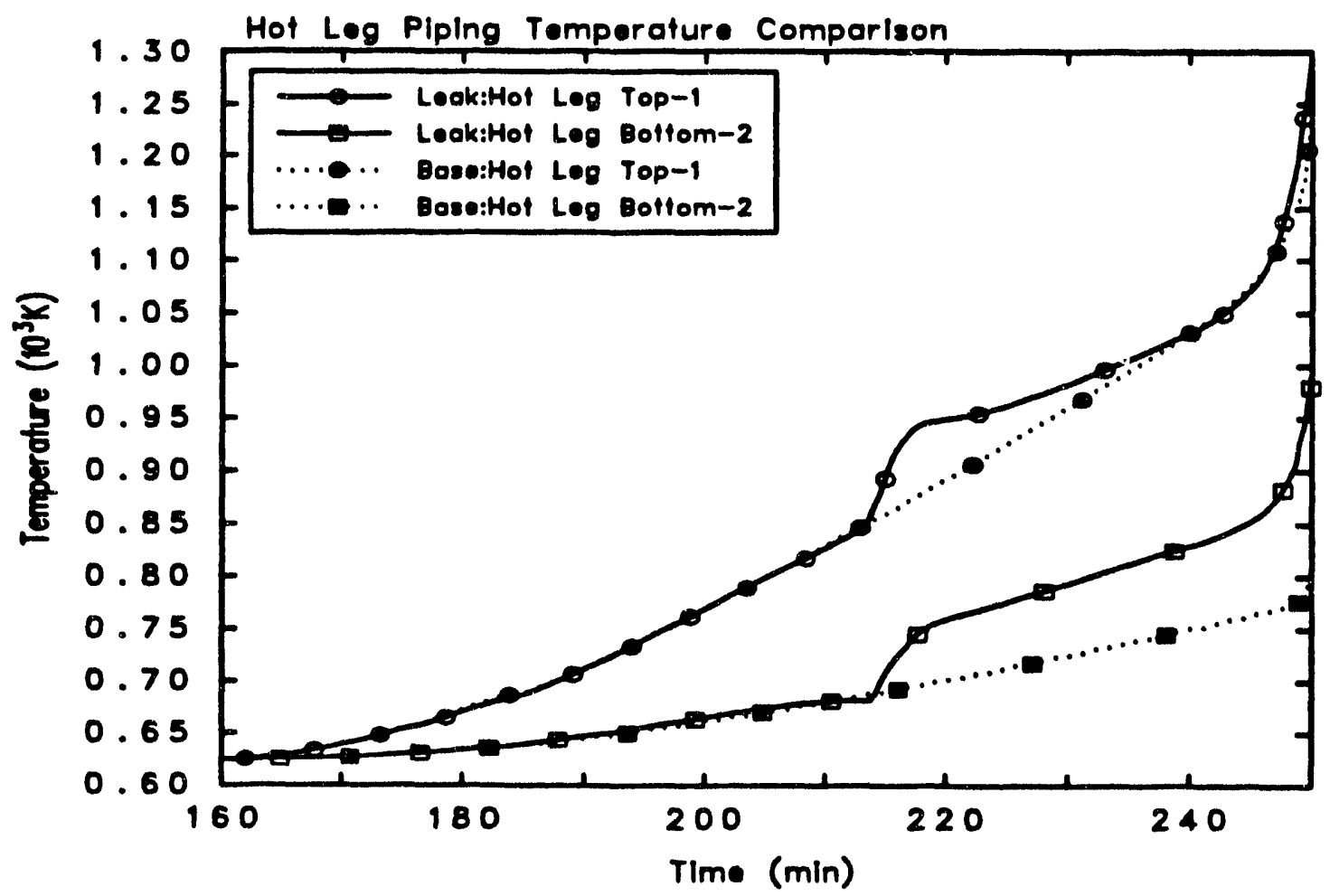

Figure 11.2.13 Effect of the pump seal leak on the hot leg piping temperatures. 


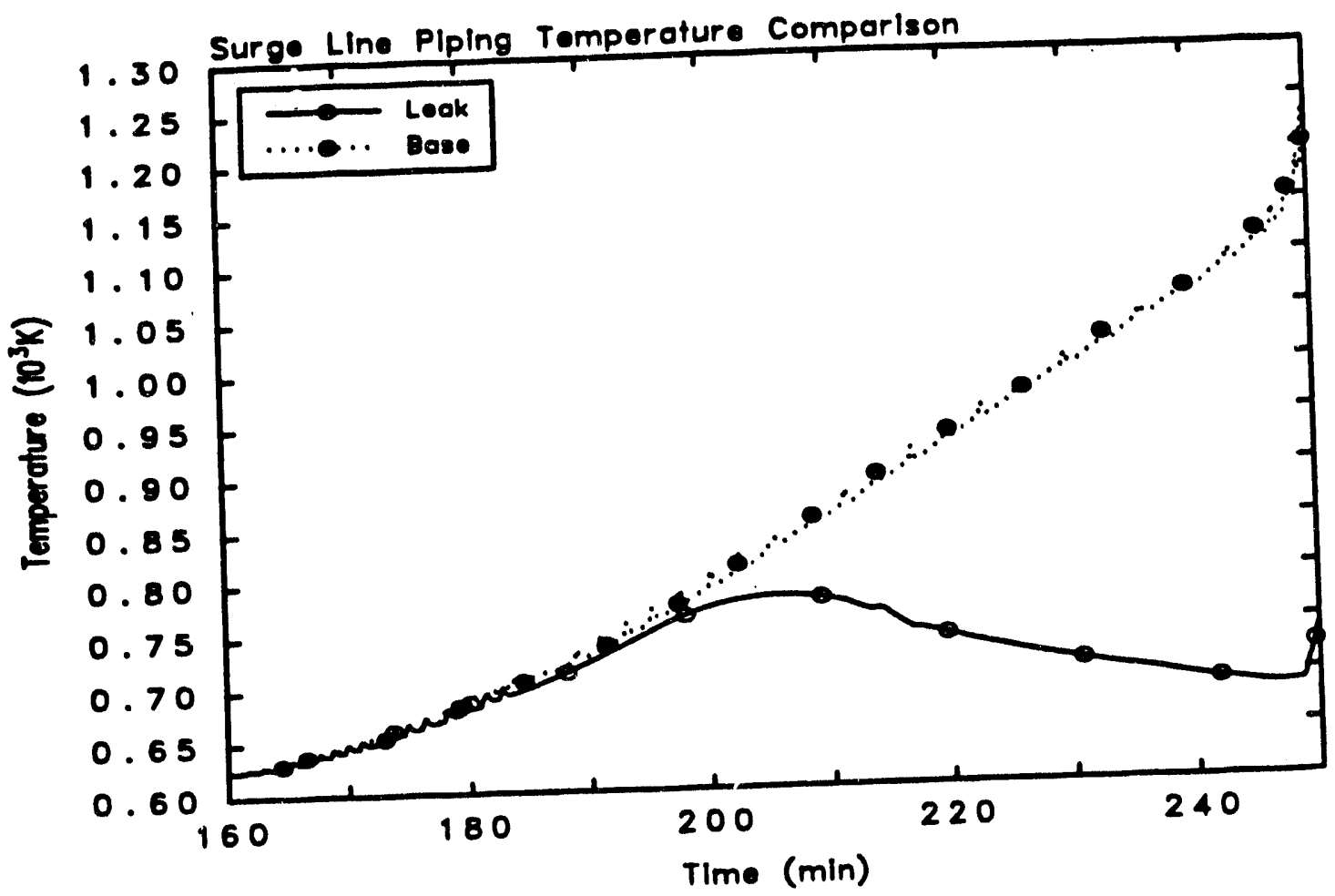

Figure 11.2.14 Effect of the pump seal leak on the surge line piping temperature.

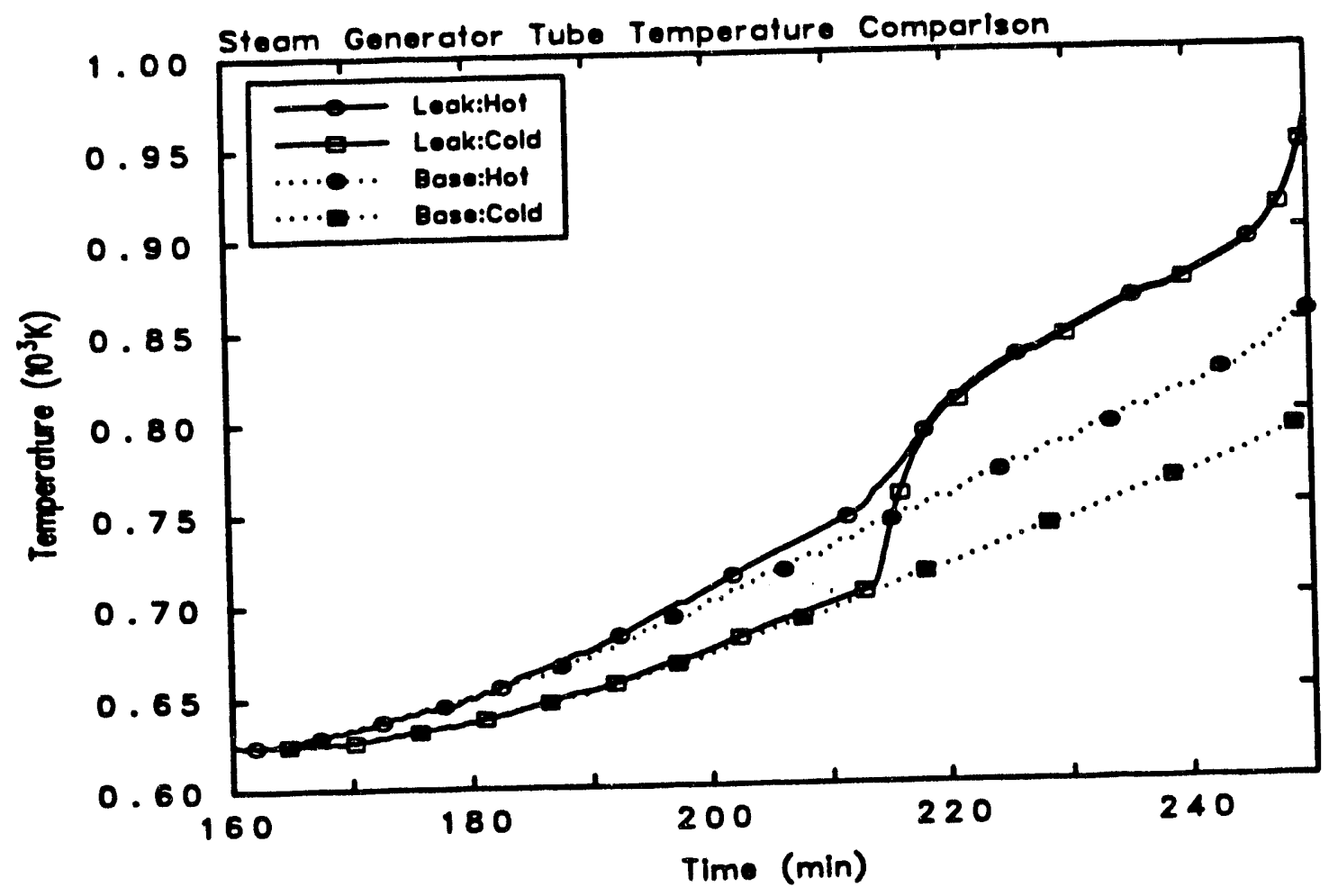

Figure 11.2.15 Effect of the pump seal leak on the steam generator tube temperatures. 
A comparison of the vulnerable structural components in the RCS is shown as a summary in Figure 11.2.16. The major differences from the basecase natural circulation results are: (1) the surge line was considerably cooler, and (2) the steam generator tubes were hotter. Table 11.2.1 compares the structural component temperatures at the time of RCS failure of the basecase (249.7 minutes).

TABLE 11.2 .1 COMPARISON OF COMPONENT TEMPERATURES (K) AT 249.7 MINUTES

\begin{tabular}{lcc}
\hline Component & Basecase & Pump Seal Leak Scenario \\
UP Internals & 1700 & 1343 \\
Hot Leg & 1212 & 1278 \\
Surge Line & 1219 & 743 \\
Stm Gen Tubes & 855 & 950 \\
\hline
\end{tabular}

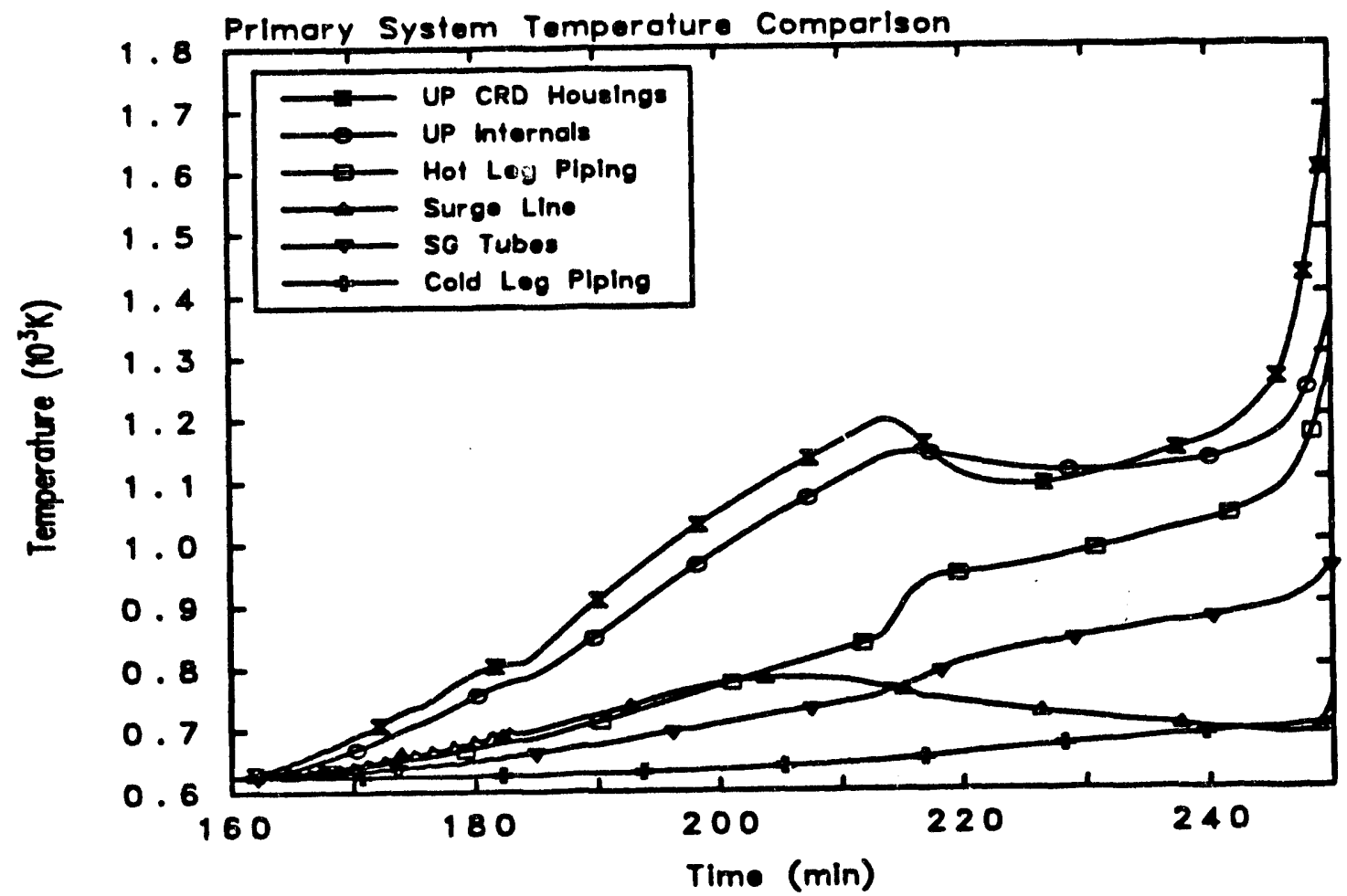

Figure 11.2.16 Comparison of critical component temperature histories for the MELCOR pump seal leak calculation. 
The steam generator tubes were hotter by $100 \mathrm{~K}$ and the surge line was cooler by over $475 \mathrm{~K}$ in the S3-TMLB' simulation. The hot leg was $66 \mathrm{~K}$ hotter at the same time. These temperatures do not necessarily indicate failure of the hot leg sooner for the S3-TMLB' scenario than the basecase. The failure is dependent not only on temperature, but also pressure and length of time at those conditions [28]. Since the pressure at this time is on the order of $7 \mathrm{MPa}$, the components may be capable of withstanding higher temperatures before creep rupture failure would occur. The possible failure of the Inconel steam generator tubes may be of greater concern, however, since the thin Inconel tubes probably cannot withstand as high a temperature before failure as the thick stainless steel hot leg pipe. The capability to calculate mechanical failure of structures was not included in these MELCOR calculations, although it could be incorporated by the use of control functions. Therefore, a secondary analysis based on the MELCOR-calculated pressure and temperature histories of the hot leg and steam generator tubes, which are significantly hotter than the basecase, is necessary to predict the failure time for full coolant loop flow under pump seal leak conditions. This analysis, however, did show that the hot leg or steam generator tubes will fail first, well before the surge line.

\subsection{Limitations of the Pump Seal Leak MELCOR Analysis}

Several limitations existed in this analysis which are worthy of mention. The intent was to merely show the differences in expected results from the natural circulation calculations emphasized in the MELCOR and SCDAP/RELAP5 analyses rather than complete a best estimate calculation of the pump seal leak scenario.

First of all, the same oxidation energy assumptions were used in this analysis as for the basecase. These assumptions do not represent the real situation. The beginning of significant oxidation, and consequently the addition of energy to the core depends on the surface temperature history of the fuel rods and the steam flow. Since the MELCOR model did not include detailed core modeling, the actual timing and extent of oxidation could not be modeled accurately. As Figure 11.3.1 shows, the fuel rod surface temperature history at a typical rod near the center of the core was quite different after full coolant flow developed. The rods transferred more heat to the fluid which was carried from the vessel to the other components in the RCS. Therefore, the large increase in oxidation energy, which started at approximately 240 minutes, would actually be delayed. The piping components, then, will inevitably heat up more slowly than shown by this calculation. 
Secondly, the SCDAP/RELAP5 model upon which the MELCOR basecase was built, assumed very large loss coefficients in the split hot leg and steam generator piping components, presumably to match the low pressure Westinghouse data and COMMIX results. The justification of this choice has already been questioned considerably. However, the question concerning this analysis that must be raised is: Are these same high loss coefficients applicable to full coolant loop flow? They were not modified in this analysis since MELCOR does not offer the capability to do so during a calculation. Typically, RCS coolant thermal/hydraulic analyses done with MELCOR and SCDAP/RELAP5 do not use such artificial values. Determination of the correct values, therefore, requires further examination.

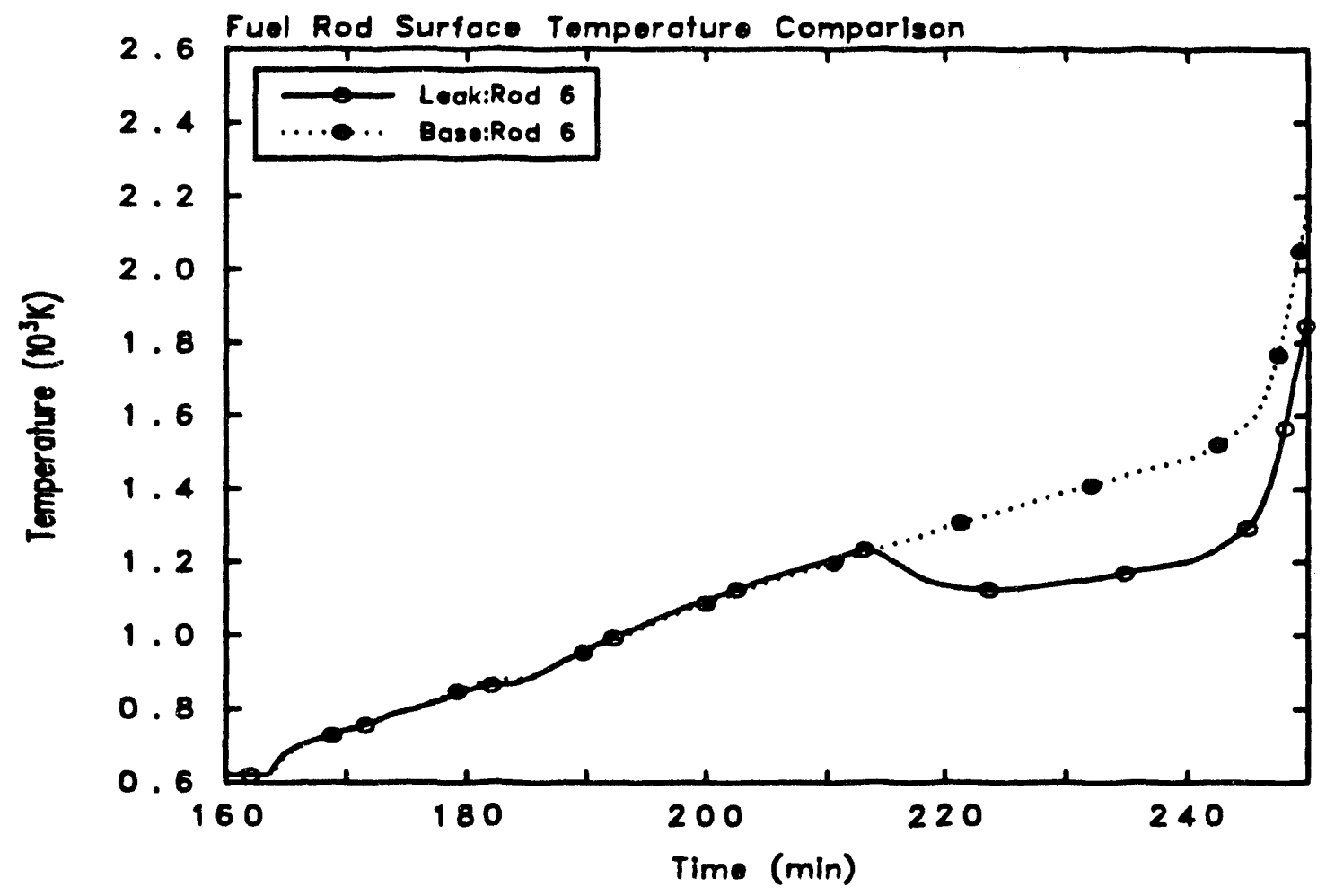

Figure 11.3.1 Effect of the pump seal leak on the MELCOR calculated fuel rod surface temperature history. 


\subsection{Summary of Findings}

An independent review of the SCDAP/RELAP5 calculations of natural circulation in the Surry Pnwer Plant during a station blackout accident has been completed. The reports describing the relevant analyses have been reviewed, including supporting analyses using the COMMIX code as well as Westinghouse data reports. In addition, other analyses have been reviewed and discussed.

The SCDAP/RELAP5 natural circulation analyses determined that primary system depressurization from natural circulation-induced primary system failure is more likely to occur than failure of the reactor vessel due to severe core damage at high pressure. However, this review has indicated several modeling assumptions, code limitations, and analysis uncertainties of the SCDAP/RELAP5 calculations. These uncertainties were grouped into two main categories: (1) core modeling issues and (2) hot $1 \mathrm{eg} /$ steam generator countercurrent flow modeling issues. Further, the results of this review indicated that the two key parameters which determine the system response and ultimate failure time and location, are: (1) the hot leg inlet vapor temperature history and (2) the mass flow rate in the hot $1 \mathrm{eg} / \mathrm{steam}$ generator countercurrent flow loop. Accurate calculation, then, of these parameters determines the heat transfer and hydraulic characteristics as well as the system response.

The major uncertainties of the SCDAP/RELAP5 analysis were grouped in terms of primarily influencing one of these two parameters. The intent of the MELCOR code calculations was to assess these uncertainties and determine how the key parameters were affected. The MELCOR model was first adjusted to best match the results of the SCDAP/RELAP5 analysis. The model used the same geometrical flow area assumptions of the SCDAP/RELAP5 model as a basecase. Then, sensitivity studies were performed on various modeling parameters presumed to affect the two key parameters. The complicated core modeling details were not addressed in these analyses. The inlet vapor temperature history resulting from the complex core oxidation, degradation, and relocation processes was the major focus, and was examined in the MELCOR sensitivity studies by varying the decay heat and oxidation energy developed in the core of the reactor vessel. The effect of hydrogen generation during oxidation was also considered on a separate effects basis. The hot leg/steam generator flow rate modeling was assessed by (1) varying loss coefficients, (2) including radial conduction modeling between the top and bottom halves of the split hot leg pipe model, (3) modeling heat and mass transfer between the split hot leg countercurrent flows, and (4) modeling total loop circulation which would occur if the pump seals leaked.

The major findings of these calculations that were previously described in Section 9 will be summarized below. It is worthwhile to 
view these findings in light of the MELCOR model limitations. These include:

1. The MELCOR model did not simulate core oxidation and degradation processes in detail. In particular, the oxidation heating was not coupled to the fue 1 rod temperature history. A best estimate of the oxidation heating, probably conservative, was used in the calculations.

2. The hot leg/steam generator countercurrent flow model assumptions were taken from the SCDAP/RELAP5 model direct1y.

3. Modeling of water draining from the pressurizer was neglected.

4. Oxidation of upper plenum structures was not modeled.

Note that assumptions (1) and (3) above are not MELCOR code limitations. These input modeling assumptions were chosen to perform these calculations in a timely manner.

The MELCOR basecase calculation compared well with the SCDAP/RELAP5 results despite the model simplifications used. The predicted fallure time of the surge line was within 3.4 minutes of the the SCDAP/RELAP5 results.

The results of the sensitivity studies are summarized in Table 12.0.1. As shown in the table, the decay heat and oxidation variations had the largest impact on the timing of results. Variations of $25 \%$ in decay heat shifted the failure time within 20 to 25 minutes of the basecase results. In most of these cases the failure location was the surge line. The no oxidation heating case, however, predicted failure in the hot leg to occur first. Case 11, the hydrogen addition case, only showed the effect of steam and hydrogen mixture properties due to hydrogen production during the oxidation transient on the course of the scenario. Possible hydrogen stratification within various regions of the RCS could not be simulated with MELCOR.

The results were relatively insensitive to large variations in hot leg flow rate in the studies in which the flow loss coefficients were varied by orders of magnitude. The major limitation of this study was that the effect of steam generator inlet plenum mixing versus hot leg flow rate was not known and assumed to be unaffected. The failure location changed from the surge line to hot leg for the higher flow rate cases. The studies designed to more realistically model the split hot leg countercurrent flow phenomena by including radial conduction in the hot leg pipe and heat and mass transfer between the 


\section{TABLE 12.0.1 SUMGYRY OF MELCOR SENSITIVITY STUDY RESULTS}

\begin{tabular}{|c|c|c|c|}
\hline$\underline{\text { Case }}$ & Description & $\begin{array}{l}\text { e Time (min) } \\
\text { ve to Basecase }\end{array}$ & $\begin{array}{l}\text { Fallure } \\
\text { Location }\end{array}$ \\
\hline 1 & $-25 \%$ Decay Heat & +5.2 & Surge Line \\
\hline 2 & $-10 \%$ Decay Heat & +2.0 & Surge Line \\
\hline 3 & $+10 \%$ Decay Heat & -1.2 & Surge Line \\
\hline 4 & $+25 \%$ Decay Heat & -4.2 & Surge Line \\
\hline 5 & $\begin{array}{l}-25 \% \text { Decay Heat with } \\
\text { oxidation Offset }\end{array}$ & +23.5 & Surge Line \\
\hline 6 & $\begin{array}{l}-10 \% \text { Decay Heat with } \\
\text { Oxidation Offset }\end{array}$ & +9.1 & Surge Line \\
\hline 7 & $\begin{array}{l}+10 \% \text { Decay Heat with } \\
\text { Oxidation Offset }\end{array}$ & -8.0 & Surge Line \\
\hline 8 & $\begin{array}{l}+25 \% \text { Decay Heat with } \\
\text { oxidation offset }\end{array}$ & -20.4 & Surge LIne \\
\hline 9 & No Oxidation Heating & +28.0 & Hot Leg \\
\hline 10 & Double Oxidation Heating & -2.6 & Surge Line \\
\hline 11 & Hydrogen Addition & -1.8 & Surge Line \\
\hline 12 & Highest Flow Rate & -3.7 & Hot Leg \\
\hline 13 & 2nd Highest Flow Rate & -0.2 & Hot Leg \\
\hline 14 & 3rd Highest Flow Rate & 0.0 & Surge Line \\
\hline 15 & Lowest Flow Rate & -2.4 & Surge Line \\
\hline 16 & Radial Hot Leg Pipe Conduction & 0.0 & Surge Line \\
\hline 17 & $\begin{array}{l}\text { Heat Transfer Between Hot Leg } \\
\text { Countercurrent Flows }\end{array}$ & +0.2 & Surge Line \\
\hline 18 & $\begin{array}{l}\text { High Mixing Between Hot Leg } \\
\text { Countercurrent Flows }\end{array}$ & -10.7 & Hot Leg \\
\hline 19 & $\begin{array}{l}\text { Medium Mixing Between Hot Leg } \\
\text { Countercurrent Flows }\end{array}$ & -1.7 & Hot Leg \\
\hline
\end{tabular}


countercurrent flows had negligible effects also. Note, however, that adequate treatment of mixing between countercurrent flow streams is not available in lumped volume analysis codes 1ike SCDAP/RELAP5 and MELCOR .

A simple model of the steam generator buoyancy driven thermosyphon loop was also developed. The intent of this model was twofold: (1) to provide an independent investigation of the relation between steam temperatures in the inlet plenum and the steam generator circulation rate, and (2) to provide a computationally efficient model to study the effects of the two key parameters. Again the heat rate was varied to assess the effect of inlet temperature history on the system behavior. The parameters affecting the developing mass flow circulation rate that were examined were (1) steam generator inlet plenum mixing modeling, (2) ratio of forward to backward flowing steam generator tubes, (3) hot leg to steam generator flow rate ratio, and (4) loss coefficients. In addition, the influence of heat transfer to the secondary side of the steam generator was addressed.

The base simple model calculation shed more uncertainty on the SCDAP/RELAP5 results. The flow rate in the steam generator tubes predicted by the simple model was in agreement with the SCDAP/RELAP5 results; however, the heat transfer to the secondary side of the steam generator tubes was not well reproduced. COMMIX-predicted mass flow rates and heat transfer characteristics were never duplicated with this model even when adiabatic conditions to the secondary side, as assumed in the COMMIX analysis, were simulated.

The sensitivity studies performed with the simple model indicated that the parameters which most affect the circulation rate in the steam generator tubes are:

1. Heating rate of the fluid entering the steam generator tubes which is also a function of the decay heat and heat transfer to the hot leg pipe.

2. Effect of secondary side heat transfer. With less heat transfer to the secondary $s$ de, the circulation flow rate decreased.

3. Increasing the flow loss coefficients in the circulation loop decreased the developed flow rate.

The flow rate and heat transfer characteristics were relatively insensitive to the assumed mixing fraction in the inlet plena of the steam generators, the ratio between hot 1 eg and steam generator flow rates, and the ratio of tubes carrying flow from the inlet plena to outlet plena versus the tubes carrying the fluid back to the inlet plena (for ratios greater than 0.5 ). The SCDAP/RELAP5 analysis showed 
similar insensitivity of results to the inlet plenum mixing fraction variations as documented in Reference 2.

Lastly, the pump seal leak analysis with the MELCOR code examined the expected changes if full coolant loop flow was reestablished in the Surry RCS. If the pump seals cleared by damaged seals when the water reached saturation temperatures, the system began a slow depressurization. Full loop flow was established and resulted in a larger circulation flow rate than in the natural circulation case. The surge line was cooled considerably in this scenario since flow of hot gases to the PORV was eliminated by the pressure relief through the leak. The surge line, in this case, was not the vulnerable component. The hot leg response was similar to the natural circulation results and was the hottest component during the transient. The steam generator tubes, however, were heated 50 to 100 $\mathrm{K}$ higher than in the natural circulation cases. The tubes became much more vulnerable in this scenario. If the tubes were the first to fail, possible fission product release to the secondary side and eventually the environment could result. 


\subsection{Applicability of Results and Analyses to Full-Scale Plants}

The limitations and uncertainties regarding each of the analyses, from the SCDAP/RELAP5 analysis to the Westinghouse $1 / 7$ th scale experiments have been enumerated in each relevant section. In this section, we wish to combine some of these discussions to determine the applicability of the results to the full-scale TMLB' accident. Also, issues which have not yet been discussed will be raised.

First, the SCDAP/RELAP5 analysis relied on data obtained from the COMMIX analysis which in turn relied to a point on data obtained from the Westinghouse low pressure experiments. The limitations of the low pressure data to the full-scale TMLB' accident scenario under study, and there are some major ones, have already been pointed out. It is this data that serves as a foundation for the other calculations. In addition the MELCOR study presented in this report relied on the SCDAP/RELAP5 study, especially in the area of flows in the hot leg and steam generator.

Second, both SCDAP/RELAP5 and MELCOR create what are basically zero dimensional models. A true continuum model of the Surry plant that adhered to strict Courant limits would require a three-dimensional finite-difference or finite-element model composed of at least tens of thousands of nodes. The fact that these codes rely heavily on empiricism is emphasized by the use of friction factors for fluids phenomena and heat transfer coefficients for heat transfer phenomena. True dimensional constructs do not require such artifacts but are not feasible for many nuclear reactor safety analyses.

In various reports, investigators have attempted to quantify the ability of SCDAP/RELAP5 and MELCOR to model certain phenomena. There are two important characteristics of all codes that cannot be quantified. First, the model must contain all of the pertinent physics models. For the wide range of phenomena that SCDAP/RELAP5 and MELCOR are expected to model, this is a difficult task. Unknown, poorly understood, or CPU intensive models of certain events may not be included in the code, or if included, may be coded improperly due to a lack of model validation. Second, even if the model is included properly in the code, the modeler may choose not to use it, or if included, may use it improperly. Constructing a model that captures all of the pertinent physics, and yet is practical in terms of computer CPU time still must be considered an art.

Yet these models represent the state-of-the-art in performing nuclear reactor safety analyses and they do reasonable jobs in simulating many experiments. The MELCOR code did reasonably well in simulating the four phases of the TMI-2 Standard Problem, and also the HDR Standard Problem [23]. Continuing work towards improving models, efforts towards validating these codes, and advancements in computational 
resources are why they model complex experiments as well as they do. The sensitivity studies are especially useful, because even if the basecase run was not completely accurate, the importance of various phenomenon can be singled out (in general) and examined. Thus, the effect of conduction in the hot leg piping and heat/mass transfer between the countercurrent flows in the hot leg were both found to be minimal. On the other hand, th. magnitude of decay heat and oxidation rate were found to be significant.

The major failing of the analyses to date is the very weak link between well-performed experiments and the numerical work. The uncertainty of actual flow and heat transfer rates in the hot $\mathrm{leg} /$ steam generator assemblies is particularly disturbing, even though the MELCOR flow loss coefficient sensitivity study showed the results did not vary greatly when this parameter was varied. We believe that the basecase should always represent the best possible effort to model the event as closely as possible. The SCDAP/RELAP5 simulation was the best that could be done at that time, but a greatly improved effort is now possible. Our recommendations in consummating this effort are addressed in Section 14. 


\subsection{Conclusions and Recommendations}

The review summarized in this report and the analyses completed and described indicate the complexity of the natural circulation issue. Modeling techniques are under development to simulate the important physical phenomena involved in a reactor accident scenario such as the Surry high pressure boiloff transient, but require further improvement and assessment. Modeling of natural circulation regimes is very difficult for system-level computer codes, yet very expensive for detailed finite-element or finite-difference fluid dynamic codes. The simulation of the SURRY TMLB' accident scenario included both levels of analysis: system-level code analyses were completed with SCDAP/RELAP5 and MELCOR, and a finite difference single phase fluid dynamics analysis was performed with COMMIX. The use of experimental data toward benchmarking these codes is also an indispensable part of this code development and validation. Attempts were made at this also, by incorporating Westinghouse experimental data into these modeling efforts.

The uncertainties in these analyses have been emphasized several times in the course of this discussion. The SCDAP/RELAP5 analyses supported the conclusion that primary system depressurization can occur due to primary system failure induced by natural circulation. It was a very extensive analysis that was state-of-the-art for its time. Nevertheless, certain underlying modeling assumptions have been shown to place a great amount of uncertainty on the results.

First of all, the computational modeling effort to date relied on the data from the low pressure experiments, the majority of which were steady state. This was a useful exercise insofar as building geometries of the reactor assembly, running the computational model and getting a "feel" for the accuracy of the model compared to experiment. However, based on the definition outlined in this document, no low pressure baseline tests were available, while four well-executed baseline high-pressure transient tests were later performed. It is strongly recommended that the computational models be validated against results of the greatly improved high pressure test series, particularly the transient tests.

Benchmarking the SCDAP/RELAP5 and COMMIX analyses to the nonprototypic data results was the best that could be done at the time to set appropriate model parameters in the code analyses, but was definitely not an acceptable or reliable analysis technique. The simple model development described in Section 10, which independent1y analyzed the expected system response, contributes to the uncertainty of these calculations. The parameters affecting the developing flow rate in the system were dependent on the heating rate, secondary side heat transfer, and frictional losses in the piping. Neither the COMMIX nor Westinghouse experiment simulated the correct heat transfer 
and heating rate conditions, yet the SCDAP/RELAP5 model assumed that similar natural circulation flow rates and heat transfer characteristics would exist under the conditions of the TMLB' transient. A basis for these assumptions was never established and is necessary for a complete, analysis.

The SCDAP/RELAP5 uncertainties addressed by performing sensitivity studies with the MELCOR code also supported the hypothesis that primary system depressurization due to natural circulation failure of the hot leg or surge line piping could occur before debris could fail the lower head of the reactor vessel. This is not surprising, however, since the MELCOR model was benchmarked to the SCDAP/RELAP5 model. It only confirms this hypothesis if the underlying modeling technique is correct and has been shown to be consistent with all available data and information. Unfortunately, this has not yet been demonstrated.

It is highly recommended, therefore, that the following steps be taken to provide more substantial evidence to support the natural circulation depressurization scenario:

1. Model the high pressure transient Westinghouse experiments with the SCDAP/RELAP5 code. Adjust flow and heat transfer parameters appropriately.

2. Scale the model to the full-scale Surry reactor plant and adjust empirical coefficients determined from (1) to the full-scale conditions as necessary.

3. Recalculate the Surry TMLB' scenario of natural circulation in the primary system vessel and hot leg coolant loop when the loop seals are blocked.

4. Apply the revised model to full loop circulation as well, such as the pump seal leak scenario previously modeled with the MELPROG and MELCOR codes.

Completing this step-by-step analysis which incorporates as much consistency as possible will aid in determining whether the results of these studies completed with the SCDAP/RELAP5 and MELCOR codes are still applicable. If the results are consistent, confidence in these analyses can be justified and the conclusions reached by the MELCOR analysis presented in this report can be believed and used as complementary results to the SCDAP/RELAP5 analyses [2].

Furthermore, analyses concerning the uncertainties not examined by this report should then be investigated. These include core degradation modeling uncertainties and effects of fission product transport during the transient. Other effects, such as hydrogen 
stratification also must be addressed by experiments and more detailed finite element or finite difference code techniques. 


\section{REFERENCES}

1. Silberberg, M., Mitche11, J.A., Meyer, R.0., and Ryder, C.P., Reassessment of the Technical Bases for Estimating Source Terms, NUREG-0956, July 1986.

2. Bayless, P.D., Analyses of Natural Circulation During a Surry Station Blackout Using SCDAP/RELAP5, NUREG/CR-5214, EGG-2547, EG\&G Idaho, Inc., Idaho Falls, ID, October 1988.

3. Domanus, H.M. and W.T. Sha, Analysis of Natural-Convection Phenomena in a 3-Loop PWR During a TMLB' Transient Using the COMMIX Code, NUREG/CR-5070, ANL-87-54, Argonne rational Laboratory, Argonne, IL, January 1988.

4. Stewart, W.A., A.T. Pieczynski and V. Srinivas, "Experiments on Natural Circulation Flows in Steam Generators during Severe Accidents," Proceedings of International ANS/ENS Topical meeting on Thermal Reactor Safety, pp. XIX.6-1 - XIX.6-8, San Diego, CA, February 2-6, 1986.

5. T.C. Cheng et al., "RELAP5/SCDAP - An Integrated Code for Severe Accident Analysis," Proceedings of the Thirteenth Water Reactor Safety Research Information Meeting, NUREG/CP-0072, pp. 347-355, Gaithersburg, MD, October 22-25, 1985.

6. Stewart, W.A., A.T. Pieczynski and V. Srinivas, "Experiments on Natural Circulation Flow in a Scale Model PWR Reactor System During Postulated Degraded Core Accidents," Proceedings of the 3rd International Topical Meeting on Reactor Thermal Hydraulics, Newport, RI, October 15-18, 1985.

7. Sehgal, B.R., W. Stewart and W. Sha, "Experiments on Natural Circulation During PWR Severe Accidents and their Analysis," Presented at International ENS/ANS Topical Meeting on Thermal Reactor Safety, Avignon, France, October 2-7, 1988.

8. Dallman, R.J., INEL, Letter to J.T. Han, NRC, "COMMIX Natural. Circulation Calculations," November 25, 1986.

9. T.J. Heames and R.C. Smith, "Integrated MELPROG/TRAC Analyses of a PWR Station Blackout," Nuclear Engineering and Design, 125, Elsevier Science Publishers B.V. (North-Holland), (1991), pp. $175-188$.

10. Kelly, J.E., SNL, Memo to W.J. Camp, SNL, "SCDAP Assessment," February 15, 1985.

11. Tomkins, J.L., SNL, Letter to J. T. Han, NRC, "A Comparison of SCDAP/RELAP5 and MELPROG/TRAC," December 9, 1988. 
12. Kelly, J..E., Henninger, R. J., Dearing, J. F., "MELPROG-PWR/MOD1 Analysis of a TLMB" Accident Sequence," NUREG/CR-4742, SAND862175, Sandia National Laboratories, Albuquerque, NM, January 1987.

13. Chung, B.D., S.Y. Lee, and J.S. Kim, "Station Blackout Accident for the Korea Nuclear Unit 1 Using RELAP5/MOD1," Proceedings of the ANS Topical Meeting on Anticipated and Abnormal Plant Transients in Light Water Reactors, Volume 1, Jackson, WY, September 26-29, 1983 .

14. P. D. Bayless, C.A. Dobbe, and R. Chambers, Feedwater Transient and Smal1 Break Loss of Coolant Accident Analyses for the Bellefonte Nuclear Plant, NUREG/CR-4741, EGG-2471, EG\&G Idaho, Inc., Idaho Falls, ID, March 1987.

15. Dosanjh, S.S., Me1t Progression, Oxidation, and Natural Convection in a Severely Damaged Reactor Core, NUREG/CR-5316, SAND88-3476, Sandia National Laboratories, Albuquerque, NM, February 1990.

16. Domanus, H.M., R.C. Schmitt, W.T. Sha, V.L. Shah and J.T. Han, "Natural Convection Phenomena in a Nuclear Power Plant During a Postulated TMLB' Accident," Presented at Symposium on Heat and Mass Transfer, Univ. of Illinois at Urbana-Champaign, October 1$2,1987$.

17. Larson, T.K. and G.G. Loomis, "Semiscale Program: A Review of MOD-2 Results," Nuclear Safety. Vo1.29, No.2, (April-June 1988).

18. Surry Power Station Final Safety Analysis Report (FSAR)", Vol. 1. 2 , and 3 , Virginia Electric and Power Company (VEPCO), December 1969 .

19. H.M. Domanus, R.C. Schmitt, W.T. Sha and V.L. Shah, Analysis of Natural Convection Phenomenon During Postulated Station Blackout Transient Accident, ATHRP-30, (January 1987).

20. Stewart, W.A., et. a1., Experiments on Natural Circulation in a Pressurized Water Reactor Model for Degraded Core Accidents, EPRI Project Number RP2177-5 Final Report, EPRI, Palo Alto, CA.

21. Stewart, W.A., et. al., "Experiments on Natural Circulation in a Pressurized Water Reactor Model with High Pressure $\mathrm{SF}_{6}$," preliminary draft report, EPRI, Palo Alto, CA, 1990.

22. Panton, R. L., Incompressible Flow, (John Wiley \& Sons, New York, 1984), p. 241.

23. Summers, R.M. et a1., MELCOR 1.8.0: A Computer Code for Nuclear Reactor Severe Accident Source Term and Risk Assessment Analyses, NUREG/CR-5531, SAND90-0364, Sandia National Laboratories, Albuquerque, NM, January 1991. 
24. J.A. Gieseke et a1., Source Term Code Package-A User's Guide (Mod1), NUREG/CR-4587,BMI-2138, Batte1le Columbus Division, Columbus, $\mathrm{OH}$, July 1986.

25. L.N. Kmetyk, "MELCOR PWR Demo", Presentation and handout given at the Fourth MELCOR Peer Review Committee Meeting, March 4-6, 1991, Sandia National Laboratories, Albuquerque, NM.

26. A.G. Croff, A Users Manual for the ORIGEN2 Computer Code, ORNL TM-7175, Oak Ridge National Laboratory, Oak Ridge, TN, July 1985.

27. American Nuclear Society Standards Committee Working Group ANS5.1, American National Standard for Decay Heat Power in Light Water Reactors, ANSI/ANS-5.1-1979, American Nuclear Society, La Grange Park, IL, 1979.

28. F.T. Harper et al., Evaluation of Severe Accident Risks: Quantification of Major Input Parameters, Vo1. 2, Rev. 1. Part 1 , NUREG/CR-4551, SAND86-1309, Sandia National Laboratories, Albuquerque, NM, December 1990.

29. H.S. Carslaw, and J.C. Jaeger, Conduction of Heat in Solids, (Oxford Press, Oxford, 1978, 2nd Ed.), p. 394.

30. R. Henninger, J.F. Dearing, and J.E. Kelly, "Integrated MELPROG/TRAC Analyses of a PWR Station Blackout," Proceedings of the AIChE Heat Transfer Symposium, No. 257, Vol. 83, Pittsburgh, PA, 1987.

31. A.L. Camp, Prg. Manager, Analysis of Core Damage Frequency: Expert and Internal Judgement Elicitation of Internal Events Issues, Vol. 2, NUREG/CR-4550, SAND86-2084, Sandia National Laboratories, Albuquerque, NM, 1988.

32. D.B. Rhodes, et al, Reactor Coolant Pump Shaft Seal Stability During Station Blackout, NUREG/CR-4821, EGG-2492, EG\&G Idaho, Inc., Idaho Falls, ID, 1987. 
APPENDIX A

Literature Review

$A-1$ 
$A-2$ 


\section{APPENDIX A}

\section{LITERATURE REVIEW}

In an attempt to provide an overview of the work that has been done in the area of natural circulation in reactor coolant systems, the following literature review was done. The work discussed has been grouped in terms of code analyses. Some analytical analyses and experimental results are also discussed.

\section{SCDAP/RELAP 5}

An analysis was done by Larson and Dimenna [A-1] to determine if RELAP5 preserves similitude criteria for natural circulation in a closed loop. They questioned whether phenomena observed at one scale size are a reliable representation of the phenomena expected at some other scale size. A scaling analysis was used to develop similitude criteria for: (1) defining small-scale test facility design and operation, (2) suggesting how to scale results, and (?) casting experimental results in nondimensional form so results can be used at various scales. There are three main methods used to examine scalability. This paper focused on demonstrating the ability of the code to preserve similitude criteria for simplified theoretical problems.

The analysis method was as follows. Similitude criteria were established using the work of Ishii and Kataoka [A-2]. Two different scale size models of a natural circulation loop were generated, and RELAP5 models were constructed for each. The same transient was conducted with each model and the results were examined as scaled. This procedure was then repeated adding boundary condition perturbations to examine their overall influence on the scalability of the results.

The scaled models geometrically represented a single-1oop PWR consisting of a vessel with a heat source, a single-pass, counter-flow heat exchanger, and connecting piping. The similitude criteria used were as follows. One-dimensional, area-averaged differential balance equations were written. The momentum equation was integrated around the loop to eliminate the pressure terms. The equations were nondimensionalized with respect to reference parameters in the reference component. Finally, the scaling criteria were derived by requiring dimensionless groups to be equal for the two different scale systems.

The two scaled models simulated small break, loss of coolant behavior and used the same nodalization density, model philosophy and model options. Wall heat transfer and stored energy were neglected, except in the vessel heat source and the heat exchanger. The heat source power was constant. The reference model had geometry similar to an actual PWR with pressure of $10.4 \mathrm{MPa}$, power of $64 \mathrm{MW}$ and leak size of $10 \mathrm{~cm}^{2}$. The reduced scale model was sized with $1 / 3$ the length of the 
reference model and $1 / 200$ the area. The pressure was $10.4 \mathrm{MPa}$, the power was $188 \mathrm{~kW}$ and the leak size was $2.887 \times 10^{-2} \mathrm{~cm}^{2}$.

For single-loop natural circulation, the RELAP5 code calculated qualitatively similar physical phenomena at very different geometric scales. The kinematic and dynamic relationships between the phenomena in the two different geometries were calculated to be generally as expected based on simplified similarity criteria. The model-to-model relationships in time, pressure drop, and velocity scales were in basic accordance with the similitude requirements. Areas in which scaling criteria were not appropriate for comparisons were identified, especially during periods of countercurrent flow and nonequilibrium thermodynamic conditions in the hot leg. The scale model calculations with an oversized break demonstrated the importance of maintaining consistency between the system global and the local time scales to preserve similarity of the thermohydraulic phenomena.

Chung, Lee and Kim [A-3] performed a RELAP5/MOD1 analysis of a station blackout which occurred at KNU-1 in Korea on June 9, 1981 and lasted 26 minutes. The analysis objectives were to confirm adequate core cooling as maintained by natural circulation, to establish the sequence of events, to assess the capability of RELAP5/MOD1 to predict the transient and to verify the modeling technique.

Two RELAP5 cases were performed. Case 1 involved decay heat based on infinitely long operation time, while Case 2 used $50 \%$ of the decay heat of Case 1. The analysis resulted in Case 2 yielding the more realistic simulation. Natural circulation in the loop was fully developed approximately 400 seconds into the transient. Adequate core cooling and removal of decay heat followed the establishment of natural circulation. The steam generator relief valves opened only in Case 1. The auxiliary feedwater supply was more than sufficient to remove the decay heat in Case 2, and the steam generator pressure decreased continuously. It was concluded that RELAP5 adequately predicted the transient.

\section{MELPROG}

In addition to SCDAP/RELAP5 and COMMIX, another code which has been used extensively on natural circulation/TMLB' scenarios is MELPROG. Williams and Kelly [A-4] presented results for a base case TMLB' accident and additional sensitivity cases. Each of the additional cases had a change in a key variable from the conditions of the base case. The variables were: nodalization (varied from 65 to 176 mesh cells), radial core power distribution (a flat radial core profile was used), and hydraulic resistance ( $K$ axial doubled and $K$ radial increased 1.5 times). They concluded that natural circulation is insensitive to variations in these key uncertainties. It is felt that this insensitivity can be attributed to the flow being driven by large-scale bulk conditions.

Other main insights indicated by this work include that the likely failure points after heating from natural convection flows are the hot leg welds, pressurizer surge line connections and steam generator 
tubesheet welds. The sensitivity study which applied a flat radial core power profile showed that the overall natural convective transport of energy is not influenced by the assumed core power shape. A1so, the total energy exchange process showed little sensitivity to an uncertainty in the hydraulic resistance model. A slightly increased driving density (temperature) differential was seen to compensate for the increased hydraulic resistance. Although upper plenum voiding was influenced by changes in nodalization, the natural convection behavior remained basically unchanged during the period of core uncovery and heatup. During the first 1200 seconds of core uncovery, the percentage of core energy transferred to the upper plenum structures was $20-26 \%$ for all of the cases.

Henninger, Dearing and Kelly [A-5] integrated MELPROG with TRAC in an analysis of a PWR station blackout. The integrated codes produced results which included the occurrence of both in-vessel natural circulation and loop seal clearing natural circulation. The modeled plant was the Surry three loop Westinghouse PWR. The three loops were combined into a single loop representation of the primary and a portion of the secondary cooling systems.

This study was a largely mechanistic analysis of the entire reactorcoolant system during a TMLB' accident. The calculations were initiated at the start of the transient and continued through a late recovery of cooling. This included a loss of feedwater and disruption and relocation of the core. It was indicated that the primary relief valve action did little to disturb flow and that the hot leg reached failure temperature long before vessel failure. Vessel failure was predicted to occur 14,700 seconds into the transient. After the core debris had boiled off the water in the lower plenum, natural convection flow around the loop was initiated by removing the water in the loop seal. This resulted in an increased flow accompanied by a large amount of energy removal $(1,500 \mathrm{MJ})$ from the gas to the steam generators. The SG-tubes increased in temperature from 650 to $800 \mathrm{~K}$. Approximately 100 seconds after the seal had cleared, the mixture of steam and hydrogen had such a low density at the top of the SG-tubes that it no longer could act as the driving force and the flow around the loop ended. The authors concluded that although the potential for removing large amounts of energy by loop flow natural circulation exists, the flow around the loop will most likely be blocked either by water in the loop seal or by the low density mixture of steam and hydrogen in the SG-tubes. This study found that the event sequence was the same with or without natural circulation, however the timings were delayed when natural circulation was modeled.

Another integrated MELPROG/TRAC study was done by Heames and Smith [A6). Again, the Surry 3-loop plant was represented by a single loop. A two dimensional MELPROG mode1 of the reactor vesse1 (with 3 core rings and 5 axial core levels) and a one dimensional TRAC model of the remainder of the coolant system were used. As neither MELPROG nor TRAC are capable of analyzing counter-current flows, hot leg countercurrent flow natural circulation was not considered. Thus surge line failure was not considered in these calculations. This work compared MELPROG/TRAC runs of a base case TMLB' scenario with a TMLB' 
accompanied by a pump seal leak scenario (S3-TMLB'). It was found that the latter extended the critical times in the event sequence and eliminated high pressure melt ejection and the chance of direct containment heating (DCH). Both the low pressure and the significant oxidation of the Zircaloy would prevent the DCH phenomena.

For these calculations, it was assumed that when the steam generator secondary side heat sink is lost, the entire RCS (including the liquid in the pumps) heats to saturation. The timing of seal failure when RCS temperature reached saturation was based on experimental data. Also, although a high probability of surge line or hot leg failure was predicted, it was assumed that these would not occur and calculations were continued through vessel failure. As an aside, it should be noted that in MELPROG the energy distribution in major structural components is calculated using actual shapes of the components and not generalized lumped mass heat structures which are used in TRAC and SCDAP.

In the two events considered, the end conditions were markedly different. The basic TMLB' resulted in high pressure vessel failure approximately four hours into the accident. The addition of a $12.5 \mathrm{~mm}$ hole in each purnp seal (S3-TMLB') caused the water in the loop seal to clear and led to lower pressure at vessel failure, which occurred ten hours into the accident. The two cases initially diverge at about 100 minutes when the seals fail. The timing of all subsequent events is severely changed from this alteration in the cold side component boundary condition. The loop seal clearance established full loop natural circulation providing enough steam cooling to arrest the core temperature excursion before serious core degradation (which occurred before 200 minutes in the basic, no loop circulation TMLB' scenario) could result. This had the effect of adding more than three hours to the time in which the reactor could be recovered if power returned or additional water sources became available for the S3-TMLB' scenario and of lowering the pressure at vessel failure from 16 to $0.27 \mathrm{MPa}$.

The sizing of the pump seal leak was based on NUREG-1150 expert opinion results. The $12.5 \mathrm{~mm}$ size, under constant operating conditions, would discharge over half of the RCS liquid in less than one hour. Flow areas of less than half the size chosen would not be expected to induce loop seal clearing. As the total fluid mass discharged from the two scenarios was the same, and in the S3-TMLB' scenario fluid was removed from the cold leg components, the TMLB' case must have removed more fluid from the hot components and vessel upper plenum.

\section{OTHER CODES}

Dosanjh [A-7] described a 2-D model of melt progression, oxidation, and natural convection in a severely damaged reactor core. Vapor (steam- $\mathrm{H}_{2}$ ), melt and the solid phase were modeled. The simulation began when the core was partially degraded, there was a significant loss of geometry, and relocation to the lower plenum had begun. Natural convection in the molten pools was neglected. Additionally, 
eutectic reactions of $\mathrm{Fe}-\mathrm{Zr}$ and $\mathrm{U}-\mathrm{Zr}-\mathrm{O}$ and $\mathrm{H}_{2}$ diffusion in steam were modeled.

The base case results included temperature and velocity gradients in the core. Natural convection was evidenced in the debris bed as were solid blockage formation effects. The natural convection was driven by radial gradients in density caused by spatial variations in temperature as well as non-uniform gas concentrations. Sensitivity cases were also run to determine the effect of changes in boundary conditions, oxidation, decay heat, pressure, particle diameter and the addition of $\mathrm{Fe}$.

Several key observations resulted from this study. The gas velocity increased rapidly at the onset of oxidation and decreased when the bed became steam starved. Natural convection flows were seen to be sensitive to radial variation in decay heat. Raising the bed and upper plenum pressure increased the amount of steam available for oxidation and led to much higher temperatures and gas velocities. A reduction in the average particle diameter decreased the permeability and lowered gas velocities. Small amounts of $\mathrm{Fe}$ were seen to significantly alter melt progression behavior due to low temperature $\mathrm{Fe}-\mathrm{Zr}$ interactions. Finally, the solutions achieved were found to be sensitive to conditions in the upper plenum.

Plys, Vanover, Paik, Asleford, Kenton, and Hammersley [A-8] used the MAAP code to examine the phenomena which control accident sequence progression and fission product release for a SBO for a large, dry containment design. The model was based on the Zion reactor. Three sensitivity cases were run to determine the effects of primary system natural circulation. These were: a base case, a seals clear case, and a PORV open case.

The base case resulted in an occurrence of in-vessel circulation after core uncovery, between overheated core nodes and the upper plenum. Counter-current flow between the upper plenum and the steam generators and the steam generator inlet plenum and outlet plenum through the steam generator tubes was also observed.

The second case assumed that either cycling of safety valves can allow clearing of the water seal in pump bowls or no water seal exists by design. The clearing allowed enhanced primary system natural circulation prior to vessel failure, affecting the distribution and revaporization of fission products. Unidirectional circulation through the hot leg, steam generator, cold leg and downcomer occurred and circulation was greater than for the base case.

It was assumed for the final case (PORV open), that operator action was taken to open pressurizer relief valves when core temperature reached $920 \mathrm{~K}$. The lower primary system pressure reduced natural circulation prior to vessel failure and limited debris dispersal outside the cavity following vessel failure. Larger releases of CsI and $\mathrm{Sr}$ were seen in the containment compared to the base case, but releases to the environment were approximately the same because long- 
term release of CsI due to revaporization dominates the ultinate release to the environment.

The conclusions of this report included that the distribution of core ciebris between the primary system and the containment has a strong influence on fission product release from debris. The seals clear case was found to have the highest in-vessel circulation, the highest average gas temperature in the primary system, the lowest mass of $\mathrm{H}_{2}$ produced and the longest time to vessel failure. After the seals clear case, in these categories, came the base case and finally the PORV open case. The base case had the highest release of fission products to the environment, and the seals clear.had the lowest.

Bieniarz and Deem [A-9] made code modifications to the Risk Management Associates, Inc. (RMA) code suite to enhance STCP predictions to include in-vessel natural circulation and long-term fission product behavior phenomena in the source term calculation. The MCT2 code, which is used to analyze fission product transport, modeled natural convection using a 1-D approximation in a lumped parameter approach. The natural convection velocity was determined, for two volumes located one above the other, from Bernoulli's equation with a buoyancy term and the ideal gas law. The volumes were assumed to be at the same pressure so the upward flow of gases must be balanced by an approximately equal downward flow. No natural circulation was modeled between the hot leg and the surge line. It was found that MCT2 could overpredict the heat transfer between control volumes by a factor of three at temperature differences of interest for vertical geometries, but much less of an overprediction resulted for horizontal geometries (like the hot leg nozzle to vessel connection). It was assumed that the overprediction would be acceptable.

The code was used to analyze a PWR-TMLB' accident scenario. Results indicated that natural circulation established a mixed gas temperature in the reactor vessel which approximated the core exit gas temperature, though flow out of the core was much less than natural circulation flow. The natural circulation caused more severe temperature gradients in the heat structures, and volatiles which condensed on the structures were more likely to revolatilize. A drastic drop in the retention of $\mathrm{CsI}$ and $\mathrm{CsOH}$ species was seen. The higher gas temperatures resulted in very little condensation onto aerosols, except during the higher flow-through periods at the beginning of the transient. Most of the removal of volatiles was by condensation onto structure walls. The basic conclusion of this work was that natural circulation flow plays an important role in the redistributing of fission products to cooler volumes.

Nourbakhsh, Lee, Chien-Hsiung and Theofanous [A-10] presented a simplified analysis to determine the order of magnitude of various effects. Then they performed simple natural circulation experiments within a partially heated porous medium.

A simple, 3-mass, lumped parameter model was developed to model the geometry and mass of a Westinghouse 4-10op plant with a pressure of 2300 psia and decay power of 42 MW. Each mass was characterized by a 
uniform temperature, and the fluid leaving the mass was assumed to be in thermal equilibrium with it. The coolant flow was controlled by the permeability and the available heat due to temperature and density differences. Two cases were run. Case 1 simulated loop circulation and assumed that the loop seals cleared and opened a flow path. Case 2 modeled in-vessel recirculation for cases where the loop seals do not clear. From these scoping studies, it was concluded that primary system boundary failure prior to core melting and slumping is expected. It was noted that the effects of clad ballooning, oxidation, melting, and relocation could alter the predictions.

For experimental illustration, a numerical model was developed and validated against Purdue's Large Scale Debris Bed Coolability Simulation Facility. The model was a distributed parameter model where the adiabatic vessel was modeled as being occupied by a porous medium with only the core portion heated. Friction was governed by Darcy's law and the density variations were handled in a Boussinesq approximation. The model and the experiment showed good agreement and had results similar to the 3 -mass model.

It was concluded that high pressure steam natural circulation phenomena was responsible for redistributing core decay power to all the primary system components accessible to form circulating loops with the core region. The RCS boundary was expected to fail prior to core melting.

\section{GENERAL REVIEW}

A general review of the work that has been done on natural circulation was presented by Berta, Boyack and Wilson [A-11]. The paper divided the natural circulation work into two periods of interest: pre-1986 and post-1986. Several experiments and results were 1 isted and a comparison was made of how TRAC and RELAP5 model single phase, double phase and reflux natural circulation. The authors stated that new research reconfirms the conclusion that natural circulation is a viable means of heat removal. Additionally, the new research was said to complete the acquisition of an appropriate experimental data base and the development of system codes to permit the design of valid plant recovery procedures. It was also concluded that both TRAC and RELAP5 produce reflux condensation, however, the fidelity to the test data is generally less for this mode than for the other two. This decrease in simulation quality was believed to be strongly associated with the degree of detail used in modeling the SG-tubes.

\section{EXPERIMENTATION}

Experiments on natural circulation flow in a scale model PWR reactor during postulated accidents were presented by Stewart, Pieczynski and Srinivas (at Westinghouse Electric Corporation) in two papers [A-12 and A-13]. The main objectives of the first paper were to determine the flow distribution and natural circulation velocities in the core and upper plenum and to characterize the effect of forced flow from water boiling in the core and the stratified flow from the hot legs to the steam generators. Similitude was discussed based on flow 
resistances, Reynolds number versus geometry, heat transfer and time scale. It was concluded that $\mathrm{SF}_{6}$ at a pressure of 1 atm gives values for the $R e$ and $G r$ numbers similar to those for liquid water but different from those for high pressure steam.

The geometry of the experimental apparatus was a half section of a $1 / 7$ scale reactor vessel (modeled after the Indian Point II plant). The model had an acrylic front and a core composed of 193 fuel assemblies each modeled by a single $1 / 2$ inch diameter tube. Power equaled $35 \mathrm{KW}$ with radial distributions of $114 \%, 80 \%$ and $55 \%$. The lower plenum was not completely modeled but fluid could be added to somewhat simulate steaming upflow in the core. The upper plenum structure housed $1 / 7$ scale control rod guide tubes and support columns which were cooled. The upper head contained cooled tubes to model the guide tube flow path between the upper plenum and the upper head. The steam generator was not to scale but was cooled to duplicate the thermal storage capacity equivalent to the prototype tube bundle and other internal structures. The two hot legs were composed of glass. One hot leg included a valve to simulate the surge line tee.

Most of the experiments conducted were steady state and included the heating of the core and the cooling of the control rod tubes, the upper plenum wall, the upper head and the steam generator. Eleven water tests and nine $S_{6}$ tests were run. The following were varied: the blocking of hot legs, the cooling rates in steam generator, the cooling of the upper head, steaming upflow and the rate of core heating.

A large amount of upper plenum mixing was observed. The Reynold's number seemed to have minimal influence on the core loss coefficient. The hot leg flows were well stratified, displaying a sloping interface and little mixing. Additionally, the simulated steaming upflow caused the core recirculation zone to move upward. Perhaps the most important conclusion was that all similitude requirements were not met.

The second of these Westinghouse sets of experiments set out to properly model flow behavior in the experimental apparatus regarding hot leg flow, steam generator bundle flow and inlet plenum mixing. It was assumed that the loop seals would never clear, so the cold leg was not modeled. Also, the fraction of mixed flow entering the steam generator tubes from the SG-plenum was assumed to equal the mixed flow entering the SG-plenum from the SG-tubes.

The test apparatus was composed of 49 acrylic tubes. The number of active tubes was variable and the outside of the tubes was cooled by chilled water or air. The bundle flow was selected to be two times higher than laminar flow in a scaled 3260 tube generator. Again, water or $\mathrm{SF}_{6}$ at $1 \mathrm{~atm}$. pressure was the working fluid.

The experimental results showed a stratified hot leg flow with a small amount of mixing at the interface near the pipe ends. Some heat exchange did take place between the hot and cold streams. Initially fewer steam generator tubes were needed to dissipate heat. As the 
tubes heated up, mole were needed. Seventy percent of the returning tube flow to the steam generator inlet plenum mixed before returning to the vessel through the bottom of the hot leg. Less than $1 / 4$ of the tubes were seen to carry flow from the inlet plenum to the outlet plenum. It was concluded that recirculation single phase flow rapidly develops in the steam generator.

Sehgal, Stewart and Sha presented a third paper on the Westinghouse experiments [A-14]. In addition to the objectives discussed for the previous two papers, this paper studied the effect of rapid PORV venting on natural circulation, the effect of $\mathrm{H}_{2}$ generation, and the effect of core blockage due to the debris bed. The experimental conditions for these additional objectives were achieved as follows. The venting was done in single and periodic cycles. The $\mathrm{H}_{2}$ generation was simulated by rapidly withdrawing $\mathrm{SF}_{6}$ and injecting $\mathrm{H}_{2}$ for an exchange of $40 \%$. Beds of spheres were used to block the center of fuel assemblies to simulate core blockage.

The single venting resulted in hot upflow in the core periphery next to the hot leg with the vent. The original flow pattern reestablished soon after the vent closed and very little temperature change was seen away from the hot leg. Periodic venting caused the steam generator heat transfer to increase by $50-75 \%$ since a forced alternating flow through the tube bundle and the plena was produced.. The $\mathrm{H}_{2}$ tests caused a temporary stratification in the upper plenum. The $\mathrm{H}_{2}$ mixed quickly and the natural circulation flow fields reestablished quickly. Core blockages affected only local temperatures.

COMMIX version 1 -A was used as a comparison to the above experimental results. The steady state velocities and temparatures compared quite well. Venting calculations predicted higher steam generator heat removal than was seen experimentally. Blockage calculations were in reasonably good agreement with the temperature data.

Creep rupture failure of the hot leg nozzle during a TMLB' accident was studied by Harris, Shah and Korth [A-15]. Using stress theory applications they determined that the hot leg is likely to fail before the vessel lower head. This would lead to a low pressure accident. Design curves showed that the rupture time is very dependent on temperature. The critical time or permissible duration of loading at a given temperature is decreased considerably if temperatures are increased even slightly. Also, if high primary stresses are present, the components will fail by creep rupture at temperatures much lower than the melting temperatures. Therefore, an accurate thermal analysis is required to accurately predict rupture times.

An analytical method based on the application of the Larson-Miller parameter was used to determine the creep rupture time. Uniaxial creep rupture material properties were used to predict multiaxial creep rupture behavior. Also, stresses were approximated using thin shell theory and the dimensions of the nozzle tip near the safe end.

Creep rupture testing was performed to obtain the creep rupture material properties of A-508, Class 2 carbon steel at high 
temperatures. The authors warn that aging effects (prior creep damage) and consideration of weldment creep rupture properties have been neglected in this study and that their consideration could decrease the rupture time. Additionally, it was assumed that the rupture times would not be strongly affected by the difference in oxidation of the nozzle in air and the reactor steam environment.

The size of the rupture must be considered important as the leakage rate may not be sufficient to reduce the pressure significantly in the vessel. A sensitivity analysis showed that altering the temperature history or the creep rupture properties (within reasonable limits) had little effect on the order of rupture seen.

Results of the MOD-2, Semiscale experimental program were reported by Larson and Loomis [A-16]. It is pointed out that the results should not be directly extrapolated to PWR scale because of recognized compromises in the scaling of small experimental facilities and other small-scale system effects. In this work they found that although timing may be in error due to scaling distortions such as heat loss and primary to secondary heat transfer, the severe consequences of a power loss (core rod heatup) should occur on the order of 10,000 seconds following power loss in a PWR. 


\section{REFERENCES}

A-1 Larson, T.K. and R.A. Dimenna, "Preservation of Natural Circulation Similarity Criteria in Mathematical Models," NuclearScience and Engineering: Volume 100, pp. 21-32, (1988).

A-2 Ishii, M. and I. Kataoka, "Similarity Analysis and Scaling Criteria for LWRs Under Single-Phase and Two-Phase Natural Circulation," NUREG/CR-3267, ANL-83-32, Argonne National Laboratory, Argonne, IL, 1983.

A-3 Chung, B.D., S.Y. Lee, and J.S. Kin, "Station Blackout Accident for the Korea Nuclear Unit 1 Using RELAP5/MOD1," Proceedings of the ANS Topical Meeting on Anticipated and Abnormal Plant Transients in Light Water Reactors, Volume 1, Jackson, WY, September 26-29, 1983.

A-4 Williams, K.A. and J.E. Kelly, "Sensitivity Studies on MELPROGPWR/MOD1 Calculated Core Uncovery, Heatup, and Natural Convection during Severe Accidents," Draft Report, February 1987.

A-5 Henninger, R., J.F. Dearing and J.E. Kelly, "Integrated MELPROG/TRAC Analyses of a PWR Station Blackout," Proceedings of the AIChE Heat Transfer Symposium, No. 257, Vo1. 83, Pittsburgh, PA, 1987.

A-6 Heames, T.J. and R.C. Smith, "Integrated MELPROG/TRAC Analyses of a PWR Station Blackout," Nuclear Engineering and Design, 125 , Elsevier Science Publishers B.V. (North-Holland), (1991), pp. $175-188$.

A-7 Dosanjh, S.S., Me1t Progression, Oxidation, and Natural Convection in a Severely Damaged Reactor Core, NUREG/CR-5316, SAND88-3476, Sandia National Laboratories, Albuquerque, NM, February 1990.

A-8 Plys, M.G., D.E. Vanover, C.Y. Paik, R.D. Astleford, M.A. Kenton, and R.J. Hammersley, "Controlling Phenomena in PWR Blackout Sequences," Fauske and Associates, Inc., IAEA-SM296/78P, Severe Accidents in Nuclear Power Plants. Proceedings of an International Symposium on Severe Accidents in Nuclear Power Plants, jointly organized by the International Atomic Energy Agency and the Nuclear Energy Agency of the OECD, Sorrento, March 21-25, 1988.

A-9 Bieniarz, P.P. and R.E. Deem, "Effects of Natural Circulation and Post Vessel Failure Analyses on Source Term Calculations," presented at the National Heat Transfer Conference, August 912,1987 . 
A-10 Nourbakhsh, H.P., Lee, Chien-Hsiung and T.G. Theofanous, "Natural Circulation Phenomena and Primary System Failure in Station Blackout Accidents," Proceedings: The Sixth Information Exchange Meeting on Debris Coolability, EPRI NP-4455, p. 24-1 $24-9,1986$.

A-11 Berta, V.T., B.E. Boyack and G.E. Wilson, Natural Circulation Cooling in U.S. Pressurized Water Reactors, EGG-M-89008, EG\&G Idaho, Inc., Idaho Falls, ID, April 1990.

A-12 Stewart, W.A., A.T. Pieczynski and V. Srinivas, "Experiments on Natural Circulation Flow in a Scale Model PWR Reactor System During Postulated Degraded Core Accidents," Proceedings of the 3rd International Topical Meeting on Reactor Thermal Hydraulics, Newport, RI, October 15-18, 1985.

A-13 Stewart, W.A., A.T. Pieczynski and V. Srinivas, "Experiments on Natural Circulation Flows in Steam Generators during Severe Accidents," Proceedings of International ANS/ENS Topical meeting on Therma1 Reactor Safety, pp. XIX.6-1 - XIX.6-8, San Diego, CA, February 2-6, 1986.

A-14 Sehgal, B.R., W. Stewart and W. Sha, "Experiments on Natural Circulation During PWR Severe Accidents and their Analysis," Presented at International ENS/ANS Topical Meeting on Thermal Reactor Safety, Avignon, France, October 2-7, 1988.

A-15 Harris, B.L., V.N. Shah and G.E. Korth, Creep Rupture Failure of the Reactor Vesse1 Hot Leg Nozzle During the TMLB' Accident, EGG-M-20987, EG\&G Idaho, Inc., Idaho Falls, ID, January 1988.

A-16 Larson, T.K. and G.G. Loomis, "Semiscale Program: A Review of MOD-2 Results," Nuclear Safety, Vol. 29, No. 2, (April-June 1988). 


\section{APPENDIX B}

Analysis of Thermosyphoning in a steam Generator Model

B-1 


\section{Appendix B}

\section{Analysis of Thermosyphoning in a Steam Generator Model}

\section{B.1 Introduction}

An analysis of thermosyphoning in a steam generator model is presented. The motivation for developing the thermosyphon model was twofold: 1) to provide an independent investigation of the relation between steam temperatures in the inlet plenum and the steam generator circulation rate, and 2) to provide a computationally efficient model to study the effects of variation of key parameters affecting the circulation rate. The first item was itself motivated by the disagreement in the steam generator circulation rates predicted by SCDAP/RELAP5 and COMMIX.

A prominent feature in the simulation of the TMLB' scenario is the postulated development of natural circulation of superheated steam in the steam generators once the core has been uncovered. Because the return cold leg does not clear, a natural circulation pattern is assumed to develop in which steam enters the top of the hot leg from the vessel, flows along the top of the hot leg to the inlet plenum where it mixes, flows through some fraction of the steam generator tubing to the outlet plenum, returns to the inlet plenum via the remaining tubes and returns to the vessel through the lower half of the hot leg. An important aspect of simulating this phenomena is proper modeling of the circulation rate and the heat transfer rates in the steam generator, since heat removal in the steam generator is the source of bouyancy driving the natural circulation phenomena.

The governing equations which model the thermosyphoning phenomena in the steam generator are developed from a mass, momentum and energy balance on the system. Momentum conservation includes a balance of the rate of change of momentum with buoyancy and viscous forces in a typical tube. The buoyancy is treated via the Boussinesq approximation. The pressure drop over forward- and backward-flowing tubes is eliminated by an appropriate summation of these respective equations. The energy balances include storage, convection and heat exchange between the flowing vapor and the tubing. Heat exchange to the secondary-side in the steam generator is modeled by treating the secondary-side steam as a lumped volume. The resulting coupled system of equations is solved numerically for the steam generator circulation rate, the vapor and tubing temperature distributions along the length of U-tubes, and the secondary-side steam temperature.

The model is applied to simulate thermosyphoning in a steam generator representative of one of three such generators in a 3-Loop Westinghouse Pressurized Water Reactor (PWR). Only the thermosyphoning phenomena is considered in this model. The vessel and hot and cold legs which comprise the primary components in a PWR are not modeled explicitly. Their effect in producing and transporting steam vapor to the steam generator is modeled by specifying the heating rate of gases entering the inlet plenum from the top 
of the hot leg. Heating rate values are varied about values predicted with large systems codes which have been employed to model the entire PWR under the TMLB' transient.

To reiterate, the objective of this analysis was to provide an independent analysis, that is apart from those performed with the systems codes SCDAP/RELAP5 and MELCOR, of the circulation rate in the steam generator during the TMLB' transient. Furthermore, the resulting model is much less CPU intensive than the systems codes and sensitivity studies can be permformed in a much more cost effective manner.

\section{B.2 Steam Generator Model}

In this work only the buoyancy-driven flow in the steam generator tubing is modeled in some detail. Mixing of gases in the plena and the counter-current flow in the hot leg are not treated explicitly. These effects are modeled by use of a thermodynamic mixing model developed by Stewart et. al [B-8], which contains various mixing parameters whose influence is to be determined. The objective of this study was to develop a model which contains the essential mechanisms which generate the circulation in the steam generator, and not to address the complex flow that arises in the plena.

\section{Assumptions and Approximations}

There are several assumptions and approximations that were invoked in developing the model; these are enumerated below:

1. Temperature and velocity are assumed to depend only on distance along tubes, $x$, and on time, $t$, i.e., equations are area-averaged.

2. Boussinesq approximation is invoked.

3. Streamwise heat conduction is small compared to convection and is not included in gas energy balance.

4. Heat conduction along the piping is also neglected. This invokes the small Biot number assumption since the pipe walls are thin compared to their length.

5. Pjpe bend is neglected.

6. Tube sheet is not modeled. The tube sheet acts as a heat sink for the plenum gases and its effect will be considered to be lumped in with the mixing parameters.

7. Temperature dependent properties are based on average temperatures, $\bar{T}_{g}=\left(T_{g}(0, t)+\right.$ $\left.T_{g}(2 L, t)\right) / 2$, and $\bar{T}_{p}=\left(T_{p}(0, t)+T_{p}(2 L, t)\right) / 2$, where $T_{g}$ denotes the vapor temperature and $T_{p}$ is the steam generator tube temperature. 


\section{Thermosyphon Equations}

A schematic of the steam generator is shown in Figure 10.2.1 of the main report. This schematic shows only one forward and one backward flowing tube, however, the steam generator modeled below includes a total of 3348 inverted $\mathrm{U}$-shaped tubes. It is assumed that $n_{f}$ tubes carry steam from the inlet plenum to the outlet plenum, and that the remaining $n_{b}$ tubes carry the same total mass flow from outlet plenum back to the inlet plenum. The mass and momentum equations governing the buoyancy-driven flow in the steam generator are displayed below.

Mass:

$$
v=v(t), \quad \dot{m}_{S G}=n_{f} \rho_{g} v \frac{\pi}{4} d_{i}^{2}=n_{b} \rho_{g} u \frac{\pi}{4} d_{i}^{2}
$$

Momentum:

$$
\begin{gathered}
\rho_{g} L\left(1+\frac{n_{f}}{n_{b}}\right) \frac{d v}{d t}=\rho_{g} g \beta\left(\int_{0}^{L / 2} T_{g} d x-\int_{L / 2}^{L} T_{g} d x+\int_{L}^{3 L / 2} T_{g} d x-\int_{3 L / 2}^{2 L} T_{g} d x\right) \\
-2 C_{f} \rho_{g} v^{2} \frac{L}{d_{i}},
\end{gathered}
$$

where $C_{f}$ is the integrated friction coefficient,

$$
C_{f}=f(v)+\left(\frac{n_{f}}{n_{b}}\right)^{2} f(u) .
$$

The mass balance equation states that the velocity depends only on time, however, the momentum equation couples the velocity to the temperature distribution over the entire length of tubing. In these equations, $\rho_{g}$ is gas density, $d_{i}$ is the tubing inner diameter in the steam generator, $v$ is the velocity in a forward flowing tube, $u$ is the velocity in a backward flowing tube, $\beta$ is the coefficient of thermal expansion, and $L$ is the length of an inverted U-tube. The forward flowing and backward flowing momentum equations have been summed to eliminate the pressure drop from inlet to outlet plena, resulting in Eqn. (B.2). The forward-to-backward flowing tube ratio enters in this process by elimination of $u$ according to $n_{f} v=n_{b} u$, given in Eqn. (B.1).

Energy balances for the steam flowing in the tubing and for the tubing material itself are shown below.

Steam Energy Balance:

$$
\rho_{g} C_{p g}\left(\frac{\partial T_{g}}{\partial t}+v \frac{\partial T_{g}}{\partial x}\right)=-4 \frac{h_{i}}{d_{i}}\left(T_{g}-T_{p}\right), \quad 0 \leq x<L,
$$

and,

$$
\rho_{g} C_{p g}\left(\frac{\partial T_{g}}{\partial t}+\frac{n_{f}}{n_{b}} v \frac{\partial T_{g}}{\partial x}\right)=-4 \frac{h_{i}}{d_{i}}\left(T_{g}-T_{p}\right), \quad L<x \leq 2 L,
$$




\section{Pipe Energy Balance:}

$$
\rho_{p} C_{p p} \frac{\partial T_{p}}{\partial t}=4 \frac{h_{i}}{\delta\left(2+\delta / d_{i}\right)}\left(T_{g}-T_{p}\right)-4 \frac{h_{o} d_{o}}{d_{o}^{2}-d_{i}^{2}}\left(T_{p}-T_{s}\right), \quad 0 \leq x<2 L,
$$

where $h_{i}$ and $h_{o}$ are heat transfer coefficients for the inner and outer surface of the tubing, respectively, $\delta=d_{o}-d_{i}$ is the tube thickness, $d_{o}$ is the outer tube diameter and $T_{s}$ is the steam temperature on the secondary side of the steam generator. As noted above, streamwise heat conduction is neglected compared to convection for the steam and is also neglected for the piping. This latter approximation is essentially a small Biot number assumption based on the thin piping relative to the length of piping (see Table B.1).

Heat transfer from the tubes to steam on the secondary side is assumed to be entirely due to natural convection. The steam on the secondary side of the steam generator is modeled as a lumped volume. The energy balance reads,

$$
\rho_{s} C_{p s} V_{s} \frac{\partial T_{s}}{\partial t}=\pi d_{o}\left(n_{f} \int_{0}^{L} h_{o}\left(T_{p}-T_{s}\right) d x+n_{b} \int_{L}^{2 L} h_{o}\left(T_{p}-T_{s}\right) d x .\right)
$$

Note that in the current model $h_{o}=\operatorname{func}\left(\bar{T}_{p}-T_{s}\right)$, and so is independent of pathlength. Secondary side steam properties were evaluated at $350 \mathrm{C}$ and $7.5 \mathrm{Mpa}$ (properties taken from Kays and Crawford [B-6]).

These equations are subject to the following initial conditions;

$$
\begin{gathered}
v(t=0)=v^{0}, \\
T_{g}(x, 0)=T_{p}(x, 0)=T^{0},
\end{gathered}
$$

and to the boundary condition

$$
T_{h}(t)=T^{0}+\dot{r} t
$$

where $T_{h}$ denotes the steam temperature entering the inlet plenum from the top of the hot leg. The values of heating rate $(\dot{r})$ considered are $5.5,8.85$, and $16.2 \mathrm{Kelvin} / \mathrm{min}$. The nominal value, taken to be $8.85 \mathrm{Kelvins} / \mathrm{min}$, roughly matches the results of Bayless [B-1] using SCDAP/RELAP5. The lower values is from calculations done with COMMIX [B3 , and match the temperature history of gases into the steam generator tubes. The upper value is also from COMMIX, and represent the temperature history of steam entering the top of the hot leg at the reactor vessel.

The inlet plenum mixing model, to be discussed shortly, provides the coupling with $T_{h}$. This boundary condition specifies an assumed heating rate for the steam entering the inlet plenum. The model computes the resulting steam temperatures exiting the steam generator tubes after flowing to the exit plenum and returning to the inlet plenum. 
In these simulations we used $T^{0}=620 \mathrm{~K}, v^{0}=0$. The system pressure was assumed constant at $16 \mathrm{Mpa}$, the set point for pressure-operated relief valves in the system. This initial temperature corresponds to average temperatures in the steam generators as predicted by Bayless [B-1] at 160 minutes into the simulation of the TMLB' transient.

\section{Inlet Plenum Mixing Model}

Flow in the inlet and outlet plena is a complicated three-dimensional flow [B-2] which is not explicitly modeled here. Instead, the thermodynamic mixing model proposed and verified by Stewart et. al [B.8] is employed:

$$
\begin{gathered}
T_{m}=\frac{\left[f_{m i x} T_{g}(2 L, t)+\left(\frac{m_{H L}}{m_{S G}}-\left(1-f_{\text {mix }}\right)\right) T_{h}\right]}{\left[\frac{m_{H L}}{m_{S G}}-\left(1-2 f_{m i x}\right)\right]}, \\
T_{g}(0, t)=\left(1-f_{m i x}\right) T_{h}+f_{\text {mix }} T_{m}, \\
T_{c}=\frac{\left[\left(1-f_{m i x}\right) T_{g}(2 L, t)+\left(\frac{m_{H L}}{m_{S G}}-\left(1-f_{\text {mix }}\right)\right) T_{m}\right]}{\frac{m_{H L}}{m_{S G}}},
\end{gathered}
$$

In this model, $f_{m i x}$ represents the fraction of hot gas $\left(T_{h}\right)$ that mixes in the inlet plenum; the remainder $1-f_{m i x}$ goes directly to the steam generator tubes. $T_{m}$ represents the "mixing cup temperature" for the mixed gases in the inlet plenum. $T_{c}$ is the fluid temperature entering the bottom of the hot leg after mixing in the inlet plenum. This model also allows for a different flow rate in the steam generator than in the hot leg.

\section{Friction and Heat Transfer Correlations}

Standard correlations for frictional losses and heat transfer were employed in the model. The friction factor was specified as

$$
f(v)=\frac{2 \tau_{w}}{\rho_{g} v^{2}}= \begin{cases}16 / R e_{v} & R e_{v} \leq 1209 \\ 0.078 / R e_{v}^{1 / 4} & R e_{v} \geq 1209\end{cases}
$$

where $\tau_{w}$ is the wall shear and $R e_{v}=\rho_{g} v d_{i} / \mu_{g}$. The expression for $f(u)$ is similar, obtained by replacing $v$ with $u$ in the above.

The heat transfer rate from the flowing steam to the piping is specified according to, 


$$
N u_{i}=\frac{h_{i} d_{i}}{k_{g}}= \begin{cases}4 & R e \leq 667 \\ 0.022 R e^{4 / 5} & R e \geq 667\end{cases}
$$

where the Reynolds number based on $v$ and $u$ is used for the forward and backward flowing tubes, respectively. The heat transfer from the tubing to the secondary side is assumed to be by natural convection. Hence, the Nusselt number is specified with respect to a Rayleigh number,

$$
N u_{o}=\frac{h_{o} d_{o}}{k_{g}\left(T_{s}\right)}=0.59 R a^{1 / 4}
$$

where $R a=g \beta\left(\bar{T}_{p}-T_{s}\right) L_{c}^{3} / \nu_{g} \alpha_{g}$. Thermophysical properties for steam at $7.5 \mathrm{MPa}$ and $620 \mathrm{~K}$ were used in this expression. Normally, the characteristic length, $L_{c}$, would be the height of the tubes at the $\mathrm{U}$-bend. However, this would assume an unimpeded boundary layer development about each tube. Owing to the close packing of tubes in the steam generator, boundary layer interference from adjacent tubes is likely. Depending on the degree of interference, the characteristic length may lie somewhere between the length of tubes and the distance between adjacent tubes. Due to lack of data on natural convection heat transfer characteristics in steam generators for this configuration, the characteristic length was set to one meter. We find that this value is sufficiently large to result in very effective heat transfer from the flowing steam to the secondary side. In order to address the uncertainty in this value, we also considered a simulation with completely insulated steam generator tubing, as discussed in the main text.

\section{Thermophysical Properties and Dimensions}

The temperature variation of steam density, kinematic viscosity and thermal expansion coefficient at $16 \mathrm{Mpa}$ was specified as follows:

$$
\begin{gathered}
\rho_{g}\left[\mathrm{~kg} / \mathrm{m}^{3}\right]=53610 / T-13.41, \\
\nu\left[\mathrm{m}^{2} / \mathrm{s}\right]=4.406 \times 10^{-7}+2.309 \times 10^{-9}(T-700), \\
\beta\left[\mathrm{K}^{-1}\right]=1.733 \times 10^{-3}-1.775 \times 10^{-6}(T-850) .
\end{gathered}
$$

The temperature is specified in Kelvins. The fact that the viscosity of steam (and all gases) increases with temperature will impact the mass flow rates that are predicted.

Table B.1 gives the remaining properties and dimensions that were specified to model the 3-Locp Westinghouse PWR. 
Table B.1. Thermophysical properties and dimensions.

\begin{tabular}{|c|c|c|}
\hline Parameter & Value & Dimensions \\
\hline \multicolumn{3}{|c|}{ Steam } \\
\hline$\overline{k_{g}}$ & 0.0998 & $\mathrm{~W} / \mathrm{m} / \mathrm{K}$ \\
\hline \multicolumn{3}{|c|}{ Secondary Side Steam } \\
\hline$\rho_{s}$ & 29 & $\mathrm{~kg} / \mathrm{m}^{3}$ \\
\hline$C_{p s}$ & $0.3129 \times 10^{4}$ & $\mathrm{~J} / \mathrm{kg} / \mathrm{K}$ \\
\hline$k_{s}$ & 0.0606 & $\mathrm{~W} / \mathrm{m} / \mathrm{K}$ \\
\hline \multicolumn{3}{|c|}{ Steam Generator Tubing } \\
\hline$\rho_{p} C_{p p}$ & $0.3502 \times 10^{7}$ & $\mathrm{~J} / \mathrm{m}^{3} / \mathrm{K}$ \\
\hline \multicolumn{3}{|c|}{ Dimensions } \\
\hline$V_{s}$ & 166 & $\mathrm{~m}^{3}$ \\
\hline$L$ & 22 & $\mathrm{~m}$ \\
\hline$d_{i}$ & 0.01968 & $\mathrm{~m}$ \\
\hline$d_{o}-d_{i}$ & 0.001215 & $\mathrm{~m}$ \\
\hline
\end{tabular}

\section{B.3 Numerical Treatment and Code Testing}

The thermosyphoning phenomena are described by Eqns (B.2)-(B.6), together with initial and boundary conditions. This system is solved numerically by the so-called Method-of-Lines (MOL), see reference [B-5]. The technique is suitable for parabolic or hyperbolic systems, as we have here. The method simply involves discretizing the spatial dimensions by finite differences, resulting in a system of coupled nonlinear ordinary differential equations (ODEs). The ODEs are integrated in time by use of the stiff backward difference solver DEBDF [B-7] available in the SLATEC mathematics library [B-4].

Based on a convergence study, it was determined that discretizing the spatial derivatives in the energy equations into 80 finite difference volumes was sufficient to obtain an accurate solution. Typical CPU requirements were about 4 seconds per simulation on the CRAY-YMP. 


\section{B.4 References}

B-1 Bayless, P. D., 'Analysis of natural circulation during a Surry station blackout using SCDAP/RELAP5,' NUREG/CR-5214,(EGG-2547), EG\&G Idaho Inc., September, 1988.

B-2 Cha, Y. S., Domanus, H. M., and Sha, W. T., 'Numerical simulation of mixing in the inlet plenum of the Westinghouse $1 / 7$ scale steam generator model,' $A N L / A T H R P$ 40, Argonne National Laboratory, Argonne, IL, January, 1990.

B-3 Domanus, H. M., and Sha, W. T., 'Analysis of Natural-Convection Phenomena in a 3-Loop PWR During a TMLB' Transient using the COMMIX code,' NUREG/CR5070, ANL-87-54, Argonne National Laboratory, Argonne, IL, January, 1988.

B-4 Haskell, K. H., Vandevender, W. H., and Walton, L. E., 'The SLATEC common mathematics subprogram library: SNLA implementation, SAND80-2792, Sandia National Laboratories, Albuquerque, New Mexico, 1980.

B-5 Hyman, J. M., 'Method of lines approach to the numerical solution of conservation laws,' LA-UR-79-837, Los Alamos Scientific Laboratory, Los Alamos, New Mexico, 1979.

B-6 Kays, W. M., and Crawford, M. E., Convective Heat and Mass Transfer, 2nd. Ed., McGraw Hill, New York, 1980.

B-7 Shampine, L. F., and Watts, H. A., 'DEPAC - Design of a user oriented package of ODE solvers, SAND79-2374, Sandia National Laboratories, Albuquerque, New Mexico, 1980.

B-8 Stewart, W. A., A. T. Pieczynski, and V. Srinivas, 'Experiments on natural circulation flows in steam generators during severe accidents,' Proc. of Int. ANS/ENS' Topical Meeting on Thermal Reactor Safety, San Diego, CA, pp. XIX.6-1, XIX.6-8, February 2-6, 1986. 
Distribution:

Externa1:

Argonne National Laboratory

ATTN: H. M. Domanus

W. T. Sha

9700 South Cass Avenue

Argonne, IL 60439

Battelle Columbus Laboratory

ATTN: J. Gieseke

M. Carme 1

505 King Avenue

Columbus, OH 43201

H. W. Ryals

Bettis Atomic Power Laboratory

Bettis Internal 34NN

P.O. Box 79

West Mifflin, PA 15122

Brookhaven National Laboratory

ATTN: I. Madni

32 Lewis Avenue

Upton, NY 11973

Mohsen Khatib-Rahbar

Energy Research Inc.

P.0. Box 2034

Rockville, MD 20852

EPRI

ATTN: W. A. Stewart

3412 Hillview Ave.

Palo Alto, CA 94203

M. A. Kenton

Gabor, Kenton \& Associates

770 Pasquinelli Drive

Suite 426

Westmont, IL 60559

D. McMullan

General Electric Company

Knolls Atomic Power Laboratory

Bldg. F3, Room 8

P.O. Box 1072

Schenectady, NY 12301-1072 
Idaho National Engineering Laboratory

EG\&G Idaho, Inc.

ATTN: C. Allison

P. D. Bayless

G. Berna

C. Dobbee

D. Hagrman

D. Hanson

D. Knudson

L. Siefken

P.0. Box 1625

Idaho Falls, ID 83415

Los Alamos National Laboratory

ATTN: B. E. Boyack

J. Ireland

R. Jenks

L. L. Smith

D. R. Lues

Oak Ridge National Laboratory

ATTN: S. E. Fischer

S. R. Greene

S. A. Hodge

R. H. Moms

L. Ott

P.0. Box 2009

Oak Ridge, TN 37831

R. Viskanta

Purdue University

Heat Transfer Laboratory

School of Mechanical Engineering

West Lafayette, IN 47907

Science Applications International Corp.

ATTN: K. C. Wagner

M. T. Leonard

2109 Air Park S.E.

Albuquerque, NM 87106

V. K. Dhir (UCLA)

2445 22nd Street

Santa Monica, CA 90403

M. L. Corradini

University of Wisconsin

Dept. of Nuclear Engineering

Engineering Research Building

1500 Johnson Drive

Madison, WI 53706 
U.S. Nuclear Regulatory Commission

$\mathrm{M} / \mathrm{S}$ NL/N -344

ATTN: Y. S. Chen (5)

F. E1tawila

R. B. Foulds

J. Han

N. Lauben

F. Odar

B. Sheron

L. M. Shotken

M. Cunningham

C. G. Tinkler

R. Landry

C. P. Ryder

M. I. Robertson

United Kingdom Atomic Energy Authority

Safety \& Reliability Directorate

Wigshaw Lane, Culcheth, Warrington

Cheshire, WA3 4NE

ENGLAND

Technical Research Centre of Finland

Nuclear Engineering Laboratory

ATTN: Ilona Lindholm

Esko Pekkannen

P.0. Box 208 (Tekniikantie 4)

SF-002151 Espoo

FINLAND

Sang Lung Chan

Swiss Federal Nuclear Safety Inspectorate

CH-5232 Villigen-HSK

SWITZERLAND

T. Haste

United Kingdom Atomic Energy Agency

Reactor Safety Studies Dept.

Winfrith Technology Center

Winfrith, Dorchester, Dorset

UNITED KINGDOM, DTS 8DH

Internal:

1500

1511

D. J. McCloskey

1511

J. S. Rottler

1513

M. J. Martinez (4)

6111

R. D. Skocypec

6400

G. M. Martinez (10)

6404

N. R. Ortiz

6412

D. A. Powers

A. L. Camp 
6412 S. E. Dingman

6413 F. T. Harper

6414 J. E. Kelly

6418 S. L. Thompson

6418 E. A. Boucheron

6418 R. K. Cole

6418 R. J. Gross (5)

6418 L. N. Kinetyk

6418 R. M. Summers

6422 T. J. Heames

6515 G. S. Rightley (2)

7141 Techncial Library (5)

7151 Technical Publications

7613-2 Document Processing (10)

8523 Central Technical Files 

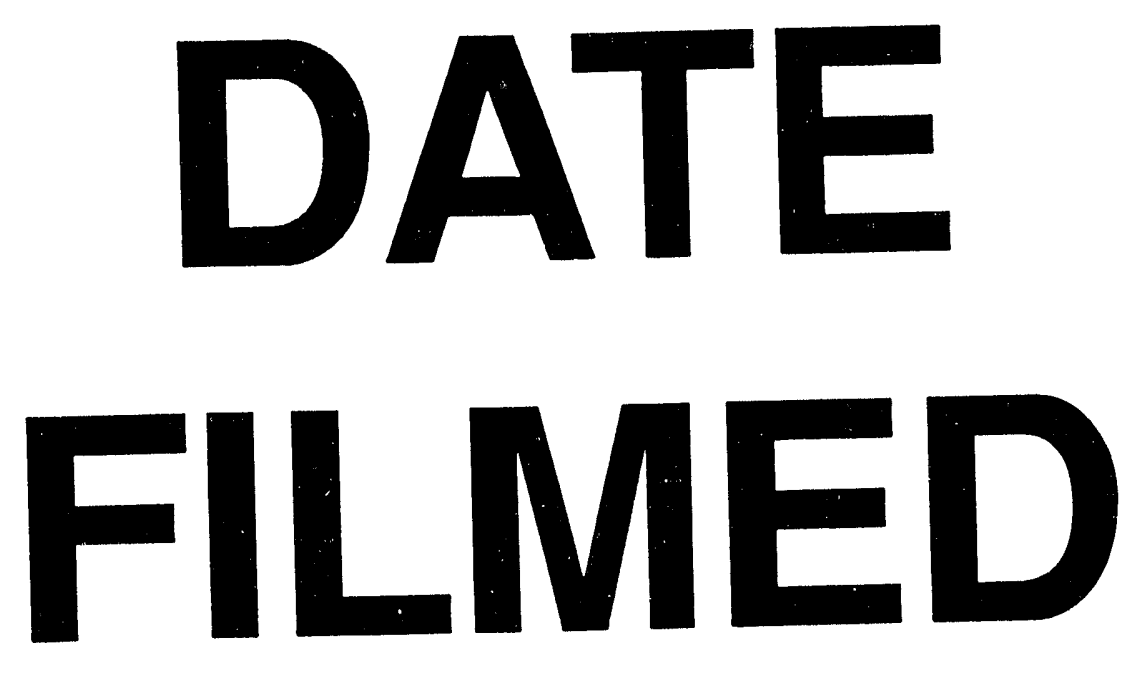

$6 / 3 / 94$
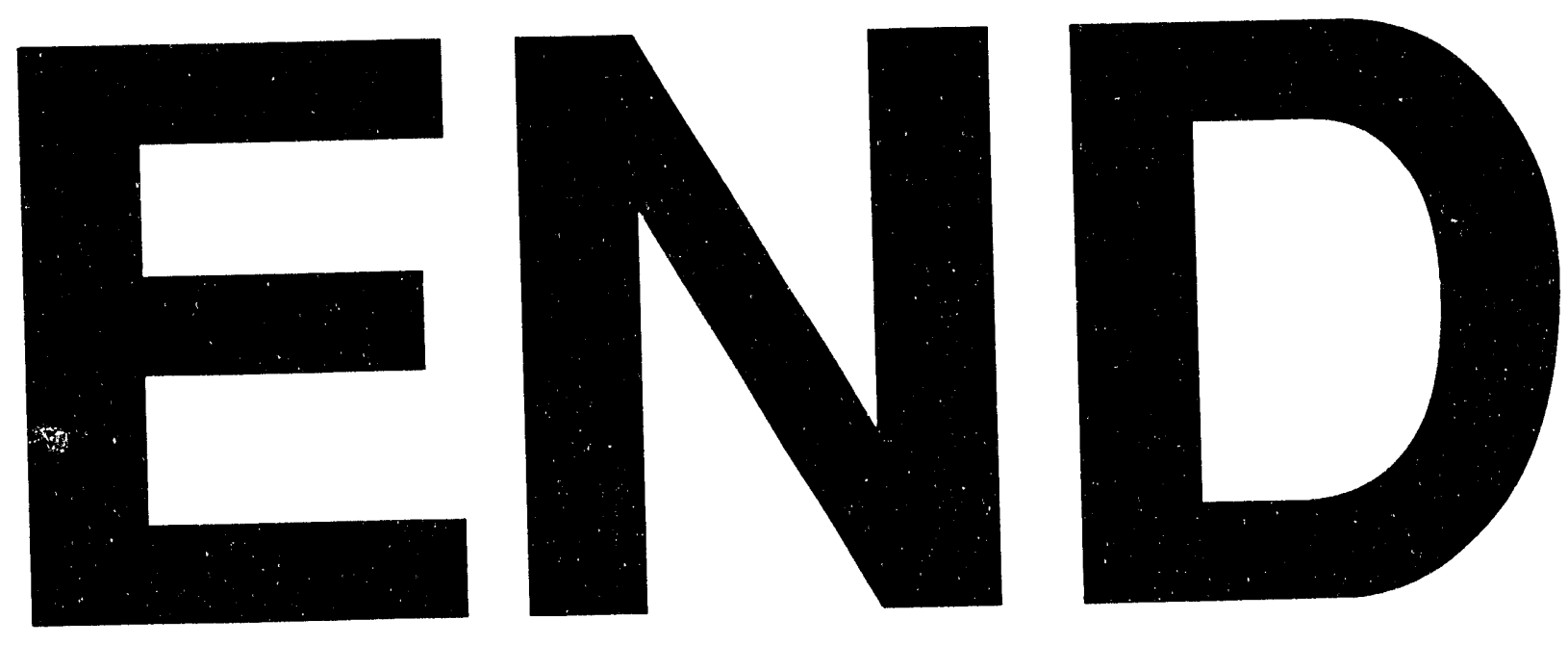
